\title{
RECONFIGURING HUMAN, NONHUMAN AND \\ POSTHUMAN IN LITERATURE AND CULTURE
}

Edited by

Sanna Karkulehto, Aino-Kaisa Koistinen and Essi Varis 


\section{Reconfiguring Human, Nonhuman and Posthuman in Literature and Culture}

The time has come for human cultures to seriously think, to diligently conceptualize, and to earnestly fabulate about all the nonhuman critters we share our world with, and to consider how to strive for more ethical cohabitation. Reconfiguring Human, Nonbuman and Posthuman in Literature and Culture tackles this severe matter within the framework of literary and cultural studies. The emphasis of the inquiry is on the various ways in which actual and fictional nonhumans are reconfigured in contemporary culture - although, as long as the domain of nonhumanity is carved in the negative space of humanity, addressing these issues will inevitably clamor for the reconfiguration of the human as well.

Sanna Karkulehto is Professor of Literature at the University of Jyväskylä, Finland. She has published books, articles, and book chapters on the critical study of representations of gender and sexuality, the politics of discourse, and the politics of difference. Her latest co-edited anthology offers theorization on the ethics and politics of reading when studying representations of gender and violence.

Aino-Kaisa Koistinen currently works as postdoctoral researcher in Contemporary Culture Studies at the University of Jyväskylä, Finland. Her research interests include feminist theory, posthumanism, crime and speculative fiction, transmediality, and monster studies.

Essi Varis hails from the University of Jyväskylä, Finland, where she has worked as a comics scholar and graduate student in Comparative Literature since 2013. She defended her doctoral compilation dissertation, Graphic Human Experiments: Frankensteinian Cognitive Logics of Characters in Vertigo Comics and Beyond, in 2019. 


\section{Perspectives on the Non-Human in Literature and Culture}

Series Editor: Karen Raber, University of Mississippi, USA

Literary and cultural criticism has ventured into a brave new world in recent decades: posthumanism, ecocriticism, critical animal studies, the new materialisms, the new vitalism, and other related approaches have transformed the critical environment, reinvigorating our encounters with familiar texts, and inviting us to take note of new or neglected ones. A vast array of non-human creatures, things, and forces are now emerging as important agents in their own right. Inspired by human concern for an ailing planet, ecocriticism has grappled with the question of how important works of art can be to the preservation of something we have traditionally called "nature." Yet literature's capacity to take us on unexpected journeys through the networks of affiliation and affinity we share with the earth on which we dwell - and without which we die - and to confront us with the drama of our common struggle to survive and thrive has not diminished in the face of what Lynn White Jr. called "our ecological crisis." From animals to androids, non-human creatures and objects populate critical analyses in increasingly complex ways, complicating our conception of the cosmos by dethroning the individual subject and dismantling the comfortable categories through which we have interpreted our existence. Until now, however, the elements that compose this wave of scholarship on non-human entities have had limited places to gather to be nurtured as a collective project. "Perspectives on the Non-Human in Literature and Culture" provides that local habitation. In this series, readers will find creatures of all descriptions, as well as every other form of biological life; they will also meet the non-biological, the microscopic, the ethereal, the intangible. It is our goal for the series to provide an encounter zone where all forms of human engagement with the non-human in all periods and national literatures can be explored, and where the discoveries that result can speak to one another, as well as to scholars and students.

\section{Reconfiguring Human, Nonhuman and Posthuman in}

Literature and Culture

Edited by Sanna Karkulehto, Aino-Kaisa Koistinen, and Essi Varis

For more information about this series, please visit: www.routledge.com/ Perspectives-on-the-Non-Human-in-Literature-and-Culture/ book-series/PNHLC 


\section{Reconfiguring Human, Nonhuman and Posthuman in Literature and Culture}

Edited by

Sanna Karkulehto,

Aino-Kaisa Koistinen

and Essi Varis 
First published 2020

by Routledge

52 Vanderbilt Avenue, New York, NY 10017

and by Routledge

2 Park Square, Milton Park, Abingdon, Oxon, OX14 4RN

Routledge is an imprint of the Taylor \& Francis Group, an informa business

(C) 2020 Taylor \& Francis

The right of Sanna Karkulehto, Aino-Kaisa Koistinen, and Essi Varis to be identified as the authors of the editorial material, and of the authors for their individual chapters, has been asserted in accordance with sections 77 and 78 of the Copyright, Designs and Patents Act 1988.

All rights reserved. No part of this book may be reprinted or reproduced or utilised in any form or by any electronic, mechanical, or other means, now known or hereafter invented, including photocopying and recording, or in any information storage or retrieval system, without permission in writing from the publishers.

Trademark notice: Product or corporate names may be trademarks or registered trademarks, and are used only for identification and explanation without intent to infringe.

Library of Congress Cataloging-in-Publication Data A catalog record for this title has been requested

ISBN: 978-0-367-19747-6 (hbk)

ISBN: 978-0-429-24304-2 (ebk)

Typeset in Sabon

by codeMantra 


\section{Contents}

List of Figures ix

List of Contributors $\quad$ xi

Reconfiguring Human, Nonhuman and Posthuman:

Striving for More Ethical Cohabitation $\quad 1$

SANNA KARKULEHTO, AINO-KAISA KOISTINEN,

KAROLIINA LUMMAA, AND ESSI VARIS

PART 1

Toward Posthumanist Literature and

Posthumanist Reading 21

1 On the Possibility of a Posthuman/ist Literature(s) 23

CAROLE GUESSE

2 Posthumanist Reading: Witnessing Ghosts, Summoning Nonhuman Powers

KAROLIINA LUMMAA

3 Becoming-instrument: Thinking with Jeff VanderMeer's Annibilation and Timothy Morton's Hyperobjects

KAISA KORTEKALLIO

\section{PART 2}

Imagining Aliens and Monsters

4 Alien Overtures: Speculating about Nonhuman

Experiences with Comic Book Characters 
vi Contents

5 Playing the Nonhuman: Alien Experiences in

Aliens vs. Predator

JONNE ARJORANTA

6 Wild Things Squeezed in the Closet: Monsters of Children's Literature as Nonhuman Others

PART 3

Becoming with Animals

7 Dead Dog Talking: Posthumous, Preposthumous, and Preposterous Canine Narration in Charles Siebert's Angus MIKKO KESKINEN

8 Carnivorous Anatomies: Art and Being Beasts BRAD BOLMAN

9 Reconfiguring Human and Nonhuman Animals in a Guiding Assemblage: Toward Posthumanist Conception of Disability

HANA PORKERTOVÁ

PART 4

Technological (Co-)Agencies

10 Meeting the Machine Halfway: Toward

Non-Anthropocentric Semiotics

CLÉO COLLOMB AND SAMUEL GOYET

11 Journeys in Intensity: Human and Nonhuman

Co-Agency, Neuropower, and Counterplay

in Minecraft

MARLEENA HUUHKA

12 Cyborganic Wearables: Sociotechnical Misbehavior and the Evolution of Nonhuman Agency 
PART 5

Afterword: Unnarratable Matter?

13 Unnarratable Matter: Emergence, Narrative, and Material Ecocriticism

JUHA RAIPOLA

Index 

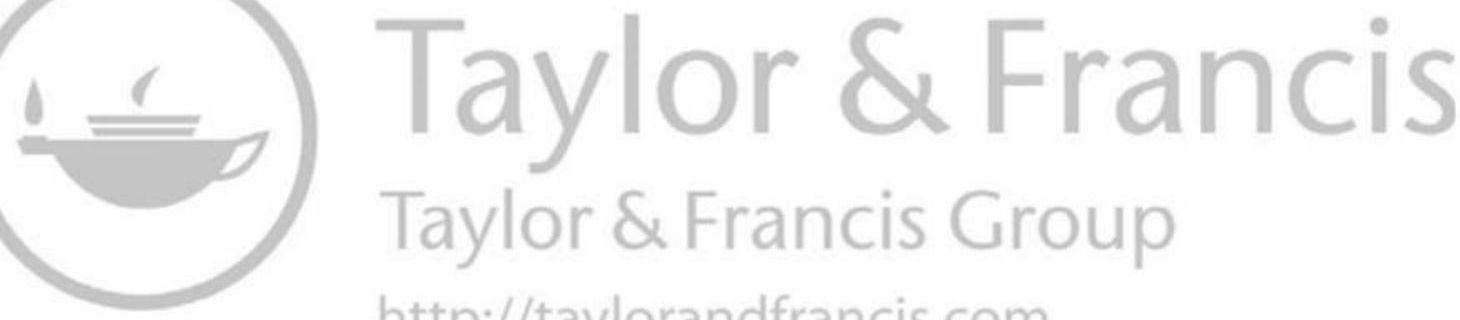
http://taylorandfrancis.com 


\section{List of Figures}

1.1 Jakobson's "constitutive factors" in speech events and any acts of verbal communication (Jakobson 1960, 353)

2.1 Excerpt from the poem "kadonneen äänen lyhyt haastattelu" by Jouni Tossavainen

2.2 Jukka-Pekka Kervinen: "damage” (2008)

4.1 The beetles must assume a human-shaped formation in order to speak, while Dream's face momentarily reflects their insectoid features $(2015, \# 3,[15])$. The Sandman: Overture (C) 2013 DC Comics. Written by Neil Gaiman and illustrated by J. H. Williams, III

4.2 Dream's fluid physical form appears to be fractured into various possible appearances by the ruby amulet he uses for long-distance communication with other god-like characters (2015, \#2, [17]). The Sandman: Overture (C) 2013 DC Comics. Written by Neil Gaiman and illustrated by J. H. Williams, III

4.3 The readers are watching the storyworld as - while also being metaleptically watched by - the Corinthian (2015, \#1, [6-7]). The Sandman: Overture (C) 2013 DC Comics. Written by Neil Gaiman and illustrated by J. H. Williams, III

4.4 This page layout plays with the "opaqueness" of written language, the apparent "transparency" of pictorial presentation, and the book's overarching motif of reflections (2015, \#1, [11]). The Sandman: Overture () 2013 DC Comics. Written by Neil Gaiman and illustrated by J. H. Williams, III

4.5 Some aspects of Dream are irrevocably hidden and unrepresentable, whereas his familiar human form results from, and appeals to, the human readers' perspectives (2015, \#1, [24]). The Sandman: Overture (C) 2013 DC Comics. Written by Neil Gaiman and illustrated by J. H. Williams, III 
5.1 A hiding ninja in Mark of the Ninja (Klei Entertainment 2012). The dim blue circle marks the range of sound produced by the dog

5.2 Sensing the surroundings in Horfest (Technically Finished 2009; image via Mobygames) 112

5.3 A dark room, seen in the light of a gun-mounted flashlight 113

5.4 Specimen 6 stalking human prey through the wall 115

5.5 The predator stalking human prey with thermal vision 117

5.6 The predator sight without filters 117

10.1 Screenshot of a Google Search request for "Reindeer", carried out on September 27, 2015

11.1 Wandering 231

11.2 Traveling in intensity 232

12.1 Bamboo Whisper, Tricia Flanagan and Raune Frankjær 237

12.2 Blinklifier, Tricia Flanagan and Katia Vega 238

12.3 BIOdress 2014, The Walter Collective (Sara Adhitya, Beck Davis, Tricia Flanagan, and Raune Frankjær) 239

12.4 Malawi boys in initiation ritual. Photo by CCBY2.0 Steve Evans (Image courtesy of Creative Commons - 2.0 Generic license)

12.5 Japanese Komuso wearing Tengai. Photo by CCBY3.0 松岡明芳 (Image courtesy of Creative Commons - 3.0 Unported license)

12.6 Inter-human communication in the form of speech is generally mastered and internalized once past toddlerhood. The act of speaking is accompanied by series of nonverbal cues, performed as well as received and analyzed subconsciously by both sender and receiver. As 70-90 percent of the process is nonverbal, and predominantly takes place unconsciously, it is not uncommon to see people interact almost automatically with the subtle signals of the other, in mutually reinforcing feedback loops (cf. Hogan and Stubbs 2003, 121)

12.7 The agency of the Bamboo Whisper is disruptive to the experience and expectations of the human wearers (or hosts) within the system 


\section{List of Contributors}

Jonne Arjoranta holds a doctoral degree in Digital Culture from the University of Jyväskylä, Finland. He specializes in philosophical hermeneutics, game studies, and internet cultures. He has published in Game Studies, Games and Culture, and International Journal of Role-Playing.

Brad Bolman is a Sosland Family Graduate Fellow in the Department of the History of Science at Harvard University, USA. His dissertation explores the emergence of beagle dogs in the twentieth-century biosciences.

Cléo Collomb is a lecturer in Information and Communication Studies at University Paris Sud, France, laboratory Idest. She works on digital traces and algorithmic governmentality.

Patricia Flanagan is an artist and academic whose work is shown internationally in Australasia and Europe, recently in Taipei Museum of Contemporary Art, Taiwan. She established the Wearables Lab, Hong Kong Baptist University, in 2009 and is the co-director of the Interactive Media Lab and lead researcher in wearables at the Creative Robotics Lab, University of New South Wales, Australia.

Raune Frankjær holds a doctoral degree in Digital Design and Information Studies at the University of Aarhus, Denmark. Her research is practice-based and centers on craft-based human-computer interaction and its implications for the design of sympoietic artifacts, crossing boundaries between humans and nonhumans.

Samuel Goyet has a PhD in Information and Communication Studies from Paris-Sorbonne IV, France. His work focuses on the relation between computing and writing from a semiotic and historical point of view.

Carole Guesse is a Literature Doctoral Fellow at the University of Liège, Belgium, and member of the Centre interdisciplinaire de poétique appliquée (CIPA). Her research interests include posthumanism, transhumanism, contemporary literature (in English, Spanish, and French), science fiction, postmodernism, and philosophy of technoscience. 
Marleena Huuhka holds an MA in Theatre and Drama Research. She is currently working as doctoral researcher in the Centre for Practice as Research in Theatre, Tampere University, Finland. Her PhD thesis examines video game worlds as places of performative resistance and searches for new counterplay practices.

Sanna Karkulehto, $\mathrm{PhD}$, is Professor of Literature at the University of Jyväskylä, Finland. She has published books, articles, and book chapters on the critical study of representations of gender and sexuality, the politics of discourse, and the politics of difference. Her latest co-edited anthology offers theorization on the ethics and politics of reading when studying representations of gender and violence.

Mikko Keskinen, $\mathrm{PhD}$, is Professor of Comparative Literature at the University of Jyväskylä, Finland. He is the author of Response, Resistance, Deconstruction (1998) and Audio Book: Essays on Sound Technologies in Narrative Fiction (2008). He has also published articles and book chapters on narrative theory, contemporary literature, and experimental writing.

Kaisa Kortekallio is a doctoral student at the University of Helsinki, Finland. In her work, she combines cognitive and posthumanist approaches to literature, exploring how speculative fiction participates in personal and ecosocial change. Kortekallio is affiliated with the Academy of Finland project Instrumental Narratives (iNARR 2018-2021).

Karoliina Lummaa, $\mathrm{PhD}$, is a postdoctoral researcher affiliated with the Department of Finnish Literature, University of Turku, Finland, and with the independent BIOS Research unit, specialized in multidisciplinary environmental research. Lummaa's publications include monographs, research articles, and co-edited anthologies devoted to environmental humanities, posthumanism, and Finnish literature.

Marleena Mustola works as a senior lecturer of Early Childhood Education at the University of Jyväskylä, Finland. She has published in various edited collections and academic journals, such as Educational Philosophy and Theory, Childhood, and New Media \& Society. Her research interests include childhood studies, children's literature and culture, and posthuman philosophy.

Mgr. Hana Porkertová, PhD, is a sociologist and works as an assistant professor at Mendel University in Brno and as a researcher at Masaryk University, Czech Republic. She uses post-structural approaches, mainly Deleuzo-Guattarian philosophy and actor-network theory, to analyze constructions of disability and visual impairment.

Juha Raipola, PhD, is a senior lecturer of Finnish Literature at the University of Tampere, Finland (2018-2019). His current research is 
centered on questions of narrative in the field of environmental humanities, with a special focus on the limits of narrative form in relation to the complexity of global ecological issues.

Essi Varis, $\mathrm{PhD}$, hails from the University of Jyväskylä, Finland, where she has worked as a comics scholar and graduate student in Comparative Literature since 2013. She defended her highly innovative doctoral compilation dissertation, Graphic Human Experiments: Frankensteinian Cognitive Logics of Characters in Vertigo Comics and Beyond, in 2019. 

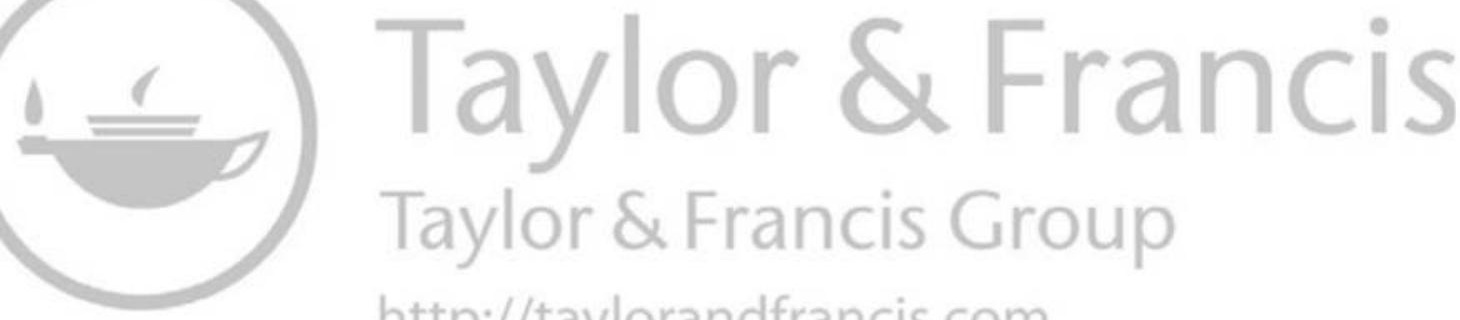
http://taylorandfrancis.com 


\title{
Reconfiguring Human, Nonhuman and Posthuman
}

\section{Striving for More Ethical Cohabitation}

\author{
Sanna Karkulehto, Aino-Kaisa Koistinen, \\ Karoliina Lummaa, and Essi Varis
}

As Donna Haraway $(2015,160)$ argues, “[i]t matters which stories tell stories, which concepts think concepts. Mathematically, visually, and narratively, it matters which figures figure figures, which systems systemize systems". The time has come for human cultures to seriously think, to diligently conceptualize, and to earnestly fabulate about all the nonhuman critters we share our world with, and to consider how to strive for more ethical cohabitation.

The aim of this book, Reconfiguring Human, Nonbuman and Postbuman in Literature and Culture, is to try and tackle this severe matter within the framework of literary and cultural studies. The emphasis of the inquiry is on the various ways actual and fictional nonhumans are reconfigured in contemporary culture - although, as long as the domain of nonhumanity is carved in the negative space of humanity, addressing these issues will inevitably clamor for the reconfiguration of the human as well.

The challenge of mapping the tangled relations between humans and nonhumans has recently been accepted by diverse disciplines, as scholars across academia must come to terms with the social, economic, cultural, environmental, and technological changes that surround, penetrate, and affect their methods and fields of study with unprecedented rapidity. This struggle to adapt has already resulted into a wealth of new approaches, research questions, and conceptualizations, but neither the saturation point nor the demand has quite been met as of yet. On the contrary, the need to find new ways of encountering, discussing, and thinking of entities and environments where human and nonhuman entangle in increasingly intricate patterns has never been more urgent.

So far at least, one of the key tools for approaching these changes has been the concept of the Anthropocene. Humans are now molding even the Earth's strata, which has prompted geologists to propose a new epoch (Crutzen and Stoermer 2000): it is commonly argued that the Anthropocene marks the time in history when the sum of human actions has a larger influence on the geology, hydrosphere, and biosphere 


\section{Sanna Karkulehto et al.}

of the Earth than all the naturally occurring cataclysms combined. Indeed, even though the contributors of this volume actively seek new, less anthropocentric perspectives, the humankind's growing influence on the planet cannot be ignored. Climate change, the sixth global mass extinction, deforestation, pollution, nuclear devastations, agricultural developments, intensive animal farming, extensive land-use, ever-increasing consumption of natural resources, and human population growth have had, and continue to have, serious consequences for the entire Earth system and for all the life forms it sustains. This includes human beings, who are hardly equal in relation to these problems either: some are more responsible for the exploitation of the natural resources, and gain shortterm benefits from it, while the less privileged ones are situated closer to the receiving, powerless end of the exploitation, along with the myriad nonhumans.

Scholars around the world are now calling for interdisciplinary research that would help us to understand how the Anthropocene came into being, and how it affects humanity and the planet. In natural sciences, for instance, anthropogenic environmental developments, like deforestation, ocean acidification, chemicalization, mass extinctions, and climate change, are no longer observed simply as separate phenomena but as systemic processes affecting the entire Earth. This has given rise to such fresh fields of research as Earth system science and global change research. At the same time, expectations for a greater convergence between natural sciences, social sciences, and the humanities are amounting (Sörlin 2012; Palsson et al. 2013; Holm et al. 2015; Brondizio et al. 2016; Heise 2016).

Bringing profoundly different disciplines to contribute in the same discussion and problem-solving will require substantial and long-standing efforts, however, and critics have already highlighted possible gaps and conflicts. Some have criticized natural sciences' tendency to ignore the ways the historical, economic, national, and social distinctions in human societies have all hastened the end of the Holocene. Various alternative coinages, like "Capitalocene", "Sociocene", "Econocene", "Anglocene", "Chthulucene", and "Neganthropocene" (Davis and Turpin 2015, 6-11; Haraway 2015, 2016; Wark 2016; Stiegler 2017), aspire to seize these ongoing global changes from different angles and call for new ways of understanding humanity itself. Others, meanwhile, have dismissed the very notion of the Anthropocene as altogether "too anthropocentric" (e.g. Haraway 2016; Wark 2016). For example, Claire Colebrook $(2017,10)$ declares it problematic to view "the Anthropocene as an epoch, as a line or stratum whose significance would not be in dispute. Rather than think of this line as privileged or epochal, we might ask for whom this stratum becomes definitive of the human". Following Colebrook and Tom Cohen's $(2016,8)$ argumentation, humans are not only regarded as the conceptual antithesis of the nonhuman, but, in a 
very concrete way, nonhumanity is what humanity denies, excludes, and destroys. In sum, humans are simultaneously world-changing agents and witnesses to processes they cannot wholly understand, predict, or manage. It is thus crucial to consider who the privileged human of the Anthropocene actually is (Colebrook 2017, 10).

Overall, definitions of humanity have grown more and more unstable in natural sciences and in philosophical discussions alike, which has led to a so-called crisis of humanism (see Badmington 2004; Braidotti 2013; Koistinen 2015, 58). Meanwhile, the material parameters of human existence have been reconfigured, for instance, by in-vitro meat, the human genome project, custom-made pharmacology, artificial intelligence, and many other manifestations of scientific and technological progress (Twine 2010; Åsberg 2013; Koistinen 2015, 59) - if progress it can be called. It is usually not that difficult to find an angle from which human innovations do not appear purely advantageous - and more often than not, those angles are more or less nonhuman in nature. A number of scholars have therefore proposed a new concept of the posthuman and accompanying theories of posthumanism, which call into question the anthropocentric biases of humanist thought, the belief in technological progress, and the ethics of current human-nonhuman relations (see e.g. Wolfe 2003a, 2003b, 2010; Badmington 2000; Åsberg 2013; Braidotti 2013; Åsberg and Braidotti 2018).

Because these posthumanist ways of thinking are, all in all, motivated not only by practical and epistemological but also by ethical interests, much of the theoretical work produced under the moniker has, to date, focused on the ethical dimensions of the (post)human. As many researchers have noted, global cultural hegemonies have labeled only a selected few as prototypes of the ideal humanity, while those deviating from this white, masculine, healthy, heterosexual standard - that is, most of the world's population - are branded varying shades of subhuman (e.g. Wolfe 2003a, 6-8; Butler 2004, e.g., 1-4; Koistinen and Karkulehto 2018). Thus, while the chapters of this book mostly scrutinize various ethically loaded relationships between humans and nonhumans, they also resonate with the ethics of encountering the so-called "others of Man" in Euro-American cultures (see also Åsberg 2008, 264-269; Koistinen 2015, 45; Braidotti 2017, 21-31; Koistinen and Karkulehto 2018).

The cultural meanings given to nonhuman animals often reflect and coincide with the attitudes and assumptions held toward repressed or marginalized groups, whereby the treatment of animals and nonhumans is connected to the treatment of the humans who are, in varying contexts, viewed as lesser, weaker, subordinate, or substandard (Herman 2018; Wolfe 2003a, 6-8). This includes, for instance, women (as well as children and elderly people), "other races", people with disabilities, and those who are not readable as members of acceptable genders, as Judith Butler (2004) has noted. Theorists of ecocriticism, critical animal 


\section{Sanna Karkulehto et al.}

studies, queer and disability studies, feminist theory, and several other disciplines have time and again challenged the notions that situate (certain kind of) human beings above all the "other" creatures (e.g. Åsberg 2013, 10; Grusin 2017; Koistinen and Karkulehto 2018). Despite the supposed crisis of humanism, these long traditions in exposing and renegotiating social and the humanities structural hierarchies actually make different branches of the humanities quite well-equipped for addressing the hegemonies and dependencies as well as the divides and continuities between humans and nonhumans.

In the intersection of these theoretical traditions and the newly surfaced concerns of the Anthropocene, forms feminist posthumanism, a streak of posthumanist thought that has been influenced by the essayistic writings of Donna Haraway (see Koistinen and Karkulehto 2018). Even though Haraway $(2008,2016)$ has criticized the concepts of posthumanism and the Anthropocene alike - because they both overemphasize the Anthropos, the human - her work on "significant others" and "companion species" highlights the mechanisms of differentiation and the ethical problems of humanist conceptualizations in ways that are overtly relevant to the discussions about posthumanism and the Anthropocene. Haraway's (2008, 69-82) thoughts on killable and livable species also relate to the ideas of several feminist thinkers; with Butler's (2006, 2010) grievable, ungrievable, and livable lives, and Ahmed's (2004) livable and lovable lives (Koistinen 2015, 58). Both Butler (2004, 12-13) and Haraway (2008) have maintained that the concept of a livable life should be extended to nonhuman life-forms. Furthermore, as Koistinen $(2015,58-59)$ has argued, both have advocated for openness and curiosity toward the potential new understandings and futures humans and nonhumans could share (Butler 2004, 204-231; Haraway $2008,289,300-301)$. The only way to tackle the ethical and political issues surrounding "killable" animals is "to reimagine, to speculate again, to remain open", and to recognize that "ways of living and dying matter" to other animals as much as they matter to human beings (Haraway 2008,88 , 93). Haraway's non-anthropocentric thinking culminates in the concept of "Chthulucene", "an ongoing temporality that resists figuration and dating and demands myriad names". This challenges the problematic concept of the Anthropocene, which, for Haraway, "is not an idiomatic term for climate, weather, land, care of country, or much else in great swathes of the world" (Haraway 2015).

Meanwhile, the more epistemological concerns of posthumanism the (im)possibility of cross-species understanding - have been linked to cognitive sciences and methodologies, to the so-called problem of other minds, and the evanescent, private nature of experience itself. These connections were already drawn in 1974 by philosopher Thomas Nagel, whose essay "What Is It Like to Be a Bat?" has inspired many of the contributors of this volume as well. In this brief but influential classic, Nagel 
notes that the instruments of natural sciences are unfit for discussing the subjective textures of lived experiences, and their grasp of minds and consciousness, whether human or nonhuman, is therefore rather limited. That is, even if natural sciences' findings of animals' behavioral patterns and their mentalistic motivations are reliably based on (certain types of) empiricism, such hypotheses and experiments only produce abstractions and generalizations valued by (certain types of) anthropocentric institutions. By contrast, they tell us little of how being a bat feels through a bat's body, or to what kind of action potentials or horizons of meaning this specific embodiment is bound.

Although these questions of embodiment are now being asked with new-found urgency by enactivist theorists, it is still up to debate whether or not these contextual, holistic, first-person qualities of nonhuman experience can ever be studied scientifically at all; the "objective phenomenology" proposed by Nagel $(1974,449)$ still remains to be developed. What is clear, however, is that humanistic approaches like philosophy of mind can think about nonhuman experiences in ways that the reductive, objectifying methods of natural sciences do not allow or value. Moreover, if philosophy of mind is understood as an informed kind of speculation (cf. ibid.), literature and other art forms can be situated on the same methodological continuum: they also tend to speculate about the unfamiliar, the unrealized, and the unknown, only on a more concrete, embodied, contextualized, and/or personal level. In other words, literature and art specialize in imagining, examining, and fostering the subjective, embodied aspects of (nonhuman) experience, which the methods of natural sciences have traditionally bypassed. Yet, this experiential dimension is where empathy and other types of personal engagements take place, whereby increasing our understanding of nonhuman creatures, especially on this level, is likely to have notable epistemological and ethical repercussions (cf. Bernaerts et al. 2014).

It also stands to reason that triangulating something so difficult to reach or comprehend through several different disciplines and methodologies such as natural sciences, philosophy, and arts - will result in more detailed and accurate insights and approximations than the employment of just one approach. Artistic takes on the nonhuman, and academic interpretations of these artworks, are thus an invaluable part of the posthumanist exploration; they cover some of the blind spots of natural sciences and other humanist approaches (cf. Herman 2018).

\section{The Nonhuman in Literature and Culture}

So, how is the nonhuman discussed and imagined - or, in Haraway's words, storied and figured - in the literature, art, and culture of the world that has entered a new era, be it the Anthropocene, the Capitalocene, the Sociocene, the Econocene, the Anglocene, the Neganthropocene, or the 


\section{Sanna Karkulehto et al.}

Chthulucene? What practices of storytelling, representation, visualization, communication, and meaning-making do we humans employ in our relations to the nonhuman or posthuman - and, more importantly, what practices could we employ and what do these practices do?

Not only scholars but also authors and artists have recently taken a keener interest in the nonhuman. However, where posthumanist (animal) studies are mostly rethinking the current ethical and political changes "in light of new knowledge about the life experiences of nonhuman animals", as Cary Wolfe (2010, xxix) maintains, arts and literature have concerned a wide variety of possible and impossible nonhumans, and their various relations to humans, all along. The European tradition of fables, for instance, dates back to Ancient Greece, and the myths of all pre-literary cultures are rife with metamorphoses and chimeric creatures. Experimental and speculative literature and art have since elaborated on these tropes and created many new ways of colliding and merging humanity with the vast domains of life, sentience, and agency that reside outside of it - for what is a story without a conflict and its resolution? So far, scholars interested in the reconfigurations of the nonhuman or posthuman in narratives, arts, and media have turned especially to science fiction, because the various possible worlds and alternative futures imagined within the genre often organize the relations between humans and nonhumans in novel ways (see Haraway 1991, 2008, 217, 2016; Braidotti 2002, 182-184, 203-204; Graham 2002; Badmington 2004, 13-15; Vint 2007, 2014; Koistinen 2015).

Practitioners of ecocritical literary studies (e.g. Soper 1995; Scigaj 1999) have, however, leveled stark criticism toward literary representations of nonhumans since the 1990s: among others, and especially following Gayatri Chakravorty Spivak, David Gilcrest (2002) has deemed any and all attempts at speaking on behalf of nonhumans misguided. Writing is a distinctively human activity, and, to a large extent, very deliberate, intentional, and interpersonal. These assumptions mainly close nonhumans outside of the spheres of literary interest, influence, and action. However, according to posthumanist, new materialist and object-oriented strands of reasoning (Malafouris 2013, 119-139; Morton 2013), lack of interest, influence, or bodily or cognitive abilities does not necessarily negate the possibility of nonhuman agency. On the contrary, many literary scholars now recognize that nonhumans influence, both materially and semiotically, the ways we perceive them, represent them, and write about them (e.g. Herman 2018). Nonhuman beings or environments thus do steer the production of literature, both directly and indirectly, although these processes are often difficult to track and explain.

Serenella Iovino and Serpil Oppermann (2014) have recently fused ecocriticism with Karen Barad's agential realism, creating a new approach they call material ecocriticism. Following Barad's ideas, this framework 
reconfigures nonhuman literary agency as intra-action that allows human and nonhuman bodies and meanings to co-emerge and, respectively, establish meanings in and through textual and material bodies - or in what Iovino and Oppermann (2014) call "storied matter". The city of Naples, for instance, is a porous entity, both materially and semiotically, which means it is constantly open to new human and nonhuman histories, which can be produced and read in cultural texts - such as literature, architecture, or sculptures portraying the city - as well as in the landscape itself. According to Iovino (2016, 39), this idea of storied matter holds great ethical and political potential:

when human creativity "plays" together with the narrative agency of matter, intra-acting with it, it can generate stories and discourses that "diffract" the complexity of our porous collective, producing narrative emergencies that amplify reality, also affecting our cognitive response to this reality.

The stories we spin - and the images we make - about certain places reflect and stem from these intra-actions, meaning that the places themselves make us experience and think about them in the ways we do experience and think about them.

Bruno Latour also discusses nonhuman literary agency briefly in his essay "An Attempt at a "Compositionist Manifesto" (2010), which includes a curious footnote about animism. "The redistribution of agencies is the right purview of literature studies", Latour claims $(2010,489)$, implying that humanists and literary scholars are especially fit to address the liveliness and effectiveness of nonhumans, tuned as they are to fictional characters. He is, of course, right in noting that literary characters are always nonhuman, artificial constructions, no matter how often and easily they are perceived and discussed in human terms. Their agencies are mostly limited to thematic levels - to raising questions about and building scenarios around all kinds of fictional subjectivities, some of which may be posed as human and some of which may be posed as nonhuman. These questions and scenarios constitute the text itself and play into its reception, possibly influencing the reader or the viewer. It is important to note, however, that these agencies of fictional characters mostly mediate, or are at least rather dependent on, the creative and interpretive processes of their human producers and audiences (cf. Bernaerts et al. 2014; Varis 2019). The question of nonhuman poetic agency - of real nonhumans' possibilities of participating in the actual, fleshly act of writing - is a slightly different matter, and one that is also attracting growing interest (e.g. Moe 2014; Lummaa 2017; Tüür 2017).

Examining these two previously overlooked nonhuman forces - the characters participating in the texts and their reception "from the inside", and the co-agencies molding them "from the outside" - calls for 


\section{Sanna Karkulehto et al.}

distinct but intertwined methodological strands, which should allow for tracking of the nonhuman currents in language and typography, as well as for describing the ways in which nonhuman agents are gathered or composed in and around the texts under investigation (following Latour 2010, 2011 and Haraway 2016). In other words, narrative studies should develop new methods of taking into account not only the traditional trinity of text, the author, and the reader but all the relevant agents and factors contributing to a given text, whether they are beings, spaces, or historical, natural, textual, cognitive, or social processes. Furthermore, it should be recognized that the meanings and experiences emerging from these processes are never fully human or nonhuman in their origin or ontology (Varis 2019, 94-104).

The hierarchies and tensions between human and nonhuman perspectives have also underlain the interests of - and the debates between cognitive and unnatural narratologies. At the end of the 20th century, Monika Fludernik's (1996) "natural narratology" redefined narrativization as an activity that both organizes and is deeply permeated by human experientiality - a view that has proved influential in at least two ways. On the one hand, later cognitive narratologies have largely developed along the anthropocentric trajectories demarcated by natural narratology: they tend to anchor both the readers' meaning-making processes and the value of literature on social, probably quite species-specific, cognitive capabilities (e.g. Herman 2013). That is, many cognitive thinkers believe that we place value and interest in fiction and art only insofar as they tell us something about other humans' minds and motivations, and train our folk-psychological skills. On the other hand, other theorists have been inspired to speak against natural narratology and, by association, its anthropocentrism. A notable portion of literary fiction includes elements - nonhuman narrators, impossible space-time, and improbable occurrences - which are blatantly at odds with humans' everyday reality. According to the now-dwindling group of unnatural narratologists, explaining this kind of "strange" fiction in terms of "natural" communication and encyclopedic cognitive structures restricts their interpretation, and possibly even the very definition of fiction. What if the main purpose of literature is not to give us deeper understanding of our immediate social and narcissistic realities but to reach beyond them? Why settle for some fellow human's diary when one might as well engage with a narrator who is "an animal, a mythical entity, an inanimate object, a machine, a corpse, a sperm, an omniscient first-person narrator, or a collection of disparate voices that refuse to coalesce into a single narrating presence"? (Alber, Nielsen, and Richardson 2013, 2).

Of course, as most binaries, this terminologically simple opposition between "natural" and "unnatural" is not as clear-cut as it might first seem. Even though most cognitive narratologists retain realistic skepticism toward our possibilities of escaping beyond human minds' inherent 
limits and inclinations, many also share unnatural narratologists' belief that art can challenge, sharpen, and expand our accustomed patterns of perception, thought, and imagination (Bernaerts et al. 2014). In fact, (transmedial) "narrative engagements with nonhuman phenomenology" has been named one of the focal areas for cognitive narratology by David Herman (2013). Furthermore, the "second generation" of cognitive literary studies also participates in "the affective turn" of the humanities (Koivunen 2010) by directing more and more attention toward the material and bodily affects and effects of literature, art, and media. This investigation of bodily responses and embodied thought complicates and complements the centrality of "the mind" established by liberal humanism (see Vermeulen 2014), and is likely to highlight previously ignored continuities between the human, the nonhuman, and the posthuman. All in all, narratives, cultures, and their constituents can be used as "instruments of mind", which can help us humans to construct more nuanced and ethical relationships not only with each other but also with nonhumans - especially if the mind is understood in an embodied, post-Cartesian sense (Herman 2011, 2012, 2018; Varis 2019).

\section{From Storytelling to Co-agency and Unnarratable Matter}

Although some critical tools and frameworks for analyzing the complex material, social, and textual ways in which humans and nonhumans entangle in the production and reception of art, media, and technology have begun to emerge, their methodological ramifications and ties to the current global troubles are still quite vague. The chapters in this book create new gripping surfaces between art, theory, and the world by conducting concrete case studies of various contemporary art works and cultural phenomena, and by contextualizing them in the Anthropocene or the Chthulucene, in a way that reconfigures artistic representations into something more than artistic representations. These studies and their target texts reach their tentacles (cf. Haraway 2016) across the growing masses of environmental humanities, multiple and multidisciplinary posthumanist theorizations, material ecocriticism, cognitive narratology, new materialism, and other emerging lines of thought, in order to scrutinize what culture and literature, and multifarious academic approaches to them, bring to the academic and the Anthropocenic or Chthulucenic worlds. Literary and cultural studies can thus realize and elaborate on Haraway's claims about systems, stories, and figures by demonstrating how these semiotic constructions fit in the ever-changing constellations of human and nonhuman entities and environments.

Zooming in to more limited contexts, the theoretical, methodological, conceptual, and analytical work done in this anthology could also be characterized as inter- or transmedial: theories and methods of literary studies are here juxtaposed with and applied to the study of other arts, 


\section{Sanna Karkulehto et al.}

media, and technology, and vice versa. "Reading" the multimodality of other media potentially opens up new ways of viewing language and literary texts, while an avid reader or literary scholar might - sometimes helpfully and sometimes not - structure the world through the same logics and sensibilities they structure texts.

In terms of methodology, many of the chapters in this anthology still represent, or at least intersect with, the traditions of literature and literary studies. Literature and its various institutions have contributed heavily to the human-centered cultural legacy, and they have also been central agents in implementing and immortalizing the ideas of humanism. This does not mean, however, that literature and narrative theory have not or could not also be turned around to examine nonhumans - or the often simplified and hegemonic conceptions and portrayals of them as well. Many of the chapters in this book are driven by the need to inquire what the research of literature can or cannot do, when faced with the profound familiarity and incomprehensibility of human and nonhuman others. This meta-disciplinary streak running through the entire book ponders on the methodological challenges and possibilities literary studies must come to terms with as they enter the interdisciplinary arena, where the burning issues of human-nonhuman entanglements are discussed, and where research materials often defy the traditional definitions of representation and textuality. Could the methods of literary research, and the wider cultural studies, grasp material meanings, or the materiality of meaning - the ways in which physical bodies, languageless organisms, nonverbal materials, and encounters signify - and if so, how? These questions take the texts, writers, and readers of this anthology to the very edges of literary study, and beyond. Many chapters grapple with phenomena that are so vast, fleeting, private, emergent, or otherwise slippery they are difficult, or even impossible, to verbalize or narrativize. Some contributors have thereby opted for discussing multimodal forms of art and media that challenge the linguistic and literary frameworks, prompting the researchers to hybridize different disciplines and approaches.

In short, different media suggest different research questions, research methods, and concepts for studying the nonhuman. In addressing literary, textual, visual, and ludic portrayals of nonhumans, this anthology opens up a wide medial field, where the human and the nonhuman can be reconfigured from as many perspectives, and with as many textual and analytical tools as possible. The first aim of this book, in other words, is to connect posthumanist concerns to the entire range of contemporary culture and, in doing so, test the transmedial (and transspecies) usefulness of the current theories and methods of literary and cultural research. The second aim is to analyze the ways in which literary texts, texts' "literariness", and literary theory could rethink or reopen ethical and political questions about the human, the nonhuman, 
and the posthuman in varying communicative and aesthetic contexts. On the one hand, literature, in its classic meaning, always exceeds interpretation both on the semantic and the affective level. On the other hand, literature and art already incorporate, embody, and detangle such unexpected kinships and issues of difference and otherness that the discourses of humanist research, natural sciences, and politics are yet to even recognize.

The question remains: what paths could literature and the increasingly interdisciplinary research of texts and narratives take in the posthuman future? How deep across disciplinary boundaries could posthumanist literary study go, and which of its methods and concepts could - and should - be exported into other fields, even outside verbality and language? The present anthology is meant to ask, rather than to answer, these questions, and it does so by offering sample analyses of a wide range of research materials. These analyses propose novel, more comprehensive, and less anthropocentric ways of reading, interpreting, and experiencing various human and nonhuman minds and worlds through diverse stories, images, texts, and practices. The multiplicity of nonhuman existence and phenomena is, in its various forms, constantly (re) presented, (re)imagined, and even (re)made across the stories and figures of contemporary culture, and humans coming into contact with these stories and figures must themselves become reconfigured through the processes of interpretation and engagement.

The book is divided into five sections, all of which approach the tensions between literature, culture, narration, meaning-making, and the nonhuman slightly differently. The first section focuses on theoretical and methodological questions, and its opening chapter, composed by Carole Guesse, simply asks if literature can truly be posthuman. First, Guesse aims to settle some recurrent confusions around the theories of posthumanism and the concept of posthuman. Then, she turns to discussing the concept of literature and the posthuman(ist) potentialities of each of its components and participants: the author, the reader, the text, the context, language, medium, and their various aspects. Finally, the chapter concludes with a case study on Michel Houellebecq's The Possibility of an Island (2005), a novel that could be considered an example of both posthuman and posthumanist literatures, due to its genetically engineered clone-narrators - which may furthermore be addressing clone-narratees. In the light of Roman Jakobson's communication model, these part-human part-nonhuman characters affect the narrative and its meanings in various ways. Overall, the chapter participates in the timely discussion concerning the possible functions posthumanism and the posthuman could serve in literary research: are they efficient or meaningful tools of literary analysis - and conversely, can literary analysis provide new, relevant understanding of posthumanism or the posthuman? 


\section{Sanna Karkulehto et al.}

The second chapter, by Karoliina Lummaa, traces the trope of spectrality in posthumanist thinking and suggests a new way of reading contemporary poetry as a summoning of nonhuman powers. The chapter begins with a review of posthumanist readings performed by Stefan Herbrechter, Ivan Callus, Neil Badmington, and Tom Cohen, all of whom have attempted to deconstruct the ambiguous boundaries and differences between human, nonhuman, and inhuman through such fictional figures as cyborgs, mutants, and monsters. Drawing on the works of N. Katherine Hayles, Aaron M. Moe, Lambros Malafouris, and others, Lummaa amends these previous analyses with a new affirmative approach that focuses on nonhuman influence and poetic agencies. For the purposes of demonstration, Lummaa goes on to apply this new posthumanist way of reading to contemporary Finnish digital, visual and sound poetry, including the works of Dan Waber and Marko Niemi (2008), Jouni Tossavainen (2007), and Jukka-Pekka Kervinen (2008).

The theory-oriented section concludes with Kaisa Kortekallio's chapter, "Becoming-instrument: Thinking with Jeff VanderMeer's Annibilation and Timothy Morton's Hyperobjects", which considers first-person narration and empathic enactment of fictional experience from posthumanist and enactivist perspectives. It introduces a new methodological device called "becoming-instrument", which opens the reader's experience to nonhuman influences. Building on Marco Caracciolo's claims about empathic engagement with first-person narratives and Merja Polvinen's notion of self-aware readerly engagement, Kortekallio argues that engagement with estranging first-person narratives, such as Annibilation (2014) and Hyperobjects (2013), can work toward dissolving the certainty of the human subject and develop in its stead a model of subjectivity as "multiple and always-in-progress" (Vint 2005). She also maintains that affective experientiality and awareness of fictionality can intertwine in the readerly experience, and that the combination of affectivity and self-referentiality is characteristic of the "dark" or "weird" ecology VanderMeer and Morton advance in their texts.

The second section, "Imagining Aliens and Monsters", presents three analyses on how nonhuman characters and nonhumans' lived experiences have been, and can be, imagined, reimagined, and simulated in multimodal fictions. In his classic essay, Nagel (1974) argues that we are fundamentally unable to imagine what it is like to be a bat, because our senses and cognition are structured in a way that is uniquely human - whereas bats' senses and cognition have a uniquely bat-like configuration. In spite of this, popular genres from children's literature and fantasy to science-fiction have routinely strived to imagine and show what it could be like to be something other than human - and different media have used vastly different means to achieve this effect. 
The fourth chapter, "Alien Overtures: Speculating about Nonhuman Experiences with Comic Book Characters", continues the experiential line of inquiry introduced in the previous chapter but recombines it with the multimodal storytelling of comics and the tricky, anthropomorphizing concept of the fictional character. More specifically, the article penned by Essi Varis explores - first theoretically and then through a cognitive analysis of Neil Gaiman and J. H. Williams III's fantastical graphic novel The Sandman: Overture (2015) - whether markedly nonhuman comic book characters are able to convey, or at least gesture toward, nonhuman experiences. On the one hand, cognitive narrative theory has repeatedly underlined that the ways in which we think and speak about narratives in general - and characters in particular - are highly subjective and, thus, heavy with human bias. On the other hand, the interactions between reading minds and experimental or imaginative texts can make these limits of our human subjectivity more visible, and even counteract our automatic human-centric assumptions through different techniques of defamiliarization and speculation. The verbal-pictorial hybridity of comics, which enables displaying countless different amalgamations of human and nonhuman traits and viewpoints, is an especially flexible tool for such explorations.

In the fifth chapter, Jonne Arjoranta continues the investigation into different medium-specific imaginations by examining how video games portray the nonhuman, what kind of assumptions they make about being nonhuman, and what kind of tools and techniques they use to convey the (imagined) experience of nonhumanness. The analysis focuses on Aliens vs. Predator (2010, Rebellion Developments), which features three different but intertwined campaigns that allow the player to play as a human, an alien, and a predator. The game thereby evokes two playing experiences that are supposedly nonhuman, and enables direct comparison between them and the "normal" experience of playing as human. Like the authors of the previous two chapters, Arjoranta draws theoretical support for this discussion from the notion of embodied cognition.

In the final chapter of the second section, Marleena Mustola and Sanna Karkulehto demonstrate through analyses of Maurice Sendak's Where the Wild Things Are (1963), Shaun Tan's "Stick Figures" (in Tales of Outer Suburbia, 2009), and Tuutikki Tolonen's Monster Nanny (2017) how monsters in children's literature embody contemporary (human) anxieties. In all of these narratives, the fear of difference agitates the human characters to mistreat the characters that represent the disempowered other: monsters - and even the monstrous characteristics lurking inside the humans themselves - are squeezed into tight closets, creatures evoking existential questions are beaten down to silence, and opportunistic quests are undertaken to tame anything wild and unruly. Children and monsters share a similar position in the world 


\section{4}

Sanna Karkulebto et al.

dominated by human adults: they are something to be either tamed, protected, or abused, because they are constructed as different and "other" from the hegemonic standard that is the full-grown, healthy (and typically white) human. Children's literature thus opens a space where the ethical relationships between humans and nonhumans can be radically reconfigured.

The third section, "Becoming With Animals", comprises three chapters that discuss humans' relationships with nonhuman animals - the semantic and material, messy and fleshy becomings, in which we, as fauna, are constantly entangled. The section opens with Mikko Keskinen's chapter, which probes the narrational peculiarities of posthumous tales told by dogs. The primary target of Keskinen's analysis is Charles Siebert's novel Angus (2000), a first-person memoir of a dying Jack Russell terrier. The novel presents its canine protagonist Angus as having an outstanding command of the English language, whereby it is no surprise that his lineage turns out to be particularly literary. Yet, there are curious idiosyncrasies in his parlance, which appear to suggest a uniquely cynomorphic language and worldview. Since Angus the dog resides on the border zone between human and nonhuman spheres of communication and knowledge, he is a hybrid creature: domesticated, yet wildly unfamiliar. A similar hybridity marks Angus the novel: backward narration may appear a "natural" analogy to canines' ability to trail lingering scents, but it also results in unnatural and counterfactual effects and storylines.

The eighth chapter, by Brad Bolman, traces the ethically complex shared history of humans and pigs, which has encompassed everything from didactic dissections and culinary consumption to artistic co-creation. One of the most prominent early anatomy textbooks, the Anatomia porci, has puzzled scholars for a long time: why were pigs selected as the main objects of dissection at the dawn of anatomical study? Moreover, how could the knowledge of early Roman pig dissection have survived the collapse of the Roman Empire, to reappear centuries later in Salerno, Italy? Inter-species anatomical knowledge has traveled with and through the bodies of hogs between the Greco-Roman and Islamicate worlds for centuries. At first, this circulation emphasized the role of edibility, until it turned into more philosophical debates concerning human-animal difference, as in the writings of Gilles Deleuze and Félix Guattari, Donna Haraway, and Charles Foster. After reviewing these lengthy and intersecting lines of scholarly discussion on pigs, Bolman concludes his chapter with an analysis of contemporary artist Miru Kim's work, which explores the fleshy similarities between humans and hogs through extended nude performances.

Next, Hana Porkertová's chapter, "Reconfiguring Human and Nonhuman Animals in a Guiding Assemblage: Toward Posthumanist Conception of Disability", examines how the relationships between human and nonhuman animals can affect the experience and the notion of 
disability. The chapter is based on ethnographic observations of and interviews with a visually impaired woman called Eva and her guide dog Nessie, whose experiences are discussed within the framework of the Deleuzo-Guattarian theory of assemblage. In the traditional humanist paradigm, conceptualizations of nonhumanity and disability are built on assumptions of human superiority as well as on negative dialectics of identity, opposition, analogy, and resemblance. These conceptual constructs are challenged by the assemblage formed by Eva and Nessie, since an assemblage is always created through dynamic, mutual processes, which have no beginning and no end, no leaders nor followers. In other words, the "guide team" is effective only when the humanist perspective, and its dichotomic view on the relationships between human and nonhuman animals, is disrupted. Employing the notion of assemblage in conceptual thinking thus entails the subversion of the modern concept of borders as well as of such related concepts as body, autonomy, and independence.

The fourth section, "Technological (Co-)Agencies", seeks to describe different (possible) relations between us humans and our own mechanical creations. Cléo Collomb and Samuel Goyet's "Meeting the Machine Halfway: Toward Non-Anthropocentric Semiotics" highlights the narrow conceptions of machines that we circulate in our daily lives, and proposes a reconfiguration to this relationship. The chapter opens with a semiotic analysis of one page of Google Search results, the purpose of which is to demonstrate how habitually and reductively machines are viewed as simple tools whose functioning is represented in terms that serve humans specifically. The second part of the chapter endeavors to describe the agency of machines in their own terms, as a specific mode of action. This computational agency can be made visible, for example, by analyzing the ways in which we think of writing: machines allow humans to write, but they are also capable of writing themselves - even if their writing is computational, rather than verbal, and thus unreadable to (most) humans. If one wishes to uncover the marks of computers' agency, one should target the semiotic characteristics of "computational writing", such as bugs or glitches, rather than the human-friendly, human-designed interfaces.

Marleena Huuhka's chapter, "Journeys in Intensity: Human and Nonhuman Co-Agency, Neuropower, and Counterplay in Minecraft", revisits Chapter 9's idea that the relations between humans and nonhumans could be viewed as a type of Deleuzo-Guattarian assemblage, and explores the human-machine cooperation conducted in the digital environments of Minecraft from this perspective. Playing video games is thus described as an activity that combines various agents, materialities, and species into operations that produce pleasure, but which - at the same time - also enable oppressive, colonialist, and violent practices inside as well as outside of the fictional worlds of the games. The chapter's 
argumentation draws especially on the concept of counterplay, which refers to the type of gameplay that somehow obstructs the rules or goals of the game being played. The concept has been previously discussed by Thomas Apperley as well as by Hanna Wirman and Rika Nakamura, but here, Huuhka identifies two entirely new practices of counterplay that allow, or even aim at, deconstructing the inherent logics of videogames.

The twelfth chapter, authored by Patricia Flanagan and Raune Frankjær, explores how the evolution of wearable technology blurs the boundaries of the body. The writers propose that emergent wearable technologies, which augment human perception and sensual capacity, may come to expand or alter our understanding of what it truly means to be human, and thus foster new, interconnected ways of understanding our place within the Neganthropocene. Building on the writings of Rosi Braidotti, Karen Barad, Donna Haraway, Bernard Stiegler, Peter-Paul Verbeek, and Bruno Latour, the chapter arrives at a theory of "cyborganic wearables", where the concept of "cyborganic" describes a fictional posthuman entity, a hybrid of human, nature, and machine. Such a figure, through its relation to cyborganic mutation and creativity, calls for a reconfiguration of humanness itself - a new conceptualization that would lay a more sustainable foundation for humanity's selfunderstanding in the future.

Finally, in the concluding chapter of the volume, Juha Raipola enquires how we - as humans and as literary or cultural scholars - could make sense of the emergent, self-organizing capacities of the nonhuman material world. The chapter returns to the insights of cognitive narratology introduced in Chapters 3-5, and uses them to reassess material ecocriticism's notion of "storied matter". Contrary to the recent claims that nonhuman matter has narrative agency, Raipola asserts that matter consists of countless emergent processes, which can never be reduced to their narrative representations. When the more-than-human world is interpreted through a narrative lens, one must always remain wary of the basic human tendency to reduce complex emergent behavior into simplified anthropocentric storylines. Instead of joining in celebrating the endless "narrative" agency of matter, the chapter thus concludes that it might often prove more fruitful to analyze the numerous ways in which different nonhuman material entities escape and defy our human desire for narrative logics and descriptions.

"If we want to respect the creativity of matter in its own terms, we have to acknowledge that its numerous agencies are not performing stories for the human audience, but exist and act of their own accord", Raipola writes. "No matter how hard we try to fit this world into our cultural landscape of narrative sense-making, a major part of its behavior always remains unreachable". Each reader of this anthology is, of course, free to interpret this (lack of) closure as either resignation or a challenge. 


\section{References}

Alber, Jan, Henrik Skov Nielsen, and Brian Richardson. 2013. A Poetics of Unnatural Narrative. Columbus, $\mathrm{OH}$ : Ohio State University Press.

Åsberg, Cecilia. 2008. "A Feminist Companion to Post-humanities.” NORA Nordic Journal of Feminist and Gender Research 16 (4): 264-269.

- 2013. "The Timely Ethics of Posthumanist Gender Studies." Feministische Studien 31 (1): 7-12.

, and Rosi Braidotti. 2018. "Feminist Posthumanities: An Introduction."

In A Feminist Companion to the Posthumanities, edited by Cecilia Åsberg, and Rosi Braidotti, 1-22. Cham: Springer.

Badmington, Neil. 2000. "Introduction.” In Posthumanism, edited by Neil Badmington, 1-10. Basingstoke: Palgrave.

- 2004. Alien Chic. Posthumanism and the Other Within. London: Routledge.

Bernaerts, Lars, Marco Caracciolo, Luc Herman, and Bart Vervaeck. 2014. “The Storied Lives of Non-Human Narrators.” Narrative 22 (1): 68-93.

Braidotti, Rosi. 2002. Metamorphoses. Towards a Materialist Theory of Becoming. Cambridge, MA: Polity.

- 2013. The Posthuman. Cambridge, MA: Polity.

. 2017. "Four Theses on Posthuman Feminism." In Anthropocene Feminism, edited by Richard Grusin, 21-48. Minneapolis, MN: University of Minnesota Press.

Brondizio, Eduardo S., Karen O’Brien, Xuemei Bai, Frank Biermann, Will Steffen, Frans Berkhout, Christophe Cudennec, Maria Carmen Lemos, Alexander Wolfe, Jose Palma-Oliveira, and Chen-Tung Arthur Chen. 2016. "Re-conceptualizing the Anthropocene: A Call for Collaboration." Global Environmental Change 39(July): 318-327.

Butler, Judith. 2004. Undoing Gender. New York: Routledge. Verso.

- 2010. Frames of War. When Is Life Grievable? London: Verso.

Colebrook, Claire. 2017. "We Have Always Been Post-Anthropocene: The Anthropocene Counterfactual." In Anthropocene Feminism, edited by Richard Grusin. Minneapolis, 1-20. MN: University of Minnesota Press.

— Idols, edited by Tom Cohen, Claire Colebrook, and J. Hillis Miller, 7-19. London: Open Humanities Press.

Crutzen, Paul J., and Eugene F. Stoermer. 2000. “The Anthropocene.” Global Change NewsLetter 41: 17-18.

Davis, Heather, and Etienne Turpin. 2015. “Art \& Death: Lives Between the Fifth Assessment \& the Sixth Extinction.” In Art in the Anthropocene. Encounters Among Aesthetics, Politics, Environments and Epistemologies, edited by Heather David, and Etienne Turpin, 3-29. London: Open Humanities Press.

Gilcrest, David W. 2002. Greening the Lyre. Environmental Poetics and Ethics. Reno and Las Vegas: University of Nevada Press.

Graham, Elaine L. 2002. Representations of the Post/human. Monsters, Aliens and Others in Popular Culture. New Brunswick, NJ: Rutgers University Press. 


\section{Sanna Karkulehto et al.}

Grusin, Richard, ed. 2017. Anthropocene Feminism. Minneapolis, MN: University of Minnesota Press.

Haraway, Donna. 1991. Simians, Cyborgs, and Women. The Reinvention of Nature. New York: Routledge.

- 2008. When Species Meet. Minneapolis, MN: University of Minnesota Press.

- 2015. "Anthropocene, Capitalocene, Plantationocene, Chthulucene: Making Kin.” Environmental Humanities 6: 159-165. http:// environmentalhumanities.org/arch/vol6/6.7.pdf.

- 2016. Staying with the Trouble: Making Kin in the Chthulucene. Durham, NC: Duke University Press.

Heise, Ursula. 2016. Imagining Extinction. The Cultural Meanings of Endangered Species. Chicago and London: University of Chicago Press.

Herman, David. 2011. "Storyworld/Umwelt. Nonhuman Experiences in Graphic Narratives." SubStance 40 (1): 156-181.

- 2012. "Toward a Zoonarratology. Storytelling and Species Difference in Animal Comics." In Narrative, Interrupted. The Plotless, the Disturbing and the Trivial in Literature, edited by Markku Lehtimäki, Laura Karttunen, and Maria Mäkelä, 93-119. Berlin: Gruyter.

- 2013. "Cognitive Narratology (Revised Version; Uploaded 22 September 2013)." The Living Handbook of Narratology. www.lhn.uni-hamburg.de/ article/cognitive-narratology-revised-version-uploaded-22-september-2013.

—, ed. 2018. Animal Comics. Multispecies Storyworlds in Graphic Narratives. London: Bloomsbury.

Holm, Poul, Joni Adamson, Hsinya Huang, Lars Kirdan, Sally Kitch, Iain McCalman, James Ogude, Marisa Ronan, Dominic Scott, Kirill Ole Thompson, Charles Travis, and Kirsten Wehner. 2015. "Humanities for the Environment A Manifesto for Research and Action.” Humanities 4: 977-992.

Iovino, Serenella. 2016. Ecocriticism and Italy: Ecology, Resistance, and Liberation. London: Bloomsbury.

— In Material Ecocriticism, edited by Serenella Iovino, and Serpil Oppermann, 1-17. Bloomington and Indianapolis: Indiana University Press.

Koistinen, Aino-Kaisa. 2015. The Human Question in Science Fiction Television. (Re)imagining Humanity in Battlestar Galactica, Bionic Woman and $V$. Jyväskylä: Jyväskylä University Press.

$\longrightarrow$, and Sanna Karkulehto. 2018. "Posthuman(ist) Feminism, Feminist Posthumanities." Genealogy of the Posthuman, Critical Posthumanism Network, July 2018. http://criticalposthumanism.net/genealogy/feminism/.

Koivunen, Anu. 2010. "An Affective Turn? Reimagining the Subject of Feminist Theory." In Working with Affect in Feminist Readings: Disturbing Differences, edited by Marianne Liljeström, and Susanna Paasonen, 8-28. London: Routledge.

Latour, Bruno. 2010. “An Attempt at a 'Compositionist Manifesto'.” New Literary History 41: 471-490.

- 2011. "Waiting for Gaia. Composing the Common World through Arts and Politics." A Lecture at the French Institute, London, November 2011, for the Launching of SPEAP (The Sciences Po Program in Arts and Politics). www.bruno-latour.fr/node/446.

Lummaa, Karoliina. 2017. Kui trittitii! Finnish Avian Poetics. Translated by Jaakko Mäntyjärvi, Emily Jeremiah, and Fleur Jeremiah. Annales 
Academiae Scientiarum Fennicae. Humaniora 371. Helsinki: Suomalainen Tiedeakatemia.

Malafouris, Lambros. 2013. How Things Shape the Mind. A Theory of Material Engagement. Cambridge, MA and London, England: The MIT Press.

Moe, Aaron M. 2014. Zoopoetics. Animals and the Making of Poetry. Plymouth, UK: Lexington Books.

Morton, Timothy. 2013. Realist Magic. Objects, Ontology, Causality. London: Open Humanities Press.

Nagel, Thomas. 1974. "What Is It Like to Be a Bat?" The Philosophical Review 83 (4): 435-450.

Palsson, Gisli, Bronislaw Szerszynski, Sverker Sörlin, John Marks, Bernard Avril, Carole Crumley, Heide Hackmann, Poul Holm, John Ingram, Alan Kirman, Mercedes Pardo Buendía, and Rifka Weehuizen. 2013. "Reconceptualizing the 'Anthropos' in the Anthropocene." Environmental Science \& Policy 28: 3-13.

Scigaj, Leonard M. 1999. Sustainable Poetry. Four American Ecopoets. Lexington, KY: The University Press of Kentucky.

Soper, Kate. 1995. What Is Nature? Culture, Politics and the Non-Human. Oxford and Cambridge, MA: Blackwell.

Sörlin, Sverker. 2012. "Environmental Humanities: Why Should Biologists Interested in the Environment Take the Humanities Seriously?" BioScience 62(9, September), 788-789.

Stiegler, Bernard. 2017. "Escaping the Anthropocene.” In The Crisis Conundrum. How To Reconcile Economy and Society, edited by Mauro Magatti, 149-163. Houndmills, Basingstoke, Hampshire: Palgrave Macmillan.

Tüur, Kadri. 2017. Semiotics of Nature Representations: On the Example of Nature Writing. Dissertationes Semioticae Universitatis Tartuensis 25. Tartu: University of Tartu Press.

Twine, Richard. 2010. "Genomic Natures Read through Posthumanism.” The Sociological Review 58: 175-179.

Varis, Essi. 2019. Graphic Human Experiments. Frankensteinian Cognitive Logics of Characters in Vertigo Comics and Beyond. JYU Dissertations 73. Jyväskylä: University of Jyväskylä. http://urn.fi/URN:ISBN: 978-951-39-7725-2.

Vermeulen, Pieter. 2014. "Posthuman Affect." European Journal of English Studies 18 (2): 121-134.

Vint, Sherryl. 2005. "Becoming Other: Animals, Kinship, and Butler's Clay's Ark." Science Fiction Studies 32 (2): 281-300.

- 2007. Bodies of Tomorrow. Technology, Subjectivity, Science Fiction. Toronto, CA: University of Toronto Press.

- 2014. Animal Alterity. Science Fiction and the Question of the Animal. Liverpool: Liverpool University Press.

Wark, McKenzie. 2016. Molecular Red. Theory for the Anthropocene. London: Verso.

Wolfe, Cary. 2003a. Animal Rites. American Culture, the Discourse of Species, and Posthumanist Theory. Chicago, IL: University of Chicago Press.

- 2003b. "Introduction." In Zoontologies. The Question of the Animal, edited by Cary Wolfe, ix-xxiii. Minneapolis and London: University of Minnesota Press.

- 2010. What Is Posthumanism? Minneapolis, MN: University of Minnesota Press. 

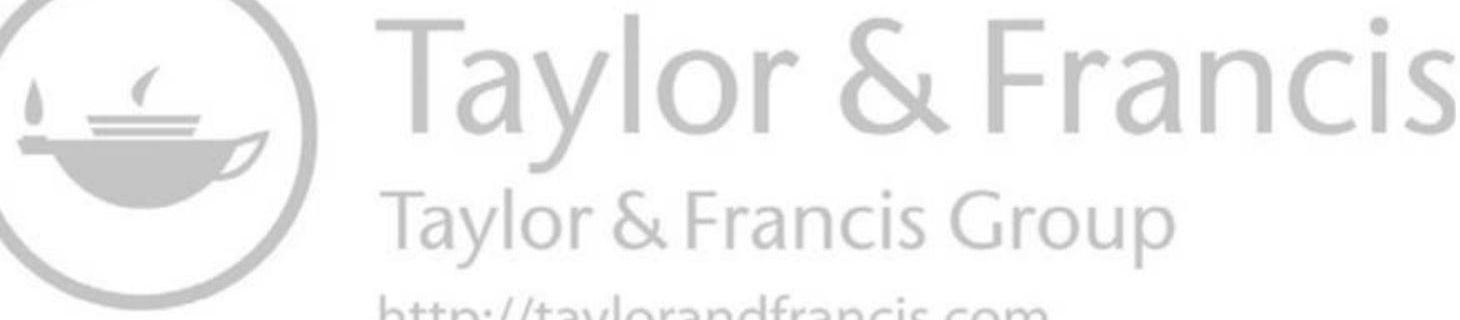
http://taylorandfrancis.com 


\section{Part 1}

\section{Toward Posthumanist \\ Literature and \\ Posthumanist Reading}



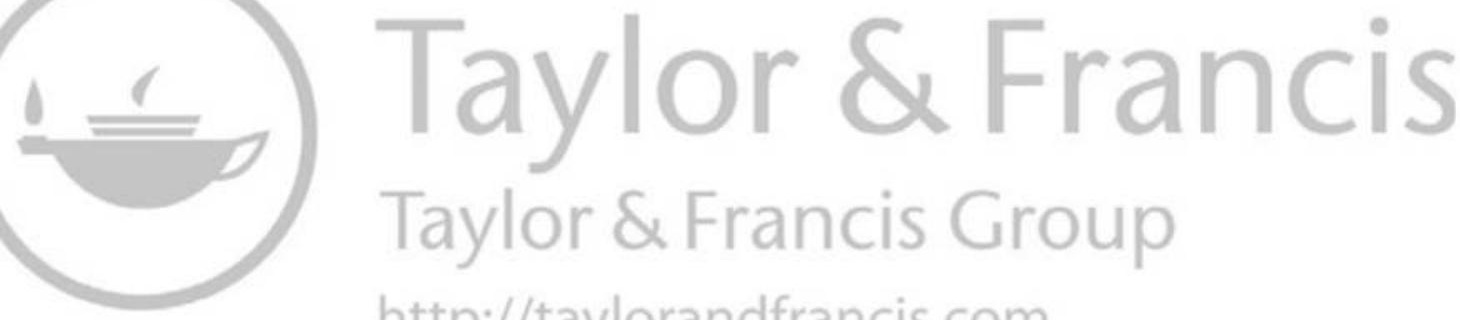
http://taylorandfrancis.com 


\title{
1 On the Possibility of a Posthuman/ist Literature(s)
}

\author{
Carole Guesse
}

After a 2015 conference speech entitled "Posthumanist Literature?" Stefan Herbrechter, author of several articles and monographs on posthumanism and the posthuman, was asked to name a novel that was, according to him, posthuman. He answered that he had not found any posthumanist literature yet, that "it would be literature written by stones [...] or based on animal traces". This answer epitomizes some of the main issues regarding the scholarship on posthumanism and the posthuman: on the one hand, "posthumanism" and the "posthuman" are sometimes confused and used interchangeably; ${ }^{1}$ on the other hand, such understanding of the posthuman as a biological other (stones, animals) is incomplete. In their Post- and Transhumansim: An Introduction, Ranisch and Sorgner $(2014,8)$ indeed insist upon the plurality of this figure: "there is no commonly shared conception of what posthumans are, and visions range from the posthuman as a new biological species, a cybernetic organism, or even a digital, disembodied entity". Acknowledging this plurality is the only way to cope with the variety of (sometimes contradictory) writings dedicated to posthumanism and the posthuman.

Clearly, the issue of posthuman and posthumanist literatures remains debatable. This chapter reassesses the possibility of such literatures with, on the one hand, a clarification of the concepts of posthumanism and the posthuman, and, on the other hand, a methodology based upon literary and communication theories. Precisely, this study dissects the concept of "literature" basing itself on Paul Ricœur's understanding of Roman Jakobson's communication theory and then discusses the possibility for these various aspects of literature to be posthuman or posthumanist. As an illustration, it also uses The Possibility of an Island (2005) by Michel Houellebecq, a novel in which genetically enhanced clones live secluded lives, spend their time reading and commenting on their ancestors' autobiography, and sometimes, consequently, tell a bit of their own story. By contemplating the possibility of posthuman and posthumanist literatures, this chapter considers whether posthumanism and the posthuman can serve as efficient and meaningful analytical tools for literary analysis, and vice versa: namely, whether a literary perspective can provide new insights on posthumanism and the posthuman. 


\section{Carole Guesse}

\section{Posthuman(s) and Posthumanism(s)}

Intuitively, the posthuman is a figure born from the concerns over what might happen to humankind now that technology provides ways of modifying, enhancing, or even wiping out humans. Economic, social, environmental, and technological upheavals have given humans reasons to anticipate - whether hopefully or fearfully - times when humankind would no longer be what it used to be. While the possibility of modifying and enhancing the human body has been conceivable since the advent of genetics in the early twentieth century, the launch of the first atomic bombs on Hiroshima and Nagasaki in 1945 forced most thinkers to contemplate the possible destruction of humankind. The posthuman epitomizes those hopes and fears, and has prompted several discourses over the last few decades that are optimistic, pessimistic, or critical toward the use of technology on the human body.

Transhumanists are a group of scholars and scientists who adopt an optimistic attitude toward technology since "[t]ranshumanism affirms the use of techniques to increase the likelihood of bringing about the posthuman" (Sorgner 2014, 30). ${ }^{2}$ The technophobics (or "technoconservatives"), for their part, do not form a group as established as the transhumanists, although Francis Fukuyama is often considered one of their most famous representatives, with his book defending the human nature (Our Posthuman Future: Consequences of the Biotechnology Revolution 2002) and his article defining "Transhumanism" (2004) as one of the world's most dangerous ideas. Lastly, between these two ideologically opposed discourses stands posthumanism, a critical movement as plural as the posthuman itself.

In the fields of philosophy and cultural theory, posthuman characters have often leaned toward the abstract and the metaphorical, such as in Donna Haraway's 1984 "A Cyborg Manifesto", in which she uses a posthuman character - the "cyborg" - partly to discuss women's condition in the late twentieth century. Many scholars consider Haraway's writings to be the cradle of the sociological and philosophical trend labeled "posthumanism", ${ }^{3}$ especially with the following quotation: "Latetwentieth-century machines have made thoroughly ambiguous the difference between natural and artificial, mind and body, self-developing and externally designed, and many other distinctions that used to apply to organisms and machines" (Haraway 2004, 11). This overcoming of traditional distinctions is precisely the focus of Stefan Lorenz Sorgner $(2014,32)$ when he defines posthumanism:

Posthumanism represents the attempt to get rid of categorical dualities within any type of judgment, as it is being regarded as most plausible that thereby the complexity of the world is grasped best within propositional form. 
Posthumanists therefore have a different understanding of "posthuman", especially since Katherine Hayles's $(1999,291)$ famous "we've always been posthuman", which Sorgner $(2014,33)$ reformulates as "we have always been dependent on technologies and there is no clear cut categorical distinction between nature and culture, genetic and environmental influences or nature and technology". This chapter, however, considers that the posthuman is primarily and more generally a figure, a character whose interpretation changes according to the discourses (transhumanism and posthumanism, amongst others) that use it.

Simultaneously, other scholars, including Rosi Braidotti, situate the origin of posthumanism in the French anti-humanism of the 1960s, promoted by Michel Foucault and his "Death of Man", which was theorized in The Order of Things (1966). Braidotti (2013, 23) explains that anti-humanists reject "the implicit Humanism of Marxism, more specifically the humanistic arrogance of continuing to place Man at the centre of world history". To posthumanists, the outdated concept is humanism and anthropocentrism, that is to say humankind's exceptionalism and central position in a system of values that is criticized for being exclusively Western rather than universal. According to Braidotti, posthumanist theory can develop in two directions: posthumanism and post-anthropocentrism. These currents undermine the supremacy of Man, respectively, as "white, urbanized, speaking a standard language, heterosexually inscribed in a reproductive unit and a full citizen of a recognized polity" and as a "hierarchical, hegemonic and generally violent species". This supremacy is held, in the first case, against "sexualized and racialized others", that is, women and non-whites, and in the second, "naturalized others", such as "animals, insects, plants and the environment" (Ibid. 65-66).

However, the overwhelming majority of posthumanist writings actually discuss issues related to Braidotti's so-called "post-anthropocentrism", which somehow questions the relevance of her categorization. Moreover, as Ranisch and Sorgner $(2014,8)$ explain, such attitude of deconstruction was already part of postmodernism; posthumanism indeed perpetuates this critical movement, yet with "a specific focus on (emerging) technologies". This chapter retains this emphasis on technology for posthumanism as well as the posthuman; a posthuman can therefore be a (bio)technologically enhanced being but not an actual organic nonhuman species such as animals and plants. One must acknowledge, however, that the posthuman is not necessarily a futuristic speculative figure such as a cyborg, a mutant, or a robot. Many thinkers indeed consider that some of the already-existing (bio)technologies - for example, surgical transplants, prostheses, neuropharmacology, or the ubiquitous devices connecting us to the Internet - are already turning humans into posthumans. 


\section{Literature and Its Constituents}

Such a terminological clarification is the first step in this investigation on the possibility of posthuman/ist literature(s). The next step is the definition - and in this case the dissection - of the concept of "literature" itself, which has never ceased to prompt interrogations and theories since the Antiquity, resulting in an unfathomable amount of writing to cover, should one aim for exhaustiveness. For the sake of conciseness, this chapter bases its reflection on Jakobson's "constitutive factors in any speech event, in any act of verbal communication" $(1960,353)$, which were schematized as follows (Figure 1.1).

Paul Ricœur has noted that this model could not fully apply to literature since it is an indirect mode of communication (Vultur 2011, 247). The "addresser" and the "addressee" are not in physical contact and thus do not share the same socio-historical context, which results in the duplication of contexts, the author's and the reader's, which creates a discrepancy in the understanding of the "message". Moreover, literature features "various possible enunciative agents": the "addresser" is not only the empirical author but also the narrator, who can be the implied author, an omniscient narrator, or a character. Similarly, the "addressee" is not only the empirical reader but also the narratee, who can be an implied reader or a character (Hébert 2011). ${ }^{4}$ The "message" is, in this literary context, the narrative but also the story that this narrative features, ${ }^{5}$ while the "code" is traditionally written language, even though many works feature other "codes" - for example, images or, in the case of digital literature, videos. Similarly, the "contact" is likely to be a book, but not in all cases, as demonstrated below. While Jakobson used his model to explore the relationship between the "message" and each of the six categories, this study uses its literary version to explore the validity of each factor when modified with the adjectives "posthuman" or "posthumanist".

In "Posthumanist Literature?" Herbrechter considers modalities to the realization of posthumanist literature: on the one hand, it should go beyond the limits of language, "a primary constituent of human nature" (Garber qtd. in Herbrechter 2015, 2), which makes literature deprived of human language and human agency quite unlikely. On the other

\section{CONTEXT}

ADDRESSER

MESSAGE

ADDRESSEE

\section{CONTACT}

CODE

Figure 1.1 Jakobson's “constitutive factors" in speech events and any acts of verbal communication (Jakobson 1960, 353). 
hand, literature is declining in favor of a "new media and virtual reality technology and might therefore be no longer at the forefront of cultural change and innovation" which renders "the phrase "posthumanist literature" contradictory (Herbrechter 2015, 5-6). While Herbrechter (2015, 8 ) considers posthuman literature as purely thematic - the posthuman only being able to influence, according to the framework developed earlier, the factor of the story - he apprehends posthumanist literature according to several factors - language, context, and book - but eventually acknowledges the impossibility for the concept to exist. His understanding of posthumanism implies that the human cannot play any part in the process of creating posthumanist literature, which turns this concept into a theoretical dead-end based on an apparently unsolvable contradiction. The purpose of this chapter is to overcome this dead-end by reconsidering posthumanist and posthuman literatures based upon a clearer and stronger theoretical and literary background.

\section{Production and Reception Contexts}

As mentioned, literature is an indirect mode of communication; this indirectness implies that the context of writing and the context of reading differ in terms of both time and place. The Possibility of an Island creates a mise en abyme of this indirectness: Daniel, a late-twentieth or early twenty-first-century stand-up comedian, writes his autobiography, each chapter of which is followed by a comment from Daniel's clone (first Daniel24, then, when the latter dies, Daniel25), who reads this autobiography centuries later. The discrepancy between Daniel's context and that of his clones - a post-cataclysmic future where humankind is on the verge of extinction - is, of course, central to the plot: Daniel was asked to write his autobiography in order to pass his memories on to his successive clones, but the 24th and 25th clones' context of reading is so different from Daniel's that they hardly understand and sympathize with their ancestor. The remaining humans have indeed returned to a primitive, inarticulate, and tribal state of life, thus preventing understanding between them and the clones, who almost regard them as animals:

I simply consider them to be slightly more intelligent monkeys, and, for this reason, more dangerous. There are times when I unlock the fence to rescue a rabbit, or a stray dog; but never to bring help to a human.

(Houellebecq 2005, 17)

Moreover, the clones live alone and secluded in their homes, with the Internet as their only means of communication with other clones, which makes this 2005 novel rather visionary in the way it echoes the current importance of social networks. Houellebecq's context of writing was 
already highly technological - he was himself a computer engineer - and the role of technology in life and society is only likely to increase over the next decades. As mentioned, technology and its achievements are precisely the focus of the theories on posthumanism, and even more so those on the posthuman. Whether the author or the reader of a literary work is situated in a posthuman context depends on how enthusiastic and optimistic one is about current technologies. Some may indeed consider that the current ubiquity of technology is a sign that we nowadays live in a posthuman context. In parallel, given the increasing questioning of human exceptionalism that the last three decades have featured, there is no doubt that they can be qualified as posthumanist.

Speculating about posthuman and posthumanist contexts of literary production and reception is hardly possible without alluding to the people living in this context: a posthuman or posthumanist context of writing would be a context in which writers are, respectively, posthuman or posthumanist. Similarly, the possibility of such a context of reading entails discussing the possibility of a posthuman or posthumanist reader altogether.

\section{Readers and Their Readings}

In "What is a Posthumanist Reading?" (2008), Herbrechter and Callus put forward the following characteristics:

[A] posthumanist reading [...] focuses on the ambiguities around the human [...][,] can strategically exploit the ambiguity of the term posthumanism [...] [,] can evaluate examples of posthuman representation in terms of their potential for a critical post-humanism [...] [,] may be critical of both representations of the posthuman and of humanism, and instead envisages the human as something or someone that remains to arrive, as a potential that remains to be defined or realised [...] [,] can nevertheless resist technological determinism and posthuman teleology, and contemplate a "posthumanism without technology" (Herbrechter and Callus 2008 passim.) [...] [,] may identify oppositions between the human and the nonhuman at work in a text or practice and demonstrate how the vital difference between the two has to be strategically breached in order to trouble protection of the "essential" purity of the category.

(Herbrechter and Callus 2008, 96-97)

Such characteristics allow the production of a posthumanist reading of almost any text, and not only those written in the speculative mode. In other words, works that do not necessarily feature posthuman characters or issues might still provoke posthumanist readings. Such a tendency is displayed in Wallace's DH Lawrence, Science and 
the Posthuman (2005); Herbrechter and Callus's Cy-Borges: Memories of the Posthuman in the Work of Jorge Luis Borges (2009); Herbrechter's Posthumanist Shakespeares (2012); and Clarke and Rossini's Cambridge Companion to Literature and the Posthuman (2017), which contains chapters on medieval, early modern, and romantic literatures. Even if a posthumanist reading does not necessarily require a posthuman character, the presence of a posthuman character in a novel is very likely to engender a posthumanist reading of the novel. Such is the case of The Possibility of an Island, which has been the object of various posthumanist readings since its publishing, mainly because of the inclusion of bioengineered clones in its plot. ${ }^{6}$

However, at the beginning of their article, the authors address the following question:

how is it possible to read as if one were not human, or at least from a position of analytical detachment in relation to the humanity whether "essential" or "constructed" - that informs and determines the very position from which it is read? What would be the nature of such an "unnatural" reading?

(Herbrechter and Callus 2008, 95)

While in the rest of their article, they use "reading" as "a particular interpretation of something", this question rather insists on "reading" as "the act of reading" (s.v. "Reading", Merriam-Webster), which emphasizes the presence of an agent, the reader. Through this question, the concept that they are actually investigating is not a "posthumanist reading" but a posthuman reader, a reader who should be able to pretend that it is not human, which leads them to the same dead-end that Herbrechter faced in his 2015 presentation.

The 2008 article, which thus uses the phrase "posthumanist reading" to allude to both the posthumanist interpretation and the posthuman reader, exemplifies, again, the importance of differentiating between "posthumanist" as a discourse and "posthuman" as a figure. A postbumanist reader is a reader who is familiar with the issues of posthumanism, which allows them to produce posthumanist interpretations of many literary works. A posthuman reader is a reader who is a posthuman, that is to say a (bio)technologically enhanced human, such as the clones in The Possibility of an Island, who are the readers of their ancestor's autobiography as well as other theoretical, philosophical, and scientific human works. Of course, being posthuman influences the reading they might produce of these human writings. Similarly, one could also speculate about posthuman readers in real life: in "The Posthuman Reader in Postprint Literature: Between Page and Screen", Jessica Pressman $(2015,55)$ explains that digital literature is forcing us to be posthuman readers because "reading [Between Page and Screen] requires a 
sophisticated digital apparatus: an Internet connection, a webcam, the right flash-based software upgrades, and, of course, the book containing the Qr codes”. The digitality of the work does not transform readers into posthumans but instead makes them realize that they had been posthuman all along, even before the reading.

\section{Posthumanist and Posthuman Authors}

Just as a reader can be posthumanist as long as they are familiar with posthumanist theories, an author can self-consciously write a posthumanist work. One could argue that some contemporary writers have been influenced by the omnipresence of posthumanism in recent theory and might have developed their narratives in order to make a posthumanist statement or even contribute to this theoretical trend, although this assumption is often hard to prove when the authors have not declared so themselves.

The Possibility of an Island was written in 2005, an era of increasing awareness of the possibilities of (bio)technology to modify humankind, which has been reflected in the increasing number of publications on posthumanism and the posthuman. ${ }^{7}$ Carole Sweeney $(2013,157)$ notes that Houellebecq's 1998 novel Atomised was already written at a time when "there was much intellectual interest in posthumanism". Houellebecq must have been influenced by both the constant technological progress and the philosophical and critical discourse inspired by this progress. Yet one cannot state with certainty that the posthumanist trend, which questions human supremacy and exceptionality as well as categorical ontological dualisms, has directly influenced him.

Posthumanist authors are very much human, but the perspective of a posthuman author still belongs, according to many, to fiction. Yet our current reality might in fact feature instances of posthuman authors. Some AI technologies can indeed imitate human communication as long as they have been programmed to do so - which still involves a form of human agency. Many researchers in computer science and narratology have been combining their knowledge to create "story generators", which are programs that can create a story, sometimes according to the rules of a certain genre (epic, romance, thriller, to name only a few), by simply following a previously established pattern. Gervás and his coauthors note that finding this pattern has precisely been the core issue for these researchers. Some of them have used Vladimir Propp's 1968 narrative morphological models, established through the study of Russian folktales. Others have used Joseph Campbell's 1968 structure of myths or Chatman's 1978 adaptation of Campbell to literature and films. Some scientists also used Robert McKee's 1997 narrative model. All of these models inspired the creation of AIs capable of writing stories (Gervás et al. 2006). One could consider these AIs to be posthuman writers, 
even though Gervás et al. (2006) established that none of the existing programs had managed to cope with the necessary ambiguities that add aesthetic value to a random narrative. Nevertheless, this does not totally deprive these nonhuman writers from their authorial status; many novels might just as well not display any aesthetic value and, according to some, do not qualify as "Literature" (with emphasis on the capital "L"), although others (publishers and booksellers, for example) may label these allegedly low-brow novels as "literature". The possibility of a posthuman author therefore depends on one's own understanding of the nature of literature. Moreover, since this 2006 article, computer engineers have made substantial progress on AIs: in Japan, in 2016, a novel written by an AI passed the first round of a literary contest (Lewis 2016) and one of Google's AIs has been writing poetry of relative quality (Gibbs 2016).

\section{Signifiers Keeping Up: Language, Books, and Narrative}

Literature and language seem to be inseparable concepts, especially in the perspective of Jakobson's theory of communication: a common "code" between the "addresser" and the "addressee" guarantees the circulation of the "message". Language is "a primary constituent of human nature" (Garber 2003, 264, qtd. in Herbrechter 2015, 2), but a posthumanist gesture would consist in bypassing such statement by considering the possibility of posthuman language. For example, computer code might be regarded as the language of the technological posthuman. Computers are, however, man-made machines, and so is the language they use to communicate, not only with each other but also with humans. Katherine Hayles $(1999,15)$ confirms that the "addressees of code $[. .$.$] include$ intelligent machines as well as humans". Posthumanists - and transhumanists, for that matter - do consider the possibility of machines breaking free from their human creators and starting to use a language of their own, impenetrable by humans. This would be a symptom of the long predicted - and feared - singularity: that moment when "the ordinary human is [...] overtaken by artificially intelligent machines or by cognitively enhanced biological intelligence and unable to keep pace" (Shanahan 2015, xvi). The narrator of The Possibility of an Island seems to be aware of the ambiguity regarding human agency in technology: "This book is intended for the edification of the Future Ones. Men, they will tell themselves, were able to produce this. It is not nothing; it is not everything; we are dealing with an intermediary production" (Houellebecq 2005 , 7). This sentence acknowledges both the role of humans in creating "The Future Ones" and the incompleteness of their work.

A post-anthropocentric perspective (which may be confused with posthumanism) on language can also provide interesting conclusions on the possibility of, if not posthuman, at least nonhuman literature. It might seem grotesque to state that animals, plants, minerals, or the 


\section{2}

environment can actually produce literature. A humanist or anthropocentric perspective would provide the aforementioned explanation that language, and thus literature, are primarily human: a "message" communicated by a nonhuman "addresser" in a nonhuman code will not be understood by a human "addressee" and cannot qualify as literature. A post-anthropocentric perspective would, on the contrary, acknowledge humankind's inability to ever know whether animals, plants, microorganisms, or minerals send "messages" that lay emphasis on themselves such as suggested by Jakobson with the "poetic function of language", the predominance of which guarantees the work's aestheticism, hence legitimacy as Literature. These messages may simply not be formulated in a language humans can understand - let alone print in a book.

Many posthumanists indeed regard printing as the emblematic institution of humanism that is bound to disappear in the digital era. The digitalization of publishing processes, and, more precisely, the rise of the e-book, might indeed threaten the materiality of the paper book but, despite its digitality and disembodiment, the e-book provokes the same reading habits as the printed book: one still reads linearly (from the first to the last page), in a range of places and situations. In this perspective, the e-book is but a mere modernization, not a true questioning of the printed book. Other undertakings do question the materiality of the book and its consequences on the reading experience and interpretation in a more profound way. The hypertext, for instance, is not a simple digitalization of a pre-existing paper novel, but a kind of literature that has been exclusively created for computers. In Shelley Jackson's notable Patchwork Girl (1995), the reader is presented with windows displaying a text full of hyperlinks that lead to other texts with other links. ${ }^{8}$ Hypertexts allow various reading paths, making each reading practically unique and enhancing the role of the reader in the production of meaning. In some cases, the computer can also generate random reading patterns, which implies that meaning production can be co-dependent on the reader and the machine, a nonhuman entity. This could be a step further toward both posthuman and posthumanist literature.

As far as its publishing process and its format are concerned, The Possibility of an Island is a very traditional novel. Published in French by Fayard in the collection Livre de Poche, a large mainstream collection that has no particular ties to any literary genre, The Possibility of an Island does not bear any idiosyncrasy compared to other printed books. One could argue, however, that its structure, which alternates between chapters narrated by Daniel and chapters narrated by his clones, invites readers to change their reading paths, by choosing to read only the clones' chapters and skip the rest, or inversely. Susannah Ellis argues further that the multiplication of narrators (Daniel, Daniel24, and Daniel25) $)^{9}$ echoes the repetitions in the novel as well as that of Houellebecq's other novel, Atomised. Cloning as a thematic motif turns into 
a narrative, diegetic, and even intertextual motif; The Possibility of an Island might be a clone of Atomised (Ellis 2014, 148-149), which might itself be a clone of Houellebecq's previous novel Whatever (1994).

\section{Speculative Fiction}

As this chapter exemplifies, critics and theoreticians rarely manage to keep speculation at bay when considering issues as futuristic as the posthuman. Novelists, for their part, can happily indulge in such an activity, for the worlds they choose to depict abide by their own laws. If reader, author, language, book, and context refer to entities belonging to our empirical universe, narratee, narrator, characters are entities of the universe of reference, ${ }^{10}$ a fictional universe in which the story takes place.

In adapting Jakobson's "addressee" and "addresser", the reader and author must be completed with their fictional versions, the narratee and the narrator, who, unlike their factual counterparts, can be posthuman (clones, robots, AIs, mutants, etc.) as long as the universe of reference allows it. The posthuman narrator and narratee help the readers accept the unnatural laws of a fictional universe by inviting them to see things through their posthuman perspective.

As already suggested, many stories can be read from a posthumanist perspective, whether this story challenges the categories and borders of the human in an obvious way (as in speculative fiction) or more discreetly. This implies that these stories - especially the oldest, non-speculative ones - are not always intrinsically posthumanist; they only become posthumanist, thanks to a contemporary posthumanist interpretation. Speculative stories, on the contrary, can be intrinsically posthumanist since they are more likely to feature tropes and characters - actual posthumans - that question or dilute the borders between the human and the nonhuman. In such speculative works, a posthumanist interpretation might seem almost inescapable - almost. Many speculative stories, especially the most popular ones, ${ }^{11}$ actually do not invoke a posthumanist discourse but, on the contrary, reinforce a dominant, humanist, and anthropocentric argument. Herbrechter and Callus $(2008,98)$ write:

There are what might be called "posthuman moments" in science fiction. They more or less deliberately threaten the integrity of a given "human essence" and are fetishistically indulged in, but all too often they are in the end closed off by the reaffirmation and reconfirmation of the human on a different plane.

In other words, the presence of a posthuman initially questions the essentiality of humanity, which it might end up reaffirming. A story featuring posthuman characters, or at least the possibility of posthuman life, can either be posthumanist or humanist or even both at the same time. 


\section{Carole Guesse}

If the posthumanist potential of a story is connected to the presence of posthuman characters, one wonders about the influence of such characters on the story and the narrative. The most obvious impact is thematic; dealing with posthumans implies the recurrence of certain topics such as the essence of humanity, human dignity, alterity, ethics, and technology. A posthuman character might also have a formal impact on the narrative when, for example, the narrator of a novel is a posthuman, as in The Possibility of an Island:

The first time I met Marie22 was on a cheap Spanish server; the connection times were appallingly long.

The weariness brought on

By the old dead Dutchman

Is not something attested

Well before the master's return.

2711, 325104, 13375317, 452626. At the address indicated I was shown an image of her pussy-jerky, pixelated, but strangely real. Was she alive, dead or an intermediary? Most likely an intermediary, I think; but it was something you did not talk about.

(Houellebecq 2005, 4)

In this extract, narrated by a clone, Houellebecq seems to be using lines of numbers to imitate computer language, and more precisely the server connection process. It has been suggested earlier that such an attempt at imitating computer code is not entirely a posthumanist gesture, since computer code is a language invented by humans to guarantee successful communication with the machine and amongst the machine themselves.

The lines in this passage, which is around the beginning of the novel, seem to emulate more than a connection between the clone narrator and other clones on the Internet; it may also express the attempted connection between the narrator and his readers, who seem to be explicitly addressed a few pages later: "I do not want to keep you outside this book; living or dead, you are readers. Reading is done outside of me; and I want it to be done-in this way, in silence" (Houellebecq 2005, 7). Since, in that post-apocalyptic future, the human species has returned to a primitive way of life, clones are the only species that is still able to process writing, able to be readers. Yet real-life readers do not know that the characters are posthuman at that point of the novel, which is why the use of the word "readers" creates an ambiguity that invites actual readers to take on the role of the narratees and therefore tricks them into identifying with the actual posthuman narratees.

This extract also epitomizes several of the oppositions that posthumanism interrogates. Computer code contrasts with the poem, which corresponds to a more traditional and ancient form of writing. 
The presence of the machine contrasts with the depiction of organic, even carnal, elements ("pussy", "jerky"), which is accompanied by an opposition between the disembodied digital ("pixelated") and the embodied "real". The question "Was she alive, dead or an intermediary?" (Houellebecq 2005, 4) adds the dead/alive dualism as another layer of opposition. The narrative thus associates, on the one hand, organic, embodied, and alive, and, on the other hand, mechanic, disembodied, and dead but seems to imply that clones are in-between ("an intermediary"). This could echo a posthumanist discourse were it not for the presence of "alive" and "dead", whose respective positive and negative connotations affect the other terms. The lack of neutrality and the praise, although discreet, of the organic and embodied maintain a reactionary and anthropocentric discourse. This uncertainty about whether this novel fosters a posthumanist discourse continues until its very ending, where Daniel25 follows Maries23's footsteps and leaves his home with his dog in order to search for a neohuman community where he could reconnect with a more human lifestyle. Throughout his journey, Daniel25 encounters primitive human beings and does not hide his contempt for them. These humans kill his dog, which leads him to experience sorrow for the first time, making him realize the nature of love. Following this traumatizing event, Daniel25 decides to lie down on the sand:

I had perhaps sixty years left to live; more than twenty thousand days that would be identical. I would avoid thought in the same way I would avoid suffering. The pitfalls of life were far behind me; I had now entered a peaceful space from which only the lethal process would separate me.

I bathed for a long time under the sun and the starlight, and I felt nothing other than a slightly obscure and nutritive sensation. Happiness was not a possible horizon. The world had betrayed. My body belonged to me for only a brief lapse of time; I would never reach the goal I had been set. The future was empty; it was the mountain. My dreams were populated with emotional presences. I was, I was no longer. Life was real.

(Houellebecq 2005, 423)

According to Posthumus and Sinclair (2011, 352-353), Daniel25 left looking for a more emotional existence and eventually finds it through experiencing sadness for the first time. In the end, he reaches a state of continual ecstasy; he is himself and everything revolves around him. His search for a more human lifestyle and an emotional existence conveys the anthropocentric idea that emotions are the essence of humanity, which reinforces the idea of human exceptionality. He eventually never finds a community but seems to accept the isolation of what remains of his existence. He seems paradoxically relieved of, on the one 
hand, leaving his ascetic home to experience love and pain ("My dreams were populated with emotional presences"), and, on the other, knowing that he will not have to experience them ever again, that "the future [is] empty". His journey stops there; he settles for an existence of pure sensation instead of seeking further for companionship. In parallel, the novel conveys a constant critique of humanity and the praise for dogs "Goodness, compassion, fidelity and altruism therefore remain for us impenetrable mysteries, contained, however, within the limited space of the corporeal exterior of a dog" (Houellebecq 2005, 63), which seems, if not really posthumanist, at least misanthropic.

The novel therefore appears to be generally torn between posthumanism and anthropocentrism, as the following extract attests: "Marie22, if she exists, is a woman to the same extent that I am a man; to a limited, refutable extend. I too am approaching the end of my journey" (Houellebecq 2005,7$)$. This primarily implies that the biotechnologically modified clones that are Marie22 and the narrator are not part of the human race (again, a human essentialist discourse), but, as suggested earlier, the reader does not know about the nature of these two characters at this point of the novel. Again, it tricks readers into identifying with the narrator and, thus, question their own identity as humans as well as the permanence of their race, which actually situates the novel in the wake of posthumanist thinkers.

\section{$* * *$}

On the one hand, The Possibility of an Island can be part of a group of fictions that would be called "posthuman literature" because its story not only features posthuman characters (narrators and narratees) and tropes (a post-cataclysmic world, genetic engineering, etc.) but also attempts at imitating a posthuman language. On the other hand, such posthuman elements inevitably prompt posthumanist interpretations of Houellebecq's novel, which could therefore be considered an instance of posthumanist literature, especially in the way it stimulates a questioning about the essence of humanity and blurs the lines between various ontological dualisms (human/nonhuman, organic/mechanic, embodied/ virtual, alive/dead, amongst others) as well as narratological dualisms (reader/author, reader/character, etc.).

The main issue when considering the possibility of posthuman and posthumanist literatures is that "posthuman", "posthumanism", and "literature" remain ungraspable concepts. Those who wish to study them must first delineate the extent of their meanings and, consequently, leave some elements out. Choosing technology as a determining constituent element of posthumanism and the posthuman - which might not suit the representatives of more natural, organic, or environmental understandings of these concepts - represents a committed stance that 
is necessary to elaborate stable definitions of these concepts. Similarly, contemplating literature through its dissection is an even more radical but well-needed stance in order to establish a viable methodology. There may surely be other ways to address such an issue, and it must therefore be acknowledged that this study is more of an experiment than a final statement on posthuman and posthumanist literatures.

The study of literature sparks off enriching considerations about posthumanism and the posthuman. The distinction between the factual and fictional constituents of literature allows for apprehending these concepts in a different way. On the one hand, the factual constituents - context, reader, author, book, and language - force the scholar to differentiate between the discourse that is posthumanism and the figure that is the posthuman simply because the existence of the former is objective - there is a discourse called "posthumanism" - while the existence of the latter is subjective; it depends on where one sets the limit beyond which humans become posthumans, somehow making it difficult to take the posthuman out of the realm of speculation completely. On the other hand, the fictional constituents - narratee, narrator, and story - tolerate such speculation, and making a clear-cut distinction between posthumanism and the posthuman in this perspective becomes irrelevant: the presence of a posthuman character in a novel evokes, if not always a posthumanist discourse, at least a posthumanist interpretation. This is the reason why the "s" in "posthuman/ist literature(s)" is between parentheses in the title of this chapter: posthuman literature and posthumanist literature are not always two categorically different types of literature.

Reciprocally, posthumanism and the posthuman may contribute to the study of literature. Acknowledging that the posthuman is a figure that has emphasized the importance of fictional characters as well as of agents in the production and reception of literature, which echoes and somehow legitimates several trends in literary theory, from the positivist interest in the author (which has recently been reactivated by the sociology of literature) to the focus on reception by reader-response criticism. Considering the implications of posthuman authors and readers has also prompted several interrogations on the future of literature, and particularly the changes literature may undergo in a more and more technological era. Similarly, the way posthumanism undermines traditional dualist categories can be applied to literary categories such as the author and the reader, or writing and reading. Moreover, a posthumanist perspective on literature provides new interpretation grids for readers as well as new themes for authors and constitutes a fertile ground for experimental and digital literature. Lastly, while "[c]lassic literature [...] does have a great deal to teach us about what it means to be human and to live in this world" (Steinberg 2013, 1), a posthumanist perspective uncovers literature's ability to convey what is means to be, precisely, something other than human. 


\section{Notes}

1 Contrary to what his answer implies, Herbrechter $(2015,3)$ actually differentiates posthumanism, which is a discourse, from the posthuman, which is the object of this discourse. Moreover, a large part of the confusion around posthumanism and the posthuman is due to the fact that some critics claim to be writing about the posthuman when their work rather belongs to the posthumanist trend. A significant example of this issue is Rosi Braidotti's The Posthuman (2013).

2 In a few writings - most notably Are you a Transhuman? by FM-2030 and the collective Transhuman Manifesto - one might come across the derivative yet less recurrent term "transhuman". It is likely to appear in transhumanist works to qualify the being that results from technological enhancement (Ranisch and Sorgner 2014, 10-11), or it can be presented in contrast with the posthuman, the transhuman thus being an intermediary step on the way to posthumanity (Ibid. 8). The nature of the frontier between the transhuman and the posthuman is unsurprisingly subjective and unlikely to be productive, which is why this chapter does not expand upon it.

3 Herbrechter $(2015,2)$ also claims the existence of another category: "critical posthumanism", "a posthumanism that is not unduly excited about cyborgs, AI, or indeed animals, plants and minerals, technologies, the media and their convergences, but which takes the time to remember, to reread and reconnect, in short which is 'critical'". Given that posthumanism has tended to question humanist principles, it is intrinsically critical, which is why this chapter will not expand on the so-called "critical posthumanism" nor use it as an analytical concept.

4 This chapter does not discuss the distinction between empirical and implied authors and readers because such distinction does not provide significant nuances as far as posthuman and posthumanist literatures are concerned.

5 "Story" and "narrative" refer to Gérard Genette's (1972, 72) typology that distinguishes between story, narrative, and narration: "Je propose [...] de nommer histoire le signifié ou contenu narratif [...], récit proprement dit le signifiant, énoncé, discours ou texte narratif lui-même, et narration l'acte narratif producteur".

6 Cf. Snyman, E. 2008. "The Possibility of an Island; or, the Double Bind of Houellebecq's Apocalypse: When the End is not the End”. Literator 29 (2): 25-45; Moraru, Christian. 2008. "The Genomic Imperative: Michel Houllebecq's The Possibility of an Island". Utopian Studies 19 (2): 265-283; Koleva, Neli. 2011. "Le Meilleur des Mondes': Kitsch and Humanity in Michel Houellebecq's La Possibilité d'une île”. Modern Horizons 1-8; Posthumus, Stéphanie and Stéfan Sinclair. 2011. "L'Inscription de la nature et de la technologie dans La Possibilité d'une île de Michel Houellebecq". Contemporary French and Francophone Studies 15 (3): 349-356; Morrey, Douglas. 2013. Michel Houellebecq: Humanity and Its Aftermath. Oxford: Oxford University Press.

7 This information is derived from my own unpublished study on the statistics of publications on posthumanism, the posthuman, and other related concepts.

8 For more information, see Regnauld (2014).

9 Ellis $(2014,149)$ nonetheless notices that this attempt at a polyphony that might carry the cloning motif further fails due to the monotony of the various narrators.

10 The "universe of reference" is part of François Rastier's interpretive semantics and must be understood as "the universe whose units are evaluated 
according to the absolute truth of the text" (Hébert 2006). Its laws can therefore differ from the author's and reader's universe, and therefore allow the existence of posthumans.

11 Herbrechter and Callus $(2008,99)$ allude to Hollywood science-fiction blockbusters.

\section{References}

Braidotti, Rosi. 2013. The Posthuman. Cambridge, MA: Polity Press.

Clarke, Bruce, and Manuela Rossini, eds. 2017. The Cambridge Companion to Literature and the Posthuman. Cambridge, UK: Cambridge University Press.

Ellis, Susannah. 2014. "Communautés (im)mortelles? La politique posthumaine à l'œuvre dans les textes de Michel Houellebecq." In PostHumain: Frontières, évolutions, hybridités, edited by Elaine Després, and Hélène Machinal, 137-152. Rennes: Presses Universitaires de Rennes.

Foucault, Michel. 1966. Les Mots et les choses: Une archéologie des sciences humaines. Paris: Gallimard.

Fukuyama, Francis. 2002. Our Posthuman Future: Consequences of the Biotechnology Revolution. New York: Farrar Straus \& Giroux.

- 2004. “Transhumanism.” Foreign Policy 144: 42-43.

Garber, Marjorie. 2003. Quotation Marks. New York: Routledge.

Genette, Gérard. 1972. Figures III. Paris: Seuil.

Gervás, Pablo, Birte Lönneker-Rodman, Jan Christoph Meister, and Federico Peinado. 2006. "Narrative Models: Narratology Meets Artificial Intelligence.”www.academia.edu/7809569/Narrative_Models_Narratology_ Meets_Artificial_Intelligence.

Gibbs, Samuel. 2016. "Google AI Project Writes Poetry Which Could Make a Vogon Proud." The Guardian, May 17, 2016. www.theguardian.com/ technology/2016/may/17/googles-ai-write-poetry-stark-dramatic-vogons.

Haraway, Donna. 2004. The Haraway Reader. New York: Routledge.

Hayles, Katherine N. 1999. How We Became Posthuman: Virtual Bodies in Cybernetics, Literature, and Informatics. Chicago, IL: University of Chicago Press.

Hébert, Louis. 2006. "Ontology and Veridiction in Dialogics." Signo: Theoretical Semiotics on the Web. www.signosemio.com/rastier/ontologyveridiction-dialogics.asp.

—. 2011. "The Functions of Language." Signo: Theoretical Semiotics on the Web. www.signosemio.com/jakobson/functions-of-language.asp.

Herbrechter, Stefan. 2015. "Posthumanist Literature?" Paper Presented at the Conference Approaching Posthumanism and the Posthuman, University of Geneva, June 4-6. www.academia.edu/13743708/Posthumanist_Literature.

— Journal of Theoretical Humanities 13(1): 95-111.

- 2009. Cy-Borges: Memories of the Posthuman in the Work of Jorge Luis Borges. Lewisburg: Bucknell University Press.

— 2012. Posthumanist Shakespeares. Houndmills, Basingstoke, Hampshire: Palgrave Macmillan.

Houellebecq, Michel. 1994. Whatever. London: Serpent's Trail. . 2005. The Possibility of an Island. London: Phoenix. 
Jakobson, Roman. 1960. "Closing Statement: Linguistics and Poetics.” In Style in Language, edited by Thomas A. Sebeok, 350-377. Cambridge, MA: The MIT Press.

Koleva, Neli. 2011. “'Le Meilleur des Mondes': Kitsch and Humanity in Michel Houellebecq's La Possibilité d'une île.” Modern Horizons, 1-8.

Lewis, Danny. 2016. "An AI-Written Novella Almost Won a Literary Prize." Smithsonian, March 28, 2016. www.smithsonianmag.com/smart-news/ ai-written-novella-almost-won-literary-prize-180958577/.

Moraru, Christian. 2008. “The Genomic Imperative: Michel Houllebecq's The Possibility of an Island." Utopian Studies 19 (2): 265-283.

Morrey, Douglas. 2013. Michel Houellebecq: Humanity and Its Aftermath. Oxford: Oxford University Press.

Posthumus, Stéphanie, and Stéfan Sinclair. 2011. "Linscription de la nature et de la technologie dans La Possibilité d'une île de Michel Houellebecq." Contemporary French and Francophone Studies 15 (3): 349-356.

Pressman, Jessica. 2015. "The Posthuman Reader in Postprint Literature: Between Page and Screen." Frame 28 (1): 53-69.

Ranisch, Robert, and Stefan Lorenz Sorgner, eds. 2014. Post- and Transhumanism: An Introduction. Frankfurt am Main: Peter Lang.

“Reading." Merriam-Webster.com. Accessed June 30, 2016. www.merriamwebster.com/dictionary/reading.

Regnauld, Arnaud. 2014. "Patchwork Girl de Shelley Jackson ou le spectre d'une mémoire dé/incarnée." In PostHumains: Frontières, évolutions, bybridités, edited by Hélène Machinal, and Elaine Després, 73-84. Rennes: Presses Universitaires de Rennes.

Shanahan, Murray. 2015. The Technological Singularity. Cambridge, MA: The MIT Press.

Snyman, Elisabeth. 2008. "The Possibility of an Island; or, the Double Bind of Houellebecq's Apocalypse: When the End is not the End." Literator 29 (2): $25-45$.

Sorgner, Stefan Lorenz. 2014. "Pedigrees." In Post- and Transhumanism: An Introduction, edited by Robert Ranisch, and Stefan Lorenz Sorgner, 29-47. Frankfurt am Main: Peter Lang.

Steinberg, Theodore L. 2013. Literature, the Humanities, and Humanity. Geneseo, NY: Open SUNY Textbooks.

Sweeney, Carole. 2013. Michel Houellebecq and the Literature of Despair. London: Bloomsbury.

Vultur, Ioana. 2011. "La Communication littéraire selon Paul Ricœur." Poétique 2 (166): 241-249.

Wallace, Jeff. 2005. DH Lawrence, Science and the Posthuman. Houndmills, Basingstoke, Hampshire: Palgrave Macmillan. 


\section{Posthumanist Reading Witnessing Ghosts, Summoning Nonhuman Powers}

\section{Karoliina Lummaa}

In his introductory chapter of Posthumanism. A Critical Analysis (2013), titled "Towards a Critical Posthumanism", Stefan Herbrechter argues that posthumanist thinking is first and foremost post-anthropocentric thinking. To leave the human behind, however, only causes it to return in spectral forms to haunt our philosophy, popular cultures, and the arts. Herbrechter writes: “The moment the human 'disappears' its repressed 'mirror images' of identity return to haunt it and the entire history of anthropocentrism has to be rewritten: the 'object' world, the 'animal' world, the entire 'cosmos"” (Herbrechter 2013, 29). Thus, posthumanism means "to acknowledge all those ghosts, all those human others that have been repressed during the process of humanization: animals, gods, demons, monsters of all kinds" (Herbrechter 2013, 9). Lists like these, lists of "monsters", are of course an elemental part of the posthumanities, both in its critical and popular forms. There are numerous cyborgs, robots, mutants, chimeras, and hybrids to be met among the more organic fauna, flora, and funghi that we can think with. For posthumanist literary scholarship, these real and fictional nonhumans, humans, and notquite-humans have functioned as powerful conceptual tools for category work, whether in epistemological, essential, or aesthetical terms. Methodologically, the focus has been on characters and the narrative form.

As fiction plays an important part in the formation of identities and ideologies, a scrutiny of fictional characters on the verge of humanness is naturally insightful and important. However, to question anthropocentrism will, of course, demand a critical view on reading and writing as well. How is the inhuman, the nonhuman, or the posthuman present in these practices, deemed species-specific to the extent that they mark the difference between Man and Animal? With reference to the monstrous, spectral figures of the posthuman, it is interesting to note that writing and reading are sometimes considered to be haunted, as well. From the antihumanist tradition, we have learned to doubt the equivalence of signifiers to their signifieds - we have even learned to suspect our access to the signifieds themselves.

Our understanding of the linguistic sign, and of reading and writing, has undergone a further series of reconsiderations over the past decade or 


\section{Karoliina Lummaa}

two. Ecocritical, new-materialist, and other related approaches to literature show that there are actually manifold nonhuman agencies involved in the creation of literary texts. The recognition of nonhuman literary or poetic agency calls for a re-evaluation of reading as well. These theoretical reconsiderations can be understood in the context of Herbrechter's notion of rewriting "the 'object' world", and even "the 'animal' world": these worlds consist of powerful agencies that influence even the most human(ist) practices or reading and writing.

In this chapter, I approach posthumanist reading as a dual practice of critical analysis and affirmative awareness of nonhuman agencies. First, I discuss the critical analysis by reviewing the influential writings of Stefan Herbrechter, Ivan Callus, Neil Badmington, Tom Cohen, and N. Katherine Hayles. Second, I sketch an additional, affirmative method of posthumanist reading by briefly analyzing three examples of Finnish contemporary poetry, "a niinkuin koira" [a as a dog], by Dan Waber and Marko Niemi (2008), "kadonneen äänen lyhyt haastattelu" [a short interview with a lost voice] by Jouni Tossavainen (2007), and "damage" by Jukka-Pekka Kervinen (2008). Conceptually, I utilize the posthumanist imagery of spectrality and will thus experiment with the ideas of witnessing ghosts and summoning (evoking, conjuring) nonhuman powers to highlight the different attitudes toward and ideas of the nonhuman.

\section{Critical Reading}

Stefan Herbrechter and Ivan Callus begin their essay "What Is a Posthumanist Reading?" with the following definition:

The claim we are making is very simple. It is possible to read 'texts', in the widest sense attributed to this word by poststructuralism, through the way they set up a catalogue of assumptions and values about 'what it means to be human.'

(Herbrechter and Callus 2008, 95)

Although poststructuralism is here mentioned with reference to its wide understanding of texts, poststructuralism naturally also contributes philosophically to our current ideas about the human. When scholars and philosophers like Jacques Derrida, Roland Barthes, Michel Foucault, Jacques Lacan, or Louis Althusser conceptualized diverse cultural and social phenomena with an emphasis on the structures and power relations beneath these phenomena, the idea of human sovereignty became highly contestable. In this line of thinking, humans are not sovereign subjects that are in control of themselves and their social and cultural surroundings, but rather, human subjectivity is formed under the preceding contexts and conditions of psychological, linguistic, social, and cultural structures and power relations. Therefore, the human is not an essential category but a historical construction. For posthumanities, then, 
the task is to observe and re-conceptualize the constant re-formation of this construction (Herbrechter and Callus 2008; see also Badmington 2000a, 7-10).

The claim for a possibility of posthumanist reading is at the same time affirmed and questioned by Herbrechter and Callus themselves. It is simply impossible to read as if we were not human. Rather, posthuman reading acknowledges the ambiguity of humanness and thus focuses on the ways cultural texts communicate (or hide) this ambiguity. Here, Herbrechter and Callus are of course following post-structuralist ideas about the self-deconstructive nature of texts, systems, and concepts. With reference to Roland Barthes's demythologization of the human, they claim: "Humanism's 'work', however, is never done because the otherness constructed and projected into the world [...] comes back to haunt and threaten the borderlines of difference drawn around the human as its protection" (Herbrechter and Callus 2008, 101). In his introduction to the Posthumanism reader, Neil Badmington (2000a, 9) makes a similar claim, in the context of Jacques Derrida's philosophy: "Humanism never manages to constitute itself; it forever rewrites itself as posthumanism. This movement is always happening: humanism cannot escape its 'post-'".

Stefan Herbrechter returns to the idea of the haunting other, or "ghostly ontology", in his book Posthumanism. A Critical Analysis (2013). The ghost is a metaphor for the "other" or the "outside" of what in any given situation counts as human: the position of outside is necessary for the formation of an inside - human essentiality or human identity - but at the same time, it poses a constant threat (Herbrechter 2013, 86, 90). As we have already seen, in fiction and film, these ghosts appear in the concrete (or not-so-concrete) forms of aliens, cyborgs, robots, and genetically altered organic creatures. For a posthumanist critic, these characters offer possibilities of witnessing the ghosts: of deconstructive readings of the ambiguous formations of differences between human and nonhuman (or inhuman). Indeed, for Herbrechter and Callus $(2008,105)$, “[a]nimalization, cyborgisation, biotechnology, robotics and cybernetics bring about an accentuated 'hauntology' of the spectralised human".

Often the ghosts are high-tech mechanical beings. This is of course related to the challenges new media and new technologies, such as digital media, virtualization, and bio-, info-, and nanotechnology, pose on the human (Herbrechter and Callus 2008, 96-97). Many of these real-life promises (or threats) are embodied in the figure of the cyborg, written into the posthumanist canon of theory and fiction already in the 1980s. Theoretically, the cyborg gains its status in the classic "Cyborg Manifesto" by Donna Haraway. In his article about Donna Haraway's manifesto and Marge Piercy's Body of Glass, Neil Badmington (2000b, 85-86) states the importance of the cyborg figure: "The cyborg seems to be the answer, the messiah who will lead 'us' to a promised land where humanism is a thing of the past". For Badmington, the cyborg is "a promising monster" only when it aids us in the deconstruction of 
humanism. He ends his essay in words that resonate with Herbrechter's ghostly visions of the human: "Man breathes 'himself' to death, raises himself to ruins. Humanism forever rewrites itself as posthumanism"(Badmington 2000b, 97).

As the characters and events in science fiction typically challenge the essentiality of humanity, and hence human essentialism, science fiction movies and fiction are the most favored objects of posthumanist analysis - up to a point where, as Herbrechter and Callus (2008, 104; see also 98) claim, "reading [...] merely needs to 'force' the narrative a little to arrive at a 'meta-fictional' level". Whether the interest lies in the bodily materialities or mind-altering communication technologies, or machinic enhancements or reproductive enterprises, science fiction delivers tools for re-imagining and re-conceptualizing the human. One popular character in this sense is the anamorphic killer machine T-2000 from the movie Terminator 2: The Judgment Day (1991, co-written, produced, and directed by James Cameron). Its first appearance in the context of posthumanist reading is in Tom Cohen's Anti-mimesis (1994), which contains a coda called "Post-human reading". Cohen focuses his critical attention on the liquid-like mechanical post-robot T-2000 and asks, "why is that which burns through all representations including the commodity form of humans, evil?" (Cohen 1994, 260, original italics). Rather than focusing on the characters themselves, however, Cohen interprets the fight against T-2000 as a fight against "anti-representational and post-humanist logic" (Cohen 1994, 260, original italics). Here, a posthuman character is given an allegorical meaning, whereby it challenges not the human as such but the ideologies supporting humanism and the human. After Cohen's influential coda, "Post-human reading", T-2000 reappears in Herbrechter and Callus's "What Is a Posthumanist Reading?” (2008, 98-100), where its death by a complete melt-down is interpreted again as the re-establishing of the human(ist) order.

For Stefan Herbrechter, Ivan Callus, and Neil Badmington, posthumanist reading is essentially post-anthropocentric (Badmington 2000a; Herbrechter and Callus 2008; Herbrechter 2013, 3, 7, 10). Rather than actively attacking humanist values and conceptualizations represented in cultural texts, they believe in the self-deconstructive nature of the human and of humanism that will occur in critical reading. The critical stance toward anthropocentrism is, of course, widely shared among scholars associated with posthumanism (e.g. Barad 2003; Haraway 2008, 9-27; Wolfe 2010, xiv-xxvi). As an ethics (or a variety of ethics), posthumanism is indeed able to question the uniqueness and the hierarchical position of humans among other beings, organic or artificial.

There is, however, one issue about centering on anthropocentrism that I would like to raise. With anthropocentrism often comes anthropomorphism, in other words, the tendency (whether conscious or intentional, or not) to think about the world, its beings, and its processes by likening 
or juxtaposing them with humans. Hence, we fear or admire the cyborg, the robot, and the computer because we have created them and feel a certain affinity with them: they reason, they may even have a consciousness. Often, they also have a body, that is, they are entities where matter and mind are combined. The latter also applies to nonhuman animals. However, we are often prone to concentrate on animals with which we can relate to; animals of "high" intellectual competence (on our standards), or animals who are familiar to us. Accordingly, we are able to recognize the agency and capacities of those things that we perceive as being similar to us. Often, we think about them in the singular: T-2000 the robot, Dolly the sheep, Theseus the electronic rat (see Callus, Herbrechter, and Rossini 2014, 108-109). To explore the borders and boundaries of the human quite obviously happens by the logic of similarity: we feel most threatened and most intrigued by the things and modes of existence that are closest to us. This is our disposition and desire (critically and otherwise): to witness ghosts.

To question anthropomorphism calls for the recognition of those agencies that are more remote, plural, or immaterial too. When Stefan Herbrechter and Ivan Callus $(2008,95)$ claim, that "[i]t is possible to read 'texts' [...] through the way they set up a catalogue of assumptions and values about 'what it means to be human'", we can understand this not only in terms of thematics. "What it means to be human" can also be a question about the reading practice itself; moreover, it can be a question about the material-semiotic emergence of texts and of language. The powers working here are more anamorphic than anthropomorphic they might not have a form at all. To witness them, like the ghosts, they need to be summoned.

\section{Nonhuman Powers}

In the Finnish poetry online website Nokturno.fi there is a curious digital poem called "a niinkuin koira" [a as a dog] by Dan Waber and Marko Niemi, first published in 2008. The flickering group of alphabets is actually an interactive zoo of signs. On the website, it is shortly introduced as "Partly a homage, partly a parody, an ongoing ultra-minimalist collection of animated letter animals" (transl. K. L.). The word "homage" functions as a link to the website which presents Roberto de Vicq de Cumptich's children's book Bembo's Zoo: An Animal ABC Book (2000) in a flash format. When you click on individual letters, an animal's name beginning with that letters appears, and the letters soon multiple and reorganize to form a picture of that particular animal. The letter-bodied animals move, and the flash poems are further enlivened by electronic sounds. The letter zoo of Waber and Niemi is, as its name implies, minimalist: when you click on a letter, only that one particular letter becomes "alive". The name of the poem offers a hint on the animal identity of the 
letter "a": when you click on it, a tiny letter "a" appears against an empty background, and it starts to wag its tail and wiggle its snout.

The connection between a letter and an animal appears to be completely random in the poem by Waber and Niemi. By scrolling down the page, it is possible to find identification for all of the letters, but the reader may also choose to watch the letters moving about without this information. Read in this way, the poem works as an identification game: "g" is flipped $90^{\circ}$ clockwise, and because of the font, it seems to have a giant head (or body) and a tail. As the tail is shaking and series of dots are squirting from the head, "g" seems to "be" a whale. The letter "f" rapidly extends its upper curvy part, and with this move, it hits to a dot right next to it, causing the dot to disappear. Thus, " $\mathrm{f}$ " can be seen as a chameleon catching flies with its tongue. In the poem, however, "f" is identified as an anteater. Other letters are trickier. The letter "o" is a pulsating little circle which has two dots inside. The first impression, a pig's trunk, soon turns problematic, as the circle flattens to a square. The poem insists it is a pig, however. Some of the letters move around, while other seem to focus on shape-shifting: " $\mathrm{t}$ " is "climbing up" by moving its upper part, and " $\mathrm{w}$ " just keeps widening and contracting horizontally. By clicking the letters, the reader may begin to question her or his desire to see the letters as recognizable animals. It is, after all, possible to imagine animated life that escapes the bodily trajectories of animals that are known to us humans. The desire to recognize the letters as specific species of animals is further diminished by the random relations between the animal names and letters, and even between the letters and animals themselves. Further, a couple of letters actually refer to humans: " $\mathrm{z}$ " is the sound of sleep and appears in a hand-drawn picture of "eero-eno" [uncle eero] sleeping on a couch!

How to approach Waber and Niemi's minimalist zoo of animated signs from a posthumanist perspective? As a flash poem, "a niin kuin koira" is an obvious example of "flickering signs", introduced by N. Katherine Hayles in her seminal work How We Became Posthuman (1999). Hayles bases her idea of flickering signs on structuralist and post-structuralist accounts on the arbitrariness of signs. According to Ferdinand de Saussure, the relation between signifier and signified is arbitrary, and signification is a conventional relation based on differences among signifiers. For Jacques Lacan, signifiers are "floating" on an inaccessible strain of signifieds, and signification is based on a double absence: signifieds are absent as things-in-themselves, and absent are also stable correspondences between signifiers (Hayles 1999, 25-30). In the (post)structuralist framework, signifiers are still understood as markers - with computational information-processing, a drastic change happens: signification processes are based on codes:

In informatics, the signifier can no longer be understood as a single marker, for example an ink mark on a page. Rather it exists as a flexible chain of markers bound together by the arbitrary relations 
specified by the relevant codes. As I write these words on my computer, I see the lights on the video screen, but for the computer, the relevant signifiers are electronic polarities on disks. Intervening between what I see and what the computer reads are the machine code that correlates alphanumeric symbols with binary digits, the compiler language that correlates these symbols with higher-level instructions determining how the symbols are to be manipulated, the processing program that mediates between these instructions and the commands I give the computer, and so forth.

(Hayles 1999, 31)

The existence and movement of the animated letter animals created by Dan Waber and Marko Niemi are materially and semiotically based on the informatics described by Hayles above. There are a number of programs and codes working to bring "life" to signs and sustain them on an electronic environment unrepresentable on a printed page. As Hayles notes, the flickering signifiers are no longer functioning on the logic of presence and absence (where signifier might be considered to be present and the signified absent), but on the logic of pattern and randomness, where pattern actually always requires randomness to establish itself (Hayles 1999, 32-35). For the reader, then, the zoo of letters is constantly open, but any one of the letters can be watched for only about ten seconds. In other words, reading is controlled by informational technologies and their dependency on patterns and codes - the play of signs is no longer solely for the human reader to engage with.

What other powers are to be summoned in reading "a niin kuin koira", besides the powers of information technologies and hardware? Implicitly present in Hayles's flickering signifiers is of course electricity, which for a long time was understood in vitalist and spectral terms (e.g. Morus 2011). Electricity forms the energetic basis of the posthuman condition, and it is also literally the life force of all flickering signifiers we are depending on in our everyday lives. In his book Earth Sound Earth Signal (2013), Douglas Kahn has rightly noted that questions of life forms and materiality have dominated over questions of energy in cultural theories and scholarship about the physical conditions of culture and art (Kahn 2013, 17). Indeed, animality seems far easier to grasp than electricity in "a niinkuin koira".

When reading Waber and Niemi's poem as animated letter animals, as we have seen, the letters are read in the contexts of real animals: their bodily shapes, trajectories, and movements - even their diets. One important factor problematizes the animality of the letters, however: almost all of them are devoid of any environment. One exception is the " $\mathrm{r}$ ", a fish that jumps up and then disappears under the water surface. That we are seeking resemblance to animal life highlights in any case the presence of nonhuman animals in the process of reading. In contrast to Stefan Herbrechter's and Ivan Callus's critical remarks on animals as the spectral Others, excluded outside humanity and returning to haunt us, the presence of animals in 
"a niin kuin koira" takes the form of power and agency. Different species of animals have bodies and forms of life that influence writing and poetry, as well. To understand the effects of this nonhuman poetic agency means to summon its power in posthumanist reading.

Until recently, the presence of nonhuman animals in poetry has been understood in terms of cultural representation: poets write about animals in specific cultural contexts and thus poetically re-present them in texts - the animals themselves are only objects for observation and representation and therefore left outside the realm of culture. Within material ecocriticism and related fields of theory and scholarship, however, some scholars have suggested that the role of animals in art can be understood in more active terms.

The discussions on animal agency are connected to the more general ideas about nonhuman agency that have been proposed by Bruno Latour, Nick Law, and Michel Callon in their Actor-Network-Theory (ANT). According to ANT, any social process always involves human and nonhuman actors, whose agencies should be observed and described on the same level. The idea of nonhuman agency has been further developed among posthumanist and new-materialist thinking and critical animal studies: for example, in the works of Donna Haraway, Cary Wolfe, Jane Bennett, and others. For ecocriticism, then, ideas of nonhuman agency have been important in re-negotiating the role of nonhumans, particularly animals, in the production of poetic texts and even in language itself. Thus, the bodily features, movements, displays, and vocalizations of different species of animals are seen to actively influence the linguistic, typographical, and other material-semiotic choices made in writing (Mason 2013, xi-xix; Moe 2014, 5-28; Tüür $2017,55-79,226-255)$. It has also been suggested that language itself is infested with nonhuman elements or currents, thereby making nonhuman agency an inevitable part of poetry (Abram 2011, 183-200; Lummaa 2017, 129-151).

The extending, trembling, bouncing, and other vivid movements and actions of the letter animals have correspondences in real animal life. Just as poetic texts can evoke a sense of a surrounding environment or a presence of nonhuman being (a group of letters swarming like bees, bird vocalizations transcribed in letters and written in undulating verses), animations in flash poems evoke nonhuman presences with suggestive movements (see Morton 2009, 32-78). These movements are often sufficiently recognizable, thus mediating the features and trajectories of specific animals. The poem by Waber and Niemi absorbs and transforms these nonhuman powers into electrically transmitted movements that still remain curiously animal-like. Sometimes the movements are minimal, and this minimalism may not only relate to poetic minimalism: the gestures and movements of nonhuman animals may be "minimal" in the sense that they are not easily observable and sensible to us humans. 
There is a lot we cannot see, even if we are actively looking, and this of course challenges the act of summoning nonhuman powers.

In opposition to minimalism, the presence of words or signs alluding to nonhumans may also be excessive. Consider the following excerpt from the poem "kadonneen äänen lyhyt haastattelu" [a short interview with a lost voice] by Jouni Tossavainen, from his collection Kerro [Tell], published in 2008 (Figure 2.1).

Tossavainen's text is actually a sound poem which contains auditory elements from many different living and nonliving sources. As it mainly contains nonsensical, verbally, or auditorily motivated wordplays that follow each other quite randomly, it is impossible to translate. Here is an English interpretation of the excerpt, created by translators Emily Jeremiah and Fleur Jeremiah (first published in Lummaa 2017):

a short interview with a lost voice

upupa said apupupu

i'm like a pelican in wild woods said the ostrich

rain rain said the brain bird teach-er teach-er teach-er teach-er chink chink chink chink so said the great tit

tia tia said the c-cassette pulled out from the innards of a black box no sa nosa say sona offon sa sa say so noya soya and dna said

kiva vika pomo mopo said ropoporo said a certain ex-starling

some ham said homebird home home said copse home many migrants in the air said pigeon in ballandia

isnt tis nist nits a-honk brot brot rat rat rot-rot-rot knag-ang-ang rrot rroak gaga-ga kjo-jo-jo kajajak klik-klik-kli kjik-jek kuju ku ju jy said the goose sparrow's a sparrow said pygmy owl

$[\ldots]$

no sa nosa sano naso kiva vika pomo mopo sano ropoporo stii stii tips tii tii äks tii tii tota ota kiin tipi tipi niin sano talitintti tia tia sano black boxin mahasta vedetty seekasetti toko toko sano kotolintu koto koto sano lehtoskoto a-honk brot brot rat rat rot-rot-rot knang-ang-ang $r$ kjik-jek kuju ku ju jy sano hanhi ekso onks eks veks sanomuan exkottarainen pal pal muuttajia ilmassa sano pulu pallolandiassa rot rroak ga-ga-ga kjo-jo-jo kajajak klik-klik-kli varpunen on varpunen sano varpuspöllo

Figure 2.1 Excerpt from the poem "kadonneen äänen lyhyt haastattelu" by Jouni Tossavainen. 


\section{0}

As the translation shows, there are many birds involved in Tossavainen's poem. Some of the avian vocalizations are wordplays with diverse, allusive meanings or no meaning at all, while others are actual call or song transcriptions recognizable from field guides: "a-honk brot brot rat rat rot-rot-rot knag-ang-ang rrot rroak ga-ga-ga kjo-jo-jo kajajak klik-klikkli kjik-jek kuju ku" are Finnish transcriptions of the calls of different species of gulls and geese. Also, man-made objects make sounds that are notably birdlike: the c-cassette says "tia tia", and, later in the poem, the fuses say "tzirp tzirp".

Whereas Niemi and Waber's flash poem introduces nonhuman elements through movement, Tossavainen evokes nonhuman presence through auditory and visual noise. In a posthumanist reading, the verbally rendered bird vocalizations can be summoned by recognizing their avian origins and resistance to human (and obviously also avian) interpretation. In addition to Tossavainen's chaotic and playful sound poetics, an avian poetic agency is involved in the creation of the poem. Ecocritic Aaron Moe has conceptualized this as zoopoetics, whereby the gestures and sounds of nonhuman animals are translated into or imitated in poetry. Moe writes about such poetry as "rich borderlands of energy exchanges between poet and animal, animal and poem, poem and reader, animal and reader, and many more interactions" (Moe 2014, 23-24).

A posthumanist reading might thus focus on summoning the nonhuman gestural, vocal, and bodily powers and artistic agencies that are involved in the creation of a text. As the poetic bird vocalizations are for the most part incomprehensible to humans and birds alike, they are not proper animal signs, approachable in a zoosemiotic frame of reference (see Tüür 2017, 64-79). Rather, they are verbal noise born of human and nonhuman origin, or "energy exchanges between poet and animal, animal and poem" to use Moe's expression. Indeed, the existence and the affective and semiosic effects of noise are important to acknowledge in posthumanist reading. In N. Katherine Hayles's (1999, 32-33) account on reading the flickering signifiers, noise refers to the necessary interplay between pattern and randomness in the electric-digital transformation of information. In printed texts (as in music), noise is semiotically and materially present to interfere with the process of reading. Noise questions human intelligibility and humans as the producers and recipients of signs and meanings (see Goddard, Halligan, and Hegarty 2012).

In his theory of art noise, artist and arts scholar Joseph Nechvatal (2011) approaches noise as a productive phenomenon. Noise created in art, or art noise, challenges human senses and consciousness and brings forth new ways of perceiving, experiencing, and thinking. Art noise even has political and ideological potential as it disrupts the un-problematized, almost un-conscious gluttonous consumption of entertainment (which, according to Nechvatal, is often linked to material over-consumption) (Nechvatal 2011, 9-11). Noise also forces us to question the origins and 
agencies of the messages we consider to be art, as it challenges the priority and superiority of human intelligibility (Nechvatal 2011, 218-227). Indeed, noise (visual, auditory, information-related) is definitely one of the powers to be summoned in a posthumanist reading. Now, what is common to all nonhuman powers that have textual or poetic agency, as well as noise, is that in texts they are transmitted materially by signs. Therefore, a posthumanist reading has to stay sensitive to the semiotic and material powers of signs.

\section{The Agency of Signs}

Due to their manifold essence, the function - and powers - of signs can be approached in many different ways. As has been mentioned earlier, the post-structuralist accounts on the divide between signifier and signified have greatly inspired posthumanist thinking. If all signification and all communication are based on the arbitrary relation between the signifier and the signified, and on the resulting referral of meaning, this means that humans are subjugated by the altering and distorting powers of language. Throughout his philosophical works, Jacques Derrida has highlighted differences and deferrals of meaning - the play of signs happens always somewhere else, in the distance, beyond human reach. Another account on the autonomous play of signs has been proposed by Ian Bogost, a game theorist and proponent of object-oriented ontology in his book Alien Phenomenology. Or, What It's Like to Be a Thing (2012). Bogost expands his theory of objects (or units, as he calls them) to account for linguistics as well, although he only discusses them very briefly in the context of the games "Scribblenaut" and "Pickle" as well as different sorts of word lists. His idea of words as operating units helps to further understand the nonhuman powers at play in posthumanist reading:

Words do not just denote, they also operate. We can understand
signs themselves to have experiences of one another that remain
comprehensible only by tracing their own relations to our engage-
ment with them as signifiers.

(Bogost 2012, 56)

Bogost here seems to limit human conception of the unit operations of signs (or "the strange graspings of stuffs linguistic") to their status as signifiers tied to specific signifieds in a somewhat constant manner (Bogost 2012, 56). In other words, from a human perspective, words operate according to the objects they signify. But what happens in a poem like Tossavainen's "kadonneen äänen lyhyt haastattelu”, where we hear high "stii stii tips tii tii" from the Great tit (Parus major), delicate "tia tia" from the c-cassette, and sharp electric "tzirp tzirp" from fuses? 


\section{Karoliina Lummaa}

These vocally similar words of organic and mechanical origin seem to resonate with each other auditorily: they "have experiences of one another" (Bogost 2012, 56) and operate on a material basis, and through sensual similarities, they make new strange semantic bonds between noise-making objects: birds, c-cassettes, fuses.

To summon the powers of signs requires sensitivity to their materiality, which always introduces the possibility of interference and noise. The visual poem "damage" (2008) by Jukka-Pekka Kervinen, published in Nokturno website, opens up a seemingly three-dimensional space of partly effaced words on a gray background (Figure 2.2).

The impression of three-dimensionality is created partly by the changing font size and partly by the different colors: words with smallest font size printed in white and different shades of gray appear to linger in the background and fading to it, while words with bigger font size dominate "the foreground" with brighter colors of blue and magenta. The crowd of words creates an impression of plenitude and hence noise, but at the same time, the letters seem effaced, or damaged as the title of the poem implies. N. Katherine Hayles's (1999, 30-32) remarks on the changing experience of reading text from the screen is particularly important here, as Kervinen's poem literally changes when the angle of the computer's screen is changed. By moving the screen, the reader is thus able to manipulate the color contrasts and thus the material makeup of the poem.

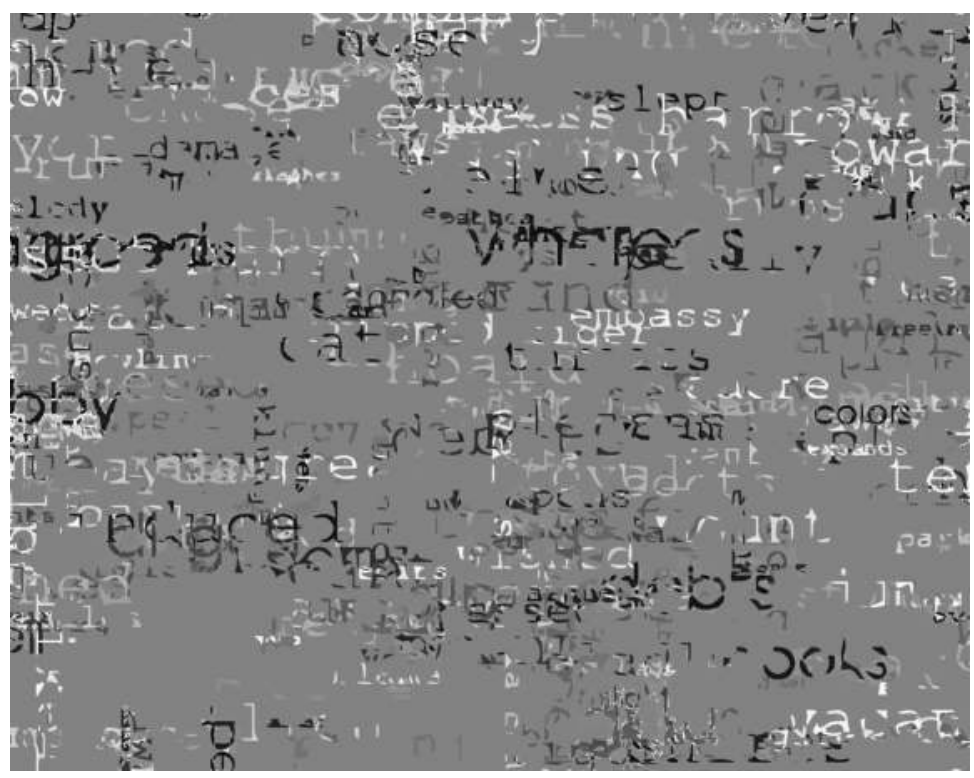

Figure 2.2 Jukka-Pekka Kervinen: "damage” (2008). 
Generally, we are accustomed to read poetry in order to make sense of it. In visual poems, we concentrate on letters and reading even though other sensual or even visual features might be more noticeable. Thus, in Kervinen's poem, we might concentrate on recognizing individual words: they are definitely in English, but what specific words are there? The broken forms of the words make it difficult to identify them: maybe "slept", "cat", "damage", "whereas", and "colors"? But there are dozens of other, unrecognizable ones. Noise (visual or auditory) does not have to be loud or irritating - it can be subtle, but it always challenges interpretation and understanding. Kervinen's "damage" plays with the effacement of words and their patterned distribution in the visual field, as if to suggest that the patterns or colors of the words might convey a message after all.

The poem "damage" is created with a computer program written by Kervinen himself, based on an initial idea of how the poem should look like. Chosen words and colors and the overall patterning and structure of the poem are generated by a program based on stochastic/cybernetic algorithms. In "damage", the words appearing as partly erased have actually new layers of text written on them with the same color that appears in the background. This visual impression is computer-generated but designed and thus intended by the poet. To achieve a desired image requires several runs of the program.

The visual arrangements and formations of letters and other signs are an important aspect of the aesthetics of visual poetry. Denotation is not the primal function of signs; instead of (metaphorically) looking through the signs, the reader ends up looking at them. This is exactly what happens in the poems by Marko Niemi and Dan Waber, and by Jouni Tossavainen and Jukka-Pekka Kervinen: the multiple nonhuman agencies and powers of animals, electricity, hardware and software, and other objects, systems, and processes uncommon to any classical humanist notion of poetry require the attention of the reader. They challenge the reader to account for their strange, influential materialities.

To think this further, it might be helpful to turn to the material engagement theory proposed for archaeology by Lambros Malafouris. In his book How Things Shape the Mind (2013), Malafouris composes a materialist theory of human prehistory by examining and conceptualizing the role of things, objects and materials in the development of human cognitive skills (counting, writing, conceptual thinking). Malafouris's focus is thus on the long-term change of human thinking, which for Malafouris $(2013,77)$ "is, first and above all, thinking through, with and about things, bodies, and others." One of the crucial things with which humans have thought is "the material sign": a carving, a painted mark, a molded figure or another sign object with an expressive (and thus not completely describable or definable) meaning. Material signs do not function as abstract symbols but rather participate in the signifying process through their particular makeup. 


\section{Karoliina Lummaa}

The relation between the (material) sign and the mind (or social universe) is reversed in this line of thinking, since material signs physically shape the human mind and world - they do not represent anything that already exists in the mind or in the social world (Malafouris 2013, 97).

Malafouris's argument is grounded in ideas about nonhuman agency and associations of humans and nonhumans proposed by, for example, Bruno Latour. Malafouris focuses on the (pre)historical development of human thinking through material practices, relations, and engagement. What I am suggesting is that the concept of material sign describes instructively the entangled agencies of signs in contemporary poetry, whether printed or electronic, as both these platforms are material in their own specific ways. Further, as the signs in poetry are influenced and partly formed by nonhuman powers and agencies, their signification is always partly alien and thus expressive and engaging rather than symbolic and controllable.

\section{Sorcerers}

To conclude, I would like to return to Stefan Herbrechter's $(2013,29)$ prediction about the posthumanist task of "rewriting the entire history of anthropocentrism". Above, I have suggested that posthumanist reading involves the critical reading of human's others as well as an acknowledgment and an analysis of the diverse nonhuman powers involved. In more concrete terms, posthumanist reading as a summoning of nonhuman powers pays attention to the plural material-semiotic makeup of texts: the materialities of text production (whether in print or in electronic platforms), possible movements, and other changes in the makeup of electronic texts, visual and auditory textual features of nonhuman origin, and so on. In the context of Herbrechter's task of rewriting the history of anthropocentrism, I want to ask; aren't these nonhuman agencies or powers themselves partly rewriting the history of anthropocentrism through changing our understanding of language, writing, and reading? Accordingly, aren't these powers also helping (or forcing) us to re-address the question "what it means to be human"?

With terminology adapted from occultist traditions - summoning, evocation - I have elaborated on the spectral rhetorics of posthumanism with a specific purpose in mind: to bring forth associations with the old traditions of negotiating, interacting with and commanding forces and entities below, above, and beyond humans. These associations highlight the prevailing centrality and unquestionable authority of humans in the midst of the posthumanist turn. We are the ones to question the exclusive tradition of humanism, and we are the ones to initiate any alternative epistemologies, ethics, and ontologies. With regard to art, literature, and poetics, ours is the challenge to summon nonhuman powers. We are the sorcerers. 


\section{Acknowledgments}

The author wishes to thank warmly the poet Jouni Tossavainen for the permit to reprint a part of the poem "kadonneen äänen lyhyt haastattelu" in this chapter.

\section{References}

Abram, David. 2011. Becoming Animal. An Earthly Cosmology. New York: Vintage Books.

Badmington, Neil. 2000a. "Introduction: Approaching Posthumanism." In Posthumanism, edited by Neil Badmington, 1-10. Hampshire and New York: Palgrave.

- 2000b. "Posthumanist (Com)Promises: Diffracting Donna Haraway's Cyborg Through Marge Piercy's Body of Glass." In Posthumanism, edited by Neil Badmington, 85-97. Hampshire and New York: Palgrave.

Barad, Karen. 2003. "Posthumanist Performativity: Toward an Understanding of How Matter Comes to Matter." Signs: Journal of Women in Culture and Society 28: 801-831. doi: 10.1086/34532

Bogost, Ian. 2012. Alien Phenomenology, or What It's Like to Be a Thing. Minneapolis and London: University of Minnesota Press.

Callus, Ivan, Stefan Herbrechter, and Manuela Rossini. 2014. "Introduction: Dis/Locating Posthumanism In European Literary and Critical Traditions." European Journal of English Studies 18: 103-120. doi: 10.1080/13825577.2014.916999

Cohen, Tom. 1994. Anti-Mimesis from Plato to Hitchcock. Cambridge, MA: Cambridge University Press.

Goddard, Michael, Benjamin Halligan, and Paul Hegarty, eds. 2012. Reverberations. The Philosophy, Aesthetics and Politics of Noise. London and New York: Continuum.

Haraway, Donna. 2008. When Species Meet. Minneapolis and London: University of Minnesota Press.

Hayles, N. Katherine. 1999. How We Became Posthuman. Virtual Bodies in Cybernetics, Literature and Informatics. Chicago and London: The University of Chicago Press.

Herbrechter, Stefan. 2013. Posthumanism. A Critical Analysis. London: Bloomsbury.

Herbrechter, Stefan, and Ivan Callus. 2008. "What Is a Posthumanist Reading?” Angelaki, 13: 95-111. doi: 10.1080/09697250802156091

Kahn, Douglas. 2013. Earth Sound Earth Signal. Energies and Earth Magnitude in the Arts. Berkeley and Los Angeles: University of California Press.

Kervinen, Jukka-Pekka. 2008. "damage.” Nokturno.fi Poetry Online website. Accessed October 28, 2018. http://nokturno.fi/poem/viisi-runoa. Originally published on Tuli\&Savu Net.

Lummaa, Karoliina. 2017. Kui trittitii! Finnish Avian Poetics. Translated by Jaakko Mäntyjärvi, Emily Jeremiah, and Fleur Jeremiah. Helsinki: Finnish Academy of Science and Letters.

Malafouris, Lambros. 2013. How Things Shape the Mind. A Theory of Material Engagement. Cambridge, MA and London, England: The MIT Press. 


\section{Karoliina Lummaa}

Mason, Travis V. 2013. Ornithologies of Desire. Ecocritical Essays, Avian Poetics, and Don McKay. Ontario, Canada: Wilfrid Laurier University Press.

Moe, Aaron M. 2014. Zoopoetics. Animals and the Making of Poetry. Plymouth, UK: Lexington Books.

Morton, Timothy. 2009. Ecology without Nature. Rethinking Environmental Aesthetics. Cambridge, MA and London, England: Harvard University Press.

Morus, Iwan Rhys. 2011. Shocking Bodies. Life, Death \& Electricity in Victorian England. Stroud, Gloucestershire: The History Press.

Nechvatal, Joseph. 2011. Immersion Into Noise. London, England: Open Humanities Press. www.openhumanitiespress.org/books/titles/immersion-intonoise/.

Tossavainen, Jouni. 2007. Kerro. Helsinki: Like.

Tüür, Kadri. 2017. Semiotics of Nature Representations: On the Example of Nature Writing. Tartu: Tartu University Press.

Waber, Dan, and Marko Niemi. 2008. "a niinkuin koira." Nokturno.fi Poetry Online website. Accessed October 28, 2018. http://nokturno.fi/poem/aniinkuin-koira.

Wolfe, Cary. 2010. What Is Posthumanism? Minneapolis and London: University of Minnesota Press. 


\title{
3 Becoming-instrument Thinking with Jeff VanderMeer's Annibilation and Timothy Morton's Hyperobjects
}

\author{
Kaisa Kortekallio
}

When I finally picked up my husband's journal and started to read, the brightness washed over me in unending waves and connected me to the earth, the water, the trees, the air, as I opened up and kept on opening.

(VanderMeer 2014, 160)

Annibilation (2014), a novel by American writer Jeff VanderMeer, presents the reader with a strange area where nonhuman life flourishes and humans change into something else. All that is left from the researchers sent to investigate the area are their journals - the novel being presented as a journal too. These textual traces entice readers into feeling with the focalizing characters, but they also guide the readers' attention toward the recognition of artificiality: the characters are there to interact with, and yet they are not people.

Hyperobjects: Philosophy and Ecology after the End of the World (2013), a philosophical monograph by American writer Timothy Morton, presents the reader with strange, imperceptible objects that have the power to change humans into something else. A first-person narrator invites readers to feel the visceral force of global capital and the burn of climate change on one's body. Yet the text also guides the reader's attention toward the artifice of this experientiality: the narrator is there, his name is printed on the cover, and yet he is not a person.

This chapter concerns the experience of reconfiguration - and especially the experience of being opened up to nonhuman influences through self-aware engagement with estranging first-person narratives such as the ones introduced above. The question is simple, really: how can literature change its readers? And in particular, how can literature open readers up to environmental change? As a way of approaching an answer, I try out a mode of engagement I call becoming-instrument. "Becoming", overused in post-structuralist and posthumanist discussions to the point of turning into a dead metaphor, has been used to denote "a continued sense of the subject as multiple and always-in-progress, a becoming rather than being" (Vint 2005, 288). This basic notion is at the heart of 
my approach, too. "Instrument" connotes both musical instruments and scientific instruments: something that is manufactured, calibrated, and played for a specific creative purpose. I suggest that a first-person reader/ writer construct can function as an instrument for making sense of both personal and environmental change. My approach loops back to one of the primary texts I think with, that is, Timothy Morton's Hyperobjects:

The thinking style (and thus the writing style) that this turn of events necessitates is one in which the normal certainties are inverted, or even dissolved. No longer are my intimate impressions "personal" in the sense that they are "merely mine" or "subjective only": they are footprints of hyperobjects, distorted as they always must be by the entity in which they make their mark - that is, me. I become (and so do you) a litmus test of the time of hyperobjects.

(Morton 2013, 5)

Morton evokes the physical connotations of "impression", turning the scholarly body into a material indicator by which the traces and effects of environmental change become available for research. In this chapter, the self-instrument is tuned and tweaked in order to become more impressionable: that is, more receptible to the various effects of textual ecologies. ${ }^{1}$

\section{Enactive Theory Meets Posthumanist Practice}

I think with posthumanist thinkers, but the thinking also links to another conversation: the enactive approach to literature, developed in recent years in the cognitive humanities (Kukkonen and Caracciolo 2014). The view of reading that often arises in enactive approaches to literature involves distributed agency and co-constitution: both the text and the reader bring something into the reading event, and the reader is to some extent "played" by the text (see Polvinen 2012). Scholars adopting the enactive approach to cognition often also promote a holistic understanding of the cognizing subject: they consider the subject of perception to be "the whole animal, actively exploring its environment" rather than a disembodied mind or a body-independent brain (Noë 2004, 30; see also Varela, Thompson, and Rosch 1992; Thompson 2007). Moreover, the emergence of such a mind involves skillful activity. Philosopher Alva Noë would claim, for example, that perceiving "isn't something that happens in us, it is something we do" (Noë 2004, 216, see also O’Regan and Noë 2001).

Enactive approaches to literature trace the skillful activity of this "whole animal" in the dynamics of reading. It is, however, still rare for enactive scholars to methodically employ the model of co-constitutive, holistic reading. In the common rhetoric, the role of "the embodied 
reader", the one who engages with the texts emotionally and experiences bodily sensations, still tends to be reserved for lay people. One exception to this trend is Emily Troscianko (2014), who has applied her particular experiential background of eating disorder to her interpretative work. Troscianko's phenomenological account of starvation is thick and detailed, but from a posthumanist perspective, it is problematic in another respect: it mentions the particular experiential background of the scholar as a basis of interpretation, but does not discuss the dynamic and material constitution of that experientiality. Rethinking the condition of embodiment as a more-than-human process would require practices that foreground the embodied activity of becoming-with nonhumans.

Enactive approaches do provide tools for considering the nonhuman actors that contribute to literary engagement - both textual devices themselves, and environmental forces and entities that work through text. Merja Polvinen (2012), for example, thinks "of readers as the audience of a magician, being tricked even as they are aware of the trick, and of readers as instruments, producing music specifically by allowing themselves to be played by the text" (Polvinen 2012, 108). Polvinen's metaphors are tied to a specific understanding of mimesis as poiesis: in this understanding, fictions act upon the actual world rather than merely imitate it. Polvinen, along with other enactive scholars, such as Alva Noë (2015), Karin Kukkonen, and Marco Caracciolo (2014), considers fictions as suggestive artifacts and the reading event as active bodily engagement with those artifacts. Enactive approaches also acknowledge that texts and reading are constituted in material relations with biological, social, and cultural ecologies (for an overview, see Caracciolo 2014a).

In the following, I want to connect enactive ideas about environmental and literary engagement to certain posthumanist reading practices - in which even the professional reader is allowed to enter into embodied and emotional engagement with textual ecologies. The strong naturalscientific influence in the tradition of cognitive literary studies guides scholars to employ detached, rationalized methodologies that posit the text as an object of inquiry rather than an actor to think with. As the very brief review of enactive approaches to literature above demonstrates, enactive theory is where this tradition is being challenged. This is where the new cognitive approaches could, in my opinion, gain from crossbreeding with critical posthumanisms, which are informed by natural sciences but methodically problematize their epistemological attitudes.

Posthumanist approaches, especially in the strands employing feminist methods, have produced first-person research exploring the entangled aspects of more-than-human engagements. Often this research is labeled as "thinking-with": Donna Haraway thinks with dogs, Astrida Neimanis thinks with bodies of water, Stacy Alaimo thinks with toxins. Feminist posthumanists tend to emphasize the material processes in 
which selves and others are constituted, and yet move away from naturalized conceptions of identity ${ }^{2}-$ a predilection that also often characterizes enactivist approaches to cognition, even if the style of research is remarkably different. In the posthuman phenomenology of Astrida Neimanis, for example, "the understanding of 'body' that we inherit from a dominant Western metaphysical tradition (a bounded materiality and individual subjectivity)" is bracketed, and the scholarly body is reconfigured as a more-than-human collective constituted by various flows of metabolism, memory, and attention (Neimanis 2017, 41). In this practice, the more-than-human aspects of experience are brought to focus and amplified (Neimanis 2017, 5).

I propose that the posthumanist feminist method of thinking with literature (rather than about it) can enrich enactive approaches to literature by way of "practicing what you preach" - that is, applying an enactive conception of cognition to one's personal process of scholarly interpretation. In this chapter, I focus on mobilizing and testing a particular theoretical claim. Marco Caracciolo suggests that the literary techniques of first-person narration can 'take readers' empathic involvement with a fictional character to a higher level than would be likely in real life" (Caracciolo 2014b, 32). He argues that reading first-person narratives differs remarkably from both the empathic involvement with second- or third-person focalizers and the empathic involvement with actual people, which tends to follow the second- and third-person patterns of relating. The evocative force of first-person narratives lies, on one hand, in their ability to produce simulated experiences in the mind of the reader and, on the other hand, in the performative power whereby a certain kind of narrator can validate some fictional states of affairs as true within the fiction, called "authentication" by Lubomír Doležel (Doležel 1998; Caracciolo 2014b).

The concept of empathy has been criticized in the posthumanist discussion for its dependency on the recognition of sameness (e.g. Ahmed 2004; Braidotti 2013; Gomel 2014). It is thus important to note that Caracciolo's definition of empathy necessarily contains an imaginative aspect - he uses the term to denote not just "the capacity to experience another person's mental states in a first-person way" (Caracciolo 2014b, 32) but as interchangeably with "mental simulation" (ibid. 32, 38). Empathy, construed in this way, does not imply a hermeneutic understanding of the experiences of the other, but rather the imaginative reconstruction or enaction of such experiences. In the imaginative process of reading a first-person narrative, the simulated experience emerges as the collaboration of textual cues and readerly imagination. In the process, the textual cues activate the readers' "experiential backgrounds" - in all their variation - and in that respect, the imaginative reconstruction of fictional experience is based on recognition of familiar elements (Caracciolo 2014c, 24-26). However, through his analysis of strange 
and "unnatural" narrators, ${ }^{3}$ Caracciolo suggests that the reading process can also stretch the readers' capacities into imagining experiences remarkably different from their own (Caracciolo 2014b, 2016). ${ }^{4}$

Deliberately integrating this idea about the evocative force of firstperson narration into an actual interpretative process means opening up to the reconfigurative potential of first-person narratives and becoming vulnerable to change. I suggest that this kind of self-aware first-person engagement - called becoming-instrument in this chapter - can work toward dissolving the certainty of the human subject and develop instead a model of subjectivity as "multiple and always-in-progress" (as phrased by Sherryl Vint). In this regard, the engagement could resemble certain mindfulness-based contemplative practices, such as Zen Buddhist meditation, that guide the practitioner's attention toward the illusionary and contingent features of personal experience. Echoing Fransisco Varela's (1996; see also Thompson 2009) wish of bridging the gap between studies of mind-as-object and mind-as-experience, I suggest that combining enactive theory with posthumanist methodology can - with a labyrinth of caveats to be negotiated ${ }^{5}$ - give rise to new insights into our original question: how can literature change its readers?

To map out the potential of this combined approach, I think with two primary texts that evoke and thematize reconfiguration: Jeff VanderMeer's Annibilation (2014) and Timothy Morton's Hyperobjects (2013). ${ }^{6}$ In this reading, I align with the narrators, letting their experience inform mine. Unlike readings emphasizing identification or immersion, this reading strategy maintains an awareness of fictionality: this is engagement with fictional minds as "a bundle of effects stories can have on their recipients" (Caracciolo 2014b, 32) rather than fictional minds as potential persons. To steer away from the ambiguity of the term "empathic engagement", this form of engagement will from now on be called enactment of fictional experience.

\section{Annibilation: Promise of Self-Immolating Ecstasy}

One of the most remarkable similarities between Annibilation and Hyperobjects is their complex take on first-person writing. Both of them employ a distinct first-person narrator: in Annibilation, the narrator is called "the biologist", in Hyperobjects, "Tim Morton". However, both works are also committed to decentralizing the human subject "within a universe that clearly sees us as simple atoms like everything else" (VanderMeer 2015), developing instead a mode of ecological existence that has been called "dark ecology" (Morton 2013, 2016) or "weird ecology" (Tompkins 2014). I suggest that both of these first-person perspectives invite readers to engage with them in ways that draw on their experiential background, and yet, through defamiliarizing techniques, foreground the fictional aspects of that engagement. Moreover, I suggest that 


\section{2}

Kaisa Kortekallio

this twofold move of intimate engagement and cognitive estrangement serves to encourage an environment-oriented sense-making process. ${ }^{7}$

The novel Annibilation is written in the form of a field journal, narrated by a secretive biologist who shies away from stable identities, becoming part of the ecosystems she studies rather than keeping an observational distance. The biologist is part of an expedition group sent to study a post-catastrophical site referred to as "Area X": a place somewhere on the coast of the Gulf of Mexico, a place where traces of human life have been almost obliterated by an unknown event. The journal is part of her assignment: all members of the group are instructed to keep one, private from the eyes of others. Her mission is to report her observations about Area $\mathrm{X}$ and about the group. From the observations, it becomes apparent that the flora and fauna of the area are not your usual stable objects of scientific description, and the biologist is not your usual scientist-focalizer:

At one point, [a pair of otters] glanced up and I had a strange sensation that they could see me watching them. It was a feeling I often had when out in the wilderness: that things were not quite what they seemed, and I had to fight against the sensation because it could overwhelm my scientific objectivity. There was also something else, moving ponderously through the reeds, but it was closer to the lighthouse and in deep cover.

(VanderMeer 2014, 30)

Tuning into the perspective of the biologist, I am guided into noticing the nonhuman environment rather than the human: the text describes marshland ecotopes in detail, making note of the color of reeds and the eerie sounds of the forest at night, always leaving room for the unknown. It does not provide me with the names of the other group members, nor does it narrate their history. They are deemed insignificant - by the narrative, and by my reading. I make note of the color of the reeds, and I wait for something to emerge from the dark forest.

Soon into the expedition, the biologist is exposed to a transforming event. There is a tower under the ground, and the inner walls of the tower are filled with writing made of fungal growth. She leans in to read the text: by then, she is already contaminated by the emanating spores. This is a moment familiar to me from earlier reading of science-fictional and Weird texts - from J. G. Ballard, William S. Burroughs, Stanislav Lem, and H. P. Lovecraft. After this, everything will be made psychedelic, or perhaps psychotic: the individual mind will soon be flooded by the inhuman forces, and a horrific ecstasy will wipe away all rational subjectivity. I will give into that ecstasy too, I will let the text fill me and carry me, and I will be annihilated. This is, according to Burroughs, the dynamic of panic: I realize that everything surrounding 
me is undoubtedly and uncontrollably alive, and as a consequence lose the sense of being the center of my world (Burroughs 1985). Philosopher Val Plumwood (1996) describes a similar loss of subjectivity in her essay "Being Prey", in which she accounts for her experience of being attacked by a crocodile.

And so it happens in Annibilation. Except it does not. Many things are made psychedelic: the walls are alive, the biologist feels a "brightness" in her body - a brightness that sculpts her into becoming something else entirely - and she becomes impervious to the hypnotic inductions practiced by the group's leader. She cannot help but perceive differently. But she is as stubborn as she is scientifically trained: she refuses to give in to transformation. She does not trust the hypersensitivity that makes walking in the forest feel like listening to "an intense and expressive aria", and as a result, she remains a consistent subject even in the face of annihilation.

In the tradition of science-fictional "forbidden zone" narratives such as Lem's Solaris (1961) or Ballard's The Drowned World (1962), the deciding moment of transformative estrangement is soon followed by the disintegration of the knowing subject. Annibilation stretches the moment of estrangement, making the biologist's resistant practices more like a deliberate inquiry than an inevitable slide into asubjectivity. This is also apparent in the style of the novel: even when reporting moments of utter panic, the narration does not turn into the more sensational type of horror-writing that would break the sentence structure or the borders between subject and environment. Neither is there any sentimentality. Even the confessional passages such as the one below, in which the narrator reveals previously hidden information about the brightness, retain a tense formality in the name of "scientific objectivity".

It may be clear now that I am not always good at telling people things they feel they have a right to know, and in this account thus far I have neglected to mention some details about the brightness. My reason for this is, again, the hope that any reader's initial opinion in judging my objectivity might not be influenced by these details.

(VanderMeer 2014, 150)

In the novel, several processes of transformation overlap and intersect: the ecosystemic change of the geographical area that is Area X and the resulting loss of an anthropocentric worldview; the progressing brightness that transforms the biologist's body; and, perhaps most obscured of them all, a psychological process of grieving the death of her husband who took part in the previous expedition to Area X. Even though the end of the novel provides a resolution to some of the psychological tension, the conflict between the distanced tone and the transformative subject matter holds. ${ }^{8}$ The tone can be understood in the context of the biologist's resistance to emotional and ecological transformation: in order 
to retain her humanity under the onslaught of nonhuman forces, she practices techniques that affirm her as a consistent, discrete self: repeatedly wounding her body, and compartmentalizing her thoughts through research and writing. Distancing thus becomes a technique for affirming the boundaries of the subject, and for keeping the self-annihilating ecstasy of the brightness at bay.

My side burned, but I could tell that too-quick repair was taking place, enough for me to move about [...]. I knew not to trust this feeling of well-being, that it could simply be the interregnum before another stage. [...] To keep the brightness in check, I would have to continue to become wounded, to be injured. To shock my system.

(VanderMeer 2014, 151)

As the narrative accounts for the events, readers are invited to enact the fictional experience of the character in all its sensory texture and complex emotionality. At the same time, the report-like tone of the account asserts a distance between the readers and the fictional mind of the biologist: the reader is repeatedly reminded of the artifice of writing that mediates the biologist's experience - and, perhaps, also of the fictionality of the novel itself. In other words, this may not be the kind of first-person narrative that Caracciolo (2014b) intends to draw out in his article, as it does not provide an unhindered illusion of first-person access to a fictional mind. However, the experientiality of reading is not annulled by the awareness of fictionality. Rather, the distancing style activates those parts of one's experiential background that are salient to the cognitive tasks of analysis and resistance. In enacting this particular fictional experience, a certain fearful tension builds in the body, and the experiential contrast between scientific objectivity and more-thanhuman entanglement is enhanced. Becoming-instrument involves becoming aware of the ways in which this contrast is produced in reading. Timothy Morton's work on the impressive forces of nonhuman objects can enrich this awareness.

\section{Hyperobjects: Ecological Thought as Becoming Impressed}

The dark ecology of literary scholar Timothy Morton, particularly the book Hyperobjects, also narrates bodily transformations stemming from environmental transformations: the effects of climate change, globalization, and ubiquitous oil in the body of a scholar. In doing so, it calls for an engagement with its first-person narrator. As Stephen Muecke has noted in his review of Hyperobjects, the correct category for this book is not any particular scholarly discipline but the cross-intellectual practice of "theory" - and "you don't read theory to advance the discipline you 
might belong to - you read it for stimulation" (Muecke 2014). I claim that Morton's writing thematizes this very function, making the act of being stimulated a requirement for ecological thought.

In dark ecology, first-person experience is presented as constituting of encounters with other objects. The "object-oriented" approach Morton promotes is committed to revealing the activity, unknowability, and strangeness of material things. For an object-oriented ontologist, human subjectivity inhabits no special ontological category - "the being of a paper cup is as profound as mine" (Morton 2013, 17). By turning the reader's attention to nonhuman objects, and the material relations of humans-as-objects and other objects, Morton foregrounds the limitations of human cognition. Like the writers of Weird tales such as Annibilation, Morton insists that the real is permeated by weird and awesome processes. He also uses similar literary techniques to evoke estranging, grotesque, and sublime effects: the evocation of material monsters, visceral imagery, first-person narration, and a reversal of subject-object relations (see VanderMeer 2011 for the Weird). ${ }^{9}$

The monstrous concept of byperobject is a particularly effective tool in the project of reconfiguration. A hyperobject is defined as "a thing that is massively distributed in time and space relative to humans" (Morton $2013,1)$ - a system or a process that escapes human sensory perception and cognitive capabilities, but still has the power to transform human existence. Global warming, radioactive materials, and ubiquitous plastic can be considered hyperobjects, but so can the processes of evolution and extinction, and so can things like the English language and money. A hyperobject is both pervasive and viscous: in the idiom of Cara Daggett, it

penetrates you to the cellular level and yet sticks to you and everything you know on Earth and everywhere: it is something like a wasp drowning in a jar of honey - the more you panic and resist it, the more stuck you become.

(Daggett 2014)

Morton presents this as an inescapably personal experience:

I do not access hyperobjects across a distance, through some transparent medium. Hyperobjects are here, right here in my social and experiential space. Like faces pressed against the window, they leer at me menacingly: their very nearness is what menaces. From the center of the galaxy, a supermassive black hole impinges on my awareness, as if it were sitting in the car next to me at the traffic lights. Every day, global warming burns the skin on the back of my neck, making me itch with physical discomfort and inner anxiety. Evolution unfolds in my genome as my cells divide and mutate, as my body clones itself, as one of my sperm cells mixes it up with an 
egg. As I reach for the iPhone charger plugged into the dashboard, I reach into evolution, into the extended phenotype that doesn't stop at the edge of my skin but continues into all the spaces my humanness has colonized.

(Morton 2013, 27)

Morton connects the invasive qualities of hyperobjects to the practice of writing. For him, accounting his personal impressions is a technique for studying hyperobjects. His approach to environmental thinking requires an openness to nonhuman objects - including art objects. Openness is a counter-move to the kind of distanced observation usually considered as the proper scientific attitude (the same attitude Annibilation's biologist fails at), which Morton considers "a psychic and ideological construct designed to protect me from the nearness of things" (Morton 2013, 27; see also Morton 2010, 8). The "things" that call for attention in the time of radical environmental change are not merely near, but in crushingly invasive contact with human bodies. This invasion is also at the heart of VanderMeer's Area X, in the transformation of the ecotopes, and in the contamination of the biologist. What unites Morton and VanderMeer, and sets them apart from most environmental writers, is their call for opening up to the strangeness of environmental transformations rather than preserving nonhuman Nature as a harmonious and stable setting for human activity. First-person engagement plays a great part in this project: one's personal impressions become "litmus tests in the time of hyperobjects" (Morton 2013, 5; see quote in the introduction to this chapter).

According to Morton, the existence of hyperobjects forces thinking into acknowledging a paradox: that there are real, material things that exist and act independently of human perception - and that there is no metaposition from which to approach these things. It becomes impossible to write from a position "outside" hyperobjects. Rather, the self is always impressed by hyperobjects, and to some extent constituted by them. By following the "footprints", the traces of hyperobjects in individual bodies, one can make hyperobjects perceptible. The human body thus becomes a measuring device, and the rhetorical self becomes a phenomenological instrument - an affordance, a handle by which you can grasp a hyperobject and communicate the feel of it.

The rhetorical self Morton frequently uses is quite effective in evoking embodied experientiality. Consider, for example, the kinetic and physical way in which he evokes the experience of listening to a musical track by the group My Bloody Valentine:

When I listen to My Bloody Valentine, I do not reach out toward the sound - instead, I am assaulted from the inside by a pulsation that is also sound, a physical force that almost lifts me off the floor. Kevin Shields's guitar sears into me like an x-ray, scanning me, strafing me. 
The chords lurch around one another sickeningly, gliding in and out of tune, amassing towers of harmonics through dissonance. Distortion pulps and fragments the sound into a welter of gravel and thick oil.

(Morton 2013, 29)

The strategic purpose of the passage is to support the notion of the viscosity of hyperobjects - that is, the impossibility of distancing oneself from them, either intellectually or aesthetically. In Morton's line of thought, aesthetic experience in general is not "attunement" of a subject to an art object (in the Kantian sense) - instead, the art object "tunes to me, pursuing my innards, searching out the resonant frequencies of my stomach, my intestines, the pockets of gristle in my face" (Morton 2013, 30). This relationship between objects, termed interobjectivity by Morton, can be considered a visceral form of Polvinen's (2012) "being played" and an extreme form of becoming-instrument. Interobjectivity differs remarkably from the general understanding of empathic engagement, which is considered to be an intersubjective phenomenon that requires participants capable of experiencing mental states. Morton, however, sees intersubjectivity as "a particular instance of interobjectivity with which humans are familiar [...] 'intersubjectivity' is really human interobjectivity with lines drawn around it to exclude nonhumans" (Morton 2013, 81-82). ${ }^{10}$

Reading the above passages from Hyperobjects through the conception of interobjectivity, one can acknowledge the text as an aesthetic object that evokes embodied experientiality and draws its power both from the material affectivity of nonhuman objects and from the specific practices of interhuman affectivity - such as first-person narration. Both Doležel's (1978) authentication and Neimanis's (2017) amplification are helpful here. In the passages, a first-person narrator authenticates the physical effects and bodily feelings of interobjective relations as true within the theoretical construction presented in Hyperobjects: they are true as experiences. The overt stylization of the passages (metaphors and similes; repetition of structures such as "as I"; rhythm; synesthetic expressions) marks them as distinctly literary, as already saturated with skill, learning, and culture. Instead of seeking an objective stance outside hyperobjects, Morton's approach embraces personal impressions as means of inquiry. As such, this is a performative mode of writing, one that develops an understanding of the impressive and invasive qualities of hyperobjects by amplifying the experiential feel of them.

\section{Enactment of Fictional Experience as a Mode of Inquiry}

Returning to the reading of Annibilation further demonstrates how this kind of deliberate engagement applies to engaging with a literary object. 
As mentioned above, Annibilation is presented as an expedition journal. Over the course of transformational events, the process of analytical writing is presented as a tool for making sense of the experience. It is an insufficient tool - there seems to be no way of getting to the truth about Area X - but it is presented as necessary for psychological purposes. In accounting for the oppressive vitality of Area $\mathrm{X}$ and the brightness that works its way in her body, the narrator makes a note of the impossibility of thinking about Area X without writing.

[T]here is a limit to thinking about even a small piece of something monumental. You still see the shadow of the whole rearing up behind you, and you become lost in your thoughts in part from the panic of realizing the size of the imagined leviathan. I had to leave it there, compartmentalized, until I could write it all down, and seeing it on the page, begin to divine the true meaning.

(VanderMeer 2014, 93, italics in the original)

The most apparent mental strategy applied by the biologist, compartmentalization, protects the mind from shattering from the impact of the hyperobject that is Area X. As the biologist walks the marsh trail toward an abandoned lighthouse, she thinks of the strange biology of the tower/tunnel. Instead of trying to consider the whole truth, "a vast biological entity that might or might not be terrestrial", she focuses on analyzing specific details of her observations. In her mind, "contemplating the sheer enormity of that idea on a macro level would have broken my mood like an avalanche crashing into my body" (VanderMeer 2014, 90). Her focus on detail is later echoed in the journals left behind by members of earlier expeditions. One particularly provocative journal focuses solely on the thistles that grow in the area, giving lengthy and detailed descriptions of them. This single focus is presented as "a way of coping" with the horror of there being a "terrible presence hovering in the background of these entries" (ibid. 114). The compartmentalizing approach is also considered as "guerrilla warfare" against the invasive agency of Area X - a way to fight an enemy you cannot directly confront, physically or mentally.

The biologist keeps on analyzing, and so do I. I read the novel several times, making note of the cues and tones provided by the text, tuning into the resistant attitude of the biologist. As she is oppressed by the vividness of her impressions, so am I: there seems to be no proper way of talking about this book in an academic context. I can dissect it and categorize all my findings, but I am always left with a feeling that I have been misled - that my analytical training, like the scientific training of the biologist, has failed to prepare me for the encounter with this strange text. Accounting for the reconfigurative potential of the novel requires surrendering to subjective experience: the enactment of theoretical 
reader models, rather than a mere critical assessment of them. Only after repeated exposure to the novel, as well as to the theory introduced above, do I find release from the analytical tension.

In the novel, the journals of the expedition members become representatives for their writers. Every member is instructed to keep one, and is encouraged to keep them private. Finding a decaying mound of discarded journals inside the abandoned lighthouse, the biologist feels as if she has encountered a "pile of ghosts". From this pile, she finds the ghost of her husband, the journal "stuck to the back of another journal by dried blood or some other substance... written in the confident, bold hand-writing I knew from birthday cards, notes on the refrigerator, and shopping lists" (VanderMeer 2014, 118). The material description of the journals makes them seem like dead bodies, a rotting mound that documents a history of unnamed expeditions gone awry. The journal of the biologist's husband carries the traces of his actual, familiar body: the blood and the handwriting.

Finding the journal of her husband, the biologist also finds a connection to him that was not realized when he was still alive. She carries the journal with her for some time without daring to open it, and when she finally does, the experience becomes a resolution of a long-accumulated tension.

When I finally picked up my husband's journal and started to read, the brightness washed over me in unending waves and connected me to the earth, the water, the trees, the air, as I opened up and kept on opening.

(VanderMeer 2014, 160)

The biologist's reading dramatizes the issue of enactive engagement with first-person narratives. Reading the journal enables an experience of intimacy that the accumulated years of shared living could not release.

My husband had had an inner life that went beyond his gregarious exterior, and if I had known enough to let him inside my guard, I might have understood this fact. Except I hadn't, of course. I had let tidal pools and fungi that could devour plastic inside my guard, but not him.

(VanderMeer 2014, 167)

There is more to this revelation than interhuman relationships: the "opening up" serves as a model for ecological subjectivity. During the story, the biologist repeatedly reports her observations of the biological life of Area X. In these passages, the emotional and aesthetic aspects of an environmental orientation emerge most clearly, evoking a sense of an experiencing subject who appreciates life in a profound way. The 
contrast between this observational sensitivity and the report-like manner of accounting for interpersonal relationships contributes to the modeling of the character as psychologically complex but unsociable. As a reader, I am invited to feel a closeness to someone who feels more comfortable in desolate marshlands than in crowded restaurants. I am also invited to observe the biologist in different habitats, to mark the changes in the tone of her narration. Toward the end of the novel, these tones and preferences emerge as expressions of her environments.

[F]un for me was sneaking off to peer into a tidal pool to grasp the intricacies of the creatures that lived there. Sustenance for me was tied to ecosystem and habitat, orgasm the sudden realization of the interconnectivity of living things. Observation had always meant more to me than interaction. He knew all of this, I think. But I never could express myself that well to him, although I did try, and he did listen. And yet, I was nothing but expression in other ways. My sole gift or talent, I believe now, was that places could impress themselves upon me, and I could become part of them with ease.

(VanderMeer 2014, 110, italics in the original)

The way to understand the biologist on her own terms, then, would be to observe her as a living creature, an organism in an ecosystem. By being impressed by her environments, she becomes their expression. In that way, she has been open for interpretation all the time she has seemed closed due to the lack of verbal expression of emotions. Being a fictional creature, she can only be tracked by the textual traces she leaves: the fictional journal text of Annibilation. But she is there, as real a thing as any narrator of a letter - and she can be engaged with. The sense of engagement may well be an illusion. That does not make it less true.

As mentioned in the introduction, Marco Caracciolo argues that the literary techniques of first-person narration can 'take readers' empathic involvement with a fictional character to a higher level than would be likely in real life". For him, first-person internal focalization provides an intimate access to the fictional experience of a character - an access the kind of which is not possible with actual persons (Caracciolo 2014b, 32). In reading Hyperobjects and Annibilation, I have chosen to accept this hypothesis as a methodical starting point: I have become impressionable, and found a way to enact the experiential states evoked by first-person narration. Furthermore, this reading has led me to suggest that the dynamic of enactment also applies to narratives that are not explicitly fictional but rhetorical devices in non-fiction texts, enabling a mode of enactive engagement with textual constructs usually conflated with actual persons - such as the rhetorical I in Hyperobjects, and, to the extent you find plausible, the rhetorical I of this chapter. 


\section{Conclusion: Becoming-Instrument and Reconfiguration}

Science fiction and fantasy stories are full of narratives about (often horrifying) assimilations with and incorporations into other entities. What sets Annibilation apart is that the biologist successfully resists the incorporation into the strange entity of Area X. Although boundaries between the biologist's body and other entities in the novel are porous and mutable at times, a distinct separation remains between the narrative I and the experiential environment. Neither the acknowledgment of nonhuman agency nor the realization of the constructedness of one's experiential self leads to a total annihilation of human subjectivity or to complete abandonment of rationality. At the end of the novel, the biologist leaves her journal and proceeds deeper into Area X, anticipating a "cataclysmic molting" of the area and the final transformation of herself into something nonhuman.

I will not be here when the thirteenth expedition reaches base camp. (Have they seen me yet, or are they about to? Will I melt into this landscape, or look up from a stand of reeds or the waters of the canal to see some other explorer staring down in disbelief? Will I be aware that anything is wrong or out of place?)

(VanderMeer 2014, 194)

What is annihilated here is not subjectivity as such, but the conception of the human subject as the sovereign master of a passive environment. In Annibilation, epistemic control over one's environment is a necessary but limited tool, as the "interconnectivity of living things" both transforms and transgresses human subjectivity.

In Annibilation and Hyperobjects, the characters of the biologist and Tim Morton are presented as objects for hyperobjects: their fictional bodies are affected by strange imperceptible forces, and they are transformed in the process. These modeled transformations, conveyed to readers in the first-person singular, can train the readers' abilities for imagining and enacting experiential change - for deliberately remodeling their experiential worlds to include nonhuman agency. If art and literature are considered as practices that reorganize the naturalized conventions of experience (see Caracciolo 2014a; Noë 2015), literary transformations like this reorganize a specific aspect of experience: personal change as part of environmental change.

My persistent hope is that first-person involvement, such as the mode of reading presented here as becoming-instrument, can add both intensity and detail to processes of reconfiguration. I have posited a reading self as a heuristic instrument that, in engagement with literature, produces knowledge of the biocultural mesh it is embedded in. The instrument might be inadequate - it is calibrated in the pressures of several 


\section{Kaisa Kortekallio}

disciplines with partly contradicting methodologies and agendas, and as such it is an experimental hunting dog, purposefully bred yet potentially hazardous. It might be mad science, and it might be witchcraft. Yet this mongrel approach can help us reconsider the importance of personal involvement and aesthetic experience in understanding both literature and environmental phenomena. Therefore, it is worth exploring.

\section{Notes}

1 I make no empirical claims on the effect of Annibilation and Hyperobjects on other readers than myself. The reception of both works indicates that they can indeed be read in countlessly varied ways. Rather, I focus on the evocative potential in VanderMeer's and Morton's literary techniques, specifically first-person narration, and explore what happens if one intentionally inhabits the subject position these texts supposedly offer their readers.

2 By "naturalized conceptions of identity", I refer both to the notion of human subjects as sovereign individuals, as developed in modern Western philosophy, and to the reductive notion of identity as a stable end result of biological and evolutionary processes, as proposed in popular versions of evolutionary psychology.

3 Caracciolo has worked with estranging narratives by, for example, William S. Burroughs, Julio Cortazar, Marie Darrieussecq, Bret Easton Ellis, and Mark Haddon.

4 Caracciolo's work on readerly experience rests on the notion of experientiality. The term was introduced by Monika Fludernik (1996) to designate narrative's "quasi-mimetic evocation of real-life experience" $(1996,12)$. In contrast to Fludernik's definition that construes experientiality as primarily a property of narrative, Caracciolo's use of the term focuses on the phenomenology of the event of text-reader interaction. He argues that

even if engaging with narrative does involve mental representations of some sort, its experientiality cannot be understood in representational, object-based terms. Instead, we should think of experientiality as a kind of network that involves, minimally, the recipient of a narrative, his or her experiential background, and the expressive strategies adopted by the author. At the root of experientiality is, then, the tension between the textual design and the recipient's experiential background.

(Caracciolo 2014c, 30)

This is also the sense in which the term is used in this chapter.

5 One of the more crucial caveats is that the two approaches employ different epistemological interests: posthumanist thought strives to actively transform research practices, whereas cognitive approaches, due to their naturalscience genealogies, tend to maintain a carefully apolitical stance. In this question, I side with the posthumanist ethical and political project.

6 In this chapter, I read Hyperobjects more for its literary qualities than for its philosophical implications. Therefore, I do not take up the task of considering Morton's thinking in light of the many traditions it draws from, but focus instead on the techniques he uses to affect his readers. I also acknowledge the critique of one of those traditions, namely, objectoriented ontologies or OOOs, given by many feminist new materialist scholars - the most frequent critique being that OOOs do not properly consider the world-constituting role of power-relations in their ontological 
model - but I steer away from the debate for the time being. I trust that inquiries combining feminist and object-oriented perspectives can provide important insights even if there is no consensus on the ontological aspects of knowledge-formation. (See Åsberg, Thiele, and van der Tuin 2015 for an overview of the critiques.)

7 Cognitive estrangement is one of the grounding concepts in science fiction research. Coined by the Marxist theorist Darko Suvin in 1972, cognitive estrangement has traditionally been considered as the primary effect that distinguishes science fiction proper from related genres such as horror and folkloric fantasy. In short, Suvin's theory defines science fiction as the sort of fiction that systematically presents "an imaginative framework alternative to the author's empirical environment" (Suvin 1979, 4). This systematic construction necessitates a novel element that sets the entire fictional world apart from the empirical reality of authors and readers, and enables the normative world-model of the reader to be transformed. (Suvin 1979, 63-64) While Suvin's theory focuses on the traditionally cognitive, that is, rational aspects of literary engagement, and veers away from bodily experientiality, it can give a general idea of the transformative dynamic at play in reading strange fiction such as Annibilation.

8 The issue is taken up again in the third part of the trilogy, Acceptance, with a significant change in the narrative voice of the biologist. This change will be discussed at length in my doctoral dissertation (forthcoming in 2019).

9 Object-oriented ontologists (or "speculative realists", a term that marks a slightly different but overlapping group of thinkers) have been known to affiliate themselves with Weird literature - according to philosopher David Roden, this might even be considered as the main uniting feature in the "otherwise fissiparous movement" (Roden 2016).

10 Similar ideas about the force of nonhuman matter have been developed by New Materialist and material-ecocritical thinkers (e.g. Barad 2007; Iovino and Oppermann 2012).

\section{References}

Ahmed, Sara. 2004. The Cultural Politics of Emotion. Edinburgh: Edinburgh University Press.

Åsberg, Cecilia, Kathrin Thiele, and Iris van der Tuin. 2015. "Speculative Before the Turn. Reintroducing Feminist Materialist Performativity." Cultural Studies 21 (2): 145-172.

Barad, Karen. 2007. Meeting the Universe Halfway. Quantum Physics and the Entanglement of Matter and Meaning. Durham and London: Duke University Press.

Braidotti, Rosi. 2013. The Posthuman. Cambridge, MA: Polity.

Burroughs, William S. 1985. The Adding Machine: Selected Essays. London: John Calder.

Caracciolo, Marco. 2014a. "Interpretation for the Bodies: Bridging the Gap." Style 48 (3): 385-403.

- 2014b. "Beyond Other Minds: Fictional Characters, Mental Simulation, and "Unnatural" Experiences." Journal of Narrative Theory 44.1 (Winter): 29-53.

. 2014c. The Experientiality of Narrative: An Enactivist Approach. Berlin and Boston: De Gruyter. 


\section{Kaisa Kortekallio}

2016. Strange Narrators in Contemporary Fiction. Explorations in Readers' Engagement with Characters. Lincoln: University of Nebraska Press.

Daggett, Cara. 2014. “Hyperobjects by Timothy Morton.” A Book Review. Society and Space, September 5, 2014. http://societyandspace.org/2014/09/05/ hyperobjects-philosophy-and-ecology-after-the-end-of-the-world-bytimothy-morton-reviewed-by-cara-daggett.

Doležel, Lubomír. 1998. Heterocosmica: Fiction and Possible Worlds. Baltimore and London: Johns Hopkins University Press.

Fludernik, Monica. 1996. Towards a "Natural" Narratology. New York: Routledge.

Gomel, Elana. 2014. Science Fiction, Alien Encounters and the Ethics of Posthumanism: Beyond the Golden Rule. Basingstoke: Palgrave McMillan.

Iovino, Serenella, and Serpil Oppermann. 2012. "Material Ecocriticism: Materiality, Agency, and Models of Narrativity.”Ecozon@ 3 (1): 75-91.

Kukkonen, Karin, and Marco Caracciolo. 2014. "Introduction: What is the "Second Generation"?" Style 48 (3): 261-274.

Morton, Timothy. 2010. The Ecological Thought. Cambridge, MA: Harvard University Press.

- 2013. Hyperobjects. Philosophy and Ecology after the End of the World. Minneapolis and London: University of Minnesota Press.

- 2016. Dark Ecology. For A Logic of Future Coexistence. New York: Columbia University Press.

Muecke, Stephen. 2014. "Global Warming and Other Hyperobjects." Los Angeles Review of Books. February 20, 2014. https://lareviewofbooks.org/ article/hyperobjects.

Neimanis, Astrida. 2017. Bodies of Water. Posthuman Feminist Phenomenology. London: Bloomsbury.

Noë, Alva. 2004. Action in Perception. Cambridge, MA: The MIT Press.

- 2015. Strange Tools. Art and Human Nature. New York: Farrar, Strauss and Giroux.

O’Regan, J. Kevin, and Alva Noë. 2001. "A Sensorimotor Account of Vision and Visual Consciousness." Behavioral and Brain Sciences 24 (5): 939-1031.

Plumwood, Val. 1996. "Being Prey.” Terra Nova 1 (3): 32-44.

Polvinen, Merja. 2012. "Being Played. Mimesis, Fictionality and Emotional Engagement." In Rethinking Mimesis. Concepts and Practices of Literary Representation, edited by Saija Isomaa, Sari Kivistö, Pirjo Lyytikäinen, Sanna Nyqvist, Merja Polvinen, and Riikka Rossi, 93-114. Newcastle upon Tyne: Cambridge Scholars Publishing.

Roden, David. 2016. "Dark Posthumanism: The Weird Template.” A Presentation Given at the Questioning Aesthetics Symposium, Dublin, May 12-13, 2016. David Roden's Website, May 10, 2016. http://enemyindustry.net/ blog/?p=6133.

Suvin, Darko. 1979. Metamorphoses of Science Fiction: On the Poetics and History of a Literary Genre. New Haven, CT: Yale University Press.

Thompson, Evan. 2007. Mind in Life. Biology, Phenomenology, and the Sciences of the Mind. Cambridge and London: The Belknap Press of Harvard University Press.

- 2009. "Life and Mind. From Autopoiesis to Neurophenomenology." In Emergence and Embodiment. New Essays on Second-Order Systems 
Theory, edited by Bruce Clarke, and Mark B. N. Hansen, 77-93. Durham and London: Duke University Press.

Tompkins, David. 2014. "Weird Ecology: On the Southern Reach Trilogy." Book Review in Los Angeles Review of Books. September 30, 2014. https:// lareviewofbooks.org/review/weird-ecology-southern-reach-trilogy.

Troscianko, Emily T. 2014. "First-Person and Second-Generation Perspectives on Starvation in Kafka's 'Ein Hungerkünstler'.” Style 48 (3): 331-348.

VanderMeer, Jeff. 2011. "Conversation \#1: China Miéville and the Monsters.” In Monstrous Creatures. Explorations of Fantasy through Essays, Articles and Reviews, edited by Jeff VanderMeer, 55-64. Bowie: Guide Dog Books. 2014. Annibilation. New York: Farrar, Strauss and Giroux.

2015. "The Slow Apocalypse and Fiction." Electric Literature, April 23, 2015. https://electricliterature.com/the-slow-apocalypse-and-fiction-8ecd $53136 \mathrm{e} 23$.

Varela, Fransisco. 1996. "Neurophenomenology. A Methodological Remedy for the Hard Problem.” Journal of Consciousness Studies 3 (4): 330-349.

_, Evan Thompson, and Elena Rosch. 1992. The Embodied Mind. Cognitive Science and Human Experience. Cambridge, MA: The MIT Press.

Vint, Sherryl. 2005. "Becoming Other: Animals, Kinship, and Butler's Clay's Ark.” Science Fiction Studies 32 (2): 281-300. 

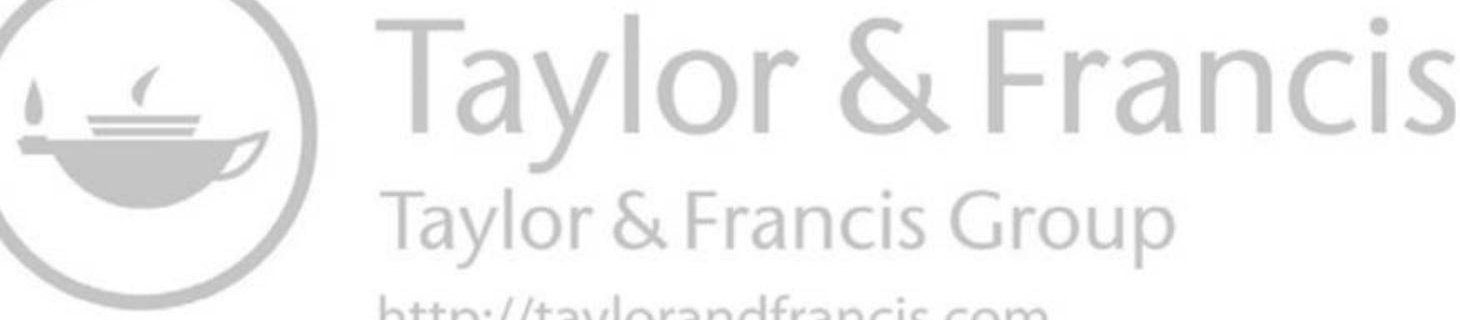
http://taylorandfrancis.com 
Part 2

Imagining Aliens and Monsters 

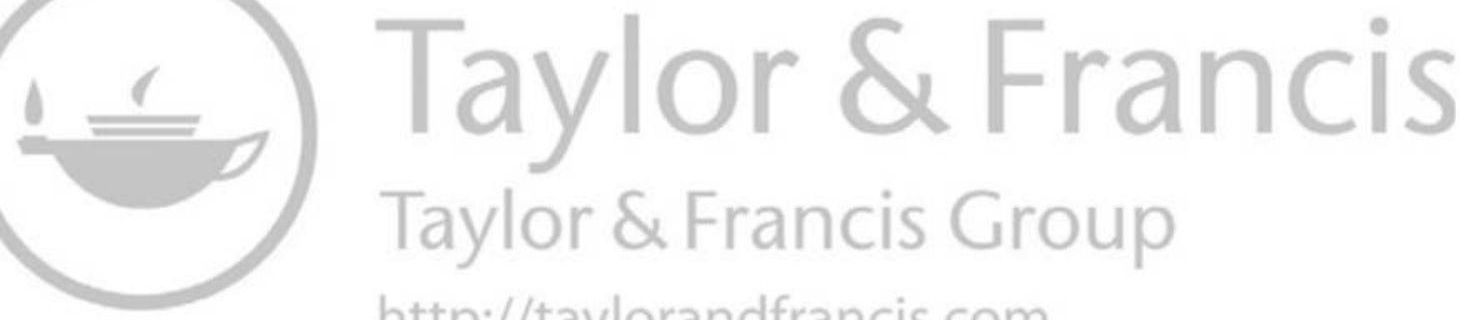
http://taylorandfrancis.com 


\section{Alien Overtures \\ Speculating about Nonhuman Experiences with Comic Book Characters}

\section{Essi Varis}

When you leaf through the very first pages of the collected edition of The Sandman: Overture (2015), your eyes are filled, spread after spread, with swirls of bright colors. Bleeding pricks of blinding white intermingle with nebulous, translucent shapes that appear to be clouds, mist, or perhaps stardust - until, on the page preceding the author Neil Gaiman's foreword, an Earth-like planet is shown from a distance. Colorist Dave Stewart's paratextual efforts thus highlight the tone and the themes of this strange graphic novel even before the story begins: by flinging you directly into fantastical space-scapes, the opening pages prime you into leaving your Earthly, anthropocentric presuppositions behind. Even the lone, inviting planet in the midst of the fanciful color explosions provides less of a reference point than you might initially think because, rather than our Earth, it is revealed to be a home to hairy humanoids and dreaming flowers - a world that is both familiar and strange (\#1, [1]). ${ }^{1}$

The Sandman: Overture, an acclaimed mini-series published by DC Comics' Vertigo imprint, first appeared in six issues from 2013 to 2015, constituting a retrospective prequel to Gaiman's 76-issue dark fantasy comic The Sandman, which has enjoyed enduring cult fame ever since its publication in 1989-1996. Both the original series and the new prequel revolve around the moody but responsible Morpheus, or Dream, who - the series asks us to imagine - is a personified distillation of stories and dreaming. The comic explores the functions, similarities, and idiosyncrasies of human and nonhuman minds more generally as well, by experimenting with varying visual styles, and by constructing agential creatures that defy the very definitions of 'character' - especially the term's anthropomorphic connotations. The original series gained its visual richness from switching between more than twenty different pencilers, and in regard to characters, it introduced the Endless: Dream and his family of personified abstract concepts. In addition, numerous minor characters turned out to be places, nightmares, or one and many individuals at the same time. Although Overture is only a limited series and penciled by just one artist - J. H. Williams III - it continues these traditions by constantly switching up its visual styles and color palettes, and by telling its story without involving a single human character. 
Then again, most of the characters posed as aliens or abstractions in The Sandman: Overture appear to have extremely human-like minds and physical features, which makes one wonder how the comic actually constructs its characters as nonhuman and, in doing so, evokes the illusion of mediating nonhuman experience. The question is not only tangled in the previous discussions about narrating nonhuman or "unnatural" minds but also in the logics of fictional characters and in the expressive arsenal of comics storytelling. Thus, this chapter will start by summarizing how different branches of cognitive narrative studies have approached the possibilities of portraying nonhumans in fiction so far. Although these ponderings have not yielded much consensus, definite answers, or even optimism for interspecies understanding, they have at least begun to explain why engaging with fictional aliens may be a worthwhile enterprise, rather than just an exercise in escapism. The second subchapter will go on to consider what new perspectives character theory and comics analysis might bring to this already crowded but exceedingly important debate. Finally, the third subchapter will catalogue the main strategies The Sandman: Overture employs in constructing odd but relatable characters, and in marking the boundaries between human understanding and nonhuman realities more generally.

\section{Narrating the Nonhuman: From Species-Specific Solipsism to Celebration of Speculation}

Should one ask a crowd of humanist scholars if works of fiction can help their audiences to understand nonhuman experience, some philosophers of mind would immediately stand up, waving Thomas Nagel's seminal essay "What Is it Like to Be a Bat?" (1974) and yelling no. Several proponents of cognitive and natural narratology (cf. Fludernik 1996; Zunshine 2008; Vermeule 2010) would likely nod in acceptance to this demonstration of restraint and realism. "Is this really what we should be discussing? Narratives and the cognitive capacities we use to interpret them are designed to extract social information about human identities and buman interactions", they would say. "Perhaps", other cognitive narratologists (cf. Herman 2011; Bernaerts et al. 2014; Caracciolo 2014a, 2016) might retort, "but that does not mean different imagined scenarios could not challenge our pre-existing cognitive frames and thus affect our preconceptions of nonhumans". By this point, unnatural narratologists (cf. Alber 2009) or practitioners of genre fiction (cf. Gaiman 2016) would likely interject: "Maybe we should start with these speculative and postmodern works you put aside here in the corner? Strange narrators and nonhuman creatures a-plenty - and, in case you haven't noticed, they make up almost half the library!"

From this point on, the disagreements and digressions would only grow even more substantial and complicated, as the question cuts across 
two extremely current, multifaceted, and cross-disciplinary areas of inquiry: "research on the nexus of mind and narrative" (Herman 2013) and research on human-nonhuman entanglements. What is more, the key concept tying them together - experience - is not an easy target for research, due to its dynamic, multisensory, situated, and uniquely subjective character (Nagel 1974, 437; Caracciolo 2014b, 6, 14). However, as Thomas Nagel $(1974,438,449)$ has famously argued, we humans do not necessarily lack the vocabulary to describe and the methods to approach nonhuman experiences because such tools are categorically unattainable but because we have been looking for them in the wrong places - in the framework of natural sciences, which systematically dismisses subjective experientiality. Since an experience is "fully comprehensible only from one point of view" - that of the experiencer - "then any shift to greater objectivity" - which the physicalist sciences always strive for - "does not take us nearer to the real nature of the phenomenon" but "farther away from it" (Nagel 1974, 444-445). Narratives, by contrast, are "tailor-made for gauging the felt quality of lived experiences”, as David Herman (2013) suggests, since they tend to unfold specific circumstances from the specific point of view of a specific character, sometimes in a way that even invites the reader to simulate the characters' experiences "in a first person way" (Caracciolo 2014a, 29).

There are obvious epistemological limitations to this narrative mediation of subjectivities, however. Since we can only receive experiential input through our human senses and bodies, and since we can only process them with our evolved species-specific cognitive faculties, the output of our imaginations must be determined by patterns of perception and thought that are central, or even unique, to human experience (Nagel 1974, 238-441). Moreover, for most people, much of the input derives from social interactions with other humans, and much of the output is targeted at yet more fellow humans, which means that most of our everyday thinking is filtered through several layers of assumptions about what matters to this specific species. In other words, humans tend to write fiction about humans for human readers, because all these human readers are likely interested in the ways other humans experience their human condition.

Accordingly, Monika Fludernik's $(1996,9,26)$ natural narratology equated narrativity with "mediated human experientiality". The base argument for many subsequent cognitive theories has, likewise, been that the readers' mental representations of fictional worlds, characters, and scenarios draw on the cognitive structures and "encyclopedic knowledge" they have accumulated through their continued engagement with the real world, real people, and real-life situations (see e.g. Schneider 2001; Eder, Jannidis, and Schneider 2010; Herman 2013; Jannidis 2013; Caracciolo 2014b, 58-59). As Nagel $(1974,439)$ formulates: “Our own experience provides the basic material for our imagination, whose range is therefore limited". 


\section{Essi Varis}

Although the reasoning behind these claims is difficult to deny - one cannot create anything from nothing - they hardly reflect the scope of characters and subjectivities that narrative arts and media have actually attempted to (re)produce. Instead of being limited to scenarios that mimic "natural", spontaneous storytelling situations, fiction - especially postmodernist (cf. Alber 2009) and contemporary (cf. Caracciolo 2016) fiction - is awash with stories in which "[t]he narrator may be an animal, a mythical entity, an inanimate object, a machine, a corpse, a sperm, an omniscient first-person narrator or a collection of disparate voices" (Alber, Skov Nielsen, and Richardson 2013, 2). Thus, adopting a moniker that is explicitly antithetical to Fludernik's project, unnatural narratologists like Jan Alber $(2009,80)$ have experimented with applying the same cognitive reasoning to works that "radically deconstruct the anthropomorphic narrator, the traditional human character, or real-world notions of time and space".

Yet this strife to expand the canon outside of the "mimetic bias" - which has reigned over narrative studies for the past century (Alber 2009, 79; Fehrle 2011, 240) - has usually stopped short of challenging the "anthropomorphic bias" framed by Fludernik (1996, 9). Alber (2009, 82, 94) has only reasserted that "even the strangest text is about humans or human concerns", because "nobody would be interested in such narratives" that do not "say something about us and the world we live in". Of course, naming a movement that focuses on strange narrators as "unnatural" already implies that mimetic, human-like characters are the only "natural" subject of storytelling. Moreover, employing the rhetoric of natural versus unnatural, rather than human versus nonhuman, connotes that unnatural narratologists' inquiry is mostly focused on the ways in which narratives can deviate from mimetic norms and conventions, not on the ways in which they could suggest nonhuman experience, as embodied by characters that represent types of actual nonhumans. By keeping their claims largely to formal, metafictional, and meta-disciplinary levels, unnatural narratologists have thus been able to bypass the solipsistic concerns voiced by Nagel but they have also resigned from placing much ethical weight or consequence on their own work or on the fictions they research.

More recently, other cognitive theorists have been inclined to see nonhuman fictional characters as potential sites of negotiation and exploration, as artistic and didactic thought experiments that can actually "destabilize anthropocentric ideologies" by underlining the continuities and downplaying the differences between human and nonhuman experience (Bernaerts et al. 2014, 74-75). For Herman (2011, 166, 2012, 97-101), the first step for establishing such continuities is crafting more "fine-grained representations" of nonhumans as genuinely nonhuman - not "emptying" them out and making them vessels for allegorical meanings and "experiences imported from the human domain". 
Indeed, even if one cannot truly know what and how nonhuman animals feel or think, it is always possible to depict them accurately from a behavioristic viewpoint, that is, to produce mimetic representations based on the knowledge gained by observing real nonhuman animals "from the outside".

According to current philosophy of mind, these "Cartesian geographies" that situate the mind on the "inside", as if separate from outward behavior, should be discarded, however, because cognitions can only arise from the "sensorimotor coupling between agent and world". Hence, the mind should be reconceptualized as "situated, embodied and extended" - and since this "basic structure" of an enactive consciousness is likely to apply to other-than-human minds as well, readers can, indeed, fumble for some approximate sense of animals' lived experience by engaging with carefully constructed (multimodal) animal narratives. (Herman 2012, 97) Inspired by the philosophy of Jakob von Uexküll, Herman $(2011,167,178 ; 2012,99)$ names such narratives "Umwelt explorations", and concludes that "increasingly detailed engagement with the lived texture of nonhuman experiences does not necessarily result in a diminishment of narrativity", as Fludernik and Alber have assumed. This is because animal comics and most other nonhuman stories still retain the most fundamental ingredient of narrative: an experiencing subject, to whom the reader can attribute at least some mental states based on how it interacts with its environment.

Two disclaimers are in order here. First, because human readers are fine-tuned by the evolution to infer mental states of other humans specifically (Zunshine 2008, 58), it seems very likely that their attributions of mental states to nonhuman characters are unavoidably anthropomorphizing and inaccurate. The narratives can, however, purposefully work against this, by anticipating and undermining some of the readerly assumptions that would aim for overstated humanization, coherence, and illusion of mutual understanding, as the analysis of The Sandman: Overture will demonstrate. Second, making the representations more "fine-grained" still does not make them verifiable or factual. No matter how expertly mimetic and resistant of cognitive biases narrative fictions might be, they can never provide the readers with reliable information on how actual bats actually experience their batness, because that is simply not the purpose of fiction. As noted above, narratives excel at subjectivity rather than objectivity, at providing alternative perspectives rather than "alternative facts".

This is not to say, however, that fictional nonhumans would be completely inconsequential - or that narratives reaching toward non-existent worlds and creatures would be purely escapistic. On the contrary, cognitive narratologists have repeatedly emphasized that the connection between real-life cognitive frames and fictional constructions is a two-way street (e.g. Herman 2013); that narratives can have a "feedback effect" 
on the selfsame knowledge structures the reader employs to make sense of them (Caracciolo 2016, 50-51). Even more crucially, the accuracy, mimesis, and truthfulness of the fictional constructions in question may not be very important variables in this equation. If anything, Marco Caracciolo (2016, 47-49) argues that engaging with "strange" characters and foreign worldviews can result in especially extensive - even if only subtle and temporary - cognitive readjustments. In other words, nonhuman or otherwise unconventional narrators often induce cognitive dissonance, which the reader has to resolve in one way or another, by employing interpretive strategies that require reflecting and reviewing the assumptions the reader holds about himself or herself, about mental functioning, and about the world in general (Caracciolo 2016, 12-14, 34-37). Similarly, Alber (2009, 80-93) believes that unnatural, or "physically or logically impossible", scenarios cannot always be naturalized as hallucinations or allegories; sometimes, they "challenge the mind's fundamental sense-making capabilities" and, as a result, "blend" or "enrich" the readers' pre-existing cognitive frameworks.

Of course, disjointing or expanding the readers' cognitive frameworks in this way has always been the main goal of all the different subgenres of speculative fiction (cf. Stockwell 2008, 518). Science fiction, fantasy, and horror typically ask the readers to concern themselves with worlds, entities, and experiences that are clearly not knowable, verifiable, real, or perhaps even possible. The very fact that these entire "unnatural" genres exist and continue to remain popular defies the reasoning of both natural and unnatural narratologists: it seems reductive to assume that authors would create fantastical scenarios only to explore different ways of diverting from natural, mimetic frameworks and conventions, or that the readers would only engage with them in order to glean "Machiavellian" social knowledge from odd creatures they ultimately see as cleverly disguised fellow-humans (Vermeule 2010, 30-33). Rather, genre fiction typically treats speculation and counterfactual thinking as goals in themselves. Neil Gaiman $(2016,15)$, the author of The Sandman, for instance, sees "what-if" thinking as the most important prerequisite for ever changing anything in the world or in oneself: "Political movements, personal movements, all begin with imagining another way of existing".

Sometimes, this "imagining another way of existing" means trying to imagine what it is like to be a bat. Even if such an attempt is doomed to fail objectively speaking, it can still influence one's understanding of bats, for better or for worse. Other times, "imagining another way of existing" means making up aliens and speculating how they might experience the world through their unique "sensory-motor couplings" with their imagined environments. In a way, this is an even better, safer form of speculation, because it does not pose the risk of misunderstanding or misrepresenting any actual nonhumans. Imagining aliens has absolutely no consequences for bats but, again, it can still be consequential 
for the reader, whose ideas of humanness, nonhumanness, and experience become foregrounded, and perhaps even reconfigured, at least for the duration of the imagining. Indeed, when faced with something unknowable - such as the subjective textures of nonhuman experiences imagining is the only option for getting any purchase on the matter.

\section{Hybrid Humanity: Possibilities of Multimodal Fictional Characters}

On a more practical level, these theoretical strands intertwine in nonhuman fictional characters - a strange concept in itself as characters are, of course, never truly human. Instead, they are constructions that are meant to be mistaken for humans, much like the living scarecrow Mervyn, who serves as the janitor in Morpheus' dream kingdom in The Sandman series. Although he pointedly describes himself in very material terms - as "a moist wet pumpkin with the seeds scooped out, carved into the shape of a face and rammed onto a hard, rough, rampant wooden stick" (\#1, [19]) - his physical form and verbal self-expression are so analogous to those of regular humans that the reader is, nevertheless, likely tempted to anthropomorphize him into an agential individual with the mind to mock Freudian interpretations of dreams. The juxtaposition between this anthropomorphic "feel" of the character and the passing foregrounding of his artifactual materiality are likely to cause a jolt of defamiliarization, however, and remind the reader that agency and sentience are more fundamental to the concept of characterness than anthropomorphism is. In this section, I will argue that the inherent nonhumanness of characters is always ranged against the humanness of the reader, and that comics' capacity to evoke characters' subjectivities with monosensory yet multimodal narrative means can highlight these tensions in unique ways.

As James Phelan's $(1989,4)$ rhetorical character theory sums, all characters are artificial constructions - but they are constructed in such a way that conjures forth a mimetic illusion of personhood. Many literary theorists (e.g. Eder et al. 2010; Jannidis 2013) have since concurred that characters are born when textual cues are read through cognitive frames of humanness. This supposedly involves both "top-down" and "bottom-up" processing, meaning that the reader can either instantly recognize the character as belonging to a certain category - such as the category of character or the category of humanity - or extrapolate such categories by collecting specific textual cues (Schneider 2001, 619-626). Cues like a proper name or a speech balloon imply agency, sentience, and individuality, and thus invite the reader to place the entities associated with these cues into the category of character - and, most likely, into the category of humanity as well. Thus, to summarize Phelan's theory in another way, the category of characterness binds agential 
narrative functions and illusory humanity together, so that the readers are compelled to humanize agential textual constructions as well as to expect narrative agency from such textual constructions that manifest human-like traits. Furthermore, it would seem that placing a different amount of interest and emphasis on these two aspects - the synthetic and the mimetic aspects of character (Phelan 1989) - forms the main fault-line between natural and unnatural narratology's approaches to nonhuman minds.

Arguably, Fludernik's natural narratology and the cognitive narratology formed in its wake have mainly concentrated on explaining the formation and functions of the mimetic aspect. That is to say, they have largely equated the human readers' ability to understand, animate, and flesh out fictional characters with human species' evolved "ability to interpret other people's behavior in terms of underlying mental states" (e.g. Zunshine 2008, 58; Vermeule 2010, 34-37) - the so-called theory of mind. Some have further inferred that the opportunity to safely use and train this ability must be the main "point" and pleasure of reading fiction (Alber 2009, 94; Vermeule 2010, 246). Thus, while the exact chains of argumentation vary, many theorists drawing on this framework have essentially reformulated Fludernik's $(1996,28)$ claim that narrativity "centers on experientiality of an anthropomorphic nature". Narrativization is consequently bound up with anthropomorphization, and the blame for this bias rests on the human readers: because readers use human-centric cognitive capabilities to make mimetic sense of narratives and their characters, they are inclined to read about humans even when they are not reading about humans. In other words, even overtly nonhuman fictional characters are seen merely as "proxies for traits of human difference or otherness" (Keen 2011, 147) or as "strategic and parodic" "mask[s] or costume[s]" for the human, "whose universality is reaffirmed and reified in the process" (Chaney 2011, 130, 135).

The agenda of unnatural narratologists, by contrast, implies that characters' synthetic aspect is not subservient to mimetic interpretations but vice versa: the illusion of personhood is only one of the effects the textual cues can be used to produce. Indeed, since characters are always ontologically nonhuman, all one needs to do in order to create an "unnatural" character is to allow this nonhumanity to seep onto the representational level. Many unnatural narratologists have therefore analyzed such postmodern works that flaunt the artificiality of their characters. The very fact that such characters typically have a jarring, disruptive, "unnatural" effect actually ends up being a testament to characters' supposed anthropomorphism, however. Following Lisa Zunshine (2008, 63-75), portraying a character simultaneously as a person and as an artifact upsets essentialist assumptions that are fundamental to human minds' ontological reasoning. Since readers are unlikely to ever truly forget that characters are non-existent constructions created by the author, 
the dissonance evoked by openly artificial characters must rise instead from the readers' inability to ignore the expectations of humanness they associate with characterness.

Then again, whether or not fictional characters themselves are human is less pertinent to the present research problem than whether or not they can be used as a tool for approaching other, actual or imaginary, nonhuman creatures. Some theorists claim that tampering with the synthetic level of characters' textual construction can produce other defamiliarizing effects on the interpretational layer as well - effects that can read as nonhuman in a more general sense, not only in the sense of postmodern artificiality (cf. Bernaerts et al. 2014). This relates to the blending of cognitive frames discussed in the previous section. When something presented in a text does not fit the readers' existing, anthropomorphically biased cognitive frames, they tend to react both cognitively and affectively. Together, the epistemological conflict and the accompanying feeling of strangeness constitute what Viktor Shklovsky named "defamiliarization": the reader becomes aware of the newness or the alienness - of what he or she perceives and is thus prompted to reflect on it, to discard automatized heuristics, and to find new pathways for thinking and perceiving it (Caracciolo 2016, 35, 48-49). If this is caused by or coupled with two other narrative devices or experiences - a character posed as nonhuman and an empathetic stance toward him or her - defamiliarization could arguably give the reader the sensation that they are glimpsing a nonhuman subjectivity.

As Bernaerts et al. $(2014,71,75)$ argue, creating characters that appear both relatable and nonhuman requires striking a delicate balance between the two "poles" corresponding to natural and unnatural narratologists' main interests: the texts' deliberate, "anti-mimetic" strangeness, and the reader's "natural" projection of "assumptions and expectations about human life and consciousness". That is, a text can season a character with textual cues evoking the dissonant cognitive categories of "animal", "plant", "artifact", or "substance" (Zunshine 2008, 56-65), but the character still has to remain anthropomorphic enough to be recognized as a character. Also, the defamiliarizing effects of nonhuman subjectivities can only truly be experienced through empathy - or the imaginative, first-person adoption of the "the perceptual, emotional, or axiological perspective of a fictional character" (Bernaerts et al. 2014, 73). However, the empathetic simulation of the nonhuman character's mind requires projecting partial memories of the reader's own past, embodied experiences onto the nonhuman character (Caracciolo 2014b, 123-132), which both presumes and results in some degree of anthropomorphization. In other words, although characters are always nonhuman, even the representationally nonhuman characters can be classified as characters only by the virtue of their illusory anthropomorphic qualities, and the reader must paradoxically relate 
nonhuman characters to his or her own human experiences in order to bear witness to their nonhumanness. Thus, nonhuman narrators always manifest "the conceptual integration of human and nonhuman traits"; impossibly, they blend "similarity and otherness" and "empathy and defamiliarization", the category of human and the many possible categories of nonhuman (Bernaerts et al. 2014, 71, 72-74).

Suzanne Keen (2011) and David Herman (2011) have come to similar conclusions: they both note that comics especially can hybridize human and animal traits in different proportions for different effects. Animal features can be superimposed on human characters - for instance, in order to establish a distancing allegory (Herman 2011, 169) - or animal characters can be made more understandable and sympathetic by anthropomorphizing them to some degree (Keen 2011, 142, 148). There is no way off the continuum, however. Keeping in line with the "natural" argument that characters always have a mimetic aspect and that the mimetic aspect is based on the cognitive application of anthropocentric folk psychology, Herman and Keen imply that nonhuman characters unavoidably incorporate some human features. At the same time, they point toward a medium that can juxtapose these dissonant streams of character information with particular ease: the medium of comics.

On the one hand, comics have traditionally fostered an exceptionally high "tolerance", or even a preference, for the fantastic and the unnatural (Fehrle 2011, 211). Not only are the institutions and fandoms of speculative fiction and comics historically linked - for example, Neil Gaiman is known as both a fantasy author and a comics writer - but cartoonish and expressive graphic styles presuppose story content that does not necessarily follow the laws and conventions of realism. That is, because comics are rarely photorealistic, they might activate the cognitive frames and memories readers have of fantastical fictions, rather than of real life or realistic fictions, inviting them to actually expect such "unnaturalities" as altered laws of physics or nonhuman characters (Fehrle 2011, $215)$. On the other hand, contemporary comics show an increasing interest toward the inner worlds of characters (Groensteen 2013, 129). This inward turn is likely related to the recent surge of critically acclaimed autobiographical comics, from Art Spiegelman's Maus (1991) and David B's 'Lascension du haut mal (1996) to Marjane Satrapi's Persepolis (2000) and Alison Bechdel's Fun Home (2006). Meanwhile, in academia, cognitively informed scholars have started to notice how the multimodality of comics allows depicting "minds in action" - that is, evoking fictional minds through repeated visual bodies embedded in "physical contexts" (Mikkonen 2008, 303, 316; Herman 2011; Kukkonen 2013, 154). Where these two tendencies - fantastical speculation and innovative depiction of embodied minds - collide, comics and comics research can contribute to the speculative exploration of nonhuman experiences. 
What is more, colliding or paralleling different discourses is what comics do best. This is because a page of a graphic narrative is always a composite of several, more or less independent elements: pages are divided into panels, and panels consist of foregrounded and backgrounded elements belonging to "two distinguishable semiotic tracks", the verbal and the pictorial (cf. Kukkonen 2013, 136). All of these parts and tracks can stand in vastly different relations to one another: transitions from panel to panel typically introduce some changes in time, location, perspective, or even graphic style (McCloud 1993, 70-79); a single page or panel can parallel several simultaneous events (Kukkonen 2013, 136); and the words and images can either complement or contradict each other (e.g. Fehrle 2011, 221). As Keen and Herman's analyses already testify, this modularity of comics' expressive arsenal provides plenty of options for such human-nonhuman hybridization Bernaerts and his colleagues assume that nonhuman narration necessitates.

Unlike film - to which it is often unfavorably compared - comics is also "a monosensory medium" (Groensteen 2013, 122), meaning it must pack all the information and expression on the static, two-dimensional space of a page. As a result, things belonging to different sensory domains and different levels of mimesis become forcibly juxtaposed. The most prevalent example of this is the speech bubble, "a desperation device" (Eisner 2008, 24) that allows auditory and abstract information to intrude the visual, physical reality of the storyworld. For regular comics readers this device has, of course, become naturalized (Groensteen 2013, 122 - no one really imagines the characters walking around with white balloons on which they write their thoughts - but translating thoughts into images can take other, more elaborate or defamiliarizing situational forms as well. Since the 1920s, cartoonists have remixed objective and subjective perspectives both within and between panels, devoting specific story elements or entire passages to flashbacks, daydreams, and other character-focalized outlooks on the storyworld (Groensteen 2013, 130). Bill Watterson's Calvin and Hobbes, for instance, constantly demonstrates how imaginatively and vividly Calvin experiences his toy tiger and everyday situations: in his mind, teachers become dinosaurs, girls appear as disgusting aliens, and Hobbes is alive (cf. Groensteen 2013, 129; Varis 2013, 60, 120). Although these changes from more objective to more subjective and private perspectives are typically signaled by changes in the graphic expression, they can still leave quite a bit of room for ambiguity and interpretation. That is, the reader may be left hesitating between what is real and what is imagined, and for which characters (Groensteen 2013, 124, 131).

Of course, this kind of oscillation between interpretations, between empathetic and more external stances, is also closely related to character-centric defamiliarization (Caracciolo 2016, 47, 55). As noted above, the concept of defamiliarization is an important ingredient 


\section{Essi Varis}

in the discussion about nonhuman narration as its emotive component marks the textual source of the defamiliarization as new or alien, while the cognitive dissonance prompts the reader to blend and reconcile his or her pre-existing cognitive structures in relation to this alien, possibly nonhuman domain. In the context of comics, however, this hesitation may also target the "Cartesian geographies" and the subjectivity of mind and experience, heightening the readers' awareness not only of the presence of something Other but also of the ways and extent in which its subjectivity can be known and shared.

To sum, the necessity to express both the storyworlds and the characters' subjective experiences solely through the "visual channel" causes them to blend with and through different semiotic devices and graphic qualities, so that the dichotomies between the "inside" and the "outside", the mental and the fleshly, the subjective and the objective become deconstructed. Indeed, although the minds of the characters can be revealed by direct, verbal means in speech and thought balloons (Mikkonen 2008, 306-307; Groensteen 2013, 122), the imaginary subjectivities rarely remain confined in them. Instead, anything from colors and graphic qualities of the lines to the shifting perspectives and appearances of the characters can convey (aspectual) character-focalization (cf. Thon 2014). Such visual devices allow evoking subjective experiences without verbalizing them, which is especially important when aiming for mimetic depiction of the experiences of creatures that do not think or communicate in written or spoken language. Then again, traditional, "behaviorist", third-person graphic narratives, which provide no direct access to their characters' minds at all, also depict their characters as visually embodied and embedded in social, spatial, and temporal situations (Mikkonen 2008, 303). Thus, the reader can draw on much of the same cues they would take note of when observing sentient creatures in real life. Facial expressions and bodily postures, for instance, can be observed directly from the visual track, which, according to Suzanne Keen $(2011,135,146)$, allows comics to tap into the readers' immediate affective responses: the characters' core emotions are recognized before the neocortex has time to judge whether the character in question is one of "us" or one of "them", a human or a nonhuman.

Of course, one crucial difference between reading comics and observing real life is that the visual perspectives of comics' panels do not only situate and embed the characters in the storyspace, but they also situate the reader in some relation to the characters: near or close, opposite or over the shoulder, outside or as-if inside (Mikkonen 2008, 309-312). This is likely to have some effect on the empathetic perspective-taking, which, as noted above, is a logical prerequisite for engaging with the nonhuman characters' experiences. As the page designs keep leading the reader from panel to panel, through the different perspectives and trajectories, "the representational and experiential dimensions of the fictional 
mind" are often brought together (Kukkonen 2013, 154). In other words, the overlap between the visual storytelling and character focalization can force some degree of aspectual overlap between the narrated, speculatively nonhuman experience of the character and the real viewing experience of the reader (cf. Caracciolo 2014b, 123). As a result, it becomes more difficult to view the character only as a static, alien object, whose unfamiliar way of seeing the world can forever remain completely outside of the reader's considerations. The next chapter will demonstrate, among other things, how the page designs can manipulate the reading experience in this way, and how they can thus underline what the reader can and cannot assume to know about the nonhuman characters' minds and perceptions.

\section{Fables and Reflections: A Brief Experiential Analysis of The Sandman Overture}

When discussing the fictional experiences of nonhuman characters as well as the readers' experiencing of those characters, it seems necessary to employ a method that also leaves some room for experience. Therefore, this section presents not only an analysis of The Sandman: Overture but also an analysis of my personal process of (re-)reading it. Of course, this process involved the kind of subjective layers, inaccuracies, and irrelevancies that academic research typically rejects, but it is only against this experiential backdrop that I have been able to ask the questions the present chapter seeks to answer: how does this unusual comic and its nonhuman characters make the reader think and feel about the borders of humanity and nonhumanity? It seems to me that all researchers engaging in close reading must implicitly go through this same step; we build our appropriately distanced analyses on more holistic, embodied, and immersive interpretive experiences (cf. Kukkonen 2014). The only novelty of my approach is that I have endeavored to make this preliminary experiential juncture of my reading slightly more visible and systematic. In practice, this means that as I read The Sandman: Overture for the third time, I recorded, by hand, spread by spread, as many of my observations and associations as possible. I do not claim that this method captured more than a fraction of my entire experience or that the presence of a pen, a notepad, and a specific interpretive agenda did not affect the experience itself. Despite these inadequacies in comprehensiveness and authenticity, the method did yield some merit, however: it revealed which elements on each page potentially draw the reader's attention, highlighted the metatextual layers and trajectories implied by the page designs, made it more obvious which pages and panels might make one stop or misread, and generally added nuance to my understanding of the work - as well as to my understanding of my understanding of it. The findings of this initial, subjective, and visually 


\section{Essi Varis}

oriented raw analysis are here grouped, contextualized, and refined further, into a more objective and less digressive, fairly traditional discussion. Nevertheless, whenever I am referring to "the reader", I am still primarily referring to myself.

Without further ado, let us dive into the space-scapes evoked in the beginning: The Sandman: Overture's plot unfolds nonlinearly, and at a cosmic scale, but underneath all the formal experiments and stretches of imagination, it actually follows the familiar formula of an apocalypse and a messianic intervention. Long ago, in a fit of compassion, Morpheus - a god-like personification of dreaming and stories - refused to kill a star, who had gone mad from seeing into other creatures' sleeping minds. This madness has since spread through the "four hundred billion galaxies in the universe - , like a cancer" spreading through the "four hundred billion cells in the human brain", which means that "soon enough, the mind that is the universe will cease to think and all things will cease to be" (\#2, [17-18]). After Morpheus learns that he is the one responsible for this apocalyptic domino effect, he sets on an intergalactic, interdimensional journey to stop it. He succeeds - after a fashion - with a little help from the rest of his family of metaphysical concepts: Father Time, Mother Night, and his siblings Destiny, Death, Destruction, Desire, Despair, and Delirium.

The scenario Overture sets up is thus the one scenario that positions all imaginable life forms and existents on an equal footing: the destruction of the entire universe affects everything in the universe in the same way, from monocellular organisms to star systems. The impending erasure of such fundamental common denominators as dimensional space effectively nullifies the more refined dichotomies we normally use to classify different entities: organic or inorganic, sentient or non-sentient, human or nonhuman. Combined with a protagonist like Morpheus, whose ability to understand, traverse, create, and destroy different worlds exceeds even those of regular gods, this premise invites the reader to stretch their imagination far beyond the scope of human reality. Author Neil Gaiman is well aware that this is a tall order, and explains in his introductory chapter-by-chapter notes how he wanted to intersperse the "spectacle" and "futuristic spatter" with "something contained and very human", in order to make "people care" ("The Accompaniments", ${ }^{2}$ [40]). The dual strategies of nonhuman narration (Bernaerts et al. 2014) are thus very much present throughout the work: the near-systematic, multimodal induction of defamiliarization alternates with invitations to more anthropocentric, more empathetic perspective-taking, which covertly presupposes a human reader.

Before pointing out its inevitable limitations, let us first consider the ways in which the comic does manage to evoke cognitive and emotive strangeness through its character designs. The very first character whose inner world the reader of Overture glimpses is clearly situated 
on a foreign "small planet" and belongs to a "race of huge carnivorous plants, with limited mobility, but beautiful minds" (\#1, [1]). Subsequently, each issue keeps introducing ever more fantastical alien species: "there are ships that live and warriors who are worlds" (\#3, [1]); there is a "a cluster of metallic beetles", who "have come to participate in the destruction and to make art from the wreckage" (\#3, [3]); and there is "a bacteria complex", who is "one of the universe's greatest mathematicians, yet immediately lethal to the majority of life-forms it encounters" (\#6, [1]). While the diversity of these nonhuman characters seems striking at the first glance, they are all made concurrently comprehensible and strange by the same, simple strategy: by cross-attributing traits from several, normally irreconcilable "ontological categories" to one single character (Zunshine 2008, 63-64). A "carnivorous plant" already defies prototypic thinking, as meat-eating is much more common for the existents in the "animal" category than for the existents in the "plant" category. As such creatures exist in the actual world, however, they are not that defamiliarizing or difficult to imagine. What pushes such a creature outside the known reality is complementing it with a mind that "dreams", because - while this trait may still be weakly commensurate with the carnivorous category of "animal" - it is rarely associated with the barely sentient category of "plant". The following page heightens the dissonance even further by connecting the plant creature with speech bubbles, which imply a cognitive ability associated exclusively with personhood: language. Still, this talking plant pales in comparison to the increasingly simple organisms - beetles and bacteria complexes - who in the later issues are claimed to be capable of even more sophisticated human feats, of making art, and of understanding high-level mathematics.

All in all, The Sandman: Overture makes use of a much wider selection of ontological categories than the usual talking animals, which some theorists consider to have already become naturalized (Alber 2009, 94). That is, anthropomorphic animals, or zoomorphic people, are so familiar from fables and comics, they no longer require cognitive adjustments from the readers' part. In addition, one could claim that the majority of such characters sit firmly on the allegorical, "coarse-grained" end of Herman's $(2011,165)$ continuum, meaning that Donald Duck, Blacksad, and their ilk mostly convey human experiences, like having a job and a family, or fighting against criminals and racism. By contrast, they convey very little of their experience of using wings for arms, of seeing in the dark, or of being coated in fur or feathers. The Sandman, too, teems with so many colorful critters there is hardly any space to render the depiction of individual characters' experiences particularly "fine-grained", but the ontological blends manifested by the crowds of Gaiman's odd figures are so many, extreme, and unusual they can at the very least surprise the reader and thus open a door for thinking outside 


\section{Essi Varis}

the established cognitive frames. Moreover, many of these nonhuman characters are portrayed multimodally, which allows the reader to experience their strangeness in an even more concrete, multifaceted, and defamiliarizing way.

One of the most striking ontological fusions in The Sandman: Overture is achieved completely non-verbally, through a gradual development of a disturbing visual motif. Many of the backgrounds and landscapes incorporate inappropriately organic features: architectural structures of the City of Stars (\#4, [11-12]) mesh with red, tree-like shapes that could be interpreted as blood vessels, and an abandoned dream hospital (\#2, [4-5]) appears to be in possession of sensory and internal organs - teeth, eyes, and tongues poke out of the windows, and the attic is filled with brain tissue. The comic delivers on these background details in the final issue, where the near-death of the universe is signaled by a giant EKG chart running through several blacked-out spreads $(\# 6,[18-19 ; 24-35])$ : the very space of the universe - and, by analogy, the narrative space of the comic - has both veins and a heartbeat. This effectively hybridizes the categories of entity and its environment, of foreground and background, giving places the kind of biological traits that are usually associated with characters, due to their anthropomorphism.

As for the verbal narration and dialogue, they constantly attribute very human-like, language-mediated minds to very nonhuman-looking creatures, which in itself might have a dissonant effect. In addition, the verbal track can be used to twist around the more abstract and cultural laws and conventions that define human life. For instance, the narrator boxes describe the air on a warring planet as "undrinkable", while the aliens living on that planet discuss their interspecies "fourmarriage" $(\# 5,[11])$. Even the names of the aliens are made dissonant by picking them from unconventional grammatical categories or by making them extremely difficult to reproduce with English alphabet or human vocal tract: the late "Clearly" (\#3, [16]) and "the floating jelly-balloon" called Rr'arr'rr'll (\#6, [2]) are unlikely to have any namesakes in the comics' readership.

Along with the pictorial and the verbal tracks, some of the comicsspecific metatextual elements also add to the defamiliarization and dehumanization of the characters. First, and most notably, the page designs of Overture avoid regular, angular grids to an unusual degree, utilizing various organic, nonlinear, and representational shapes instead. As a result, almost every spread boasts a sense of striking visual novelty, which might even leave the reader unsure of the proper reading order. This makes the affectual dimension of the reading experience regularly coincide with the confused mental states of the focalizing characters: both the reader and the character are often equally unsure about the stability of the spatio-temporal parameters defined by the panel frames and equally 
amazed at the developments of the story. This experiential overlap reaches its crescendo in the fourth issue, where the gradual tilting of the frames prompts the reader to turn the entire album upside down for the duration of two pages (\#4, [17-18]). Williams, the illustrator, specifically explains that the trick is "intended for the reader to sort of feel what Morpheus is feeling": disoriented, and possibly frustrated ("The Accompaniments", [6]). Caracciolo $(2016,74-75)$ has named these parallel and "shared" experiences between characters and readers "mirroring effects".

Second, The Sandman series is extremely well known for its use of unconventional-looking speech bubbles. Letterer Todd Klein remembers having created over 50 individualized fonts and bubble styles for different characters in the original series ("The Accompaniments", [17]). Variations of bubble styles and fonts are widely used in comics for suggesting different qualities of voice and prosody (Eisner 2008, 24), but in the context of The Sandman, this device has also served as an additional marker of nonhumanity (Bender 1999, 74). In Overture, too, the more anthropomorphic characters have rather standardized black-and-white speech bubbles, whereas the more overtly nonhuman figures speak in various colors, or in letterings that are slower to decipher - an apt way of simulating cross-species communication problems.

In the same vein, some of the characters are doomed to complete silence due to their extreme alienness: the reader never hears the mathematically gifted bacteria complex speak, and even when the artistic metal beetles do speak, they collectively assemble into a very human-looking configuration (\#3, [15], see Figure 4.1). By contrast, an alien girl called Hope, who appears emphatically human apart from her blue skin, is given an extremely central role toward the end of the series: her human-like face, human-like body, human name, and reported needs for food, warmth, sleep, and companionship (\#3, [13]) apparently qualify her for the role of a full-blown character-focalizer. The final issue (\#6, [1-3]), for instance, opens with her breaking the fourth wall, by looking challengingly out of the panel, as if asking for attention. After this, her first-person internal monologue and her recurring, translucent but very human-like figure guide the reader's eye across several pages of completely opaque, much less anthropomorphic aliens in a way that seems to truly illustrate, or even prove, the alleged necessity to nest defamiliarizing effects within a more anthropocentric narrative discourse.

All in all, no matter how alien or nonhuman ontological categories the characters evoke, humanity is always one component in - or at least congruent with - the resulting blend. There are no half-animal, halfmushroom blends or half-substance, half-AI blends, but the animals always speak in human language, the machines are always androids, and every non-carbon-based creature has a human face. As a result, in this 


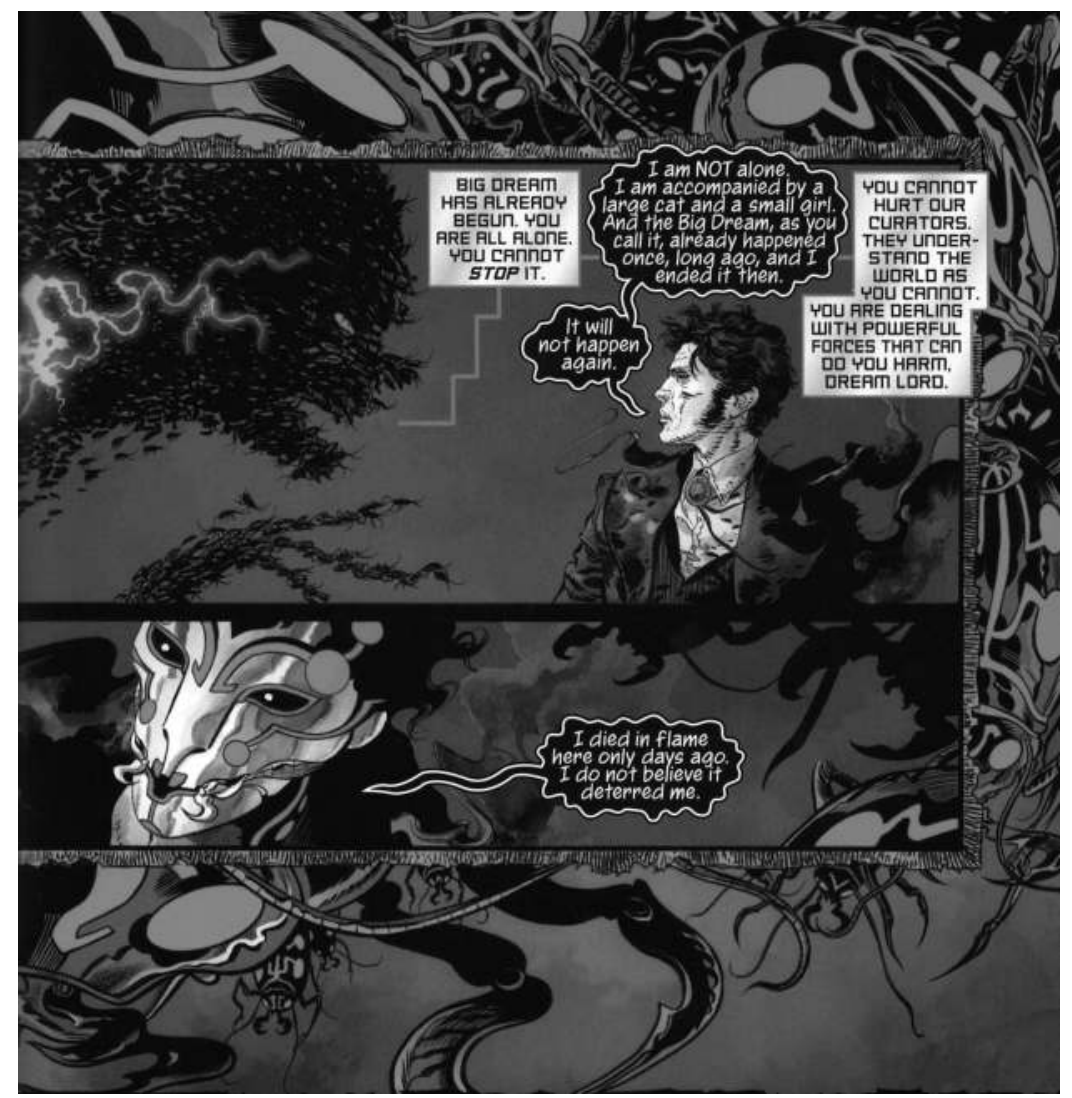

Figure 4.1 The beetles must assume a human-shaped formation in order to speak, while Dream's face momentarily reflects their insectoid features (2015, \#3, [15]). The Sandman: Overture (C) 2013 DC Comics. Written by Neil Gaiman and illustrated by J. H. Williams, III.

comic of cosmic concerns and zero human characters, there is still a clear continuum between the less human-like and the more human-like characters (cf. Herman 2011), and this continuum largely dictates the hierarchies of saliency and agency: the more human traits a character incorporates, the more the reader is shown its inner world and, as a result, the more the reader is invited to empathize with it.

The most egregious example of this is that Morpheus the protagonist and his six equally god-like siblings are mostly depicted as white, able-bodied human adults. They do transgress the borders of ontological categories rather radically, of course: as "anthropomorphic personifications of -- universal forces" (Bender 1999, xii), they give fleshly, individualistic forms to things that are so abstract and non-sentient they do not 
normally even qualify as 'existents', let alone 'persons'. Yet how narcissistic is it to portray Death - which should be equal to all living creatures - as a perky Goth girl? Similarly, it is quite difficult to think of Dream purely as an abstract concept when he so clearly experiences solitude $(\# 5,[1])$, never calls on his mother (\# 5, [6]), eats an occasional bite (\#5, [7]), and even dresses appropriately for battles and state visits (\#1, [20]). If anything, the Endless only seem to reinforce the human tendency to comprehend and construct even gods in terms of human mental states (Vermeule 2010, 145-146). The mythologies of ancient cultures amply demonstrate this tendency, of course, and the pantheon of The Sandman does bear some resemblance - and, in fact, some blood relation (Bender 1999, 152) - to Greek deities: the spindly, moody, black-robed young man in the midst of the ontological, intergalactic tempests of Overture even shares the name with the Greek god of dreams. However, as the multimodal storytelling repeatedly underlines, Morpheus is only one aspect - indeed, the anthropomorphic aspect - of the incomprehensibly complex entirety of Dream.

One of the most fascinating aspects of The Sandman's storytelling is how it constantly attends - again, both visually and verbally - the ways the characters see each other. This allows the more nonhuman characters to passingly project their nonhuman minds on the more anthropomorphic characters, momentarily dehumanizing, or at least defamiliarizing them. For instance, the aforementioned, human-like but blue-skinned alien girl is branded a "meat child" and ultimately "deleted" (\#4, [8, 20]) by a community of stars - who, Overture assures us, are "flaming balls of gas in space" but "also alive" (\#3, [12]). An even more sustained, more multimodal example of this inter-character projection is provided by the shifting appearances of Dream and the other Endless. As the rare heterodiegetic narrator underlines in the original series, "we perceive but aspects of the Endless, as we see the light glinting from one tiny facet of some huge and flawlessly cut precious stone" (Gaiman et al. 1992, \#21, [11]). On every given moment, any and all of their apparent attributes are merely a matter of perspective - and comics are especially deft at creating rapid shifts of perspective. The entire gem metaphor is thus concretized 15 years later in The Sandman: Overture, when Dream uses his ruby necklace to contact another character in another dimension. For the duration of their conversation, the page designs resemble giant rubies, so that the facets comprise the panels, and in each panel, Dream assumes a different physical form - a cyclops, a robot, a bat, and an ice creature. Yet the conversation can carry on as normal, underlining that all these seemingly different figures share the same godly mind and identity (\#2, [16-18], see Figure 4.2).

The appearances of all the Endless siblings morph to mirror the implicit expectations, worldviews, or self-images of whichever characters they are interacting with (Bender 1999, 25) in various other sequences 


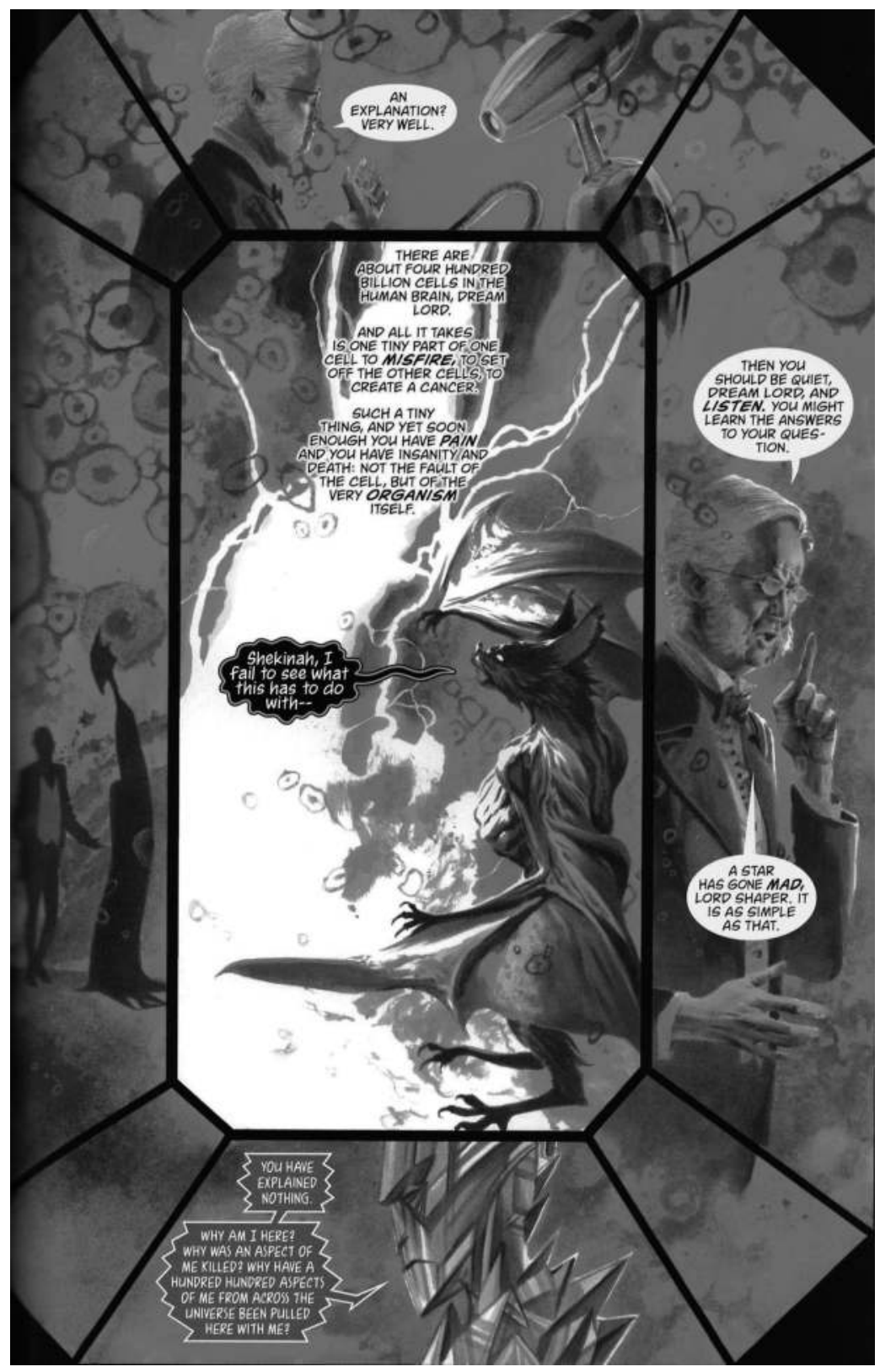

Figure 4.2 Dream's fluid physical form appears to be fractured into various possible appearances by the ruby amulet he uses for long-distance communication with other god-like characters (2015, \#2, [17]). The Sandman: Overture (C) 2013 DC Comics. Written by Neil Gaiman and illustrated by J. H. Williams, III. 
as well. In a flashback concerning an ancient world of anthropomorphic panther creatures, for instance, all the appearing Endless - Dream, Death, and Destruction - look as if they belonged to this same unnamed half-human, half-feline species (\#4, [13-16]). Similarly, when negotiating with the metal beetles, Dream's face becomes decorated with the same orange patterning as their elytrons, just for the flash of one panel (\# 3, [15], see Figure 4.1). Such quickness and fluidity suggest that these changes are not really metamorphoses but effects of focalization - a way of showing something of an alien mind by projecting it on to something slightly more palpable and familiar. Meanwhile, the coherence of the morphing characters is maintained by contextual clues like continuous action, dialogue, or monologue as well as by stable visual "pointers" (Varis 2013, 135). These can be part of the character's physical appearance - for instance, Death always wears an ankh - or metatextual, like Dream's black, amoeba-like speech bubbles.

One could thus deduce that the Endless wear their human skins as their default mode because of the one onlooker they cannot possibly shed, not even for a single panel: the human reader. Even when there are no other characters around Dream and his siblings, they are still being watched and read by the reader, whose anthropocentric worldview and anthropomorphizing cognitive strategies they thereby reflect. Although The Sandman comics never address or acknowledge the presence of the real-life reader with overt metalepses, especially Overture demonstrates an implicit awareness of the reader. Particularly in the first issue, this awareness is realized through the prevalence of reflections as a visual motif.

The first and possibly the most unsettling instance of this motif is the spread that resembles a giant gaping mouth: each bared tooth frames one panel, giving the impression that scenes of the storyworld are actually reflected on their enamel surfaces. The effect is further heightened by the fact that some of the panels are clearly depicted from a first-person perspective, and even incorporate the rims and dark tint of sun-glasses. The fans of the series are likely to instantly associate these visual signs - the mouth and the glasses - with the Corinthian, a murderous nightmare who looks like a normal, white-haired man but has two extra mouths where his eyes ought to be. The spread thus situates the reader into two equally disturbing but dissonant positions, which concretize the concurrent "insideness" and "outsideness" of (defamiliarizing) character engagement. On the one hand, the first-person panels place the reader behind the glasses of this horrific serial killer, forcing empathetic perspective-taking on the level of visual perception. On the other hand, the page is not, in fact, a gaping jaw but an extreme, metaleptic close-up of the Corinthian's eye, staring back at the reader (\#1, [6-7], see Figure 4.3). Indeed, in creating Corinthian, Morpheus says he "wished only to build something that would reflect humanity -- would show it itself, show it everything about itself it did not want to acknowledge" (\#1, [14]). 


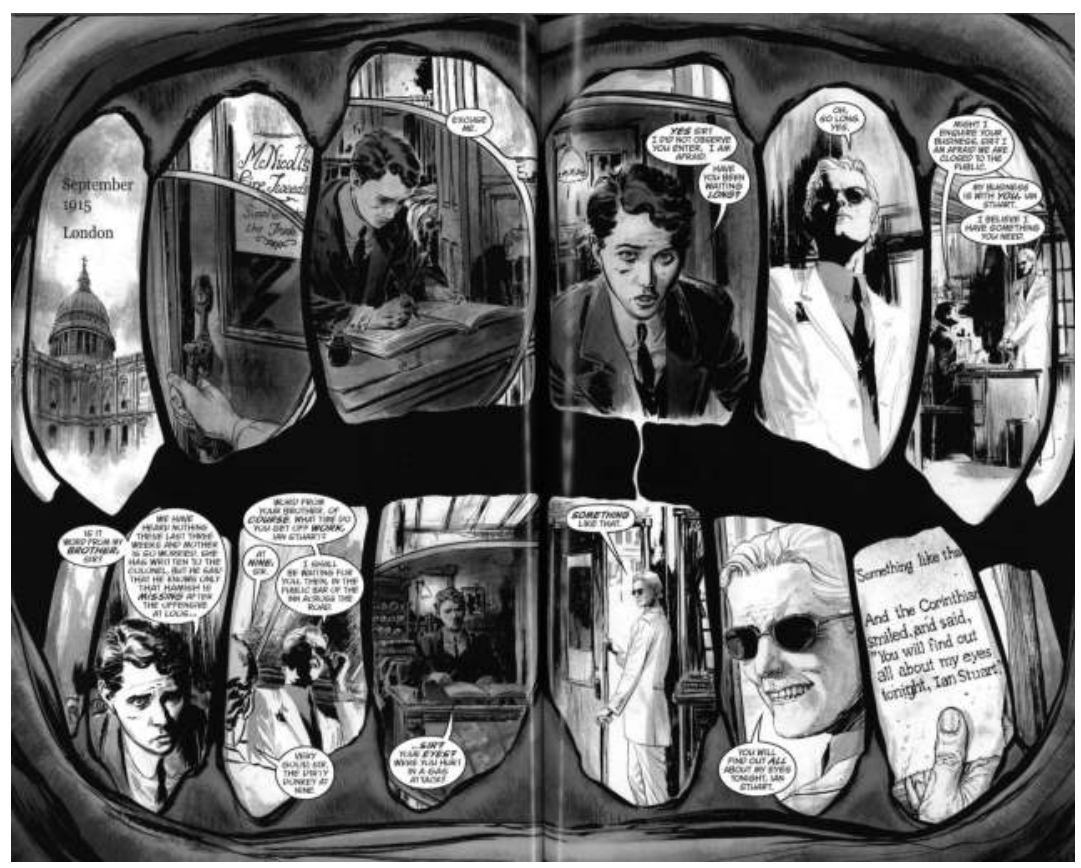

Figure 4.3 The readers are watching the storyworld as - while also being metaleptically watched by - the Corinthian (2015, \#1, [6-7]). The Sandman: Overture (C) 2013 DC Comics. Written by Neil Gaiman and illustrated by J. H. Williams, III.

The reader is again challenged to a similar metaleptical staring contest only a few page-turns later, on a page whose composition resembles a lithograph of old-fashioned window panes (Figure 4.4). The visual style of this sequence deviates greatly from the rest of the series, and may allude to the works of M. C. Escher, who was famous for creating the kind of visual illusions this scene aims to deliver. First of all, the single squares of the window constitute the panels, but in a way that plays with medium-specific illusions of transparency: squares containing text are completely opaque and thus function as narration boxes - they tell of abstract things rather than show concrete things - whereas squares that only contain images give the impression that the reader can peer through them, straight into the storyworld, as if peering through a window. For the first few panels, the only character on the other side of the window seems unaware of being watched, busying himself with everyday tasks. In the fourth panel, however, he turns around, as if to look back toward the reader. What makes the effect especially startling and convincing is that his face appears to be replaced by a mirror, which reflects the frames of the same window, but from the inside. (\#1, [11]) The changes of angles 


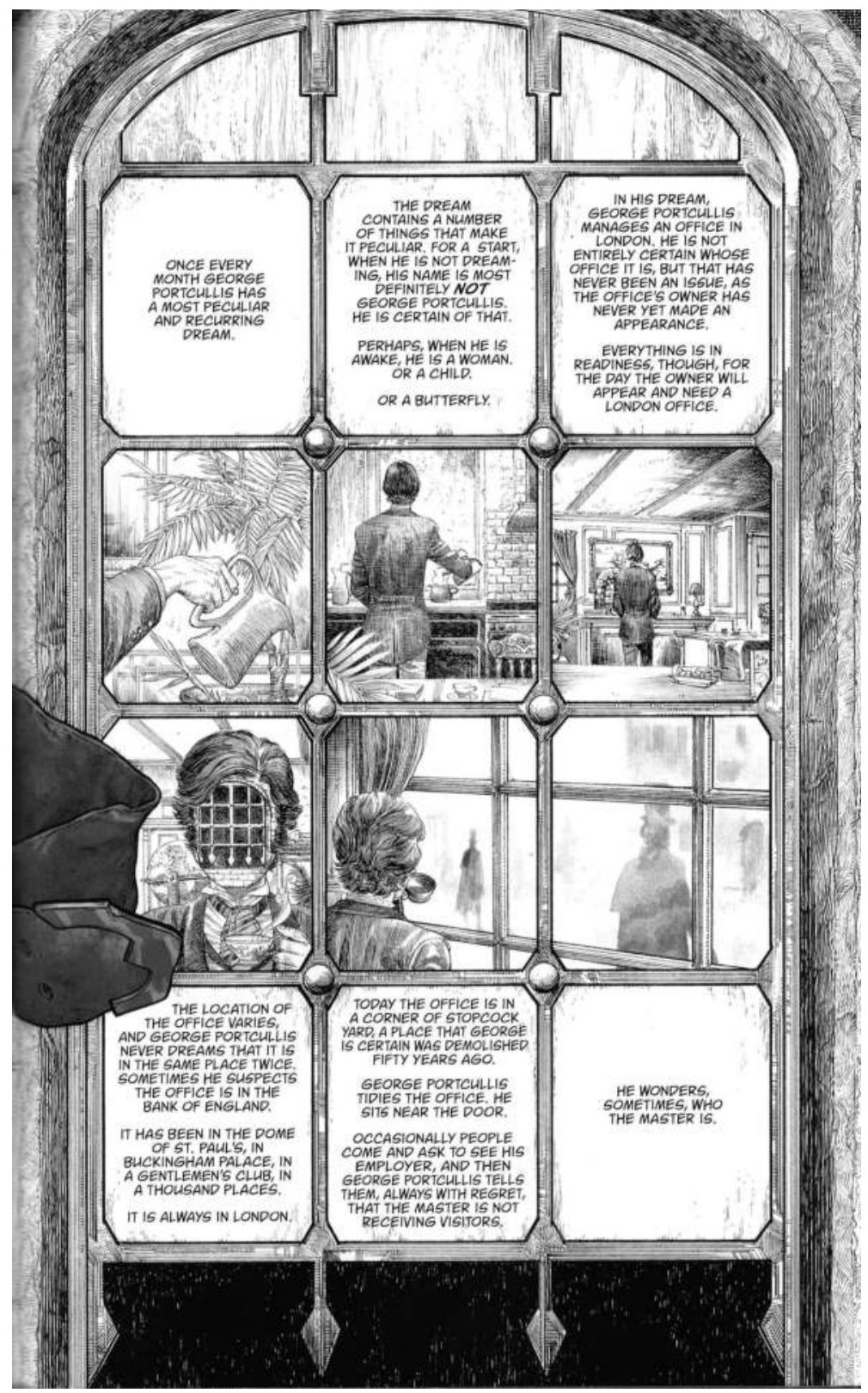

Figure 4.4 This page layout plays with the "opaqueness" of written language, the apparent "transparency" of pictorial presentation, and the book's overarching motif of reflections (2015, \#1, [11]). The Sandman: Overture (C) 2013 DC Comics. Written by Neil Gaiman and illustrated by J. H. Williams, III. 


\section{Essi Varis}

on the next page reveal that the character's face is not, in fact, a mirror, but permanently shaped like a portcullis - as per the character's name, George Portcullis (\#1, [12]). Yet the illusion that the reader is separated from the storyworld only by a thin, transparent surface has already been formed - momentarily but memorably. Put in the larger context, the scene seems to imply that while the page is "transparent", the characters are not; they are mirrors at least as much as they are windows.

The same theme is once again evoked on the final page of the issue, which shows three interlocking, circular panels, all focusing on Morpheus from the straight-on, eye-level angle. In the uppermost panel, he is wearing his bone helmet, which makes his head appear elongated, insect-like, and alien. A myriad of his nonhuman aspects - whom he has just encountered - is reflected, small and distorted, on its lenses. In the second panel, the helmet disappears, so that the final panel can clearly display Morpheus' familiar human face, expressing a familiar human emotion - which, again, is likely to reflect the readers' confusion about what has just happened. This simple, fairly static threepanel sequence containing only one word - "What?" - thus states quite clearly what the comic and its protagonist can and cannot convey. The human Morpheus is emotive, vocal, and clear, but the parts of him that reflect the nonhuman world - only partially and imperfectly - remain unreadable and incomprehensible, hidden behind the helmet. (\#1, [24], see Figure 4.5)

All in all, the framing of the panels throughout Overture gives the reader a very palpable sense that something is always left outside the frame. Scenes where different aspects of Dream and different alien species gather together are given plenty of space: an entire spread (\#6, [2-3]) and even a rare double-wide fold-out spread (\#1, [22-23]) show all types of creatures, which gain added diversity from the fact that some are drawn with digital, some with analogue techniques ("The Accompaniments", [16]). Yet the framing and the composition emphasize that only a small part of the crowd is shown. Only the feet of one creature and an arm of another have been fitted in the frame, suggesting that the nonhuman multitudes extend beyond the page - and beyond imagination.

To summarize, The Sandman: Overture seizes an ambitious scenario that requires adopting a universal perspective and, accordingly, triggers constant defamiliarization by blending human and nonhuman traits in all of its characters, often multimodally. Yet, before long, the story runs into the insurmountable wall of subjectivity outlined by Nagel, and gets tangled up in the human experientiality implied in the very act of narration. Although The Sandman series has always been an unabashed celebration of stories and their power - one of Dream's sobriquets is "Prince of Stories" - an oddly familial encounter between Morpheus and his mother Night indicates that in Overture, the triumphant narrativity 


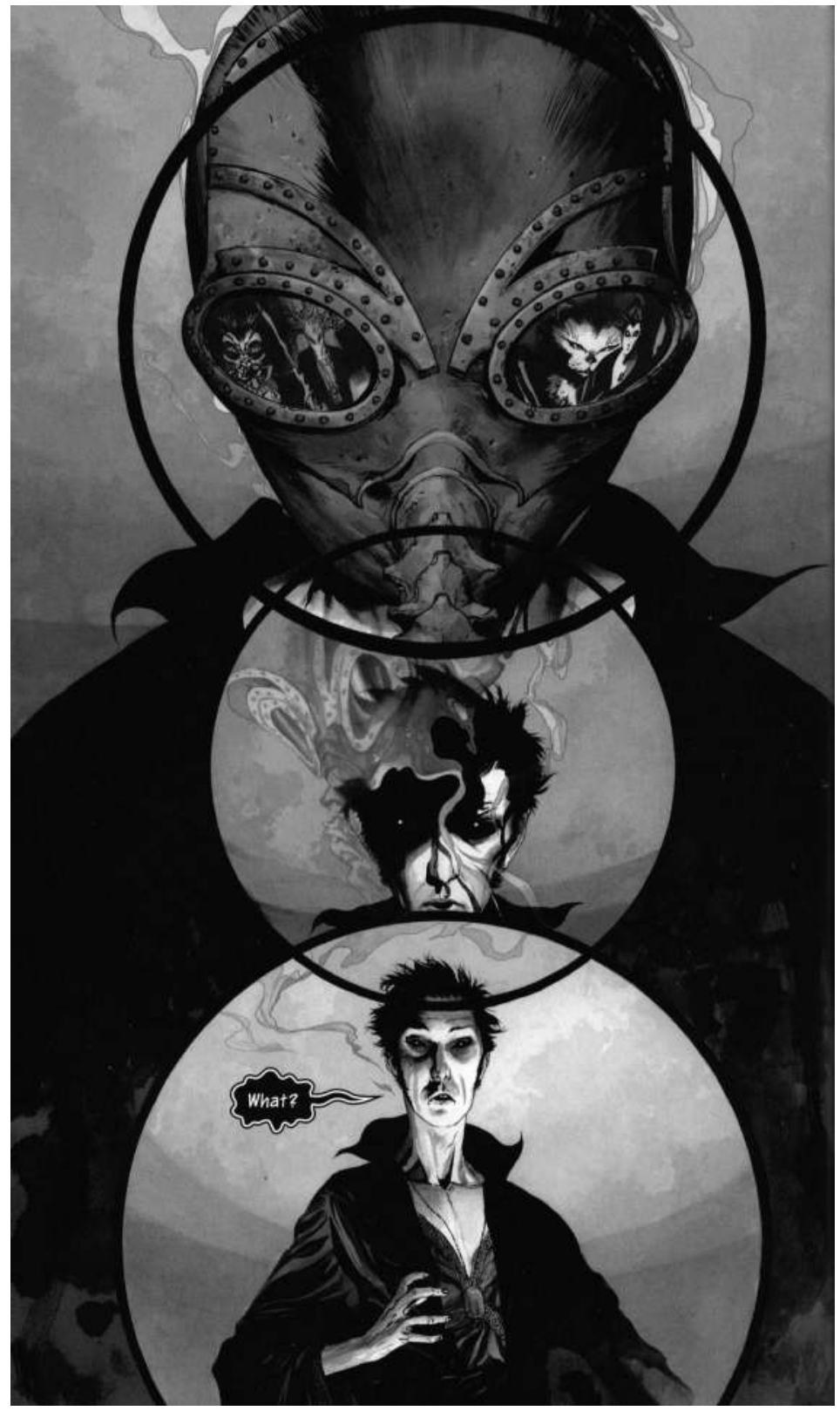

Figure 4.5 Some aspects of Dream are irrevocably hidden and unrepresentable, whereas his familiar human form results from, and appeals to, the human readers' perspectives (2015, \#1, [24]). The Sandman: Overture (c) 2013 DC Comics. Written by Neil Gaiman and illustrated by J. H. Williams, III. 


\section{Essi Varis}

finally reaches its limits. "It's one of your stories, isn't it?" Night mocks as she realizes that Dream is trying to stage a conventional happy ending for entropy itself: "In the reunion of Time and Night the mad stars will become sane, and peace and wisdom and joy and beauty will reign for ever and aye...". Being less tied to entities and subjectivities than her son, Night understands that only certain aspects of universes can be contained, controlled, and understood by the narrative logics employed by Dream, the human reader, and the comic that brings them together.

Thus, The Sandman: Overture attempts to stay aware of its creators' and readers' human perspective while it avoids totalizing it. The more nonhuman the character, the more consistently the illusion of "transparent minds" - and the over-projection of anthropomorphic experience it entails - is avoided. Instead, nonhuman creatures are often approached with wonderment and curiosity. For instance, as Hope, the human-like alien girl, weaves between the less human, more opaque aliens, she ponders how they might experience the refugee situation they are presently sharing: "But we are all here. I wonder what they see. I wonder how they talk" (\#6, [3]). Similarly, the reader can attend the perspectives and the emotions of the characters quite closely and concretely "from the outside": Morpheus especially is often depicted either straight-on - which reveals his emotional state - or so that the reader looks over his shoulder - seeing an approximation of what he sees (see e.g. \#3, [24], which gives both views simultaneously). This encourages empathetic perspective-taking and alignment with the character without any need or pretense of conveying his private, lived experience. The abundance of extreme close-ups of eyes may be symptomatic of this same epistemological stance: the reader can look into the characters' eyes and wonder what would be going on behind them if characters truly were minded beings - what they would see if they could see - but as with real life, there are no thought bubbles to explain away any of it. In this way, the comic encourages "non-intrusive" ways of approaching and empathizing with nonhuman characters - ways that circumvent at least some of the anthropocentrism inherent in verbalized subjectivities and spelled-out folk psychology.

\section{Conclusions}

In conclusion, The Sandman: Overture mostly evokes nonhuman experience by not really depicting it at all but by gesturing - vigorously - to its general direction. For this, the comic has two overarching strategies. First, it does not even pretend to represent any actual nonhuman creatures but invents instead an array of aliens that blend human and nonhuman features in imaginative ways. The nonhuman traits tease the readers' imagination with little, counterfactual alternatives, which the reader can grasp in an embodied way due to the intertwined human traits: we know how humans dream, but how would plants dream; or 
how would my life change if I had mouths for eyes? The tension between the familiar and the unfamiliar - the defamiliarization - thus provides a manageable, but potentially consequential challenge to the reader's cognitive capabilities. Second, the reflection motif constantly confronts the reader with his or her own humanity and the epistemological limits it entails. The comic seems to imply that it narrates the tale that it is narrating from the point of view it is narrating it from because that is what the human reader is ready, willing, and able to receive. Various vast nonhuman domains always lie beyond the panels, but depicting them, either in words or images, is either difficult or impossible. All The Sandman: Overture can do is to remind the reader that they are there. Like the sun, nonhuman experience cannot be looked at directly, but speculative fiction and the multimodal storytelling of comics are quite competent at dancing around it and making the reader wonder about it.

Unfortunately, discussing nonhuman experiences is not any easier to a researcher than it is to a comics creator. It seems clear that discussing the possibility of understanding nonhuman minds through narratives requires considering several layers of discourse, representation, and cognition, but the texts, worlds, and minds are so tangled together, it is often difficult to discern where they truly intersect and when they are collapsed together more or less needlessly. The concept of character is an excellent case in point: in spite of actually being nonhuman constructions, they are, in practice, burdened by very anthropomorphic connotations. It may thus be worth considering whether detangling mimetic personhood and narrative agency would actually be possible, and whether the resulting agential concept would allow narrativizing nonhuman experiences in a less anthropomorphizing manner.

One could also ask to which extent these entanglements between characters' mimetic aspect and the readers' anthropomorphizing assumptions depend on specific medial contexts and their affordances. For instance, comics clearly draw very non-Cartesian cartographies, where the mind and the physical world cannot be separated any more than the verbal and the pictorial elements can, without losing something crucial of the characters' imagined experience. The constant presence of visual bodies makes it awkward to even refer to the characters as "minds", which is perhaps a signal for the slowly transmedializing narratology to start theorizing characters more holistically. Indeed, in the face of the mimetic, anthropomorphic, and literary biases of current narratology, considering speculative, nonhuman comic book characters poses an aptly defamiliarizing challenge.

\section{Notes}

1 Because the collected hard-back edition of The Sandman: Overture lacks page numbers, all the references are made to specific issues or chapters, 


\section{Essi Varis}

whose pages have been counted manually: “\#” designates the number of issue, and the unmarked page numbers are specified in the square brackets.

2 "The Accompaniments" is a collection of interviews and other extra materials included in this specific hardback edition of the comic. The page numbers are, again, based on manual counting, as they have not been marked on the original documents.

\section{References}

Alber, Jan. 2009. "Impossible Storyworlds - and what to do with them." Storyworlds: A Journal of Narrative Studies 1: 79-96.

, Henrik Skov Nielsen, and Brian Richardson. 2013. A Poetics of Unnatural Narrative. Theory and Interpretation of Narrative series. Columbus, $\mathrm{OH}$ : Ohio State University Press.

Bender, Hy. 1999. The Sandman Companion: A Dreamer's Guide to the Award-Winning Comics Series. New York: Vertigo/DC Comics.

Bernaerts, Lars, Marco Caracciolo, Luc Herman, and Bart Vervaeck. 2014. "The Storied Lives of Non-Human Narrators." Narrative 22 (1): 68-93.

Caracciolo, Marco. 2014a. "Beyond Other Minds: Fictional Characters, Mental Simulation, and 'Unnatural' Experiences." Journal of Narrative Theory 44 (1): 29-53.

- 2014b. The Experientiality of Narrative: An Enactivist Approach. Narratologia 43. Berlin: De Gruyter.

- 2016. Strange Narrators in Contemporary Fiction. Explorations in Readers' Engagement with Characters. Frontiers of Narrative Series. Lincoln, NE and London: University of Nebraska Press.

Chaney, Michael A. 2011. "Animal Subjects of the Graphic Novel." College Literature 38 (3): 129-149.

Eder, Jens, Fotis Jannidis, and Ralf Schneider. 2010. "Characters in Fictional Worlds. An Introduction." In Characters in Fictional Worlds: Understanding Imaginary Beings in Literature, Film, and Other Media, edited by Jens Eder, Fotis Jannidis, and Ralf Schneider, 3-64. Berlin: de Gruyter.

Eisner, Will. 2008. Comics and Sequential Art. New York: W. W. Norton \& Co. Fehrle, Johannes. 2011. "Unnatural Worlds and Unnatural Narration in Comics? A Critical Examination.” In Unnatural Narratives - Unnatural Narratology, edited by Jan Alber and Rüdiger Heinze, 210-245. Berlin: de Gruyter.

Fludernik, Monika. 1996. Towards a 'Natural' Narratology. London and New York: Routledge.

Gaiman, Neil. 2016. "Why Our Future Depends on Libraries, Reading and Daydreaming: The Reading Agency Lecture, 2013." In The View from the Cheap Seats: Selected Nonfiction, 5-25. New York: William Morrow/Harper Collins.

_ J. H. Williams III, and Dave Stewart. 2015. The Sandman: Overture. Deluxe edition. New York: Vertigo/DC Comics.

— Kelley Jones, Mike Dringenberg, Malcolm Jones III, Matt Wagner, Dick Giordiano, George Pratt, and P. Craig Russel. 1992. The Sandman Vol. 4: Season of Mists. New York: Vertigo/DC Comics.

Groensteen, Thierry. 2013. Comics and Narration. Translated by Ann Miller. Jackson, MI: Press of University of Mississippi. 
Herman, David. 2011. "Storyworld/Umwelt: Nonhuman Experiences in Graphic Narratives.” SubStance 40 (1): 156-181.

- 2012. "Toward a Zoonarratology: Storytelling and Species Difference in Animal Comics." In Narrative, Interrupted: The Plotless, the Disturbing, and the Trivial in Literature, edited by Markku Lehtimäki, Laura Karttunen, and Maria Mäkelä, 93-119. Boston, MA: De Gruyter.

—. 2013. "Cognitive Narratology." Last Revised December 24, 2013. The Living Handbook of Narratology. www.lhn.uni-hamburg.de/article/ cognitive-narratology-revised-version-uploaded-22-september-2013.

Jannidis, Fotis. 2013. “Character.” Last Revised September 13, 2013. The Living Handbook of Narratology. www.lhn.uni-hamburg.de/article/character.

Keen, Suzanne. 2011. "Fast Tracks to Narrative Empathy: Anthropomorphism and Dehumanization in Graphic Narratives." SubStance 40 (1): 135-155.

Kukkonen, Karin. 2013. Contemporary Comics Storytelling. Frontiers of Narrative Series. Lincoln, NE: University of Nebraska Press.

- 2014. "Presence and Prediction. The Embodied Reader's Cascades of Cognition.” Style 43 (3): 367-384.

McCloud, Scott. 1993. Understanding Comics: The Invisible Art. New York: Harper Perennial.

Mikkonen, Kai. 2008. "Presenting Minds in Graphic Narratives." Partial Answers 6 (2): 301-321.

Nagel, Thomas. 1974. "What It Is Like to Be a Bat?" Philosophical Review 83 (4): 435-450.

Phelan, James. 1989. Reading People, Reading Plots: Character, Progression, and the Interpretation of Narrative. Chicago, IL: University of Chicago Press.

Schneider, Ralf. 2001. "Toward a Cognitive Theory of Literary Character: The Dynamics of Mental-Model Construction.” Style 35 (4): 607-640.

Stockwell, Peter. 2008. "Science Fiction." In Routledge Encyclopedia of Narrative Theory, edited by David Herman, Manfred Jahn, and Marie-Laure Ryan, 518-520. London and New York: Routledge.

Thon, Jan-Noël. 2014. "Subjectivity across Media: On Transmedial Strategies of Subjective Representation in Contemporary Feature Films, Graphic Novels, and Computer Games." In Storyworlds Across Media. Toward a Media-Conscious Narratology, edited by Marie-Laure Ryan, and Jan Noël Thon, 47-72. Frontiers of Narrative Series. Lincoln: University of Nebraska Press.

Varis, Essi. 2013. "A Frame of You: Construction of Characters in Graphic Novels.” Licentiate's diss., University of Jyväskylä. https://jyx.jyu.fi/dspace/ handle/123456789/41711.

Vermeule, Blakey. 2010. Why Do We Care about Literary Characters? Baltimore, MD: The Johns Hopkins University Press.

Zunshine, Lisa. 2008. Strange Concepts and the Stories They Make Possible: Cognition, Culture, Narrative. Baltimore, MD: The Johns Hopkins University Press. 


\title{
5 Playing the Nonhuman Alien Experiences in Aliens vs. Predator
}

\author{
Jonne Arjoranta
}

What is it like to play a nonhuman? In a classic philosophical article, Thomas Nagel (1974) argues that we are fundamentally unable to imagine what it is like to be a bat. Because our senses and cognition are structured in a certain way, imagining what it would be like to be other is difficult, if not impossible (cf. Barsalou 2008). Yet, in media genres from fantasy to science-fiction, we are routinely shown what it is like to be something else or asked to imagine it. Different media do this with different tools, from descriptions in text to moving images on the screen. Some of the portrayals of aliens may be similar, but different media also have different tools at their disposal.

This chapter examines how videogames portray the nonhuman, what kind of assumptions they make about being nonhuman, and what kind of tools they use to convey the experience of nonhumanness. I focus on Aliens vs. Predator (Rebellion Developments 2010), because it has three different but intertwined campaigns, where you play as a human, an alien, and a predator. Therefore, it depicts two nonhuman experiences that can be compared to the human experience. This analysis is complemented with examples from other games that represent playing nonhuman characters. The discussion here draws from the theory - or a loose family of theories - of embodied cognition to better explain the nonhuman experiences discussed.

\section{(Non)Human Cognition}

The idea that cognition is a neutral, withdrawn observer with an objective view of the world is an idea created largely during the Enlightenment. The rational, withdrawn cognition is the classic view of reason propagated by the philosopher René Descartes, who established his ideas on the foundation of a mind-body dualism. This view considers the mind to be separate from the body, and identifies personality, cognition, and identity with the mind. Bodies are seen as little more than containers for the minds within. This creates philosophical problems, like explaining the relation of the immaterial mind to the material body - a problem famously solved by Descartes by suggesting that the pineal gland acts as 
a conduit between the two. The relation between the mind and the body was seen as two-way, with the rational mind sometimes compromised by the passions of the body.

In comparison, embodied, situated (Anderson 2003), or grounded cognition (Barsalou 2008) relies on the notion that action, context, and the body are central to cognition. ${ }^{1}$ In opposition to Descartes, this tradition of thinking is more in line with philosophers like Maurice Merleau-Ponty (2002), who emphasize how humans are not simply minds put into the containers of bodies, but how being in the world bodies and all - is necessary for being human. The idea of embodied cognition is complex and multifaceted, but these six typical ideas associated with it offer a brief overview (Wilson 2002):

1 Cognition is situated.

2 Cognition is time pressured.

3 We off-load cognitive work onto the environment.

4 The environment is part of the cognitive system.

5 Cognition is for action.

6 Off-line cognition is body based.

What these six things mean for the present discussion is that bodies matter for thinking. The difference between a human body and different alien bodies is therefore meaningful when discussing cognition and experience in videogames. However, it should be noted that not all of these ideas are equally rooted in research. For example, Wilson (2002) shows that the fourth idea (the environment is part of the cognitive system) does not have strong evidence in research (for a general critical overview of claims often associated with embodied cognition, see Adams 2010).

Videogames are largely based on the false assumption that human bodies are uniform. It is an assumption shared by the game examples discussed here: the human perspective detailed later in this chapter is that of a capable soldier. The analysis conducted here examines this normative assumption of what humans are like. While it would be outside the scope of this chapter to deconstruct the ableist assumptions presented, it is shown that even the normative bodies represented here can be weak and lacking.

\section{Nonhuman Perspectives in Games}

Games, both digital and analogue, use multiple media to convey ideas and experiences of human and nonhuman alike. I've played characters ranging from cyborgs to aliens, vampires and elves, all embedded in physical, social, and experiential surroundings that reflect what it is like to be them (Lankoski 2011) or what their perspective on the world is (Allison 2015). 
Games can give us the possibility of experiencing things we normally cannot experience, and which would be hard to portray in other media. For example, Gualeni (2015) details how the game Hoerfest (Technically Finished 2009) can provide at least a glimpse of bat phenomenology. ${ }^{2}$ One of the most common ways of representing nonhumanity in games is to include characters that have senses different from humans. A few of the typical ways of doing this are using synesthetic design, visual indicators, and color filters.

Although there are exceptions, many - if not most - games aim for a naturalistic portrayal of human experience. ${ }^{3}$ This means that things like visual representation aim to convey a relatively "normal" look to the player. Often, this includes some stylistic flair, and genre conventions shape how things are portrayed, but the overall effect is more or less recognizable as human experience. Changing the visual representation is one of the easiest ways of portraying alien experiences - perhaps because vision is such a central sense to most able-bodied humans. Games deviate from the standard representation of human visual experience in a few ways. Using different color filters is one of the typical ways games portray alternative ways of perceiving the world. The way humans usually perceive the world falls within a small range of variation, even when accounting for the stylistic filters and alterations videogames use. Large differences from the naturalistic norm are easy to notice and generally change the feel of the visual experience significantly.

Games could use other methods than the visual to portray nonhuman experiences, for example, by using sounds. When playing nonhuman characters, it is common to have them grunt, hiss, gurgle, or otherwise make sounds not typical to humans. For example, the playable zombies in Left 4 Dead 2 (2009) make a variety of unpleasant sounds. However, these noises sound identical whether one plays a zombie or a human, so the experience of hearing seems identical for the zombies.

Before moving on to analyze Aliens vs. Predator in more detail, I will introduce the concept of synesthetic design. I use synesthesia to refer to game design where one sense is expressed through another sense. One of the typical forms of synesthetic design used in games is portraying hearing through sight. For example, in Mark of the Ninja (Klei Entertainment 2012), the interface provides several types of clues on what the player should be focusing on. Yellow circles represent areas of interest, while blue circles serve as warnings of how far sound can be heard. This is constantly telegraphed to the player, as any loud sound will be accompanied by a blue circle. Because Mark of the Ninja is a stealth game where keeping quiet is important, the player has to be aware of the noise they are making. However, actual sounds in the game are not accurate enough to convey information to the player, so the location of sounds needs to be conveyed through another sense. By looking at the blue circles, the player can accurately gauge how far noise travels (Figure 5.1). 


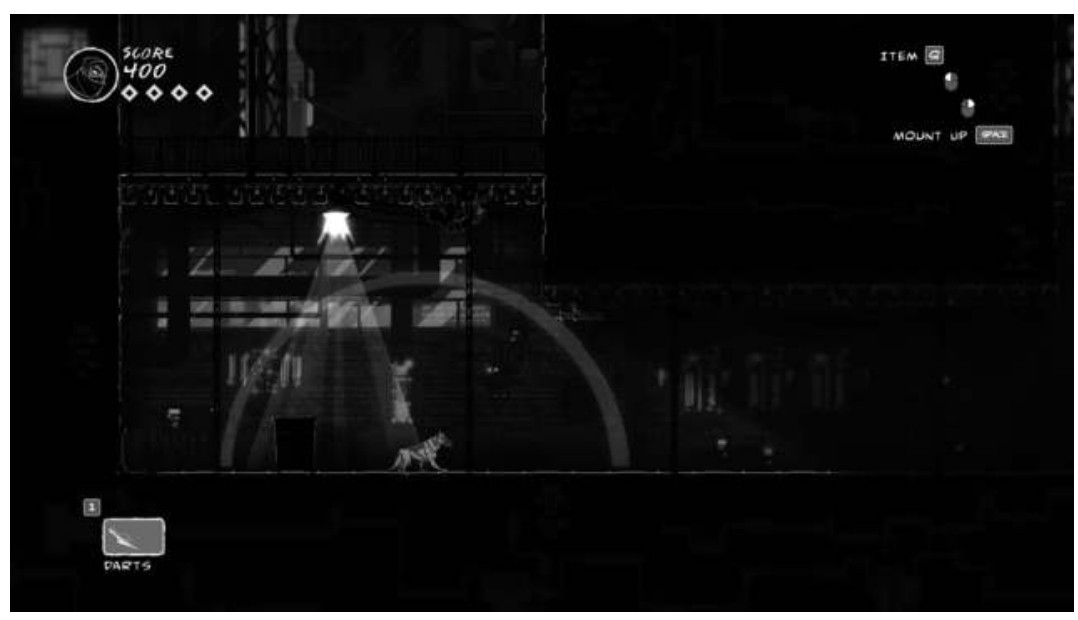

Figure 5.1 A hiding ninja in Mark of the Ninja (Klei Entertainment 2012). The dim circle marks the range of sound produced by the dog.

Similar techniques are used to communicate information in cases where the player character is not human. For understanding nonhuman experience, it is useful to look at how bats are portrayed in games. Bats are interesting examples because they are prototypically different in the sense Nagel (1974) discussed, but still evolutionally close to humans. Bats have also been represented in videogames. Thus, there are some common techniques for portraying what it is like to be a bat.

For example, in Hoerfest, one can see the environment only by activating a pulse-like sense that washes over the surrounding area and reveals everything briefly in striking purple. Otherwise the world is covered in darkness and only visible when it is very close. Presumably, this is the developer's impression of what it is like to be a bat, or at least what it is like to sense like one. However, because humans lack the actual sensory organs for perceiving the world like a bat, the experience is simulated through vision (Figure 5.2).

Several games from the Global Game Jam 2014 tried to portray the experience of playing a bat, for example Breaking Bat (2014) and Echo (2014). These games use techniques similar to the earlier Horfest, with light being used as metaphor for the bat's ability to sense its surroundings. All three of these games use synesthetic design, mapping one sense (echolocation) to another sense (sight).

Global Game Jam 2014 included another game, confusingly also named Echo (2014), that tried to portray the experience of being a bat without synesthetic design. Playing it requires (at least) two players: one referred to as "the bat" and another called "the eyes". The bat is blindfolded and given headphones that the eyes can send 


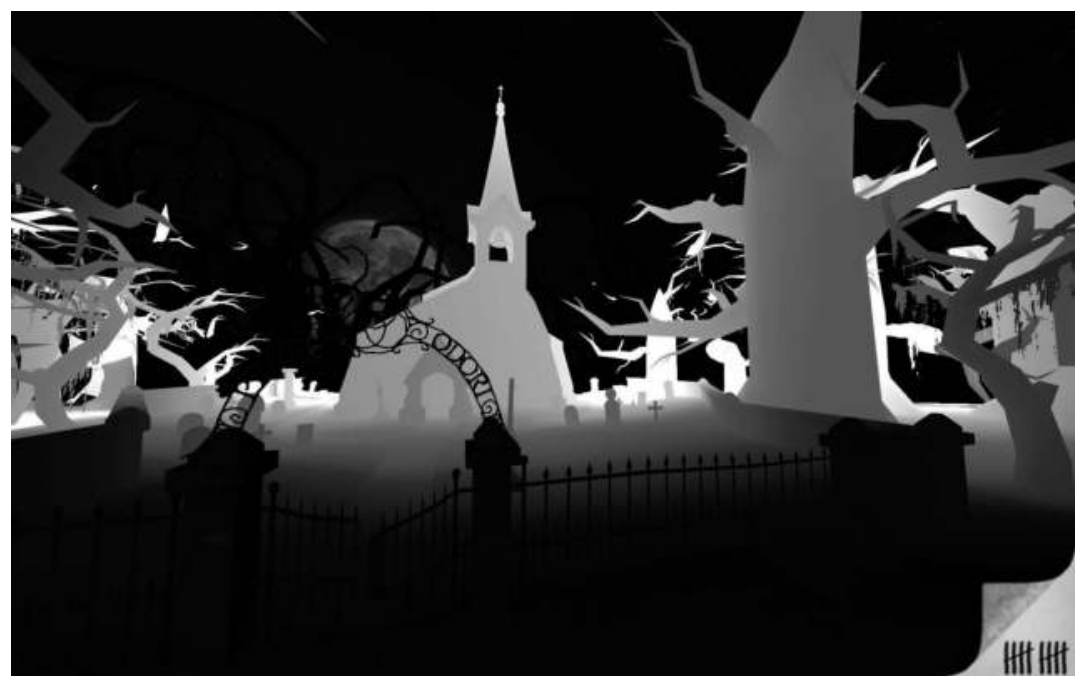

Figure 5.2 Sensing the surroundings in Hoerfest (Technically Finished 2009; image via Mobygames).

audio messages to. The goal of the game is for the eyes to navigate the bat through a physical maze using a computer to send audio messages to the bat. This approach does not use synesthetic design, instead letting the second player to act as the bat's sense of space. Because that information is conveyed through hearing, the bat player has to use their hearing to navigate a space - not an easy task for someone not used to that kind of navigation.

\section{Aliens vs. Predator}

Aliens vs. Predator (Rebellion Developments 2010) is a perfect example for examining how videogames portray alien experiences: it features gameplay with three protagonists, two of which are alien. All three have a unique storyline, shown from their perspective.

The three storylines are intertwined, all relating to the planet BG 386. The Weyland-Yutani corporation is breeding aliens in a laboratory that is located next to an ancient predator temple. While examining the temple, the Weyland-Yutani accidentally activates a predator device. The device temporarily deactivates their systems, thus freeing the aliens the Weyland-Yutani was breeding from their captivity. The device also sends a distress signal to the predators' home planet. The predators send a party of young predators to investigate, while a group of marines is also sent to combat the aliens freed from the Weyland-Yutani breeding facility.

The first group of predators sent to the planet is killed, which prompts the predators to send in a more experienced hunter. When it arrives, it 
destroys the marine ship orbiting the planet. Some of the marines survive the destruction of their ship on a smaller space vessel. The predator also lands, trying to make sure that humans do not tamper with the bodies of the dead predators from the first group. The human protagonist is one of the surviving marines. The second playable character is the more experienced predator sent to the planet to make sure humans do not desecrate the bodies of the first group sent there. The last player character is one of the aliens that is freed during the power-out caused by the activation of the predator device.

\section{Afraid of the Dark: Playing as a Human}

Playing the human protagonist - called simply Rookie by the other characters in the game - presents a fairly standard view of human perception. The view is first-person, meaning that the world is portrayed through Rookie's eyes. Most of the areas are dark, so the world is experienced with the help of the shoulder-mounted flashlight. Only a small area is in the visual focus, with most of the world covered in darkness. Rookie can also throw flares, providing stationary light in a small area. Perhaps the most important tool for getting information about the surroundings is the motion sensor, which produces constant sound while scanning the surroundings and emits a beep whenever it detects movement. Movement is also shown on the small indicator on the lower left side of the screen. The motion sensor seems to be a part of a heads-up display, worn by Rookie, meaning it is supposed to indicate things also visible to him. The heads-up display shows an objective marker, a small arrow on top of the motion tracker, to show the direction of the next objective (Figure 5.3).

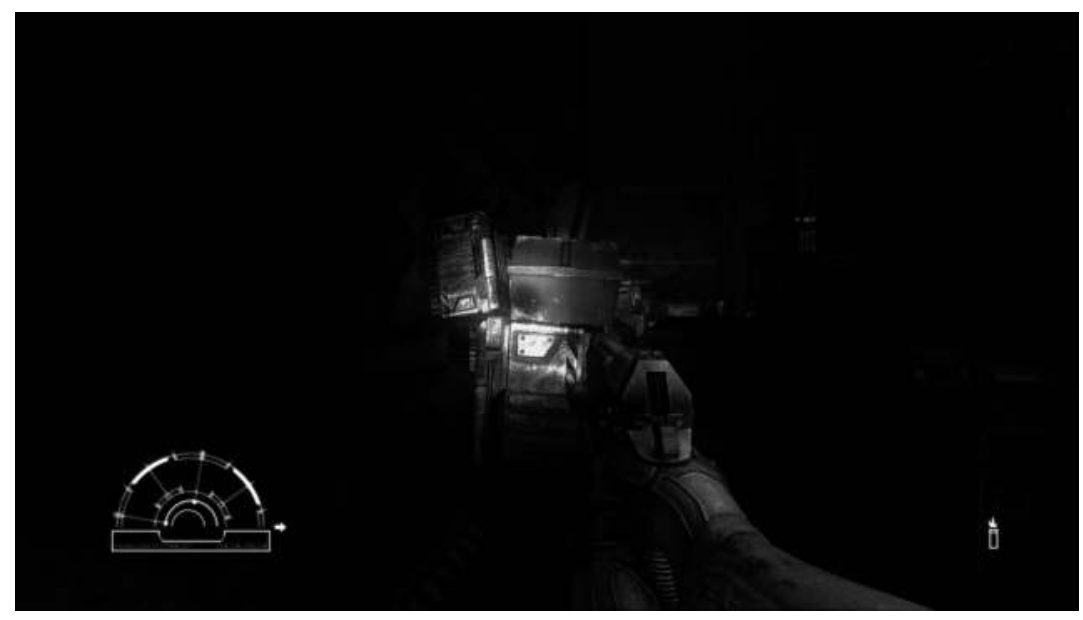

Figure 5.3 A dark room, seen in the light of a gun-mounted flashlight. 


\section{Jonne Arjoranta}

The combination of darkness, small areas of light, and the beeping of the motion sensor combine to create a claustrophobic, tense atmosphere. The motion sensor is an iconic part of the Aliens vs. Predator franchise, a technological tool to enhance the limited senses humans naturally possess. It is also a constant source of dread: a beep might mean deadly creatures in the dark - or not, as it is also prone to false positives.

The only refuge against the enemies in the dark is the arsenal of weapons at Rookie's disposal. He starts the game with only a pistol, but can later find an assault rifle, a shotgun, a flame-thrower, and an automatically aiming smartgun. If wounded by the aliens or other threats, Rookie can heal himself with stims, medical syringes that he sticks to his wrist. There is a limited supply of these, but Rookie is also easily killed, so there is a big incentive to use them as often as possible. He can also access areas off-limits to most other personnel on the planet because he carries a hacking device capable of opening locked doors. Through using these technological apparatuses, Rookie is able to survive in the hostile environment, despite being the weakest type of organism around.

Playing Rookie is an experience of uncertainty. Human senses are limited, and the darkness can only be made to make sense with the help of technology. The flashlight is the main source of light, but the motion sensor is almost as important, as it warns about the approaching aliens. Humans in Aliens vs. Predator are frail and slow and lack the sensory capabilities of the other species. It is only with technology - especially weapons - they are able to match, and best, the natural abilities of their enemies.

\section{"A Structurally Perfect Organism": Playing as an Alien}

In comparison to Rookie, the alien - known as Specimen 6 by the Weyland-Yutani - is much more capable. It can see in almost complete darkness and can use its other senses to track prey - meaning humans without any light sources. It is fast, heals quickly, and can rip humans to pieces with its claws and sharp tail.

These abilities are presented to the player in a short tutorial, which is framed as a testing of Specimen 6's abilities by the Weyland-Yutani scientists. Victims of increasing dangerousness are sent into a room with it, allowing the player to learn the abilities Specimen 6 possesses: walking on walls, seeing in the dark, sensing its prey through walls, moving and attacking quickly and ferociously. ${ }^{4}$

Specimen 6's ability to see in the dark is easily achieved by making the environment slightly less dark for the player. The world is still dark, but navigation is easier than it was for Rookie because the world is not focused on a small area of light. Specimen 6 is also able to sense the presence of humans. A tutorial text states that "The smell of a human betrays its nature". In practice, this means that different types of humans have outlines of different colors, with civilians differing from hostile 


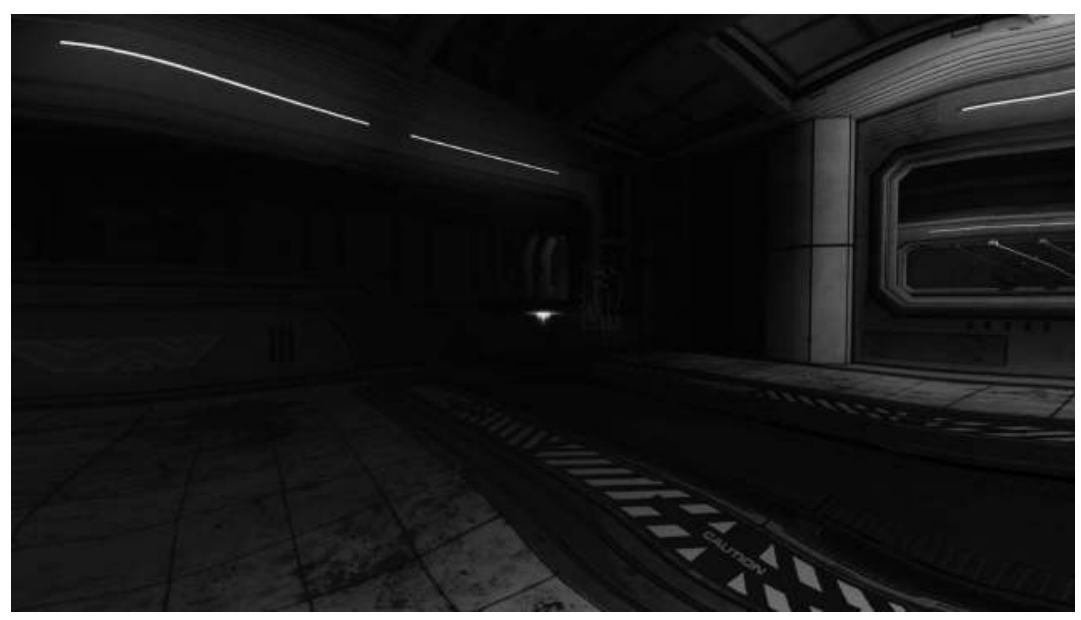

Figure 5.4 Specimen 6 stalking human prey through the wall.

prey. The tutorial continues by stating that "the stronger their scent, the greater the danger they pose" (Figure 5.4).

The text seems to imply that it is the alien's sense of smell that it uses in detecting humans. This information is conveyed to the player through a visual outline around human characters, seen even through walls (see previous figure). This is an example of synesthetic design, converting olfactory stimuli into visual representations. It is unclear how, exactly, the alien sense of smell works as it can smell even humans in enclosed spaces but has no information on how the characters have moved around or how many of them have been present in a space; humans may have a scent, but it is not present in the spaces they have occupied. The representation of scent seems to be simplified into a singular visual outline. ${ }^{5}$

Easily the most disorienting part of playing Specimen 6 is its ability to walk on any surface. This differs greatly from human everyday experiences of how humans relate to gravity, verticality, and surfaces. It takes even the most experienced human climbers a great deal of effort to climb vertical surfaces, and the speed is much slower than what they can accomplish on horizontal surfaces. In comparison, Specimen 6 can move on any surface much faster than a human can run, and switch between surfaces of different orientations with dizzying speed. This means that all surfaces are affordances for movement, whether they are upside down, vertical. or horizontal.

An indicator in the middle of the screen always points toward the floor to make it easier for the player to get their bearings after running around the walls and ceiling (see previous figure). This crosshair is also used to aim jumps and attacks, but it is probably not appropriate to read it 
literally as part of Specimen 6's visual field (cf. Jørgensen 2013). Instead, it is another example of synesthetic design, conveying to the player what humans usually experience with the help of their inner ear and through their whole body: the effect of gravity, a sense of up and down. The game cannot convey the feeling of your body being pulled toward the ground, so instead, it relays this experience with a visual indicator. A comprehensively bodily sense is translated into a visual representation.

The indicator serves another purpose by changing color: it tells you whether Specimen 6 is covered by darkness or not. The indicator is completely light yellow when Specimen 6 is in direct light and turns smaller when it moves toward darkness, turning black in the middle when the alien is completely covered in darkness. There are few possible ways of reading this: it is possible that the indicator simply corresponds to how much light is hitting Specimen 6's visual organs, and is just another way for the player to evaluate the surroundings - they could also just look around and see how much light there is in the surroundings. It is also possible that this indicator is supposed to suggest that the alien possesses another sense, an ability to sense how much light it is in. This could be likened to a human sensing sunlight touching their skin. The tutorial simply states that "In the shadows, you are almost invisible".

However, the alien's relation to darkness is never explained. Clearly, they are accustomed to using darkness against their prey, which seems to imply that they are used to being more perceptive and adapted to darkness than their prey.

The experience of playing Specimen 6 is alien. It moves quickly on all surfaces, interacts with its surroundings mostly by killing, and stays hidden until it is ready to strike at its prey. It is very much like a predatory animal, preying on the humans wandering in its territory.

\section{“Those Creatures You Hunt": Playing as a Predator}

The last of the player characters is the predator, who is never named in the single player game, but is identified as Dark in the multiplayer part of the game. He starts the game with a demonstration of superiority, first killing aliens in close combat and then stalking and killing humans. ${ }^{6}$ His abilities are a combination of physical qualities and advanced technology.

Dark is able to use the technology in his mask to choose three different modes of seeing, two of which are available at the beginning of the game. Two of these modes are specialized in seeing particular prey (humans and aliens), while the third one is closer to the human visual experience, with any unnatural parts explained by the heads-up display of the helmet Dark is wearing. The two modes specialized in hunting particular prey use strong color filters to achieve a strong contrast, with enemies marked by clear, bright colors. The vision mode for hunting humans uses a visual look often associated with thermal vision ${ }^{7}$ (Figure 5.5). 


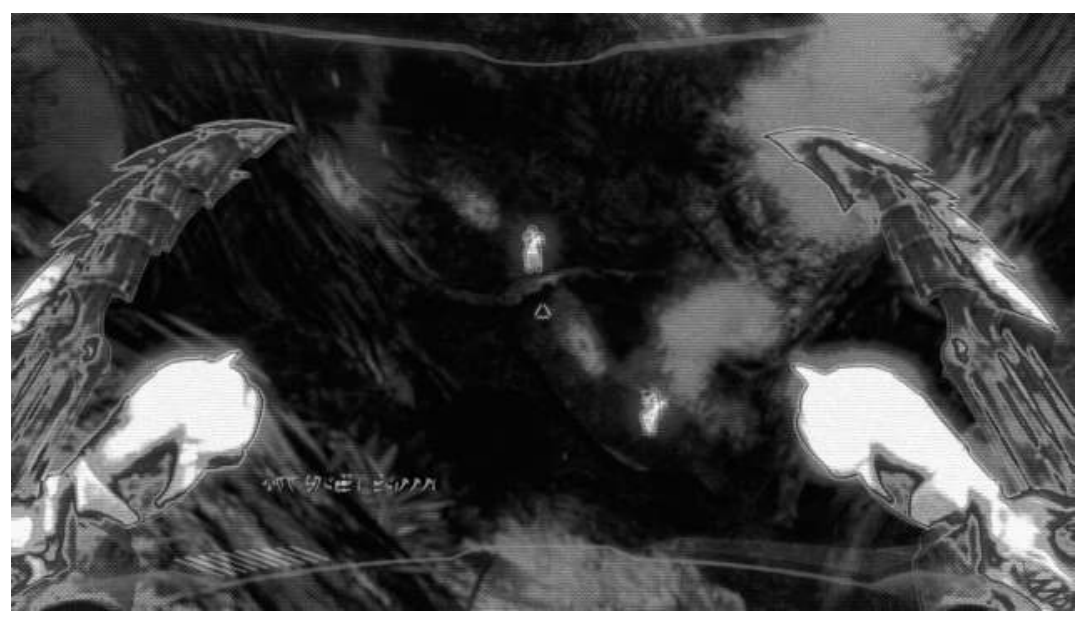

Figure 5.5 The predator stalking human prey with thermal vision.

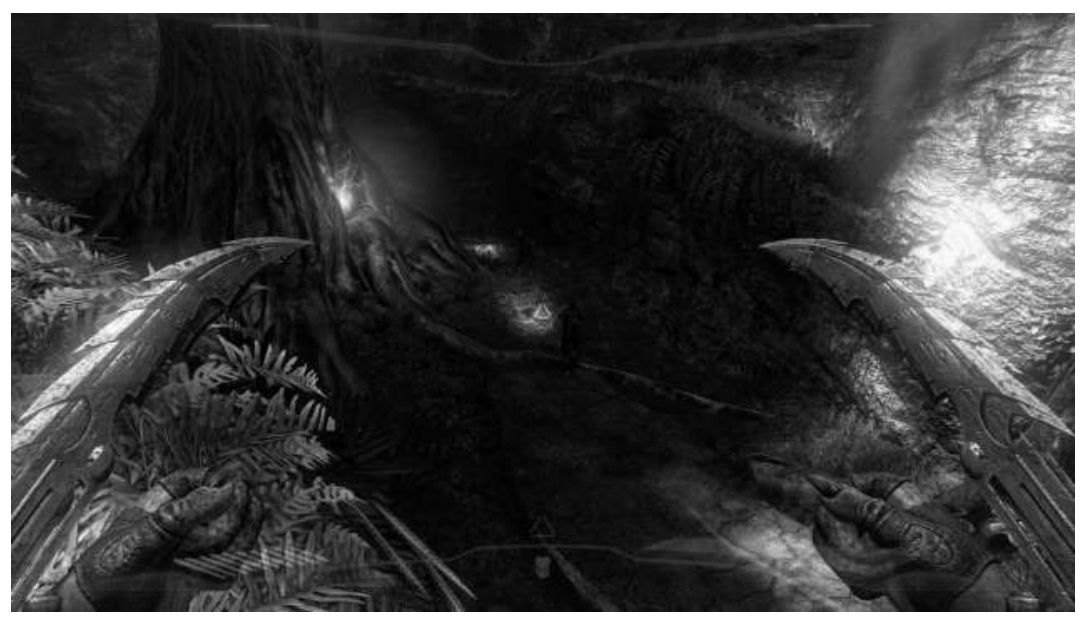

Figure 5.6 The predator sight without filters.

The game is played from Dark's perspective, with the mask covering his face, so it is difficult to separate what is his unaugmented experience and what is part of the mask's technology. However, there is one part of the game that clarifies this. Dark encounters a tomb of an ancient predator and recovers his mask. Dark removes his own mask and replaces it with the one he found. The sequence is shown from a first-person perspective, and when Dark removes his mask, the visual experience is equivalent to human vision. Therefore, it seems likely then that the predator's visual experience of the world is similar to the human experience ${ }^{8}$ (Figure 5.6). 


\section{Jonne Arjoranta}

The way the predator moves around is close to human movement. It walks and runs, but because it is much stronger, it can also jump to places not available to humans. The player can aim the jumps using a special indicator that appears when aiming them, making it clear where and how far the jump will take Dark. The game would work without the indicator as well, forcing the player to learn by trial-and-error how far Dark can jump. However, this would change the experience of playing Dark considerably. Now the jumping is deliberate as the player knows exactly where the jump will end - unless they aim the jump in haste. The indicator could be read as a representation of Dark's ability to evaluate the aim and length of his jumps. It is implicit, embodied knowledge made explicit for the player through a visual indicator.

His great strength means that Dark can also take on both humans and aliens in close combat. In fact, aliens are much less a threat to the predator than they are to humans, and even a large group of aliens can be killed with the predator's many weapons. Humans are even less of a threat. If close by, Dark can simply grab them and tear them apart. Only human technology - guns, turrets, combat androids - is a real threat to the predator.

Dark's natural abilities are enhanced by advanced technology. In addition to the vision-enhancing mask, Dark has the ability to turn transparent, almost invisible, with a technology called Cloak. When hidden in this manner, humans are unable to see him, unless he is very close to them. Dark can heal himself with a device that consists of two sets of needles that he sticks into himself, apparently hurting him because he roars in pain. The mask he wears is also able to mimic human voices, enabling him to lure unsuspecting humans away from their allies and toward their deaths. Predators are not without their own weapons technology, which combines archaic weapons with advanced energy weapons. Dark uses sharp blades worn on the wrists, a retractable spear, a self-guiding, thrown disc, mines, and a plasma weapon worn on the shoulder.

Although in some senses Dark is closer to humans than aliens, with his advanced technology and culture, the experience of playing him is probably closer to the alien. He stalks human prey, carefully waiting for opportunities to tear them apart in close combat. However, when this fails, he can fall back to using his technology. Dark is powerful, in many senses of the word. With his great physical power, he is able to jump around to areas that would be unreachable to humans. From atop high vantage points, he can survey as the humans nervously huddle together and try to guard themselves against their superior enemies.

\section{Alien Experience, Human Technology}

This chapter has highlighted the practice of synesthetic design in portraying nonhuman experiences in videogames. Humans have limited 
sensory capabilities, so things that would be hard to experience or conceptualize are instead translated into forms that are more easily grasped. Often this happens by turning other senses into visual indicators, since vision is usually so dominant in making sense of the world for humans. This might also be due to conventions within the medium even the name "videogame" refers to an experience of looking at moving pictures.

Some of the experiences that are represented visually would be hard to represent otherwise. For example, the experience of feeling what is up and what is down that is indicated by an arrow when playing Specimen 6 is hard to convey with other means. However, it seems that the game takes the easy way out in other cases. It seems, for example, that both Dark and Specimen 6 hear sounds in very similar manner than humans, even though their auditory systems are presumably very different from humans. They do make nonhuman sounds, screeching, gurgling, and clicking while hunting their way through the levels, but both their own sounds and the noises made by other beings sound the same as when playing Rookie. There is no reason the sounds experienced while playing the two alien creatures in the game had to correspond to the ones heard while playing Rookie.

While experiencing the different bodily representations of Dark and Rookie is one way Aliens vs. Predator creates the alienness of playing something nonhuman, it also requires the player to take on a very particular perspective on humans. Killing other humans in videogames is not uncommon, but hunting your own species is rarer. The antagonism between the species cannot be described as a fair fight: it is often easy to avoid the humans encountered during the game, especially when playing as Dark. The choice to kill humans is more akin to sport than to fight. This is fitting, since the predators treat it like a mixture between sport and a rite of passage.

When playing as Specimen 6, the relation is even more alien. In addition to being prey to an alien hunter, humans are also a way to procreate. If Specimen 6 grabs a non-combatant human from behind, it can hold the human in place while a small alien facehugger appears from somewhere off-screen and plants itself on the human's face. The human collapses helplessly, while the facehugger uses it as a host for breeding more aliens. Humans are not treated by Specimen 6 only as prey, but also as unwilling hosts.

While humans are reduced to the roles of prey and host, there is one factor that seems to give them a fighting chance against the physically superior aliens: technology. Using different technological apparatuses, humans are able to match the other species. Rookie is not able to physically best aliens or predators, but using his gun he can kill dozens of them during the campaign. He is almost blind in the dark, but using his flashlight, he can see. The motion sensor is also an example of this, 
allowing Rookie to sense threats around him. The motion sensor also highlights how technology becomes embodied, turning into just another way of sensing the surroundings.

Even the predators that are technologically more advanced than humans in many ways still have to be wary of human technology. Right from the beginning of the game, the autonomous turrets humans use are a threat to Dark, even when the humans themselves are not. Later in the game, Dark encounters even more advanced technological threats as Weyland-Yutani military androids try to stop him. These are human-shaped, but much more dangerous than the human enemies encountered before.

The game seems to imply that humans have an ambivalent relation to technology. Technology is what makes humans capable of meeting the other species on an even level, even when the capabilities given by nature make them weaker. But humans are also very reliant on that technology, unable to survive without it. The weapons Dark uses seem like tools for sport and ritual, and he is able to fight his enemies even without them. One of the defining weapons he uses is the set of blades attached to his forearm. Rookie, on the other hand, needs his flashlight, motion sensor, and weapons in order to have a fighting chance of surviving.

\section{Creating Alien Experiences}

It seems that while there are differences in playing the different characters in Aliens vs. Predator, there is also a lot of common ground, from the similar goal-structure to the constant fighting of similar enemies. What would a game that took into account all the embodied differences look like? Making such a game might not be easy, but at least it would pay attention to the following things:

1 The game would focus on different things when playing different characters: different things are important for bats or aliens than for humans. For example, much of Aliens vs. Predator is focused on proceeding through areas that are shut off by electronic locks. Rookie hacks these locks, while Dark and Specimen 6 bash the control panels to gain access. This is a remarkably similar way to proceed in the game despite the differences between the characters. This feels particularly artificial in Specimen 6's case: it is able to walk on walls and could presumably bypass most (but not all) obstacles by finding an alternative route.

2 Different things would be appealing or repulsive, based on the embodied experiences with these things. For example, the aliens secrete a thick resin that they use to build nests and cocoon prey. This seems repulsive to humans, but would be perfectly normal to the aliens in question. Aliens vs. Predator does use this to a great effect by 
making Rookie proceed through areas enveloped by alien cocoons, which highlights the alienness of these areas. However, that is the easiest way of using this aspect of embodiment, because it draws on our embodied experiences as humans.

3 Different things would seem dangerous, based on what kinds of things endanger the creatures. For example, the predators discussed in this chapter routinely hunt aliens, meaning that they have a very different attitude toward them than humans. The aliens are usually portrayed as afraid of fire, but this does not seem to play a large role in Aliens vs. Predator. Some of the marines encountered use flamethrowers, but they are not a particularly serious threat. Portraying emotional reactions can be difficult, since they are partially dependent on the player. However, other games deal with similar situations by, for example, making characters that are afraid less effective in combat.

4 The game would focus less on visual input in cases where other senses are more important. However, these experiences can be hard to translate to humans, which is why most games seem to translate other senses to visual indicators. This applies to senses not possessed by humans: for example, the alien light-sense in Aliens vs. Predator.

Combining these approaches would enable one to design a game that would take embodiment into account more comprehensively. However, it is possible that a game focused on conveying the embodied experience of something completely alien would not be particularly playable, since many of the compromises made in the examples discussed in this chapter are due to design choices made to allow better gameplay experiences. The fact that the examples discussed are games and not simulations intended for the purpose of simulating embodiment is important. Nonhuman experiences are, by definition, alien, which might explain why games tend to use the human experience as the norm. Alien experiences are then portrayed by slight changes in that default approach. Another reason for adopting this approach is probably related to the economics of creating entertainment products. For example, it is more cost-effective to create one set of sound effects and use them in all of the three campaigns instead of creating unique sound effects for each Dark, Specimen 6, and Rookie.

The relation of this discussion to technology merits a mention. While the alien relies on its physical abilities, both the human and predator protagonists lean heavily on their technologies. Technology enhances their senses and allows them to recover from harm and fight against enemies that would be impossible to best without their tools. This is despite the predator being physically the most powerful of all three of the characters - it would seem to need technology less than the alien.

However, it is not that straightforward to tell apart the experience of embodiment with and without technology. Technology tends to become 


\section{Jonne Arjoranta}

normalized and embodied: eyeglasses tend to become the norm for seeing after wearing them for a while, while lacking them runs counter to everyday experiences of always having them on (cf. Hirose 2002; Merleau-Ponty 2002). In games where technology plays an important role, using that technology becomes as natural as any other form of interacting with the surrounding. For example, Batman in Batman: Arkham Asylum (2009) may scale a wall and use his Detective Mode and punch enemies, with all of the modes of interaction feeling as essential to being Batman. This is as true for playing Rookie and Dark, as many of their essential abilities are based on the technologies they are using.

As the comparison to Batman shows, there is no one way of being human. Both Rookie and Batman rely on technology to solve problems and survive, but being Rookie and being Batman are very different kinds of experiences. The comparison to the other ways of being in Aliens $v s$. Predator highlights certain types of being human, which would be absent if those other ways of being were absent. The game produces a certain way of being human: uncertain, afraid, and weak, but ultimately triumphant due to technological tools - and some luck. Every danger and adversity can be overcome with perseverance. Ultimately, the game seems to carry the same kind of anthropocentrism typical to most science fiction narratives. Human may be weak and hunted, but their experiences are what matter.

\section{Notes}

1 Embodied, situated, and grounded cognition each deal with slightly different things, but for the purposes of this chapter, they are closely related. In cognitive literary studies, similar approaches are sometimes grouped together as "e-approaches", because they concern with the "enactive, embedded, embodied and extended qualities of the mind" (Kukkonen and Caracciolo 2014, 261). The rest of this chapter focuses on the idea of embodied cognition.

2 There is also a separate category of play where you play objects or things, like I am Bread (Bossa Studios 2015). I will here mostly focus on playing things that are nonhuman, but still easily recognized as intentional beings: animals, aliens, and fantasy creatures.

3 Some games intentionally aim for unnatural visual look while still portraying human experiences, usually for aesthetic reasons. For example, dys4ia (2012) uses simplified pixel-graphics and abstract shapes to illustrate the experience of going through hormone replacement therapy.

4 Another game in the franchise, Alien: Isolation (Creative Assembly 2014), also portrays aliens as deadly, perceptive, and dangerous, but this is often invalidated by events in the game where an alien fails to notice the protagonist if she is even slightly hidden. The aliens are still the most deadly thing present in the game.

5 This seems to differ from how the alien senses are represented in other media, like the movie franchise or the multiple comic books published. These media do not mention sophisticated olfactory senses, while the aliens are mentioned as being able to sense heat and have specialized hearing. I will here focus only on the Alien vs. Predator game and how it portrays things. 
6 The gender of the predator is never made explicit, but other media in the franchise portray the predator society as very sexist, with limited roles reserved for female predators. It is likely that the predator played is male.

7 Humans in other videogames regularly use similar technology to enhance their vision. For example, in Batman: Arkham Asylum (2009), Batman can use Detective Mode to see things humans normally cannot see. His senses are also enhanced by technological means, and it is portrayed in the game in a manner similar to how the predator's visual overlays work. Other games that use a mechanic similar to Batman's Detective mode include games like Assassin's Creed (Ubisoft Montreal 2007), Dishonored (Arkane Studios 2012), and Hitman: Absolution (IO Interactive 2012). In some of these games, the mechanic represents specialized training or mystical ability, not technological apparatuses.

8 There are different versions of the predator species in different media of the franchise, and how their senses are portrayed is not always consistent. The canonical version seems to be that the infrared vision is the predators' natural vision, but this does not seem to be true in the game being examined.

\section{References}

Adams, Fred. 2010. "Embodied Cognition." Phenomenology and the Cognitive Sciences 9 (4): 619-628. doi: 10.1007/s11097-010-9175-x

Allison, Fraser. 2015. "Whose Mind Is the Signal? Focalization in Video Game Narratives.” In DiGR A 2015: Diversity of Play, 1-16. Lüneburg: DiGRA.

Anderson, Michael L. 2003. "Embodied Cognition: A Field Guide.” Artificial Intelligence 149 (1): 91-130. doi: 10.1016/S0004-3702(03)00054-7

Anthropy, Anna. 2012. dys4ia. http://wizardofvore.itch.io/dys4ia.

Arkane Studios. 2012. Dishonored. Rockville, MA: Microsoft Windows, PlayStation 3, PlayStation 4, Xbox 360, Xbox One; Bethesda Softworks.

Barsalou, Lawrence W. 2008. "Grounded Cognition." Annual Review of Psychology 59 (January): 617-645. doi: 10.1146/annurev.psych.59.103006. 093639

Bossa Studios. 2015. I Am Bread. London: Microsoft Windows, OS X, PlayStation 4, iOS; Bossa Studios.

Creative Assembly. 2014. Alien: Isolation. Tokyo, Japan: Linux, Microsoft Windows, OS X, PlayStation 3, PlayStation 4, Xbox 360, Xbox One; Sega.

Gualeni, Stefano. 2015. Virtual Worlds as Philosophical Tools: How to Philosophize with a Digital Hammer. London: Palgrave Macmillan.

IO Interactive. 2012. Hitman: Absolution. Tokyo, Japan: Microsoft Windows, OS X, PlayStation 3, Xbox 360; Square Enix.

Jørgensen, Kristine. 2013. Gameworld Interfaces. Cambridge, MA: MIT Press.

Klei Entertainment. 2012. Mark of the Ninja. Xbox 360, Microsoft Windows, Linux, OS X; Microsoft Studios.

Kukkonen, Karin, and Marco Caracciolo. 2014. "Introduction: What Is the 'Second Generation?'” Style 48 (3): 261-274.

Lankoski, Petri. 2011. "Player Character Engagement in Computer Games." Games and Culture 6 (4): 291-311. doi: 10.1177/1555412010391088

Merleau-Ponty, Maurice. 2002. Phenomenology of Perception. Translated by Colin Smith. Routledge Classics. London: Routledge. 


\section{Jonne Arjoranta}

Nagel, Thomas. 1974. "What Is It Like to Be a Bat?" Philosophical Review 83 (4): 435-450. www.jstor.org/stable/2183914.

Rebellion Developments. 2010. Aliens vs. Predator. Tokyo: Microsoft Windows, PlayStation 3, Xbox 360; Sega.

Rocksteady Studios. 2009. Batman: Arkham Asylum. Wimbledon: Xbox 360, PlayStation 3, Mac OSX, Microsoft Windows; Eidos Interactive.

Technically Finished. 2009. Haerfest. Windows.

Ubisoft Montreal. 2007. Assassin's Creed. PlayStation 3, Xbox 360, Microsoft Windows; Ubisoft.

Valve Corporation. 2009. Left 4 Dead 2. Microsoft Windows, Xbox 360, OS X, Linux. Left 4 Dead. Bellevue, Washington: Valve Corporation.

Wilson, Margaret. 2002. "Six Views of Embodied Cognition." Psychonomic Bulletin \& Review 9 (4): 625-636. www.ncbi.nlm.nih.gov/pubmed/12613670. 


\title{
6 Wild Things Squeezed in the Closet
}

\author{
Monsters of Children's \\ Literature as Nonhuman \\ Others
}

\section{Marleena Mustola and Sanna Karkulehto}

It is no coincidence that monsters abound in children's literature. According to a simplistic explanation, the purpose of these raging, monstrous creatures is to help children cope with their fears and anxieties. It is worth noting, however, that the seemingly innocent children and the openly untamable, threatening monsters of children's fiction have something axiomatic in common: they are both creations of adults and, as such, different from and "other" to them. Childhood itself may be considered a social construction (e.g. Ariès 1996; Cook 2009), as adults need to see and construct children as pure, cute, and innocent (e.g. Jenkins 1998) and monsters as their polar opposites, in order to control their own ambivalent emotions toward their offspring. Likewise, the mechanism that aims to reject otherness by "taming the supposed out-ofcontrol", which is an oft-used theme in children's literature, may justify both othering and separating the self from the difference, and abjection and abuse of these others (cf. Hellstrand et al. 2018). Children - the main target audience of child-friendly, adult-created cultural artifacts, such as toys and "children's" books - are always positioned as "others" in a world where the adult perspective is the perpetual default. This inevitably brings them closer to other "others", such as monsters (cf. Kincheloe 1998).

Even if adults have mostly been reluctant to address the undeniable monstrosity and vulgarity associated with and expressed by children, there is also some thematic affinity between monsters and children. Gary Cross (2004, 12-13) and Marina Warner (1994) note that "innocence" is not a self-evident characteristic of children but, rather, the romantic creation of adults, which entails a covert demand for children to live innocent lives on behalf of those who are no longer children themselves. Even though infants in our own era are virtual objects of worship because they represent some kind of primordial innocence, for most of Western history, babies have actually represented the fall from grace. Today's unwillingness to recognize children's unpleasant or repellent 


\section{Marleena Mustola and Sanna Karkulehto}

qualities, which has been perceived to be manifested in, for example, an increasing eagerness to diagnose children's behavioral or emotional disorders and treat them with tranquilizers (e.g. Breggin 2014), leaves them adrift in adult fantasies, without a road map for maturing. This has led to the invention of the image of the "cool kid", the rebellious child who works against adult myths and fashions their own identity (Warner 1994; Cross 2004, 5-7, 124-125). Cool children and monsters, thus, share the position of independent but inescapably inferior beings that are alien to the dominant adult-centered culture.

The cultural category of monstrosity and the figure of the monster can be approached from various angles. They can be regarded, for example, as projections of the repressed facets of the self; as the unthinkable and the unnameable; as various representations and embodiments of difference; as political symbols of otherness; as metaphors of chaos and threat; and as manifestations of wildness or humans who have abdicated their humanity, such as aggressive criminals (Cohen 1996; Gilmore 2003; Asma 2009; Beville 2014). Maria Nikolajeva (2002, 38-39) sees monster characters in children's literature as alienating, because they enact the subversion of identity that is typical of postmodern aesthetics $^{1}$ (cf. Butler 1990). Maria Beville (2014, xii), for her part, describes nonhuman monsters in literature and film as unnameable and slippery, as impossible to fully explain, and thus as figures that offer humans valuable experiences of the unknown or unexpected, and difference and otherness (see also Hellstrand et al. 2018). Donna McCormack's (2018, 155 ) account goes on to make an important amendment to that of Beville: usually this otherness "comes to signify inferiority in opposition to the imagined superiority of the 'rational, autonomous, [human] subject'" (see also Shildrick 2002, 121). In the analysis that follows, we try to figure out the messy meaning-making processes that the representations of nonhuman monsters in children's literature offer. How do they, first, represent and embody contemporary (human) anxieties and deal with the unknown or unexpected that we humans face in our everyday lives? How may they even justify both othering, and abjection and abuse of others? Keeping all this in mind, we ask, second, if the monsters could also offer ways in which to explore and reconfigure the ethical relationships between humans and nonhumans.

To elaborate, this chapter examines how monsters have been used to represent inferior otherness in children's literature, and how they could be interpreted in the context of posthumanities. The otherness, wildness, and anthropomorphism of monsters allow readers to draw parallels between them and human children, which reveals the fact that both of these groups are subjected to adults' control and both are viewed as inferior to adult subjects, the self-declared representatives of human superiority, rationality, and agency. Not only will we consider how the narrative representations of the embodied similarity of monsters and 
children signify inferiority, but we will also investigate how these inform us about the apparently unethical validation of othering. Narrative fictions can open such doors by their virtue of analyzing the many unknown and unpredictable variations of otherness, including the variations of monstrosity lurking in humans themselves. Children's literature does not shy away from asking how "the monstrous is already of the self, ontologically integral to the human" - a question that implicitly calls for an ethical reconfiguration, or perhaps even the creation of new forms of ethics (McCormack 2018, 155, 157, 162).

These complicated interrelations of nonhuman monstrosity, childhood, and adulthood are central to the three children's books discussed in this chapter: Maurice Sendak's picture book Where the Wild Things Are (2013/1963), which was also made into a film in 2009 (directed by Spike Jonze), Shaun Tan's short story "Stick Figures" (in Tales of Outer Suburbia, 2009), and Tuutikki Tolonen's novel Monster Nanny (2017). This inquiry does not cover all types of monsters or all types of children's literature containing monsters; however, the three analyzed works include monsters that both represent diverse aspects of human and nonhuman monstrosity and share crucial similarities with frequent portrayals of monstrosity in children's literature. These books are popular also outside their native countries and have aimed at global coverage: Where the Wild Things Are originates from the USA, "Stick Figures" is an Australian story, and Monster Nanny was first published in Finland. ${ }^{2}$

Where the Wild Things Are (2013/1963) by Maurice Sendak was first published in 1963 and has since established itself as a classic. The story, delivered in a traditional picture book format, is about a child called Max who, due to his aggressive behavior, is sent to bed without supper. Max then imagines an entire inner journey, during which he confronts and tames his inner monsters, that is, his feelings and emotions, until in his imagination, he returns to his room where his supper is now waiting for him. As the title suggests, Shaun Tan's "Stick Figures" (in Tales of Outer Suburbia, 2009) ${ }^{3}$ is a short story about mysterious stick figure creatures who have always been a part of the suburban landscape depicted in the story. Children play with them, but also beat them, and nobody knows the reason for their existence. The origin of monsters remains a mystery also in Tuutikki Tolonen's Monster Nanny (2017), in which the children protagonists' parents are sent away for a holiday and replaced with a peculiar monster nanny. Siblings Halley, Koby, and Mimi start to investigate their hairy nanny Grah, who takes care of them and lives in the closet of their entrance hall. The mysteries of the monsters are not fully resolved in the novel, but the children are ultimately able to help them find their way back home and escape the evil witches exploiting monsters and using them as forced childcare labor. 


\section{8}

\section{Monsters as Others}

When a big, hairy creature, smelling like a musty cellar, appears behind the front door of Halley, Koby, and Mimi's house at the beginning of Monster Nanny, the children are not sure what it is. Even after they get to know their monster nanny personally, they are generally unsure of how to make sense of it or how to interpret its communication correctly. As it grunts and murrs, the children ponder: "Was it happy murring or dangerous human-eating murring? How could one tell?" (Tolonen 2017, 51). The monster nanny is - like so many other monsters - unfamiliar, strange, and alien, which is why the children resort to a science book to acquire more information about monsters. A scientist Runar Kalli, who "found a monster in the forest behind his house, coaxed it into his home, and studied it for almost two years", wrote the book 80 years ago and the children borrow it from the library (Tolonen 2017, 33). Reading a book written in human language by a human scientist is probably the most anthropocentric way to approach a nonhuman creature, which makes the difference between humans and monsters particularly visible in the book.

In some ways, the monster nanny resembles humans and other mammals considerably, and, according to the science book, it is even classifiable as half-human: it has anthropomorphic nails, four fingers, and typical herbivore teeth. Furthermore, the children assume, for example, that mosquitos must also suck the blood of the monsters - or "whatever it is that flows in the monsters' veins" (Tolonen 2017, 153). Even though there is something recognizable about them, the monsters are obviously strangers, and some of their features seem to originate from a whole different reality. When Grah first arrives in the Hellman household, for instance, it sheds some weird substance that spreads into the whole apartment. It is described almost as some kind of "mist in the air" or "darkness stuck to the walls" (Tolonen 2017, 21), but it is clearly not any kind of a substance that the children would have come in contact with before.

Tan's monsters share the category confusion with Tolonen's. Tan's monstrous creatures are stick figures who have bodies and limbs made out of sticks, and heads that resemble grass tufts. They move around, "slowly as clouds" (Tan 2009, 65). It is a total mystery how anthropomorphic they really are or if they belong to flora or fauna. The embodied difference of these creatures thus likens them to such unworthy things as garbage or dead animals in the story: "If they are standing in the middle of the street, it's easy enough to drive around them, as you would a piece of cardboard or a dead cat" (Tan 2009, 65). Tan's depiction implies that no matter how confusing the monsters are, they are no different from dead animals left on the side of the road, or cardboard - other objects and beings that humans might not see, recognize, or even want to know 
anything about. Since the stick figures represent yet another species that humans dissociate themselves from, Tan's short story quite indisputably designates the cultural and societal status of nonhuman otherness as something worthless (cf. Beville 2014, xi).

In contrast to Tan's story, Tolonen's monster nannies are treated differently: even if strange and mysterious, they still are half-humans, whereas Tan's stick figures are impossible even to categorize. Moreover, the human characters of Monster Nanny are sincere in their attempts to interpret and understand the monsters to the best of their abilities and to fabricate at least some kind of a meaning for their existence. The children discover that the monsters have been brought to the neighborhood homes as slave labor, apparently by three witchy-looking ladies. According to the ladies, they are merely executing a "secret special experiment in which [they] are researching new options for child care work" (Tolonen 2017, 6), but the children seem to know better: the monsters are kept in human habitations against their own will. In their role as researchers and experimenters, the witches are positioned as Frankensteinian characters - as unethical superiors exploiting a nonhuman species. It is not completely certain whether the witches belong to the category of human beings either, which associates the inhumane and exploitative treatment of otherness with other nonhuman characters. That being said, the same Frankensteinian interest has clearly motivated Runar Kalli, the scientist who has examined a monster in his house for two years, and it is worth asking if the end justifies the means or only questions human experiments with nonhumans, such as nonhuman animals, in the first place. The question is only highlighted, while Grah the monster obediently prepares breakfast and uses a washing machine, despite the science book's statement that "regular human work would be alien to [the monster's] free, wild nature" (Tolonen 2017, 207).

In Tan's "Stick Figures", the monsters are generally ignored by humans. The adults either do not notice them or try to keep them away from the yard by turning on the sprinklers and playing loud music. Children are more curious, however: they sometimes dress the stick figures in old clothes and hats, as if playing with dolls or decorating scarecrows. The adults reproach the children and prohibit such behavior but, crucially, give no reason for this rule: “Just don't,' they say sternly" (Tan 2009, 65). The reader is positioned asymmetrically with respect to the fictional adults who leave both the fictional children and the actual readers to wonder at the reasons behind the compulsion. The adult authorities may guide the children because they want them to behave ethically - to give stick figures some personal space - but they may as well instruct them just to bypass and neglect the wooden creatures as well as the entire environment they evidently are all part of.

The otherness of the monsters also frightens some of the human characters, and sometimes this fear escalates into violence and aggression. 
In Tolonen's book, Bathrobe, another nonhuman character who only comes alive in the company of select children, explains this by saying that humans are afraid of monsters, and, because of their fear, "people usually start to tease and bully anybody who is different" (Tolonen 2017, 201). Perhaps there is a reason for Tolonen's monster nanny to live in a closet and a Bathrobe, one of the most intimate pieces of human garment, to explain about the human fear of difference. Even if the idea of the monster, a justifiable allegory of difference and otherness, and "a figure who signifies selves and ways of living the world cannot 'bear to see" (Holman Jones and Harris 2016; cf. Butler 2014, 41), thus hiding in the closet, may have but little to do with sexual difference - or queerness - in children's literature, the significance of closets in Monster Nanny is well worth a thought. Resonances between monstrosity, otherness, sexual difference, and queerness have been more or less axiomatic in the history of Western or Eurocentric culture (e.g. Halberstam 1995; Benshoff 1997; Holman Jones and Harris 2016; Precup 2017), and undoubtedly the restraints of heteronormativity are at play in children's lives in the contemporary culture as well. According to Henry Jenkins (1998), it is the very myth of childhood innocence that naturalizes heteronormativity, and according to a classic thought of Eve Kosofsky Sedgwick (1990), heteronormativity relies on the "epistemology of the closet", meaning that gender and sexual difference are often suppressed by culturally dominant acts of control, denial, and concealment, all of which can be considered forms of symbolic, gendering violence in culture and society (Bourdieu and Wacquant 1992, 170; Weininger 2005, 138; Butler 2015, 34, 59). This Sedgwickian context raises a question then of how we should read and interpret a monster character of a children's book who stays in a closet:

The monster squeezed into the closet. The closet was quite narrow. To fit in it, the monster had to stand straight with its arms tightly at its sides, but it didn't seem bothered by the lack of room. The monster growled contentedly.

(Tolonen 2017, 13)

We suggest that if the monster squeezed in the closet could be examined in the light of monster theory, it could also be scrutinized in the framework of queer theory. Both theories, or rather methodologies, engage critically with discourses on the strange, the weird, and the "other" and aim at

thinking otherwise about the interconnections between the production of knowledge, the disciplining and creation of bodies and subjectivities, and the lives that are at stake whenever one attempts to draw a distinguishing line between the inside and the outside, self and other.

(Hellstrand et al. 2018; Karkulehto 2010; 2012) 
This interrelatedness reveals, first, that not only the disciplining of monstrosity or queerness - that is, everything that does not "stand straight" (Tolonen 2017, 13) - but also of all kinds of marks or signs of differences and otherness are, even if inherent in all humans, often disciplined or controlled, or even in a prohibited or closeted form. Second, the novel shows how the monster has to "stand straight" in order to fit into the closet, having no room around him/her for any natural movement. Yet Grah accepts this controlling cultural demand for confinement and "straightness" "contentedly". This image of a monster growling complacently in its tight closet space invokes the forced cultural assimilation that many minority groups - not only gender and sexual but also ethnic and religious minorities and, for example, indigenous people - have been subjected to, solely because of the differences they embody. Associations with the tragic, violent human history of colonialism and its severe consequences are difficult to avoid: imagining the monster purring in its little cell is eerily reminiscent of the imaginary figure of a "happy slave" and phenomena like the "Uncle Tom syndrome". However, no matter how tightly the monster is squeezed into the closet, there is still, undeniably, a monster in the closet; no matter how much symbolic denial and concealment we practice, the closets of human history are still packed with violence against otherness, all caused by the fear of difference.

An analogous fear of difference leads to physical violence in Tan's story. Boys beat the stick figures with "baseball bats, golf clubs, or whatever they have at hand, sometimes including the victim's own, snappedoff limb[s]" (Tan 2009, 66). Initially, the boys find this activity fun, and it goes on for hours, until it finally ceases to be entertaining: "It becomes boring, somehow enraging, the way they just stand there and take it. What are they? Why are they here? What do they want? Whack! Whack! Whack!" (Tan 2009, 67). This unprovoked violence toward the stick figures, who do not even defend themselves in any way but just take the beating, exemplifies the processes of the fear of difference, the dehumanization of otherness, and the consequent violence, which together expose the hidden monstrosity of humans themselves. As wooden creatures, the stick figures are also closely associated with nature, which reminds about the monstrous human abuse of nonhuman natural environments.

The constructed binaries that divide humans from the "other" position monsters at the margins reserved for the repressed, the abject, and the uncanny (Beville 2014, 1). The vulnerable position the monsters have is only partly shared by the children in these fictional works. The minors are, like monsters, dependent on the adult humans' authority and arbitrariness, and they are at risk of being bypassed or neglected by their parents. The Hellman kids are left alone for days in Monster Nanny because their mother simply decides to leave for a special holiday she has won and their father's return flight is late from a business trip. In Where the Wild Things Are, Max is instructed to stay in his room 


\section{Marleena Mustola and Sanna Karkulebto}

without supper, and the kids in the suburban neighborhood are told to behave as the adults command. Nevertheless, the fictional children, at least in these books, evidently have a more secure position compared to that of monsters, since they can mainly rely on adults' care and assistance. However, even if they are not violently beaten, used as free labor, or stuck in the dusty closet like the monsters, the adults seem to have ambivalent feelings toward their children: they are tired and angry with them, and from time to time, they find them a burden rather than, for example, symbols of innocence. This pushes the children to act independently and develop emotionally and intellectually on their own (cf. Warner 1994; Cross 2004, 5-7, 124-125), which, in a way, tears them more apart from their parents and brings them closer to the monsters and the alien otherness they represent.

It has been argued that the acknowledged independence and otherness of children and childhood grants children at least some weight and visibility in various political and ethical spheres, and this acknowledgment helps us to consider otherness a meaningful ethical construction (Jones 2008, 197). According to Owain Jones (2008, 197), otherness is not only healthy for children and for child-adult relationships but essential to what children are. By the same token, this otherness is also essential to what adults are, and even essential to what humans are, in relation to the nonhuman others - and monsters or, what we regard as monstrous in particular. In this way, the monster narratives in children's literature may persuade us to rethink or even reconfigure what it means to live with otherness, difference, and monstrosity (cf. McCormack 2018, 161), and how to perceive and manage the otherness, difference, and monstrosity in ourselves.

\section{Wild, Animalized, Nonhuman Monsters}

"Let the wild rumpus start", Max declares once he has learned how to control the monsters that represent his own unruly emotions in Sendak's Where the Wild Things Are $(2013,22)$. Even though the monsters are essentially wild, he can confront them and even romp with them safely after he has tamed and understood them. The wildness of monsters connects them to wild nature and untamed nonhuman animals, while differentiating them from the "civilized" human culture. This dualistic divide between nature and culture, where the latter covers humans and human artifacts, and the former all the other external environments and beings (Haila 2000, 155; Åsberg and Braidotti 2018), is one of the most central conceptual human constructions that posthumanist thinking aims to challenge. In her seminal "Cyborg Manifesto" $(2000),{ }^{4}$ Donna Haraway addresses this leaky distinction by imagining a cyborg: an ironic political myth, a feminist figure, and a critter that is not unequivocally a human, an animal, or a machine but a tangled combination of them all. 
This binary nature-culture divide is visually played with in Where the Wild Things Are: the monsters look like hybrids; one has a head of an eagle, a body of a chicken, and legs of a bear; another has a head of a bull, a body of a wolf, and legs of a human. All of them have sharp teeth and claws. The hybridity of these figures indicates that the separation between different species, such as humans and other animals, should not be taken as fundamentally as it might appear in the humanist discourses of the book's time of publication. In Tolonen's Monster Nanny (2017, 47, 73, 76, 102-103, 132), the monsters are reported to look "like a pig", "like a moth, "like a hairy caterpillar", or "like a giant teddy bear", and they roar "like a lion", murr "like a large cat", or roll their eyes "like goldfish in a glass bowl". In the science book that the children study, a monster is characterized as a "peaceful humanoid animal, if not half-human" (Tolonen 2017, 102). Thus, even though the monsters are explicitly animalized and animal-like, they are also hybrid humans or even machine-like, which suggests that the nature-culture divide cannot be maintained or credibly justified.

In Tan's short story, the monsters incorporate features of humans, animals, and plants. Nonetheless, "they are not a problem, just another part of the suburban landscape" (Tan 2009, 65). The violence that the human characters direct against the stick figures brings forth the devastating actions humans direct against many kinds of others, including nonhuman animals and other aspects of the natural environment. This kind of violence that indiscriminately targets anything and everything nonhuman has a long history but has been forcefully articulated in literature since the notion of the turn to the era of the Anthropocene. As Adam Trexler $(2015,223)$ points out, before the turn of the millennium, climate change was considered mainly a sensational topic for science fiction, apocalyptic narratives, ecological thrillers, and dystopias. Only now that the scientific consensus concerning the destructive impact of human actions on the Earth system has grown stronger, other literary approaches have become possible as well (ibid.).

These new approaches include starkly realistic or dystopian portrayals of the destruction that humans cause to other entities and beings, and Tan's short story, with its quietly suffering stick figures, could be counted among them. Their lithe, vulnerable bodies remain "passively upright until smashed to splinters between heels and asphalt", and the only response to such human violence is "the sound of the dead branches falling from old trees on windless evenings, and random holes appearing in front lawns, dark sockets where clods of earth have been removed during the night" (Tan 2009, 66, 68). The narration in these passages is mysterious and oddly threatening, as if some bigger retaliation or retribution would wait just around the corner. Alternatively, perhaps the ominous tone is only meant to help the reader to grasp, in an affective way, the inequality caused by human behavior and their cruelty against 


\section{4}

nonhuman otherness. At the same time, the violence and cruelty are directed to hybrid figures representing humans themselves, which portrays a disturbing image of humans' fundamental self-destruction.

Humans' wounding of nature and nonhuman animals is also criticized in Tolonen's Monster Nanny. The aforementioned science book that the children constantly rely on in their quest to know more about the monsters speculates:

Would it be possible for us humans to live peaceful and mutually respectful lives alongside monsters? Or would we attempt to harness these gentle, strong beings as mere work animals to do our heaviest jobs? Regrettably often, human nature is far from humane.

(Tolonen 2017, 106)

Later, Koby reads more about monsters' anthropomorphic habits and finds out that "[they] would hardly choose to coexist with humans. The disparity between the two species is too great. An equal environment would not be possible" (Tolonen 2017, 207). This extract epitomizes, and admits, the exploitative history of the human species: we have always exploited each other, tortured, killed, and eaten others, as well as destroyed and enslaved anything and everything. Why would it be any different with the monsters? Tolonen's novel thus emphasizes, in an honest but child-friendly way, that the idea of human supremacy is deeply problematic, as it creates a constraining distinction between humans and the others, while simultaneously justifying human cruelty against others by depicting humans as more "valuable" than others.

Since monstrosity is also closely intertwined with wildness, one may be tempted to ask whether monsters could or should be tamed somehow, and how ethical such an approach would be. Furthermore, in the context of children's literature, this evokes the parallel question, whether children could or should be tamed as well, seeing that childhood is also regarded as a "wild" and "natural" state. After all, it is only through prolonged socialization and education that children are assumedly cultivated into full members of the "civilized" human culture and adulthood (Jenkins 1998). Where the Wild Things Are thematizes this cultivation process through Max's relation to and eventual mastery of his inner monsters. At the beginning of the story, his mom calls him a "[w]ild thing" (Sendak 2013, 5), but Max evolves as the story progresses, and toward the end, he acts in a distinctly more civilized manner, being in control of his turbulent emotions. Moreover, this civilizational and educational "progress" is visually intertwined with nonhuman animality: on the first page, Max is wearing his wolf costume, and on the last pages, he removes it. He is no longer a wild animal with inner monsters but a well-behaved, "proper" human subject.

The beasts of Monster Nanny represent more complex cases, as when the story begins, the monster nannies have already been tamed, enslaved, 
and assimilated into human habitats. Similarly, the children of Tolonen's book have already been tamed, as they are obviously well-educated and good-mannered little creatures. Halley, Koby, and Mimi seem to be very happy about their own status and position as (tamed) children, although this happiness suffers a crack when they learn - thanks to their ability to read, seek, and critically evaluate information - that monsters are miserable when being used as unpaid labor under human discipline and control. The children discover that the monsters' natural habitat is the forest, and that without their natural diet of rotten leaves, monsters' fur will grow thinner and their lives become joyless. This prompts the children to take their monster nanny Grah to the nearby forest, where it rolls and trashes around in rotten leaves, noticeably happily, and not only "contentedly". Afterward, the monster looks "magnificent and powerful", "as if it had grown in height and girth" (Tolonen 2017, 62). The monsters of Monster Nanny most likely need to be in touch with their animality, wildness, and natural habitat, or otherwise they will suffer.

This question about the taming of (inner) monsters seems to be interconnected with the question of whether or not humans themselves are happier when they tame and repress their own animality and wildness. Is the civilization that humans have created for themselves truly their natural habitat, and, if not, can any civilized human really claim to be more than merely contented? John Weaver $(2015,186-187)$ theorizes that civilization and culture are two different kinds of forces: civilization seeks morality and rationality, while culture is tasked with finding limits in order to create something novel and different. He also implodes the distinction between human culture and animality by stating that human animality is human culture. Human memory has simultaneously created civilization and forgotten about humans' creative animality, but "through human memory and animal forgetfulness, our cultivation begins" (Weaver 2015, 186). However, since the institutions that produce civilization, especially the educational system, aspire to create obedient citizens, they are in danger of the "fetishizing of 'becoming human"” (Pedersen 2015, 57).

While humans try to tame their offspring and other species in their surroundings, in order to cultivate them and to enhance life on planet Earth with diverse and often contradictory actions, the binary constructions nonhuman and human, nature and culture, child and adult - act as justifying mindsets, for better or worse. Our everyday lives are crowded with children and other others, such as pets, who constantly fail to fulfill human adults' expectations to abandon their wildness and become tame. At the same time, children's literature is crowded with child protagonists who choose to rebel against these oppressive expectations: J. M. Barrie's Peter Pan, Rudyard Kipling's Mowgli, and Astrid Lindgren's Pippi Longstocking are all examples of fictional characters ${ }^{5}$ who "reveal the depth of adult investment in a utopian childhood state" (Warner 1994). Real children, like fictional ones, have the power to subvert cultural norms, 


\section{6}

especially those associated with the myth of innocent childhood (Jenkins 1998), simply by being normal children who cannot fulfill adults' unrealistic expectations. As Marina Warner (1994) puts it, "our children can't be better than we are". ${ }^{6}$

\section{Inner Monsters}

Despite their wild and animalized features, the monsters in the three books studied in this chapter, and beyond, are also anthropomorphic. Sometimes their monstrosity is clearly positioned as a part of humanity. Where the Wild Things Are, for instance, is built around an idea of children's inner monsters, which corresponds well to the traditional assumption that children's literature ought to offer resources for their readers' psychological development. According to Bruno Bettelheim (1979, $145,191)$, fairy tales do not even attempt to describe the outer (physical) reality; instead, they aim to offer children a better understanding of their inner lives and help them resolve their psychological difficulties. This argument is made especially concrete by the otherness of the monster character called the Groke, who appears in Tove Jansson's famed Moomin stories. The Groke may exude a certain amount of existential horror, but her inclusion in the stories serves a psychological and an educational purpose, as her character presents the reader with poignant, relatable themes of loneliness and alienation (Ylönen 2014, 228, 233). Similarly, the monster nanny in Tolonen's Monster Nanny may be a horrific other, but its half-humanity can be read as a metaphor for humans' monstrous qualities and inner battles. As a result, the monster nanny also becomes a symbol for "the changing relationships between the human and nonhuman, culture and nature, technology and the body, and Other and Self” (Åsberg and Braidotti 2018, 11). In other words, it embodies the Harawayan "processes of becoming with all that is other-than-human" (Koistinen and Karkulehto 2018).

As humans empathize with monsters or identify with them, even in the context of fictional narratives, the boundaries between the two categories are momentarily shaken. In Monster Nanny, the youngest child, Mimi, is especially good at understanding their beastly, hairy caretaker. While her siblings are terrified of the huge "hairy cigar" that appears at their front door, Mimi simply observes: "It's not dangerous. [...] Look at its eyes. It wants to stay here" (Tolonen 2017, 12-13). The six-yearold Mimi as the character that understands the monster the best is an easy choice, as smaller children typically have to rely more on nonverbal communication than spoken, "civilized" human language. When Mimi's father wants to know how Mimi is able to understand Grah, she gives him a surprised look and says: "Just normally. [...] In the same way as one understands anybody. Just like I understand you" (Tolonen 2017, 256). The response suggests that the perpetual binaries and the 
stark pragmatic and conceptual separation of different beings are actually learned, man-made constructions of adults. Children, by contrast, are represented as the ones who are more in touch with the natural, plain mutuality, and the feeling of togetherness that encompasses all creatures, which resonates well with the myth of innocent childhood.

In summary, the anthropomorphism of the storybook monsters as well as the monstrosity of the human characters in these narratives can lead the readers to question the deep-ingrained human/other distinction and encourage them to face their own inner monstrosity. In Monster Nanny, the human characters make a crucial discovery: "now that the monster was in sight again, it was much more difficult to forget it" (Tolonen 2017, 29). The increased visibility of humans' inner conflicts and an insistent feeling of otherness leave no other choice but to face them with courage or to repress them - to squeeze them in the closet. The narrative representations of monsters thus serve the same general function as the fictional monsters in Tolonen's novel do: they lure us into seeing them and facing them. In Where the Wild Things Are, Max boldly confronts his inner challenges, and his process of gaining control over his feelings is described in a way that really emphasizes the pluck it takes to examine oneself realistically and without fear:

And when $[\mathrm{Max}]$ came to the place where the wild things are they roared their terrible roars and gnashed their terrible teeth / and rolled their terrible eyes and showed their terrible claws / till Max said 'BE STILL!' and tamed them with the magic trick / of staring into all their yellow eyes without blinking once and they were frightened and called him the most wild thing of all / and made him king of all wild things.

(Sendak 2013, 17-21)

There is, however, a mystery at the heart of this citation that seems to also be at the heart of all humans' inner battles: the emotion-monsters may be successfully tamed, but only with the help of a "magic trick". This gives the readers little applicable advice on how to actually cope with difficult emotions.

Even as the nonhuman monsters are construed as others, they are also (inner) companions, and their human "hosts" may have grown quite attached to or even fond of them. For instance, once Max starts to miss his mom and feel homesick, he decides to leave the place where the wild things are but faces some unexpected resistance: "But the wild things cried, 'Oh please don't go - we'll eat you up - we love you so!” (Sendak 2013,31 . The monsters' reaction to the abandonment is quite forceful, and it reflects the paradoxicality of human emotions: the distinction between love and hate is vague and flickering. Moreover, the monsters' words echo Max's own words from the beginning of the book, where he 


\section{Marleena Mustola and Sanna Karkulebto}

cites the same angry threat - "I'll eat you up" (Sendak 2013, 5) - to his mother, even though he clearly loves her. In Tolonen's novel, the children feel affection toward their familial monster, as evidenced by the sorrow they feel after they have managed to help Grah and the other monster nannies to finally get back home: "Halley felt tears rolling down her cheeks. She felt lost with the monsters gone. Like something essential had disappeared" (Tolonen 2017, 298). Others are not always others, after all; they may just as well be fundamental, although unrecognized, parts of our lives, or even parts of ourselves.

This internalization of the monstrous can make it especially frightening, although also especially powerful in other ways. Monsters do not simply signify oppositional others that are safely fenced off within their own boundaries. Instead, they act as the harbingers of the otherness of possible worlds or of possible, if as yet unrealized, versions of ourselves (Shildrick 2002, 129, 2018). As such, they force us to look at others and otherness from a different angle but also invite us to reconfigure ourselves - to tune into the alien and the strange within us. The stick figure monsters in Tan's short story, for example, prompt the people around them to guess at or create meanings for their existence, which eventually leads them to ask questions about themselves:

if you stop and stare at them for a long time, you can imagine that they too might be searching for answers, for some kind of meaning. It's as if they take all our questions and offer them straight back: Who are you? Why are you here? What do you want?

$(\operatorname{Tan} 2009,69)$

This existential questioning triggered by an encounter with nonhuman otherness can easily spread to the readers as well, guiding them to reconsider the essence and meaning of humans and nonhumans. These questions, in turn, evoke further questions about how we could reconfigure the current world, which has already entered the era of the Anthropocene, so that it reflects true humanity as well as includes nonhuman others in the sphere of ethical consideration and - cohabitation.

As Zoe Jaques $(2015,5)$ remarks, children's fiction can make sophisticated, albeit often overlooked, interventions into the ongoing debates on being human and nonhuman, and maybe even posthuman. Indeed, children's literature features interesting discussions about the ethical qualities and the cultural signification processes permeating humans' relationships with other creatures. All in all, this genre offers wads of intriguing, underutilized material for examining the construction of nonhuman otherness and its complex interconnectedness with the othered groups that have been established inside humanity itself, including children. Sendak's, Tan's, and Tolonen's works show how the distinctions between humans and nonhumans are, on the one hand, artificially 
produced, and how they could thus, on the other hand, be purposefully reconfigured. In the end, monsters seem to exist anywhere: outside of us, inside of us, and everywhere in between.

\section{Notes}

1 In traditional fiction, child and adult readers are usually expected to identify and empathize with at least one character, while in postmodern aesthetics, the reader might be detached from characters by making them repulsive: physically unattractive, morally depraved, or alien (Nikolajeva 2002, 38-39).

2 Even though Sendak's and Tan's works rely heavily on pictures, we will focus mainly on their textual elements in our analysis.

3 Despite the fact that most of Tan's award-winning stories feature child or monster protagonists, some critics have debated whether his works should be categorized as children's literature at all (see Banerjee 2013), whereas others consider him to be one of the world's most important children's authors who has transformed the entire genre with his works (see Kite 2016).

4 "A Manifesto for cyborgs: Science, technology, and socialist feminism in the 1980s" was originally published in Socialist Review 80 (1985), 65-108.

5 Not all of these characters are rebels in the same way. For instance, Peter Pan rebels against growing up, while Pippi Longstocking rebels against the expectation of being a vulnerable, dependent girl. Peter and Mowgli act as affirmation of the utopian state of childhood, while Pippi fights against it.

6 Keeping this in mind, it should be mentioned, however, that the idea of the adults giving up in their aspirations and fetishizing wild, untamed children and animals also seems quite irresponsible and destructive.

\section{References}

Ariès, Philippe. 1996. Centuries of Childhood. Translated from French by Robert Baldick. First published in 1960. London: Pimlico.

Åsberg, Cecilia, and Rosi Braidotti. 2018. "Feminist Posthumanities: An Introduction." In A Feminist Companion to the Posthumanities, edited by Cecilia Åsberg, and Rosi Braidotti, 1-22. Cham: Springer.

Asma, Stephen T. 2009. On Monsters: An Unnatural History of Our Worst Fears. Oxford: Oxford University Press.

Banerjee, Bidisha. 2013. "Utopian Transformations in the Contact Zone: A Posthuman, Postcolonial Reading of Shaun Tan and John Marsden's The Rabbits." Global Studies of Childhood 3 (4): 418-426.

Benshoff, Harry M. 1997. Monsters in the Closet: Homosexuality and the Horror Film. Manchester University Press.

Bettelheim, Bruno. 1979. The Uses of Enchantment: The Meaning and Importance of Fairy Tales. Harmondsworth: Penguin Books.

Beville, Maria. 2014. The Unnameable Monster in Literature and Film. London and New York: Routledge.

Bourdieu, Pierre, and Loïc J. D. Wacquant. 1992. An Invitation to Reflexive Sociology. Chicago, IL: University Of Chicago Press.

Breggin, Peter R. 2014. "The Rights of Children and Parents In Regard to Children Receiving Psychiatric Diagnoses and Drugs." Children \& Society 28, 231-241. doi: 10.1111/chso.12049 
Butler, Judith. 2014. "Afterword. Animating Autobiography: Barbara Johnson and Mary Shelley's Monster." In A Life with Mary Shelley, edited by B. Johnson, 37-50. Palo Alto, CA: Stanford University Press.

- 2015. Notes Toward a Performative Theory of Assembly. Cambridge and London: Harvard University Press.

Cohen, Jeffrey Jerome. 1996. "Monster Culture (Seven Theses).” In Monster Theory: Reading Culture, edited by Jeffrey Jerome Cohen, 3-25. Minneapolis and London: University of Minnesota Press.

Cook, Daniel Thomas. 2009. "When Child is not a Child, and Other Conceptual Hazards of Childhood Studies." Editorial. Childhood 16 (1): 5-10.

Cross, Gary. 2004. The Cute and The Cool: Wondrous Innocence and Modern American Children's Culture. Oxford: Oxford University Press.

Gilmore, David D. 2003. Monsters: Evil Beings, Mythical Beasts, and All Manners of Imaginary Terrors. Philadelphia: University of Pennsylvania Press.

Haila, Yrjö. 2000. "Beyond the Nature-Culture Dualism." Biology and Philosophy 15: 155-175.

Halberstam, Judith. 1995. Skin Shows: Gothic Horror and the Technology of Monsters. Durham, NC: Duke University Press.

Haraway, Donna. 2000. “A Cyborg Manifesto: Science, Technology and SocialistFeminism in the Late Twentieth Century." In The Cyberculture Reader, edited by David Bell, and Barbara M. Kennedy, 291-324. London and New York: Routledge.

Hellstrand, Ingvil, Line Henriksen, Aino-Kaisa Koistinen, Donna McCormack, and Sara Orning. 2018. "Promises, Monsters and Methodologies: The Ethics, Politics and Poetics of the Monstrous." Somatechnics 8 (2): 143-162. www. euppublishing.com/doi/full/10.3366/soma.2018.0247.

Holman Jones, Stacy, and Anne Harris. 2016. "Monsters, Desire and the Creative Queer Body.” Continuum: Journal of Media \& Cultural Studies 30 (5): 518-530. doi: 10.1080/10304312.2016.1210748

Jaques, Zoe. 2015. Children's Literature and the Posthuman: Animal, Environment, Cyborg. New York: Routledge.

Jenkins, Henry. 1998. "Introduction: Childhood Innocence and Other Modern Myths.” In The Children's Culture Reader, edited by Henry Jenkins, 1-40. New York: New York University Press.

Jones, Owain. 2008. “True Geography [] quickly forgotten, giving away to an adult-imagined universe': Approaching the Otherness of Childhood." Children's Geographies 6 (2): 195-212.

Karkulehto, Sanna. 2010. “The 'Greatest Finn' Meets the 'Gay Marshal': Foucault's Cycle, National Narratives and The Butterfly of the Urals." Journal of Scandinavian Cinema 1 (2): 177-197. doi: 10.1386/jsca.1.2.177_1

- 2012. "Genres and Genders In-Between: Genre and Gender Hybridity, and Pirkko Saisio's Novel Punainen erokirja." NORA - Nordic Journal of Feminist and Gender Research 20 (3): 199-214. doi: 10.1080/08038740. 2012.700948

Kincheloe, Joe L. 1998. "Home Alone As a Way of Life.” In The Children's Culture Reader, edited by Henry Jenkins, 159-177. New York: New York University Press.

Kite, Lorien. 2016. "How Shaun Tan Transformed Children's Literature." Financial Times August 19, 2016. www.ft.com/content/b60e8c32-64cb-11e6-a08ac7ac04ef00aa. 
Koistinen, Aino-Kaisa, and Sanna Karkulehto. 2018. "Posthuman(ist) Feminism, Feminist Posthumanities.” Genealogy of the Posthuman. http://critical posthumanism.net/genealogy/feminism/.

McCormack, Donna. 2018. "Queer Disability, Postcolonial Feminism and the Monsters of Evolution." In A Feminist Companion to the Posthumanities, edited by Cecilia Åsberg, and Rosi Braidotti, 153-164. Cham: Springer.

Nikolajeva, Maria. 2002. The Rhetoric of Character in Children's Literature. Lanham, MA and Oxford: The Scarecrow Press.

Pedersen, Helena. 2015. "Education Policy Making for Social Change: A Posthuman Intervention." In Posthumanism and Educational Research, edited by Nathan Snaza, and John A. Weaver, 56-75. New York: Routledge.

Precup, Mihaela. 2017. “To 'All the Monster Girls': Violence and Non-normativity in Noelle Stevenson's Nimona." Journal of Graphic Novels and Comics 8 (6): 550-559. doi: 10.1080/21504857.2017.1361457

Sedgwick, E. K. 1990. Epistemology of the Closet. Berkeley: University of California Press.

Sendak, Maurice. 2013/1963. Where the Wild Things Are. London: Red Fox.

Shildrick, Margrit. 2002. Embodying the Monster. Encounters with the Vulnerable Self. London: Sage.

- 2018. "Re/membering the Body." In A Feminist Companion to the Posthumanities, edited by Cecilia Åsberg, and Rosi Braidotti, 165-174. Cham: Springer.

Tan, Shaun. 2009. Tales from Outer Suburbia. London: Templar publishing.

Tolonen, Tuutikki. 2017. Monster Nanny. Illustrated by Pasi Pitkänen. Translated by Annika Silver. Original Edition Mörkövahti Published in Finnish by Tammi Publishers in 2015. New York: Houghton Mifflin Harcourt.

Trexler, Adam. 2015. Anthropocene Fictions: The Novel in a Time of Climate Change. Charlottesville, VA: University of Virginia Press.

Warner, Marina. 1994. "Lecture 3: Little Angels, Little Devils: Keeping Children Innocent." In Reith Lectures 1994: Managing Monsters. Transmission 9 February 1994 - BBC Radio 4.

Weaver, John A. 2015. "To What Future Do the Posthuman and Posthumanism (Re)Turn Us; Meanwhile How Do I Tame the Lingering Effects of Humanism?" In Posthumanism and Educational Research, edited by Nathan Snaza, and John A. Weaver, 182-194. London and New York: Routledge.

Ylönen, Susanne. 2014. “'Meidän maailmamme möröt ovat sisäpuolella': Muuminologian vaikutus lastenkirjallisuuden eksistentiaalisten kauhujen arvottamiseen." In Lastenkirja.Nyt, edited by Marleena Mustola, 217-240. Helsinki: SKS. 

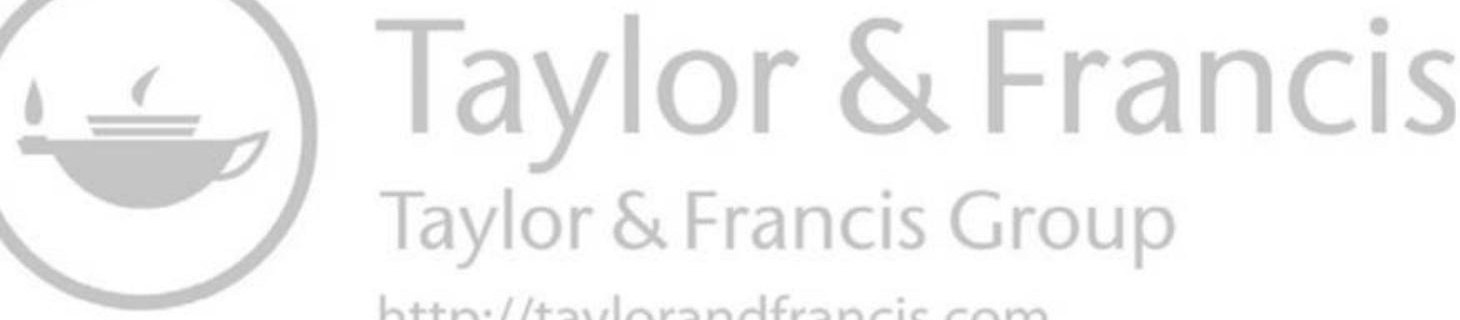
http://taylorandfrancis.com 


\section{Part 3}

\section{Becoming with Animals}



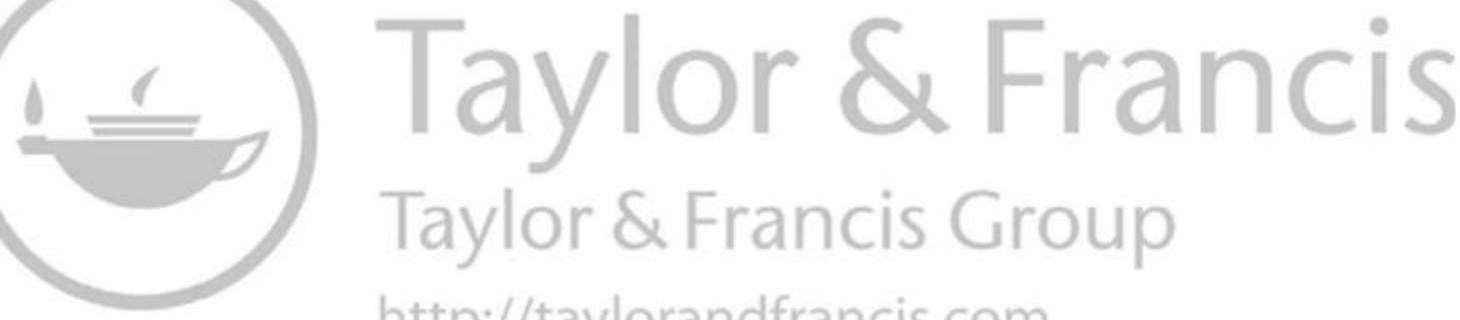
http://taylorandfrancis.com 


\section{Dead Dog Talking \\ Posthumous, Preposthumous, and Preposterous Canine Narration in Charles Siebert's Angus}

\section{Mikko Keskinen}

Talking, and narrating, dogs run more or less cynically through Western literature, from Lucian via Miguel de Cervantes to Franz Kafka, Virginia Woolf, and Thomas Pynchon. The talking canine forms a veritable literary tradition, thus familiarizing the seeming strangeness of this wildly unnatural phenomenon by making it a nearly domesticated literary trope. There is, however, a more extreme subset in the long line of loquacious canines: the supernatural case of the talking dead dog. This chapter probes the narrational peculiarities of posthumous canines' tales by reading Charles Siebert's novel Angus (2000). A talking dead dog doubly violates the usual state of affairs; unlike actual humans, dogs never really possess the ability to speak or narrate, and unlike human characters, dead dogs rarely make posthumous (ghostly or zombie) appearances in literature. In Siebert, the situation is even more preposterous, for Angus - the narrating dog - occupies, like the proverbial Schrödinger's cat, an ambiguous space between life and death. ${ }^{1}$

If we are to believe our ears, dogs do talk. A YouTube search on "talking dogs" yields some 9,590,000 videos featuring loquacious or at least noisy man's best friends engaging in what is commonly regarded as a distinctively human ability. If we doubt our ears or the auditory reliability of pet lovers' cute footage, we can turn to the abundant literature on the spoken or linguistic skills of dogs, ranging from zoosemiotics to popular pet guides, to assure faith in canid communication. Titles such as Tail Talk: Understanding the Secret Language of Dogs (2007), Dog Language (1997), If Dogs Could Talk: Exploring the Canine Mind (2005), The Rosetta Bone: The Key to Communication between Humans and Canines (2004), and Tales from the Dog Listener (2006) are by no means uncommon on the market. ${ }^{2}$

As most of these titles indicate, dog talk and talking dogs hinge on the metaphor of human speech or, more generally, on the anthropomorphization of speechless animals. But dogs are by no means silent, as any 
insomniac will testify. Spectrographic evidence shows that canids have eight basic sound types (Fox and Cohen 1977). The vocal apparatus of a canine can produce "whines (including shorter yips and yelps, and longer, softer whimpers), screams, barks, growls, coos, howls, mews, and grunts" (Fox and Cohen 1977, 735), but communication also happens "by means of more "mechanical' sounds such as clicking and tooth-snapping" (Fox and Cohen 1977, 738). The capability of producing these sounds, of course, does not imply an ability to speak, but it does make anthropomorphization easier than is the case in famously reticent fish, snakes, or pet spiders, not to mention insects.

We may never know the truth about dogs' actual mental or linguistic abilities, unless it lies in the very anthropomorphism. Friedrich Nietzsche's famous 1873 dictum on that trope states: "What is truth? A mobile army of metaphors, metonymies, anthropomorphisms [...]" (Nietzsche 1989, 250). ${ }^{3}$ It is perhaps in keeping with Nietzsche's point that we could easily imagine this statement emitting from a schnauzer's snout, especially if we bear in mind the similar looks of the philosopher and the dog in question. The Nietzsche quotation derives from "On Truth and Lying in an Extra-moral Sense" (1873), which speculates, among other things, what it would be like to be a gnat, a century before Thomas Nagel posed the same question about a bat. ${ }^{4}$ Nietzsche writes:

if we could communicate with the gnat, we would learn that it too swims through the air with this same pathos and feels within itself the flying center of this world. Nothing in nature is so contemptible and insignificant that it would not immediately be swollen up like a balloon by the slightest touch of that power of knowledge [...].

$(\text { Nietzsche 1989, 246) })^{5}$

How does Nietzsche know the thoughts and feelings of a speechless insect? Probably he does not, but projects his personal views to the external world and to its creatures. Although Nietzsche states, in the next sentence, that "the philosopher [...] believes he sees the eyes of the universe focused telescopically from all directions upon his actions and thoughts", it could rather be that he presumes, or imagines, the universe to act or, more precisely, exist according to his conception of it.

The human and nonhuman mingle in Nietzsche's rhetoric in telling ways. His answer to the question about the truth, for instance, vacillates between the two realms. The German Heer means both "army" and "herd" or "host" (a group of animals, for instance, or cloud of gnats or other insects). Although the movable army is the most felicitous translation in this connection, the nonhuman option naggingly resonates there as well. 


\section{Speaking Animals and the Posthuman}

As Margo DeMello states, the long-standing tradition of "animal speaking and writing" surfaces on different levels of oral and literary culture, and ranges from everyday pet talk and myths to poetry and written narratives (DeMello 2013, 1). The human/nonhuman animal communication of this kind can be conceived of as ventriloquism (people voicing nonhuman animal minds) or mediation (nonhuman animals used as relays between human minds) (DeMello 2013, 1, 4; Morstad 2013, 200). In Karla Armbruster's view, talking animal stories, and their readers, almost invariably show a longing for a genuine understanding of the otherness of nonhuman animals (Armbruster 2013, 19). She asks how the literary criticism tapping from combinations of animal studies and literary/cultural studies could sustain that longing or desire, especially in connection with the literary representations of nonhuman animal voices and minds (Armbruster 2013, 19). Armbruster is the only literary critic to have published a scholarly article on Angus to date and is therefore an important dialogist in my reading, both theoretically and interpretatively. ${ }^{6}$ She takes cue of Cary Wolfe's 2009 notion that the introduction of posthumanism to animal studies has often resulted in applications that still cling to the humanist subject and, consequently, anthropocentrism. Wolfe problematizes, following the tracks of Jacques Derrida, the first-person plural as simultaneously including and excluding:

"we" are always radically other, already in- or ahuman in our very being - not just in the evolutionary, biological, and zoological fact of our physical vulnerability and mortality, which we share, as animals, with animals, but also in our subjection to and constitution in the materiality and technicality of a language that is always on the scene before we are, as a radically a human precondition for our subjectivity, for what makes us human.

(Wolfe 2009, 571)

What could this reconfiguration of the human/nonhuman divide mean to literary criticism? Quite devastating changes, if Susan McHugh's notion of literary studies is correct: "a systematic approach to reading animals involves coming to terms with a discipline that in many ways appears organized by the studied avoidance of just such questioning" (McHugh 2009, 487). The re-examination of disciplinary practices as prompted by the new configuration would radically reframe literature's place "in a larger universe of communication, response, and exchange, which now includes manifold other species" (Wolfe 2009, 571). Armbruster locates the listening to "the animal voices in literature" as a beginning of that reframing (Armbruster 2013, 20). I would like to add another mode of reception to this posthuman constellation: the 
reading of human noises in nonhuman animal discourses as well. In my reading of Siebert's Angus, I will trace not only the presumed voicing of a dog's cognition, as Armbruster does, but also the human, cultural interferences in it.

\section{Narratives of Speaking Dogs}

Literary imagination, especially in the form of narrative fiction, does testify to the speaking abilities of dogs. There is indeed a long tradition of talking, philosophizing, and narrating dogs in Western literature. One might initially think of such loquacious canines as the one in Kafka's late story "Investigations of a Dog” (1922). Kafka's deeply troubled animal attempts to tackle a series of metaphysical questions, starting from the ultimate one about the source and origin of (dog) food. However, the tradition of loquacious dogs runs quite a bit further than the first decades of the twentieth century, in fact to antiquity and hence the beginning of Western philosophy and literature. ${ }^{7}$

Dogs in literature are conventionally eager to talk to one another, but Kafka's canine is alienated from his community and has no one of his species to talk to. Still, we, as readers, witness his soliloquy or investigative monologue. This puts us in the position of the "grazed witness who understands - or thinks that s/he understands - the language of the dog" (Ziolkowski 1983, 114). This is what happens also in Angus, but with an extra twist of interpretive challenge: we are to believe that we understand the language of a canine who is dead or on the verge of dying.

What constitutes language, speech, and reading in connection with dogs mobilizes a Nietzschean army, host, or herd of metaphors, metonymies, and anthropomorphisms. Language is to be acquired from the dog herself, but not solely from her mouth. Not only a nonhuman animal's body language but also her whole lived and experienced reality, inner sensibility included, forms what can be labeled as "language" (Kate Soper as quoted in Armbruster 2013, 24).

The thriving of nonhuman narrators in fiction has, predictably, caught narratologists' attention. In their useful analysis of the phenomenon of nonhuman storytelling, Lars Bernaerts, Marco Caracciolo, Luc Herman, and Bart Vervaeck note "the paradoxical idea that readers are invited to reflect upon aspects of human life when reading the fictional life stories of nonhuman narrators" and that "these narratives highlight or even challenge our conception of the human" (Bernaerts et al. 2014, 68-69). Previous literary critical and narratological accounts of nonhuman narration have had recourse to concepts such as estrangement, defamiliarization, and the unnatural (Shklovsky 1965; Richardson 2006; Alber et al. 2010). Bernaerts and his co-writers, however, understand this phenomenon as "the result of a double dialectic of empathy and defamiliarization, human 
and nonhuman experientiality" (Bernaerts et al. 2014, 69; emphasis in original). This means that

[n]on-human narrators project human experience onto creature and objects that are not conventionally expected to have that kind of mental perspective (in other words, readers "empathize" and "naturalize"): at the same time, readers have to acknowledge the otherness of nonhuman narrators, who may question (defamiliarize) some of the readers' assumptions and expectations about human life and consciousness.

(Bernaerts et al. 2014, 69)

Literature is capable of creating an illusion of an experience from a nonhuman animal's or a dead being's perspective (Bernaerts et al. 2014, 76-77). What this means for human readers is, according to the writers, that they may recognize the simultaneous similarity and otherness of nonhumans (dogness and humanness of dogs, as well as dogness and other nonhuman animalness of humans), and consequently, anthropocentric ideologies can be destabilized (Bernaerts et al. 2014, 74). These ideologies are perhaps shaken or tilted but not seriously reorganized in the very theory of nonhuman narrators as presented by Bernaerts and his group. While it is true that the last sentence in their article boldly states that "[h]uman and nonhuman experientiality are always caught up in a dialectic, so that their boundaries are constantly renegotiated as a result of complex historical and cultural dynamics" (Bernaerts et al. 2014, 89), the penultimate sentence shows definite human bias and thus reduces the destabilizing potential of nonhuman narration:

nonhuman narration may push back the limits of human experientiality - the audience's repertoire of beliefs and values by inviting them to engage with characters and experiences that they construe as strange and "unnatural", but which are in fact the products of the human creativity of their authors - and of readers' own imaginings and interpretations.

(Bernaerts et al. 2014, 89)

\section{Angus's Language and Literary Lineage}

Siebert's Angus is a first-person memoir of a Jack Russell terrier, narrated not on his deathbed but out in the woods where he is awaiting death after having been attacked by a coyote. He eloquently spins his tale for 150 pages, while he feels his body and mind disintegrating. Although in pain, he manages to narrate his life story, starting from his puppy months and ending in the present of his final hours. Like Kafka's investigating dog, Angus is cut off from his canine community, but he does have an 
outstanding command of the English language. He knows the English names for the constellations in the sky and the British and American typonyms, and he proficiently uses such words and expressions as "atom", "absorbing disquiet", and "disassemblage" placed in ornate syntax:

And then I went into the unfurnished, the room's forgotten, quadrants, the spaces orphaned by your designs, sniffing out wraiths, absorbing disquiet, knowing no hierarchy of air, no best place in the room to be; knowing in my bones that nothing is what it appears, that objects, too, ache, the way that all atom-arrangements do, for disassemblage.

(Siebert 2000, 51)

He also provides etymological explanations of terrier (of terra, "of the earth") (ibid., 38), and quotes a long passage from a book on the origins of his own breed, Jack Russell terrier (ibid., 54-55). His syntax and style vary dynamically, with the linguistic register ranging from the sophisticated to the cuddly. For instance, perhaps for sentimental reasons, he uses pet names for his guardians, Huge-Head and Sweet-Voice. His narration is aimed at a human narratee, Sweet-Voice, not at another dog as is customary in the classic cases of talking dogs.

Angus is not, hence, a dead dog talking in the literal sense of the expression. Rather, he is like a dead man walking - in the idiomatic, metaphorical sense of the phrase. A dead man walking is an inmate on death row awaiting his execution; he is still alive but certain to be killed and therefore seen as already dead. In the sense of inevitable mortality, the expression applies to all living persons, who will eventually die and, analogously, to all talking dogs, who will become (talking) dead dogs. Hence, the awkward or preposterous term preposthumous. ${ }^{8}$

Besides being between life and death, Angus is also, at least nominally, another kind of hybrid. He is a Jack Russell. The breed carries the name of its 1819 pedigree developer, the Reverend Jack Russell; the canine is, thus, the namesake of a long-dead human being (ibid., 54). His first name, Angus, points to two directions. First, he can be interpreted as being a dog in the anagrammatic disguise of a Latin sheep (agnus), or perhaps a strange amalgamation of the two. Second, his guardians jokingly dub him an angel (ibid., 75), an intermediary being between humans and gods, earth and heaven, and, significantly, between the living and the deceased. Christopher Merrill even connects Angus's angelic aspects to the elegiacally mystical spheres of Rainer Maria Rilke:

Angus is a sort of Rilkean angel, wiser than humankind deserves; and although he inhabited our "sphere of worry" for only a short while, he left behind a profound meditation of last things - a sharptoothed message from the edge of the field in which, sooner or later, we all find ourselves.

(Merrill 2000, [2]) 
Merrill's reading is permeated with other literary heredity as well:

What if The Death of Ivan Ilyich had been written from a dog's point of view? In Angus, Leo Tolstoy meets Jack London, and the result is a contemporary call of the wild, which is by turns heartbreaking and hilarious.

(Merrill 2000, [2])

If Josef K., in the end of The Trial, dies "like a dog" (Kafka 1999, 229), Angus passes away over the course of his narrative, like a man or, more particularly, a man of letters.

There is certainly more to the literary pedigree of Siebert's little novel and its protagonist. The third chapter of miniature-sized Angus starts with a line reminiscent of the veritable whale of an American novel, Moby-Dick: "Angus. They call me Angus" (Siebert 2000, 19). Just as Ishmael's true name and identity remain secrets, so are Angus's actual designation (if there is such a nominal system among dogs) and self undisclosed. Both Moby-Dick and Angus are about calling, language's attempt to name, describe, control, or hide the world and the entities in it. He asks himself: "What is Angus? What am I without that two-beat tug on my heart?" (Ibid., 52). And then he urges himself, curiously with the second-person address: "Go back now, Angus, toward your own namelessness, to the time before they arrived [...] and brought you here [...]" (ibid., 52). Name seems to be of utmost importance for Angus, even when the period before it was given to him is being recollected.

The Adamic project of naming the objects of the storyworld is given an animal twist in Angus's first-person narration. He is aware of the imposed, arbitrary, and conventional quality of name-giving, even to the degree that he chooses to disobey language's functional power when he pleases: "I go by and, when it suits me, come to, Angus" (ibid., 19). He was given that name at the age of two months, nine months prior to his fatal accident, but that nameless period of his life is by no means devoid of language. The name came along with the puppy's new owner couple, "they", and with it the supposedly submissive position in the pack of two humans and a canine.

A first-person autodiegetic narrator, Angus is free to articulate what and how he senses, but remains firmly tied to the flexible leash of the English language. In the narrative universe of his own making, Angus executes his self-imposed right of naming. He does not call his male and female guardians by their human names but systematically dubs them Huge-Head and Sweet-Voice, respectively (28 and onward). This is clearly a marking strategy. The misnaming does not derive from a lack of knowledge or understanding because he invariably provides place names in their accurate forms: for instance, "a few drinks at the Star Inn, in St. Just, the little Cornish village at the far western tip of England where we lived last fall and winter before flying home to this side of the earth 


\section{Mikko Keskinen}

[...]" (ibid., 29). The difference between the canine and human naming seems to relate to emotions, to "puppy love" for his guardians, which is articulated with nicknames of endearment, whereas the neutral names are given in their standard forms.

Angus's idiolect features some mild deviations from standard English, as if to give an impression of a nonhuman language and, with it, of a nonhuman worldview. Karla Armbruster acutely notices Angus's unconventional use of language, including sensory images for fundamental memories and the term "tug" for a dog's name (implying the bond tugging the animal toward the caller) (Armbruster 2013, 28). The tug also functions as a metalinguistic concept for the morphological structure of name. Thus, Angus is a "[t]wo- beat tug" (Siebert 2000, 57), and he also tears, in true terrier style, a number of other dog names into syllables (ibid., $58,104)$. There are also other, more striking idiosyncrasies in Angus's parlance. He seems to treat pronoun and verb forms liberally, but there is a cynomorphic logic guiding the infelicities. For Angus, "me" signifies dog as a species. Hence, dog in the plural is "me's" (ibid., 25, 104, 123). By extension, "me" sometimes includes Huge-Head and Sweet-Voice, the humans he bonds with: "He is here. Is me. I am Angus" (ibid., 57).

On the basis of his whole narration, Angus's language skills seem exceptionally developed. He clearly understands the language spoken in the human world around him, as well as reports characters' speech and gives place names accurately. During his first months of existence, however, human speech sounds cartoon-like in his puppy ears: "Blab, blab, blab" (ibid., 28, 71, 76). In his retrospective autobiographical narrative, different layers of time and development are simultaneously present and therefore make his linguistic abilities seem oddly asymmetrical or selective. For instance, the last "blab, blab" section (ibid., 76) surfaces in the linguistic universe of Sweet-Voice listening to the radio and commenting on its science interview, with each of the three voices correctly reported by Angus - or perhaps not quite. If the "blab, blab" layer represents Angus the pup's limited understanding of human language, returning to that scene with an adult dog's mind does not rescue the signification of the spoken utterances. The linguistic reconstruction of the incident is therefore a fictional dramatization or re-enactment rather than an actual account of what really was said. What Angus crystallizes at the end of the scene and chapter, applies to him as well: "So many layers and tones it has, your world" (ibid., 77).

The radio interview that Sweet-Voice happens to listen to deals with the possibility of building a machine capable of translating barks into words. ${ }^{9}$ When the inventor is about to demonstrate his miraculous apparatus, the broadcast technology fails, leaving the listeners in a quandary about what dogs really want: "a deep, warbly, metallic voice sounded: 'I want to...,' then broke into shards of static" (ibid., 77). This is reminiscent of science fiction movies in which translation devices customarily 
turn alien voices into tinny but comprehensible American English. At the beginning of the following three chapters, the dying Angus returns to the possibility of a translation machine and the question of dog's needs (ibid., 79, 81, 91) as well as elsewhere in the novel (ibid., 129). The translatability or, more generally, communicability of animal and human sensibilities and minds seems to be a pivotal question in the whole novel.

Interspecies communication or mindreading does not require a machine or software to function. Angus's Theory of Mind is of the second degree when he momentarily feels that Sweet-Voice knows what he is thinking, although "she is too impatient to hunt for the words" to express it (ibid., 105). Mindreading thus runs both ways. I suggest that this two-way traffic in Angus also applies to the realm which is, to continue and emulate Angus's metaphor, the veritable hunting ground or pasture of words: literature.

Angus's lineage is literary. The Reverend Jack Russell, who discovered and named the terrier breed in the May of 1819, did not walk emptyhanded around Magdalen Meadow toward Marston, Oxfordshire. He had, according to a lengthy quotation from a dog book, "Horace in hand" - and literature of antiquity in his mind, as the similes describing the encounter with the Ur-terrier Trump suggest:

[the Reverend Russell] halted, as Acton might have done when he caught sight of Diana desporting in her bath; but unlike that ill-fated hunter, he never budged from the spot till he had won the prize and secured it for his own. She was called Trump, and became the progenitress of that famous race of terriers [...].

(Ibid., 54-55) ${ }^{10}$

As a partly negated allusion to the transformation of Acteon into a stag in Ovid's Metamorphoses, the scene nevertheless describes the encounter in terms of hunting. Acteon, the hunter, became prey; Russell, the nonchalant stroller, became a hunter who caught a canid alive. Not surprisingly, Angus's guardians feel a need to purchase books about Jack Russells "in order to learn how best to handle the likes of [that] storied breed" (ibid., 46). Those terriers are both multilayered and consist of many narratives, as the breed's premodifier suggests.

Angus's metaphoric language, too, bears traces of Jack Russells' literary lineage. Referring to dogs' sensibilities, Angus states: "Every day is an open book of devotion to a me" (ibid., 92). In the novel's epilogue, the book metaphor is picked up by the writer of Cabin Journal in connection with the atomic "matter of existence": "It's something like words before they're set down on a page. It's the blankness of the page, inspiration without expression, pure urge [...]" (ibid., 172).

As a whole, Angus shows that fiction itself is a translation machine of sorts. It is capable of conveying meanings across species or at least 


\section{Mikko Keskinen}

of giving an illusion of such an ability. As in actual translation, some nuances are lost in the process and some meanings even become unintelligible. What is always conveyed is, however, the effort itself, complete with the semantic and cognitive friction, hiatuses, and overall static involved in the very phenomenon of translation. It should be remembered, however, that language is just "one among many different mediated relationships with reality that structure life, both human and nonhuman, at all levels" (Calarco 2014, 621). For Angus, there is no radical difference between verbal and body language: pause for effect equals paws for effect, so to speak.

A hybrid of human and nonhuman spheres of communication and knowledge, Angus is an outlandish creature. He is domesticated but wildly unfamiliar, easily recognizable but utterly strange. The same can be said of Angus the novel, and the effects that its narration brings about.

\section{The Strange and Familiar World of Human Animals}

Angus's superb command of the English language, complete with its Latinate lexical stratum and other foreign words, and his astonishing knowledge of physics make him a curious canine. However, his welleducated human-like understanding of the world around him is not quite systematic, which allows for the emergence of some typical fable motifs and stock features, such as defamiliarization or estrangement. In Angus, encounters with technology particularly tend to trigger instances of making the familiar strange via a dog's eyes and mind.

Angus gives the following account of Huge-Head's and Sweet-Voice's mysterious activities:

each of them working in their own rooms, sitting upright, motionless, only their hands clacking in front of lit glass boxes where rows of tiny black birds keep alighting and flying off and then settling back down again.

(Siebert 2000, 53)

This tinkering obviously refers to writing on laptops. Nevertheless, the estranged or defamiliarized depiction of writerly activity is in itself a peculiar mixture of different realms of knowledge. Angus does not fully describe the scene in natural or animal terms, but conceives of it as (human) "work" done with non-natural tools ("glass boxes"). The letters on the screen, however, are apprehended as an extended avian metaphor. Angus's dog-minded view of the human world around him is not simply reducible to systematic defamiliarization. The inconsistencies or slips in the system of understanding his surroundings could justifiably be read as lapses in the representation of an animal mind. I would rather interpret the cognitive infidelities as poetic decisions. Angus acts like a creative 
writer, first setting a realistic frame of reference and then transposing the familiar scenario to a metaphoric sphere.

Another extended description of the incomprehensible takes place in a building, "in a section of town I think they call Soho":

First, a glass door opened from the street, letting us into what seemed a very nice room as rooms go, but my masters seemed to know right off that it wasn't ours. This room gave away to a tiny one, not much bigger than a feed trough, the door to which slid open and closed by itself, and the whole of which - I know I didn't dream this - moved.

(Siebert 2000, 94)

This elevator ride is a nicely executed defamiliarization of an everyday urban activity as understood from a puppy's viewpoint. However, the frame of reference changes radically when the ride is over, and when Angus and his "masters" or guardians start walking down the corridor of their floor, navigating toward their new apartment. Angus produces the following simile as they are proceeding: "It was like we were peeling away the layers of the wild onions I used to dig up around Pollard's Combe, trying to get, at last, to the juicy core" (ibid., 94). This is a curious turn from the customarily canine to the popularly literary. Dogs, Jack Russell terriers included, are not usually known to have a craving for onions, which are in fact lethal for canids, even in small amounts. Here, Angus (or, rather, the author Siebert ventriloquizing him) is mapping the literary and canid domains a bit too forcedly, perhaps producing an unintentionally bland blend. In the human context, the metaphor of peeling an onion, which derives from antiquity but is probably best known from Ibsen's Peer Gynt, commonly refers to the layers of mind, personality, memory, truth, or such, with the core being the ultimate goal to be discovered after shedding the surrounding strata. Finding the right room after discarding false options may fit in this constellation, albeit not without some stylistic uneasiness, not to mention the unlikely idea of a dog participating in peeling tightly structured vegetables. This case of defamiliarization thus tends, not as much toward a maverick mongrel of styles, as toward bad human writing.

Other objects of built environment - such as cars, rooms, farms, dog crates, and airplanes - are also delivered in the form of more or less canid-human hybrid expressions. This utterance manages to both defamiliarize and refamiliarize footwear within the course of one sentence: "I learned to chew to pieces those thick, stinky shadows of traitorous human feet known as shoes" (ibid., 73). The airplane cargo hold is dubbed "the belly of the metal bird" (ibid., 95), and the airplane "the metal bird" (ibid., 53, 118, 119), reminiscent perhaps of the tribal naming of Western aircraft or, more specifically, of the so-called cargo cults. Linguistically, the underdog or pidginized position is shared by canids 


\section{Mikko Keskinen}

and natives alike in the portrayal of unfamiliar, human-made artifacts. Both could be interpreted as being seen from a subaltern viewpoint, yet rendered from a condescending position, which makes the lack of understanding of the real state of affairs cute and charming, as if mimicking the perspective of a human toddler.

\section{Sniffing Backward and Sideways: Reversed and Counterfactual Narration}

Dog's short-term memory span is notoriously brief, ranging from around thirty seconds to a few minutes. The long-term or associative memory of dogs can last for years, even for life. Instead of images and memories per se, dogs have imprints of occurrences, positive or negative associations attached to happenings of the past (Horowitz 2010, 223-228). A dog's sense of smell is, by contrast, famously accurate, and the canine mainly relies on it when interpreting the surrounding world (Horowitz 2010, 67-85). Angus's narration goes back and forth in his eleven-month life. The narrative structure and logic of the novel is at least partly motivated by the dog's limited capacity to remember and its well-developed olfactory ability.

In the novel's second chapter, Angus is laying in the woods after the deadly coyote attack and, although he has "never been one to look back" (Siebert 2000, 15), now reports:

I'm beginning to see everything now, but backward, in recollection, as though my last flash forwards into this forest is illuminating a final flashback: the things that I wasn't thinking when I charged out tonight; the steady train of events, from my life's very beginning, that lead, inevitably, here, to these dark woods [...].

(Ibid., 17)

At the near end of his existence, Angus perceives his life-story in a reversed order. Although the retention of "the steady train of events" resembles more human than canine both in its depiction of mind's working and its use of a transportation metaphor, the logic of returning to the past backward is believably dog-like. Contrary to dog's dominant sense of smell, the passage is permeated with visual perception (see, illuminating, dark), metaphoric or literal. I interpret the human traits of memory and perception in this and many other passages of Angus as products of $\mathrm{dog} /$ human translation. What is lost in translation is the surface layer of expression, the idiomatic articulation of discourse, and what remains stable is the basic structure of narrative.

Angus's going back in story time (and place) in a reversed order does not follow the train but the trail of events, starting from the most recent one, and he surveys the track with his nose down, sniffing. What is an 
unusual or unnatural form of human discourse (Richardson 2002, 49), could be imagined to be the most natural one in canine narration. Narrating backward follows the principle of tracking the chronology of odor traces. Angus does not engage in sustained backward narration, which entails consistent reversal of each event, but in the episodic variant in which the episodes follow in a reverse order but the "events of each episode move forward" as in simple flashbacks (Chatman 2009, 33). Episodic flashback narration is not systematic in Angus, but telling tends to oscillate between the past events and the present time of the dying narrator. Nevertheless, the trail of odor traces forms the narrative line along which Angus, in his mind, moves to and fro.

Angus's oscillating movement also connects separate and even extreme events along the narrative line or trail. There is an olfactory bloodline between birth and death, Angus notices, when recalling the perinatal and the near-death moment of his life:

Do you recall, did you ever really know it, the full, drowning scent, like wet, rusted iron, of your own birth's blood?

(Siebert 2000, 21)

the trail of my own leaking blood, escaping life now on the very same rusty scent that I followed into it.

(Ibid., 22)

The collection of scents in Angus's memory forms a veritable potpourri or rather a historical fragrance, which he describes with the eloquence of a perfumer:

My life was an ever-shifting sea of scents [...]. There were endless air-etched rivulets of scent to travel down: earthworm-moist and butterfly-dust; hoof-hollow, paw-pads, and seagull swill; and all of these trails subsumed in the end by that wider, base-note scent of my life at the Combe: teat, tummy, and straw, lightly baked by a day-long, drowsy sun.

(Ibid., 38-39)

Angus's canine narration is not limited to past events. The trail of scents also leads, in his snout, to future, possible, and nonexistent spheres. The vicinity of death prompts counterfactual storylines in Angus: "a possible future that doesn't at all resemble any one day [...] - hope, in other words [...]" (ibid., 15-16). The novel's first words are conditionally counterfactual: "If I could lift myself and run again" (ibid., 11). In addition, there is the predictable speculation on the trail not taken, of not going after the coyotes (ibid., 26). The smell of death also forms a "trail of scent that leads nowhere" (ibid., 41); it is a "scent both primordial and 
new" (ibid., 42). Death opens up a posthumous scenario as well. Angus, on the verge of drawing his last breath, prophesizes how his guardians will recall a recent moment of happiness:

Later, when I'm back among them, they'll remember how I went up to her earlier this afternoon here in the north field, how she had to pull me away from her. [...] I hopped up onto her lap, knocked off her book, went right into those needy hands, and then farther and on. I put my head on her shoulder.

(Siebert 2000, 155)

The Epilogue can be interpreted as continuing the sniffing strategy of Angus's narration, although the concluding chapter of the book dramatically opens with the statement "Angus is dead" (ibid., 157). The narrator of the Epilogue, the dead dog's guardian who turns out to be very much like Charles Siebert himself, speculates with his wife about what happened to Angus, as if tracking the trail of his fatal incidents, suggesting a fox, bear, and bobcat as the attacker (ibid., 168).

\section{Dog Gone: The Passing of a Nonhuman Animal}

The canine narration of Angus is posthumous, preposthumous, and even preposterous. Once the dog is dead and passed to discursive silence at the end of the book, what is left of the tale thus voiced? Alice A. Kuzniar sums up her appreciation of the novel:

Siebert does not so much anthropomorphize [Angus], imputing canine similarity with the human mind, as he probes the gaps between the two that lie at the foundation of the profoundly melancholic desire of one species for another. In so doing, he does not have the dog serve merely as the blithe narrator of external events but tries to imagine or track the dog's own form of consciousness.

(Kuzniar 2006, 61)

In Karla Armbruster's reception,

the novel conveys a sense of a posthuman world, in which voices come from all sorts of beings (including not just dogs but atoms) [and] the human voice is demoted from its conventional position of authority and control to one among many.

(Armbruster 2013, 31)

These qualities of Angus offer "the readers an opportunity to radically re-envision their relationship with other animals (and indeed, with the entire nonhuman world and material reality in general)" (Armbruster 
2013, 31). I would like to emphasize some more specific and even problematic narrational points to counterbalance these rather generalizing interpretations.

Performatively, the posthumous canine narration of Angus dramatizes the vacillating boundaries between the human and the nonhuman (dead or alive), and how they can be figured in narrative. The oscillation of Angus and his guardians' capabilities, cognition, and experientiality generate curious effects. Angus is a very human nonhuman animal, and his guardians verge on being nonhuman human animals. Especially the counterfactual and backward narration by both Angus and his guardians points to the dogness of humans, not only to the humanness of canids. Instead of multiple voices, I would call this intertwinement of characteristics and porousness of articulations and capabilities with the term "noise", with or without the attribute "cultural". That noise can awaken the reader, who might be comfortably accustomed to the metaphysical notion of discrete species and their separate minds, from her dogmatic - or should I say dog-matic? - slumber. As David Herman states, "fiction provides a domain for staging the dissolution and reconstruction of self-narratives, and for exploring the ontologies in the context of which selves are recognized as such" (Herman 2014, 141). ${ }^{11}$ The transspecies relationships imagined and performed in Angus are as ambiguous and problematic as in "real life" - but with a literary twist, further complicating the ecology of agents.

Purely formally, there seems to be two ways of interpreting Angus's eloquent monologue or soliloquy. Either it uncynically tends toward sentimentality or, in a more dog-like vein, duplicitously parodies extended death scenes in sentimental narratives (cf. Stewart 1984). In the posthuman context, neither alternative is accurate. Angus reads, not quite an allegorical or a fable-like figure, but more like a quasi-human character, and the styles and reference points of Angus and Siebert merge to a degree of undifferentiability. This hybrid produces, depending on the reader's point of emphasis, either uncontrolled and uneven writing or a serious attempt to account for the reconfiguring of the nonhuman.

In memoriam Foxwarren Sally (1993-2002)

\section{Notes}

1 The Art of Racing in the Dark (2008) by Garth Stein is also narrated by a dying dog capable of speaking (albeit in a manner poorly understood by humans). Mikhail Bulgakov's novella A Dog's Heart (1925) is a more remotely analogous case. The body of Bulgakov's mongrel, Sharik, hosts implanted glands from a dead criminal, and the dog himself virtually dies during the operation. What all this seems to point to is that Bulgakov's dog unequivocally speaks posthumously only. When he is alive in the beginning of the novella, his speech may be merely metaphorical. When he virtually dies 
during the operation, he is blessed with the ability to talk. Sharik's voice emits from a hybrid which, in effect, is constituted of two dead bodies, the dog's and the criminal's (for the dog ceases to exist as a dog, when its vital organs are replaced).

2 By Sophie Collins; Roger Abrantes, Alice Rasmussen \& Sarah Whitehead; Vilmos Csanyi \& Richard E. Quandt; Cheryl S. Smith; and Jan Fennell \& Monty Roberts respectively.

3 "Was ist also Wahrheit? Ein bewegliches Heer von Metaphern, Metonymien, Anthropomorphismen [...]" (Nietzsche 2009).

4 Unlike the boldly speculating philosopher of the insect world, Nagel chose "bats instead of wasps or flounders because if one travels too far down the phylogenetic tree, people gradually shed their faith that there is experience there at all" (Nagel 1974, 438).

5 "Könnten wir uns aber mit der Mücke verständigen, so würden wir vernehmen, dass auch sie mit diesem Pathos durch die Luft schwimmt und in sich das fliegende Centrum dieser Welt fühlt. Es ist nichts so verwerflich und gering in der Natur, was nicht durch einen kleinen Anhauch jener Kraft des Erkennens sofort wie ein Schlauch aufgeschwellt würde [...]" (Nietzsche 2009).

6 Alice A. Kuzniar provides a brief reading of Angus in her Melancholia's Dog: Reflections on Our Animal Kinship (2006, 57-61).

7 I will not go into the literary history of talking canines in detail here. For those interested in this tradition, I recommend Theodore Ziolkowski's standard work on the subject, "Talking Dogs: The Caninization of Literature", in his Varieties of Literary Thematics (1983). It is unfortunate that the articles on talking dogs in Speaking for Animals (2013) do not recognize Ziolkowski's seminal study. See also the two lengthy chapters on talking dogs in Ross Chambers's Loiterature (1999, 157-211).

8 Or should I say antemortem? Perimortem? My point is that this state precedes the condition that comes after the moment of death. On the other hand, Angus's tale is told after his death, ventriloquized by his guardian, as is apparent on the basis on the Epilogue (see also Armbruster 2013, 28).

9 Perhaps not surprisingly, there actually exists software capable of classifying dog barks and the emotions related to them (see Molnár et al. 2008).

10 This unattributed quotation derives from A Memoir of the Rev. John Russell and His Out-Of-Door Life by E. W. Davies (1878); (see Davies 1902, 52).

11 In Caracciolo's wording, the

confrontation with animal consciousness [is] constrained by the boundaries of the human imagination and that in literary texts such boundaries are renegotiated according to a cultural logic that is inherently and irreducibly anthropocentric. What fiction can do is to call attention to these limitations and stage the impossibility of transcending them in ways that are highly productive for literary interpretation and may sensitize readers to the puzzles of consciousness (both human and animal).

(Caracciolo 2014, 488)

\section{References}

Alber, Jan, Stefan Iversen, Henrik Skov Nielsen, and Brian Richardson. 2010. "Unnatural Narratives, Unnatural Narratology: Beyond Mimetic Models." Narrative 18 (2): 113-136.

Armbruster, Karla. 2013. "What Do We Want from Talking Animals? Reflections on Literary Representations of Animal Voices and Minds.” In Speaking 
for Animals: Animal Autobiographical Writing, edited by Margo DeMello, 17-34. New York: Routledge.

Bernaerts, Lars, Marco Caracciolo, Luc Herman, and Bart Vervaeck. 2014. "The Storied Lives of Nonhuman Narrators." Narrative 22 (1): 68-93.

Calarco, Matthew. 2014. "Boundary Issues: Human-Animal Relationships in Karen Joy Fowler's We Are All Completely beside Ourselves.” Modern Fiction Studies 60 (3): 616-635. doi: 10.1353/mfs.2014.0046

Caracciolo, Marco. 2014. “'Three smells exist in this world': Literary Fiction and Animal Phenomenologyin Italo Svevo's 'Argo and His Master.'” Modern Fiction Studies 60 (3): 484-505. doi: 10.1353/mfs.2014.0039

Chambers, Ross. 1999. Loiterature. Lincoln and London: University of Nebraska Press.

Chatman, Seymour. 2009. "Backwards." Narrative 17 (1): 31-55.

Davies, E. W. 1902. A Memoir of the Rev. John Russell and His Out-Of-Door Life. London: Chatto \& Windus.

DeMello, Margo. 2013. "Introduction.” In Speaking for Animals: Animal Autobiographical Writing, edited by Margo DeMello, 1-14. New York: Routledge.

Fox, Michael W., and James A. Cohen. 1977. "Canid Communication.” In How Animals Communicate, edited by Thomas A. Sebeok, 728-748. Bloomington: Indiana University Press.

Herman, David. 2014. "Narratology Beyond the Human.” DIEGESIS. Interdisziplinäres E-Journal für Erzählforschung / Interdisciplinary E-Journal for Narrative Research 3 (2): 131-143. doi: 468-20141118-113504-3

Horowitz, Alexandra. 2010. Inside of a Dog: What Dogs See, Smell, and Know. New York: Scribner.

Kafka, Franz. 1999. The Trial. Translated by Breon Mitchell. New York: Schocken.

Kuzniar, Alice A. 2006. Melancholia's Dog: Reflections on Our Animal Kinship. Chicago, IL: University of Chicago Press.

McHugh, Susan. 2009. "Literary Animal Agents.” PMLA 124 (2): 487-495.

Merrill, Christopher. 2000. "Praise for Angus." In Angus, edited by Charles Siebert, [2]. New York: Three Rivers Press.

Molnár, Csaba, Frédéric Kaplan, Pierre Roy, François Pachet, Péter Pongrácz, Antal Dóka, and Ádám Miklósi. 2008. "Classification of Dog Barks: A Machine Learning Approach.” Animal Cognition 11 (3): 389-400.

Morstad, Jill. 2013. "First Friend, First Words: Speaking of/to Talking Dogs." In Speaking for Animals: Animal Autobiographical Writing, edited by Margo DeMello, 193-203. New York: Routledge.

Nagel, Thomas. 1974. "What Is It Like to Be a Bat?" The Philosophical Review 83 (4): 435-450.

Nietzsche, Friedrich. 1989. "On Truth and Lying in an Extra-moral Sense." In Friedrich Nietzsche on Rhetoric and Language, edited and translated by Sander L. Gilman, Carole Blair, and David J. Parent, 246-257. Oxford: Oxford University Press.

—. 2009. "Über Wahrheit und Lüge im außermoralischen Sinne." In Digitale Kritische Gesamtausgabe: Werke und Briefe, Based on the Critical Text by G. Colli and M. Montiairi, edited by Paolo D'Iorio. 1967-. www.nietzschesource.org/. 


\section{Mikko Keskinen}

Richardson, Brian. 2002. "Beyond Story and Discourse: Narrative Time in Postmodern and Nonmimetic Fiction." In Narrative Dynamics: Essays on Time, Plot, Closure, and Frames, edited by Brian Richardson, 46-63. Columbus, OH: Ohio State University Press.

- 2006. Unnatural Voices: Extreme Narration in Modern and Contemporary Fiction. Columbus, OH: Ohio State University Press.

Shklovsky, Victor. 1965. "Art as Technique." In Russian Formalist Criticism: Four Essays, translated by Lee T. Lemon, and Marion J. Reis, 3-24. Lincoln: University of Nebraska Press.

Siebert, Charles. 2000. Angus: A Novel. New York: Three Rivers Press.

Stewart, Garrett. 1984. Death Sentences: Styles of Dying in British Fiction. Cambridge, MA: Harvard University Press.

Wolfe, Cary. 2009. "Human, All Too Human: 'Animal Studies' and the Academy." PMLA 124 (2): 564-575.

Ziolkowski, Theodore. 1983. "Talking Dogs: The Caninization of Literature." In Varieties of Literary Thematics, edited by Theodore Ziolkowski, 86-122. Princeton, NJ: Princeton University Press. 


\title{
8 Carnivorous Anatomies Art and Being Beasts
}

\author{
Brad Bolman ${ }^{1}$
}

The pig, we are told, has skin very similar to a human's. It is a dermal affinity attested to by regimes of experimentation in biomedicine as well as the work of contemporary artists: Miru Kim, for instance, juxtaposes these animal bodies in "The Pig That Therefore I Am", lying down amid the dirt and rough tumble of industrial hog farms, covering herself in mud.

In this chapter, I investigate the construction of similar skins, a process that occurs not only within anatomical and physiological reference works but also in a much longer genealogy, connecting early efforts to understand humans through analogy to pigs with literary, philosophical, and artistic work that probes the limits of such similarity. To do so, it is necessary to draw upon an eclectic body of sources, since similarity is produced as much in particular histories of science as it is, and was, in intermingled cultures.

I take inspiration from recent work on the global transfer of materials and skills across time, looking at how "artisanal" knowledge moves among a diversity of institutions, groups, and places. For instance, following mercury and sulfur as they trade and train hands across Eurasia, Pamela H. Smith highlights "the reciprocal processes by which matter gives rise to practices and objects, which themselves produce systems of belief that in their turn inform specific ideas about materials and practices" (Smith 2014, 132). Smith argues that focusing on the production and dissemination of particular things (in her case, "red" vermilion) pushes traditional historical approaches beyond textual interpretation to the transfer of material and technique.

Here, I would like to follow Smith's footsteps to the tracks left behind by pigs, specifically Italian pigs who made themselves present as far away as the Abbasid Caliphate before returning to jumpstart scientific anatomy in Italy. Examining the pigs and their carvers - at times their butchers, but certainly not always - allows us to understand not only the very specific emergence of human anatomy from the bodies of Salernitan hogs, but also to trace the construction of 'similarity' between human and 
nonhuman animals along with the critical role played by carnivorousness (Bolman 2015, 2018).

I begin at the founding of the body of knowledge we today call "anatomy", focusing on the work of the Roman anatomist Galen, who deserves credit, among a great many other things, for having built his science from the flesh of hogs. Here, pigs first entered the spotlight of similarity construction. Rather than merely weaving a series of fragments into a conventional origin story, I track the transmission of anatomical knowledge and technique through animals beyond the borders of Europe and back again. Employing insights from animal studies theorists like Donna Haraway and Charles Foster as well as a speculative historical approach that builds narrative out of incomplete sources, I seek to draw the attention of scholars of art, literature, philosophy, and history to the way knowledge can be stored inside living things, such as pigs, just as much as inanimate ones, such as books. I then connect this wayward transmission of knowledge about similarity to contemporary literary and artistic practices that employ and represent hogs in order to demonstrate how unstable the territory of transspecies similarity remains, even today. Throughout, we seek an answer to a deceptively simple question: How similar is our skin?

\section{Once More to the Anatomia Porci}

One of the more commented-upon mysteries of Medieval medicine is the short, orphan text known as the Anatomia porci, attributed often to Copho, a Salernitan physician, and so (perhaps mistakenly) called also the Anatomia Cophonis, though its true author remains unclear. The Anatomia sits, as Ynez Violé O'Neill noted forty years ago, in a paradoxical position: "[T]ermed the earliest Western work on anatomy in one history of Medieval science, [it] is not mentioned at all in perhaps the most widely read history of pre-Harveian anatomy and physiology", Charles Singer's A Short History of Anatomy and Physiology from the Greeks to Harvey (1957) (O’Neill 1971, 115).

The Anatomia consists of a series of dissection directives. It is an ur-textbook of anatomy and an original example of didactic medical pedagogy. In the text, pig dissection is used to explain the elements of human anatomy. Yet this tract is an amalgam of influences, a perplexing riddle for those seeking to trace the movement of textual knowledge from Greece to Rome, from the Arabicate world back to Europe. On the one hand, the Anatomia porci incorporates words and phrases that appear to come from translations, new at the time, produced by Constantine the African, a physician and prolific translator of Arabic texts, which suggests that the Anatomia's creation occurred around the time of his death at Monte Cassino (one of few relative certainties concerning Constantine's life) in 1087 (O’Neill 1971, 116). 
On the other hand, the Anatomia's first instructions suggest connections to a much older intellectual lineage, particularly the works of Galen (129-c. 200 CE):

Because the entire composition of the interior members of the human body was unknown, it pleased the ancients, and especially Galen, to make manifest the positions of the interior organs of brute animals by means of anatomy. And because among brute animals certain ones, like the monkey, are similar to us in their external structures, while others, such as the pig, are similar in their internal structures, in regard to the position of the internal organs none were found so similar as pigs. And so we have determined that dissection will be made upon them.

(Jansen, Drell, and Andrews 2011, 321; emphasis mine)

The distinction between internal and external similarity drawn in relation to primates and pigs could have been lifted directly from $\mathrm{On} A n$ atomical Procedures, where Galen notes that, for an anatomy of the larynx, "It is best if you do this on the body of a pig" (Galen 1962, 85), or again, "Leave the apes alone, and turn to these animals [i.e. a pig or a goat]" (Galen 1962, 87). That Book XI of Galen's On Anatomical Procedures begins, just as the Anatomia does, with an incision into the neck suggests some awareness of Galen's work and, in particular, awareness of his work with pigs. O'Neill argues that the order of presentation of porcine anatomy also mirrors Celsus's De medicina (c. Second Century $\mathrm{CE}$ ), an encyclopedia of Greek medical knowledge produced in Rome, despite agreement among twentieth-century historians that this text had little influence on ninth- and tenth-century medicine in Europe.

O'Neill - echoing the editors of Cambridge's edition of On Anatomical Procedures - argues that despite Salernitan awareness of Galenic teachings, few extant copies of On Anatomical Procedures would have been available in Europe - only the first half seemed to exist at all in Greek or Latin until late in the twentieth century - and thus, she suggests, these later sections, including the description of pig dissection, could not have influenced the physicians of Salerno. So, she concludes, "the question [of] how the Galenic concepts found their way into that work must for the present remain an open one" (O’Neill 1971, 122).

Historian Roger French resolved the dilemma by suggesting that it is not one: Galen's demonstrations - his famous "proof" of the connection between larynx and voice produced by publicly incising the throat of a wailing pig and "muting" it - were in the air waiting to be recovered by an eager, loosely organized school of theoretical physicians (French 1999, 15). French argues that the mixture of Arabic and Latinate terminologies is evidence of a continuous updating of older forms of vernacular knowledge. But he offers little explanation of how this process persisted. 


\section{The Persistence of Pigs}

There is, nevertheless, something puzzling in the presence of Galen's framework and argumentation without the direct presence of his texts. An appropriate answer seems to reside somewhere between O'Neill's open "question" and French's unreflexive acceptance. Perhaps the puzzle only exists insofar as we imagine the movement of knowledge strictly through the prism of its textual manifestations, as if knowledge only ever traveled via the exchange of books across lands between learned men; a powerful medium, clearly, but hardly exhaustive of the transfer and translation of knowledge across Italy, Greece, Spain, North Africa, and the Middle East.

Applying Smith's alternative historiographical approach to the problem of Galen's missing texts and the Anatomia porci provides an obvious yet under-considered possibility. We could comprehend the Anatomia porci by focusing less on the comparison of texts and more on the transmission of two kinds of extra-textual knowledge. First, a cultural-culinary knowledge of pigs (a variant of Smith's "artisanal” knowledge) emerged from the peculiar place of the pig in the culture and diet of both Greeks and Romans (and later Medieval Italians), a knowledge stored to some degree inside the pig, which offers an initial answer to one question that few commentators have seriously asked of the Anatomia: Why pigs? Second, Arabic translators and Salernitan physicians exchanged information without the clear mediation of the written page; in other words, that we should not be afraid to speculate, within limits, on the unwritten movement of medicinal thought as well as to grant a more significant role to Islamicate physicians in the development of "European" dissection and anatomy. Thus, much of the "paradox" surrounding Galen's (and Arabic physicians') presence in the Anatomia is the fact that Galen's text fails to surface in Europe until Oxford's Bodleian Library purchased a copy in 1714. But this seems more unfortunate than proof of a lack of Galen's influence on Arabic translators and Salerno. If we wanted to trace the movement of unwritten knowledge from Galen to Salerno, we ought to start with Galen himself.

\section{Mutable Mobiles}

As Charles Gross explains, Galen "conducted extensive experiments on the nerves that control breathing", and as the story goes, during the course of one such effort, "accidentally cut the recurrent laryngeal nerves that innervate the larynx" (Gross 1998, 218). The pig continued to move, but its voice ceased entirely. Boethus, Galen's patron, offered his famous physician the opportunity to display this finding publicly. Pigs were acquired, the event was publicized, many important political and philosophical figures arrived, and Galen muted his test subjects. Some were impressed, 
but others remained skeptical. Galen's retort, as sources carry it, was biting: "I was mistaken in not realizing that I was coming to meet boorish skeptics; otherwise I should not have come" (Gross 1998, 219).

From this demonstration and from others that followed, Galen produced a since-lost treatise, On the Voice. He would write about and use pigs, repeatedly, from his text On the Usefulness of the Parts of the Body to On Anatomical Demonstrations. Galen's "mute pig” demonstration remained famous for centuries, supposedly inspiring da Vinci to produce a drawing of the laryngeal nerves and Vesalius to experiment with hogs in a significant section of De fabrica. Renaissance editions of Galen's work even featured an engraving of the famous "Squealing pig" demonstration (Gross 1998, 220).

How, exactly, did news of Galen's demonstrations echo across the centuries separating their concrete instantiations from reappearances in the texts of Vesalius and their symbolic reemergence in work at the school of Salerno? The conventional accounts suggest that after a durée of relative obscurity, Renaissance humanists rediscovered the first half of Galen's On Anatomical Procedures. Then Vesalius, the "founder" of modern anatomy, took a particular interest in reviving his demonstrative pedagogical methods. This partly resolves our dilemma, since the surviving first half of Galen's book claims, at numerous points, that dissecting a pig is ideal for the purpose of demonstrating the anatomy and operation of the voice. But we are left in the dark about the extent to which Galen's demonstrations were reprised in the millennia gap between his work and his Renaissance "rediscovery". What if one crucial medium of transmission was not his texts, but the pigs themselves?

After all, that Galen himself would choose a pig for this dissection was never strictly necessary. His justifications for selecting a pig rather than the usual subjects of dissection - macaques $^{2}-$ centered on the loudness of the pig's voice and the "unpleasing expression" or "hideous" spectacle of macaques during vivisection (Galen 1962,15). These monkeys, noted Galen, are indeed more similar to humans than pigs or other creatures, but lack some of the performative luster offered by louder and more violent hogs.

One unspoken reason, however, that he might have preferred pigs to other potentially "similar" animal specimens is that pigs, unlike macaques, were in no short supply in the Roman Empire. It is common to cite the variety of Latin words for pig - porcus, aper, sus - as one of many indications that pork played a central role in Roman culture and diet (MacKinnon 2001, 649). Michael MacKinnon has shown through zooarchaeological data and texts from the period that at least two varieties of hog were critical to Roman diets throughout the Empire's duration. Though Spain and Gaul were principle locations for farming hogs, segments of Italy were heavily taxed for pigs and pork, including Lucania, in Southern Italy, close to Salerno. 
Beyond a clear culinary role, pigs frequently appeared in Roman sacrificial rituals. The "Suovetaurilia", an agricultural rite that aimed to ward of bad fortune, involved sacrificing a pig, sheep, and bull. The sacrifice of pigs, sometimes consumed after rites were finished, would have been relatively commonplace for Roman citizens, and it requires little historical-artistic license to perceive continuity between the pig as a religious sacrifice and pig as a medical "sacrifice", to retroject today's scientific parlance. Galen's pig demonstration indeed mirrors very closely the slicing-open of hogs by soothsayers to divine omens from the Gods.

The widespread availability of pigs in the Roman Empire suggests there was an economic justification for Galen's decisions to utilize pigs: acquiring multiple for a public demonstration would have been dramatically easier and cheaper than acquiring Barbary macaques. Considering the widespread nature of Galen's interests - everything from eating to the voice - there is little reason to separate his religious, culinary, and anatomical expertise into separate spheres. For Galen, diet was central to living well, and thus connected to anatomy. He was well aware of Roman pork production along with transformations in its methods, referring to the era when "acorns were formerly forage for pigs" and the contemporary situation when pigs are "slaughtered [...] at the beginning of winter and used [...] for food" (Galen 2000, 136). Pork, he notes later in the same text, "is the most nutritious" of all foods (Galen 2000, 154). Thus, while dissection was a distinct act from butchering a pig for consumption, we might see them as cross-pollinating bases of knowledge.

Yet that he ate pigs is not in itself proof of anything - few Roman chefs stand out as scions of anatomical study. But if we remain within the realm of Galen's culinary expertise, we notice something intriguing: he seemed to know very little about the taste or quality of animals such as the dog. And of the rabbit, that "little animal in Spain [that] looks like a hare", he knew even less (Galen 2000, 156). However, when he discusses the pig, he moves part-by-part, differentiating between the taste and texture of the trotters, the noses and ears. Thus, of the animals that today we might consider ideal for medical dissection or experimentation dogs, rabbits, rats - Galen had given comparatively scant consideration. Though it is probable that he did, indeed, dissect cats, dogs, and a selection of other animals (Mattern 2013, 151), pigs were perhaps the most familiar subjects - for dinner as much as for experiment.

Here science and culinary knowledge combined, influencing the conduct of experiment on nonhuman animals and, perhaps to a significant extent, what kinds of animals Galen had access to and in what numbers. There was a kind of feedback loop, in other words, where the culinary culture that produced large-scale breeding programs for pigs had also contributed to the development of some of Rome's most famous anatomical demonstrations. When hogs outlasted the Roman Empire, they helped to transmit Galen's experiments to Salerno across darker ages and 
conquests. Although such a claim might give pigs too much credit for a preserving action they could not possibly have intended, it is important to keep in mind how pigs have functioned across times and places as walking storage "banks" of knowledge and credit (Scott and Zeuske 2002). Pigs were ambulatory bodies of knowledge, and in their relationships with the humans that tended and hunted them, they kept alive anatomical-culinary knowledge.

\section{Back to Salerno}

As MacKinnon argues, a relatively intensive hog-breeding program took place in Southern Italy during Galen's day, with large numbers near to where the Salerno physicians would later practice. And, far from collapsing as the Roman Empire dissolved, pig breeding appeared remarkably consistent throughout the Medieval period when pork remained "one of the most important sources of meat and fat" throughout Europe (Adamson 2004, 30; Vanpoucke et al. 2007). A wealth of preserved recipes from Medieval Europe - "Stuffed Suckling Pig", for one - suggests that while pigs were not quotidian fodder, they were common enough in the diets of Medieval Salernitans (Redon, Sabban, and Serventi 1998, 104). There are even similarities between the style of preparing a suckling pig by incising its throat and allowing it to bleed before working through the internal organs and the instructions offered in the Anatomia porci. Thus, even if they had read none of Galen's texts, these practices and rituals of consumption could have bled into more "scientific" pursuits.

Therefore, when the Salernitans claimed that the pig should be dissected because Galen had done so before and because the pig, unlike the monkey, is the animal most similar to man, one senses culinary familiarity and ecological proximity playing a more significant role in the selection of the dissected animal than the authors care to admit. After all, as contemporary accounts of the selection of various kinds of model organisms have shown, choices for a given scientific question are not always as free from external pressures as practitioners imagine (Kohler 1994; Rader 2004). The difficulty of acquiring Barbary macaques for dissection during the twelfth century, when the Principality of Salerno was fraught by wars of succession and invasions from abroad, along with all that came from living inside a heavily fragmented Italian Peninsula, cannot be overstated. While trading networks existed, the Salernitan physicians would have had to work with what was available. That, it seems, was very likely pigs.

\section{Correct Cutting, Subjects of Pigs}

If we have seen how the economic availability of and culinary expertise concerning hogs were essential in enabling their use within scientific 
practice, particularly the earliest forms of anatomical investigation, we have done little to explore the significance of the Salernitan anatomies for the researchers themselves. If, as I have argued, the Anatomia porci included a critical subdivision of transspecies similarity, whereby there were external likenesses and internal similarities, it also established within the foundations of Eurasian science that cutting apart pigs was a proper way to understand the human. This would have a critical impact for the centuries to come.

Greek and Roman philosophers had long imagined themselves, to varying degrees, as transcendent apes - but to explicitly bring the human in line with the pig, to suggest that cutting into one offered radical insights into the other, was a relatively novel idea. Even today, efforts to draw humans and pigs together face resistance: in 2013, a self-proclaimed "expert on animal hybridization", Eugene McCarthy, suggested that human beings might be the offspring of primates and pigs (Gayle 2013). The theory, he noted, explains our hairless skin and the ease with which pig valves can be implanted in human bodies. Reprisals against McCarthy's theory were swift and dismissive, but shares, likes, and the ensuing controversy suggest that many are not altogether comfortable with the similarity of pigs and men even now.

Thus, the kind of anatomy popularized at Salerno, expanded upon later by Vesalius, and centralized in modern classroom dissection pedagogy, was also a process of self-discovery interlinked with underlying conceptual distinctions between what was human and nonhuman. Only humans that could engage in the proper "ana-tomia", the proper cutting up of the natural world. Only humans stood apart enough to recognize the necessity of this cutting, and, equally significantly, the "human" emerged from the cutting up of the nonhuman. This anatomia was a kind of ontological investigation, an effort to understand and teach what we are and what the other "brute beasts" are as well.

This perspective, one that recognizes the violence inherent in the anatomical enterprise while also acknowledging its formative and generative effects, is key, particularly due to a tendency in animal studies to perceive Western scientific rationality as a violent monolith of unthinking anthropocentrism. In contrast, it is valuable to recognize the genuine curiosity and ethical complexity at play in animal experimentation of all varieties. What, after all, do scientists do when they experiment on pigs, when they ask after similarity? Georges Canguilhem offers an eloquent answer when, reflecting on Jean Giraudoux's Elektra, he notes "the beggar" character "who stumbles across squashed hedgehogs on the road, meditat[ing] on the hedgehog's original sin that drives him to cross roads". For Canguilhem, the beggar's reflection is absurd. He writes:

Hedgehogs as such do not cross roads: they explore, in their own way, their own hedgehog milieu, on the basis of their alimentary 
and sexual impulses. On the contrary, it is man-made roads that cross the hedgehog's milieu, his hunting ground and the theater of his loves, just as they cross the milieus of the rabbit, the lion, or the dragonfly. Now, experimental method [...] is also a sort of road that the human biologist traces through the world of the hedgehog, the frog, the fruit fly, the paramecium, or the streptococcus [...]. [W] will say that the knowledge of life must take place through unpredictable conversions, as it strives to grasp a becoming whose meaning is never so clearly revealed to our understanding as when it disconcerts it.

(Canguilhem 2008, 22)

Beyond the literary appeal of seeing biological experimentation as one of so many roads carved into the animal world, Canguilhem's vision of biological experimentation as an iterative grasping at a becoming that continually disconcerts our understanding resituates experimentation as a form of life within a broader world of becoming. Knowledge of life, animal or otherwise, emerges through moments of disconcertion, rather than a unidirectionally domineering desecration of the natural world. Hogs, though hardly equal partners in the strict sense of the term, are active agents in the creation of knowledge concerning "human" existence.

Keeping in mind the relationship of anatomical knowledge to the ontological edifice of "the human", I would like, now, to jump forward to consider the ways contemporary artists have approached the issue of human-nonhuman similarity, culinary-cultural knowledge, and sacrifice that have motivated this chapter so far. If anatomy and experimental method are efforts to grasp a disconcerting becoming, so too are artistic interventions that analyze and perform different becomings (becomingswith or otherwise). In these artistic and aesthetic engagements, we find alternative possibilities for relationships between human and nonhuman animals as well as the enduring significance of mute hogs.

\section{The Body of the Pig}

At the Lódź Biennale in 2010, the artist Miru Kim staged a performance entitled "Mud Bath for Thick Skin". Kim is known for her adventurous photography, appearing nude in city sewers, atop bridges, and even in the airy sands of the Sahara. But "Mud Bath for Thick Skin" and its precursor pieces, "The Pig That Therefore I Am" and "I Like Pigs and Pigs Like Me", offered something distinct. To understand why, we need to examine the pieces in sequence.

In "The Pig That Therefore I Am", which begins the porcine series, Kim's unclothed body appears contorted in a sty: at times, her face is hidden behind long hair or turned away from the camera, her body crouched down amidst large industrial hogs, sometimes in and sometimes 


\section{Brad Bolman}

outside of their gated pens. The images draw attention to the paradoxical similarity between hogs and humans, particularly in their skin. As Kim writes, "Both a pig and I carry our exteriorized memories on our cutaneous garment-scars, blemishes, wrinkles, and rashes that manifest markings of time, anguish of the soul, wounds of love and war" (Kim 2010). Her nakedness next to the nakedness of the hogs establishes a visual regime of identification, with skin touching skin, bodies draped across each other. The resemblances and correspondences between artist and hog is so great that many of the photographs are a transspecific Where's Waldo, as one seeks the artist within a sea of hairy hog bodies, standing, lying, or walking around. More than merely concealed by a porcine camouflaging, Kim's body and the bodies of the pigs become interchangeable. In one, her head may seem connected to a hog in front of her, while in another her body appears in multiple pens simultaneously. As the photographs progress, Kim becomes dirtied by her environs, and the markings on her flesh, both those that come from the setting and the scars and blemishes that hold a longer history, mimic and mirror the marked bodies of the hogs, with their own histories of abuse, love, and an enclosed vitality. In the shadows of the sty, the clear distinction between hog and human is blurred.

The photographs are bisected by a blurred line separating skin from skin, but as the question of which bodies we are viewing becomes increasingly confused, folding into each other, the "hog" portion of each photo appears less like an opposition and more an alternate view of human skin. The artist notes, "Two bodies mingled momentarily, in the skin on skin contact. I could no longer reason whether I was feeling the pig's abdomen on my thigh, or the pig was feeling my thigh on her abdomen" (Kim 2010). For Kim, the dissolution between what is properly human and properly porcine demonstrates "two souls mingled on the plane of contact", which she contrasts to the traditionally Western notion of Cartesian subjectivity, where body and soul stand apart from one another.

At the same time, the images have a way of highlighting the dissimilarity between human and hog. While there is parallel bruising and blemish, the skin of hog bellies, for instance, displays cracks and bumps that do not mark Kim in the same way. Kim's long, dark hair acts as a clear visual separator, the smoothness of her body distinct from the hairy roughness of the pigs. Form and posture also diverge, particularly Kim's capacity to kneel as well as stand upright, moving fluidly in and out of the gates. Like Red Peter, the ape in Kafka's "A Report to an Academy" (1917), the "way out" of confinement in the pens appears to be a becoming-human - one that remains inaccessible to the hogs themselves. There is, then, a melancholy to the "external" photos in which Kim looks upon fenced-in hogs that sometimes reach out to her with their snouts or retreat so quickly that the photograph captures 
only spectral traces of escape. There is also a sexual charge to them: not so much in the interplay of nudity and eroticism, but in the echoes of an old poem by John Wilmot, Earl of Rochester, about the maiden Chloris, who lies with her pigs in their pen, inspired by their grunting dreams of sexual violence (Rochester 2013, 16-17). The vital bodies lying next to each other display a lingering sexual energy that gives way equally to nightmare and fantasy.

\section{Naked Responsibility}

Kim writes that she first came to recognize the similarity of humans and pigs in a dissection during her time as a premedical student: "I remember peeling away carefully with forceps, scalpel, and scissors, the integument of a fetal pig". "Layer by layer", she continues, "I got to the abdominal cavity. When it was finally cut open, I saw an elaborate cluster of organs arranged in a way almost identical to what I'd seen in human anatomy books" (Kim 2010). Through the proper cutting, the ana-tomia, she comes to recognize the profound similarity between species and cannot continue school. Kim's turning away from medicine because of classroom dissection mirrors the experience of many students who find something upsetting about cutting apart beings whose insides remain so like our own. PETA, People for the Ethical Treatment of Animals, for instance, describes dissection not as anatomical education but as so many "lessons in cruelty" ("Dissection: Lessons in Cruelty" n.d.).

Considered from this perspective, Kim's naked openness to the pigs echoes Jacques Derrida's mute nakedness in front of his cat. Derrida, reflecting on feeling "Ashamed of being as naked as a beast", refers to a long philosophical history that sees the nudity of nonhuman animals as impossible: the beast cannot be nude because it is already naked, knowing nothing of the techne of clothes (Derrida 2008, 4-5). Kim's work, which seeks a nudity without shame, becomes a project of vulnerability, an effort to allow what is normally impossible - the body-to-body connection of human and hog - to exist, however fleetingly. In these moments of contact where Kim's body grazes and blurs into the pig that therefore she is, and as the viewer gazes upon the photographic evidence of these precarious encounters, the firm boundary of the subject, her "human" skin, dissipates. As Judith Butler argues, vulnerability is powerful precisely because of its capacity to undermine our self-contained individuality, because it preconditions ethics of every kind: "[T]he ' $\mathrm{T}$ ' becomes undone in its ethical relation to the 'you,' which means that there is a very specific mode of being dispossessed that makes ethical relationality possible" (Butler 2015, 110). We are defined, in Butler's conceptualization, by our responsibility to and for those others around us. This vulnerability, which is less a choice than a condition of existence, 


\section{Brad Bolman}

makes ethics possible. As Kim's work emphasizes, our vulnerability and responsibility extend to those hogs that live otherwise invisible lives at the outskirts of our cities.

There is, nevertheless, a more pessimistic reading of Kim's work that resonates with what has already been suggested about anatomical education: the inescapable sense that "The Pig That Therefore I Am" remains a profoundly buman and humanizing way of approaching the porcine world. Just as Derrida's being-seen by the cat can be interpreted as merely another moment of philosophical masculinity that underplays dominance (Guenther 2009), the photographs might merely replicate the simultaneous external-internality of the anatomist who cuts apart the other in order to recognize him- or herself, both because Kim often appears included-but-separate and because the camera's gaze creates a further layer of mediation. They become, in this view, little more than "tourist" photographs (Cherry 2016, 72): the artist might choose temporarily to kneel down in tight quarters with large hogs, enduring moments of hardship to generate an alternate interpretation of human phenomenology, but this openness remains transient and objectifying.

\section{Being and Becoming a Beast}

Yet we should emphasize the significance of the transitory opening that her work provides: "The Pig That Therefore I Am" offers something beyond the "shameful" reflection that Derrida's cat inspires in him. Less an effort to rearticulate a particular phenomenological experience - and here, I depart from Kim's own analysis - her proximity to the pigs, lying with them and being dirtied as they are, enclosed and penned in, offers a kind of temporary companionship with the animals, a willingness to open up the human self to complex animal behaviors, a mutual regard that asks after their interests and desires, allowing pigs to be pigs. It might be an example of what Donna Haraway has called, rather than the Deleuzian and Guattarian notion of "becoming-animal" (Deleuze and Guattari 1987), a "becoming-with", an embodied human engagement with specific animal others (Haraway 2008, 28). According to Haraway, work with companion animals (in scientific contexts as well as our relation to pets) is not a unilateral relation of dominance, but a relationship of response-ability that transforms all parties, human and non-human. In this light, "The Pig That Therefore I Am" can be understood as the record of a practice of becoming-with, one that emerges, significantly, from the particular subject-crafting functions of anatomy.

Elizabeth Cherry has suggested that Kim's work "highlights the symbolic boundaries between humans and animals" and offers an example of art that contributes directly to mobilization into animal rights activism (Cherry 2016). But her conclusion, that "directly" political art and projects that are much less obviously so may both produce activist 
possibilities, seems relatively uncontroversial, failing to do justice to the conceptual complexity of "The Pig That Therefore I Am".

In Becoming a Beast (2016), Charles Foster seeks to articulate an alternative approach to nature-writing and another method of reflecting on animality: instead of a distanced theorization of concepts and consciousness, he argues that the truest analyses of human and nonhuman capacities will emerge from living with, alongside of, and perhaps even as those animals themselves. Following in the tradition of works like J. A. Baker's The Peregrine (2004) or, more recently, Thomas Thwaites's GoatMan (2016), Foster spends time living as a badger, a fox, and a swift, each time finding ways to transform and extend his phenomenological experience through the forms of life of the particular creature he studies (Baker 2004; Thwaites 2016). As a badger, for instance, he burrows into a hill, eats earthworms, and learns to rely more on smell more than vision.

Yet, even as he stretches his capacities, seeking new methods of exposure to the vital world, Foster remains aware of the limitations of his body, the way it differs from the birds and beasts he tracks and impersonates. As he writes:

I'm much less local [than the badgers]. Despite my best efforts, many of my molecules come from China and Thailand. I have to work a lot harder to get any kind of resonance. Yet there are many things that can help: history books; the songs and tunes of dead farmers; the stories that cling to the land and to my mind as earth clings to the back of a badger. I can slowly learn the mythological language in which the land speaks both to me and to the badger, and it suffices for some sort of conversation even if the badger and I falter in our neuronal dialects.

(Foster 2016, 25)

Echoing Canguilhem's notion of the experimental method as a tracing through the lifeworld of experimental animals, Foster sees "being a beast" as a combination of understanding through stories and more direct phenomenological experience. In Kim's work, too, there is a family resemblance to this slow practice of "being a beast", of allowing oneself to practice a becoming-with that pushes beyond archetypical "human" experience. As Kim lies among the hogs, even though she can exit their pens in a way that the pigs themselves cannot, she both limits and expands her own experiential possibilities; in Butler's terms, she embraces a vulnerability that tests the bounds of the "human", one that might allow for more ethical engagement with the nonhuman world. While these bodies remain closed up, uncut, the contact between skin - the movement of living flesh that brushes against others, offers a different kind of openness. 


\section{Brad Bolman}

"Mud Bath for Thick Skin" (2010), a multimedia installation that followed Kim's first pig project, shifts the context significantly: now she appears in an underground storage room atop a pit of mud which she gradually covers herself in over the course of six hours. At her eye level, a screen replays video from "The Pig That Therefore I Am". Spectators may watch her covering herself from afar, as well as see video of her earlier time with the pigs, footage that was not originally centered in "The Pig That Therefore I Am". Beyond the endurance required by covering one's body in mud for hours inside a cold basement - these feats of endurance, of reaching unreachable or hidden places and braving harsh conditions, are central to Kim's work - "Mud Bath" also emphasizes the hidden challenge of the previous pig photos. Rather than the almost meditative calm or peace of the photographs, we see Kim knocked around, chewed on by the hogs, fighting to maintain stability in the midst of large and unwieldy creatures.

This alternate perspective also echoes a strange but persistent American myth: that more farmers die at the jaws of their pigs than from any other comparable workplace danger. The myth is, strictly speaking, false. Nevertheless, this fable, a kind of warning that appears in diverse publications and arises out of the very real danger presented by enormous farm hogs, reminds us of the oft-occluded violence of the natural world that the increasing disconnection of urban dwellers from non-domesticated animals enforces (Cronon 1992); of violence that is both ours and theirs, a point made beautifully and hauntingly in Werner Herzog's Grizzly Man (2005), where the main character, Timothy Treadwell, attempts to live in peaceful coexistence with animals only to find himself killed by the bears he named, cared for, and sought to protect (Bolman 2012). One cannot forget that alongside the desire to atone for the violence of the human past lives the irreconcilable alterity of the other, the possibility for openness and hospitality to be radically rejected.

As Kim is knocked through the mud by large hogs that have been reconfigured - aesthetically, genetically - by breeders and factory farms, it is important to recognize that the skin she touches is not a pure barrier between bodies, a neutral screen for phenomenological experience between living beings on an equal plane, a flimsy wall between self and world. Indeed, this skin is not natural at all. Instead, this skin is itself a kind of fabrication, transformed for scientific and agricultural needs and crafted by centuries of domestication. Thus, where Kim and other commentators have focused on the presence of human and animal bodies together, even as I have located the practice of an alternate relation to animals in her work, it is equally significant that this relation cannot escape a multiplied human mediation: between human animals and animals that have been constructed by humans, almost from the bottom-up, for reasons of cuisine as much as control. "Mud Bath", then, offers a refracted view on the original work, one that emphasizes the 
presence of constructed "similarity" and fabricated "nature" in factory farms and our relationship to the natural world more broadly.

\section{Becoming-pig, Becoming Pigs}

To suggest that Kim's engagement with the pigs is lessened due to the crafted nature of the hogs would oversimplify: "Mud Bath" displaces the human gaze, as Kim's lonely performance occurs under the watchful (though pre-recorded) eyes of the pigs as well as the visitors. Kim suggests that the title of the work is derived from the "Poet" character in August Strindberg's A Dream Play (1901). Midway through the play, the Poet walks onstage "with his eyes raised toward the sky and carrying a pail of mud in one hand" (Strindberg 1913, 61). The Officer, upon seeing this strange visitor arrive, quips that a mud bath makes no sense for such a man, who "ought to be having light baths and air baths". But a third character responds that it makes perfect sense, for the poet "is roaming about the higher regions so much that he gets homesick for the mud and wallowing in the mire makes the skin callous like that of a pig. Then he cannot feel the stings of the wasps". The Officer, befuddled, notes that they live "in a queer world, full of contradictions". This homesickness, or perhaps nostalgia, is clearly at play in Kim's work, of bathing herself in the mud, making her skin callous.

But the Poet connects his mud bath not simply with a return to nature or a descent from the realms of abstraction, but also with a kind of truth-telling. To explain why justice has failed to reach all the residents of the region equally, he offers a short allegory:

That much the Caliph, Haroun the Just, came to understand. He was sitting on his throne, and from its height he could never make out what happened below. At last complaints penetrated to his exalted ears. And then, one fine day, he disguised himself and descended unobserved among the crowds to find out what kind of justice they were getting.

(Strindberg 1913, 63)

The mud bath and Haroun's descent among the people are linked as parallel methods for better understanding and responding to the failures of justice that exist among humans and their nonhuman others: two ways of covering the skin, two encounters with abjection, both highlighting differences of experience. In this way, Kim's bath becomes more than a banal, nostalgic departure from the "challenges" of the civilized world to some dirtier and more complex universe of feeling: it is also a mode of knowledge-gathering and practice that clings to the possibility of a justice that has not yet arrived.

When one watches from the perspective I have offered, this slow almost degrading - performance of mud-covering appears as a form 


\section{Brad Bolman}

of becoming-with that differs from the emergent, crazed movement between worlds and states that the most messianic interpretations of "becoming-animal" have occasionally offered (Vint 2005; Goh 2012). Instead, we have a cautious, embodied practice that is framed by the violence of nature and of creation. Despite the immediate visual perception of two natural beings together in the nudity of their creation, the "sameness" that Kim sees in the pigs was never a "wildness" that humans and animals share waiting to be discovered, but a similarity constructed, noticed, and reinterpreted through the millennia, from Salerno's anatomies to today's factory farms and medical research. As Kim performs pigness for the pigs, despite their lack of regard, seeking in a sense to erase her skin in front of the human spectators, she places herself uneasily between spaces and forms of life.

Kim's final effort in the pig series appears more direct and playful than the previous pieces, yet confirms the argument offered so far. Titled simply, "I Like Pigs and Pigs Like Me", viewers walk up to a small room, walled off by a large piece of transparent glass, inside of which Kim lives for 104 hours with two hogs. She moves with the pigs, at times protecting herself from their unwanted advances, at times feeding them or trying to steal a narrow slice of space for herself to eat unbothered. Whether the artist likes the pigs or they like her is difficult to answer from an exterior perspective, but they are nevertheless becoming-with each other as Kim attempts to build a life for herself inside the enclosure as the pigs make sense of her presence within their Umwelt. Like the pigs, she has no escape. Like the pigs, she must lie in mud, eat the small quantities of food available. Because she is not posing for photographs but merely subsisting, "I Like Pigs" appears like an additional porcine chapter in Foster's experiments with "becoming a beast". Perhaps animal becomings exist in these moments of cautious practice, rather than in strange transitions; in the willingness to commit oneself, even temporarily, to another kind of living, to becoming more than human by becoming more porcine.

\section{Becoming-with-Hogs}

In this chapter, I offered an alternate history of anatomy that emerges from the bodies of pigs. I showed how these early moments of pig experimentation laid foundations for the notion of human-pig similarity that has persisted, in numerous forms, to the present. I connected the movement of knowledge inside of bodies themselves to the way contemporary art and literature have used hog bodies, focusing particularly on the practice of contemporary artist Miru Kim, whose photographic, video, and performance pieces toy with the boundaries of human and hog. I suggested that her work serves as an example of "becomingwith" (Haraway 2008), and emphasized its pace, the slow rhythms of 
cooperative formation and being together: a philosophical approach to becoming that is nevertheless cognizant of the particular interventions that humans and pigs have made into each other's bodies. Just as culinary practices combined with scientific ones to make hogs into exemplars of human beings, Kim's work highlights the anatomical relations that haunt engagements (or lack thereof) with often invisible swine.

I want to end with another work of art, another becoming-with and intervention into the politics of human-animal bonds: an art installation by Joseph Beuys titled, "How to Explain Pictures to a Dead Hare" (1965). In the piece, Beuys strolls through a locked gallery of paintings, holding a dead hare and explaining paintings to it. Beuys's viewers are left uneasily outside, watching him pace the gallery from a large window, seeking to understand his peculiar ritual. Beuys covers himself in gold and other materials, which Kim playfully inverts with mud in her own work. Beuys then walks through the gallery as something other than "normally" human, describing paintings to the hare. What could possibly be said to this animal whose skin has been routinely cooked to produce the glue that has primed stretched canvases since the Renaissance?

In The Jungle (1906), Upton Sinclair looks at the cruel efficiency of a Chicago pork plant and wonders: "Who would take this hog into his arms and comfort him, reward him for his work well done, and show him the meaning of his sacrifice?" (Sinclair 1906). In Beuys's and Kim's works, in the aimless covering and occlusion of the phenotypical markers of humanity, human and pig are reconfigured. A faltering attempt is made to offer meaning to the hog's and the hare's sacrifice. Where Beuys might retain a certain nostalgia for lost naturalness, the severing of humans from an original wholeness, Kim seeks not to save or fully explain the hog's sacrifice but, perhaps more simply and just as powerfully, to treat them as they are and take them into her arms.

\section{Notes}

1 I am thankful to attendees of the "Reconfiguring Human and Nonhuman" conference in Jyväskylä for comments on an early version of this chapter. Original inspiration for the piece came from a course taught by Katharine Park and Ahmed Ragab. I am also grateful to Sophia Roosth for advising the thesis from which some of this material also originated.

2 Though there is some debate, it seems his primary experimental subjects were Barbary macaques, acquired from the Gibraltar region of Spain or North Africa through Roman trading networks, along with a composite of other available nonhuman primates.

\section{References}

Adamson, Melitta Weiss. 2004. Food in Medieval Times. Westport, CT: Greenwood Press.

Baker, J. A. 2004. The Peregrine. New York: New York Review of Books. 
Bolman, Brad. 2012. "Seeking Peace, Finding the Violence of the Real: Traumatic Ecologies and the Post- Political Present." International Journal of Žižek Studies 6 (1): 1-19.

- 2015. The Pigs That Therefore We Are: 20th Century Porcine Biomedical Experimentation. Undergraduate, Cambridge, MA: Harvard University.

— 2018. "How Experiments Age: Gerontology, Beagles, and Species Projection at Davis." Social Studies of Science 48 (2): 232-258.

Butler, Judith. 2015. Notes Toward a Performative Theory of Assembly. Cambridge, MA: Harvard University Press.

Canguilhem, Georges. 2008. Knowledge of Life. Translated by Stefanos Geroulanos and Daniela Ginsburg. Forms of Living. New York: Fordham University Press.

Cherry, Elizabeth. 2016. "'The Pig That Therefore I Am' Visual Art and Animal Activism.” Humanity \& Society 40 (1): 64-85. doi: 10.1177/01605976 15586620

Cronon, William. 1992. Nature's Metropolis: Chicago and the Great West. New York: W. W. Norton \& Co.

Deleuze, Gilles, and Félix Guattari. 1987. A Thousand Plateaus: Capitalism and Schizophrenia. Translated by Brian Massumi. Minneapolis, MN: University of Minnesota Press.

Derrida, Jacques. 2008. The Animal That Therefore I Am. Edited by Marie-Louise Mallet. Translated by David Wills. New York: Fordham University Press.

"Dissection: Lessons in Cruelty." n.d. PETA (blog). Accessed February 26, 2015. www.peta.org/issues/animals-used-for-experimentation/animals-usedexperimentation-factsheets/dissection-lessons-cruelty/.

Foster, Charles. 2016. Being a Beast: Adventures Across the Species Divide. New York: Metropolitan Books.

French, Roger. 1999. Dissection and Vivisection in the European Renaissance. Aldershot: Ashgate.

Galen. 1962. Galen on Anatomical Procedures: The Later Books. Edited by M. C. Lyons and B. Towers. Translated by W. L. H. Duckworth. Cambridge, MA: Cambridge University Press.

- 2000. Galen on Food and Diet. Translated by Mark Grant. London: Routledge.

Gayle, Damien. 2013. “'Humans Evolved after a Female Chimpanzee Mated with a Pig': Extraordinary Claim Made by American Geneticist.” Daily Mail. November 30, 2013. www.dailymail.co.uk/sciencetech/article-2515969/ Humans-evolved-female-chimpanzee-mated-pig-Extraordinary-claimAmerican-geneticist.html.

Goh, Irving. 2012. "Becoming-Animal: Transversal Politics.” Diacritics 39 (2): 37-57. doi: 10.1353/dia.2009.0008

Gross, Charles G. 1998. "Galen and the Squealing Pig." The Neuroscientist 4 (3): 216-221. doi: 10.1177/107385849800400317

Guenther, Lisa. 2009. "Who Follows Whom? Derrida, Animals and Women." Derrida Today 2 (2): 151-165. doi: 10.3366/E1754850009000499

Haraway, Donna J. 2008. When Species Meet. Minneapolis, MN: University of Minnesota Press. 
Jansen, Katherine L., Joanna Drell, and Frances Andrews. 2011. Medieval Italy: Texts in Translation. Philadelphia, PA: University of Pennsylvania Press.

Kim, Miru. 2010. “The Pig That Therefore I Am.” 2010. http://mirukim.com/ writing-pig/.

Kohler, Robert E. 1994. Lords of the Fly: Drosophila Genetics and the Experimental Life. Chicago, IL: University of Chicago Press.

MacKinnon, Michael. 2001. "High on the Hog: Linking Zooarchaeological, Literary, and Artistic Data for Pig Breeds in Roman Italy." American Journal of Archaeology 105 (4): 649-673.

Mattern, Susan P. 2013. The Prince of Medicine: Galen in the Roman Empire. New York: Oxford University Press.

O’Neill, Ynez Violé. 1971. "Another Look at the 'Anatomia Porci." Viator 1 (1): 115-124.

Rader, Karen A. 2004. Making Mice: Standardizing Animals for American Biomedical Research, 1900-1955. Princeton, NJ: Princeton University Press.

Redon, Odile, Françoise Sabban, and Silvano Serventi. 1998. The Medieval Kitchen: Recipes from France and Italy. Translated by Edward Schneider. Chicago, IL: University of Chicago Press.

Rochester, John Wilmot Earl of. 2013. Selected Poems. Edited by Paul Davis. Oxford: Oxford University Press.

Scott, Rebecca J., and Michael Zeuske. 2002. "Property in Writing, Property on the Ground: Pigs, Horses, Land, and Citizenship in the Aftermath of Slavery, Cuba, 1880-1909." Comparative Studies in Society and History 44 (4): 669-699. doi: 10.1017/S0010417502000324

Sinclair, Upton. 1906. The Jungle. Penguin Classics Deluxe Edition. New York: Penguin Books.

Smith, Pamela H. 2014. "Knowledge in Motion: Following Itineraries of Matter in the Early Modern World.” In Cultures in Motion, edited by Daniel T. Rodgers, Bhavani Raman, and Helmut Reimitz, 109-133. Princeton, NJ: Princeton University Press.

Strindberg, August. 1913. Plays. Translated by Edwin Björkman. London: Duckworth \& Co.

Thwaites, Thomas. 2016. GoatMan: How I Took a Holiday from Being Human. New York: Princeton Architectural Press.

Vanpoucke, Sofie, Fabienne Pigière, Ann Defgnée, and Wim van Neer. 2007. "Pig Husbandry and Environmental Conditions in Northern Gaul during Antiquity and the Early Middle Ages: The Contribution of Hypoplasia Analysis." Archaeofauna 16: 7-20.

Vint, Sherryl. 2005. "Becoming Other: Animals, Kinship, and Butler's 'Clay's Ark." Science Fiction Studies 32 (2): 281-300. 


\section{Reconfiguring Human and Nonhuman Animals in a Guiding Assemblage Toward Posthumanist Conception of Disability}

\section{Hana Porkertová}

Over the last three years, I have engaged in qualitative research with six visually impaired people, the boyfriend of one of them, a guide dog, workers in an organization providing services for visually impaired persons, and several random people with whom my communication partners came into contact. The following chapter is about two of them, a thirty-two-year-old woman named Eva ${ }^{1}$ and her guide dog Nessie, whose relationship departs from the humanist logic of the difference between human and nonhuman animals. I show how not only this boundary but also the concepts of humanity and animality are reconfigured in a guide team that Eva and Nessie have created.

I draw on ethnographic research, "based on fieldwork using a variety of (mainly qualitative) research techniques but including engagement in the lives of those being studied over an extended period of time" (Davies $2002,4-5)$. This method allows me to capture the heterogeneity, dynamics, and interconnection of the phenomenon of disability as well as the guide team. The relationship between Eva, Nessie, and I has grown into a friendship and brought forth great moments spent with both of them. The study is thus a combination of different methodological techniques, ranging from interviews through e-mail communication connected to the research to less formal ethnographic observations and conversations about the experience of a visually impaired person. Although the fuzzy distinction between research and friendship may be risky, I have allowed the relationship to flow naturally.

The methodology used in my research corresponds to "connective ethnography", which has its roots mainly in IT technologies. It can capture their dynamics (Dirksen, Huizing, and Smit 2010), and it "orients towards connection and mobility rather than to pre-defined field sites" (Hine 2007, 619). The method lies in "tracing the flows of objects, text, and bodies" (Dirksen, Huizing, and Smit 2010, 1046) instead of focusing on static and fixed borders. I draw on the presumption that connectivity and dynamics do not involve only IT technologies but are also inherent in disability. 
I analyze Eva and Nessie's relationship and the phenomenon of disability through the concept of assemblage (Deleuze and Guattari 2005). An assemblage is a construction consisting of heterogeneous connections and conjunctions, organic and inorganic, linguistic, material, and so forth that are being changed and reconfigured, gaining new qualities during the process of mutual encounters. A constant dialogue between discursive and non-discursive elements occurs, which cannot be reduced to one or the other. Connections within an assemblage are often unpredictable, imperceptible, and uncontrollable, and they enable to do something while disabling to do something else. Despite its dynamics and fluidity, an assemblage acquires certain articulations and stability in particular configurations. Stability does not stop the process but infers its predictability and continuity.

An assemblage of a visually impaired human and her guide dog is an encounter point where a human, a nonhuman animal, technology, and disability meet and acquire new discursive articulations as well as otherwise unavailable activities. Both Eva's and Nessie's bodies and experiences evolve. Further, the concept of disability attains different contours and elicits different reactions, for example, varying from the typical connection with a white cane. The dog herself is transformed, too, since she is not a pet anymore, but a professional assistant with access to territories strictly prohibited to "animals". Emerging conjunctions between these heterogeneous elements blur the mutual boundaries in which modern thinking is entrenched - above all, the division between nature and society (Latour 2002). They affect distinctions between humans and nonhuman animals, humans, and technology and nonhuman animals and technology (in other words, organic vs. inorganic). The conjunction between Eva and Nessie is an occasion for rethinking animals and humans and reconfiguring their relationship. It cannot be based on the humanist conceptualization since it defies the purified distinctions grounded in negative difference based on identity, opposition, analogy, and resemblance (Deleuze 2004, 38).

\section{A Human-guide Dog Assemblage and the Territorialization of the Guide Team}

Rod Michalko (1999), a sociologist who has written an autobiographic book about his experience with a guide dog Smokie, says: "We are often compared to other dog guide teams, and I am compared to other blind people, Smokie to other dog guides" (54). However, when the concept of assemblage is introduced, it is not sufficient to analyze "input elements" and compare a dog with a dog and a human with a human. Assemblage is a "multiplicity", that is, "the one AND the multiple", sustaining heterogeneity and independence on the one hand, but representing associations on the other (Deleuze and Guattari 2005, 26-38). 
Therefore, it is important to analyze a human together with her or his guide dog, because their assemblage does not consist of the aggregate of their original qualities; it creates new ones depending on their mutual conjunctions. My study defines the guidance itself as such a new quality, without asking the insolvable question of "who guides and who is guided". Lestel, Brunois, and Gaunet (2006) remind us that the analysis "cannot be reduced to either the behaviors of the animals with which humans interact or the representations humans have of these animals" (ibid., 170). We must focus on how they behave together and how they create a "human-dog entity" (ibid.).

The dynamic character of an assemblage implies that it is not only important to capture the current associations of which it consists, but also to analyze what had preceded its current form - precisely, how the two parties (in this example) had been preparing themselves for the future conjunction. Nessie's life had been affected by the forthcoming assemblage with Eva even before she was born as her parents had been deliberately chosen so that their puppies can become guide dogs one day. When a puppy is born, genetic tests are run, and a thoroughgoing training follows until she is ready to join a visually impaired human. Eva got her as a highly trained guide dog, but that does not imply that their assemblage had already been established at that moment.

In addition to exploring associations within an assemblage and focusing on what they $d o$, one must analyze how the assemblage is being territorialized, in other words, how it holds together. Territorialization stabilizes the assemblage, gives it form and relative permanency, which "establishes connections between certain multiplicities" (Deleuze and Guattari 2005, 23). Simultaneously, there are numerous deterritorializations. They occur when a process of becoming is detached or escapes from its original territory. A new connection enters the territory, which results in the reassembling of an assemblage. Deterritorialization not only generates possibilities of change and rupture but also represents an indispensable part of territorialization itself (ibid.). Deleuze and Guattari thus reconcile two seemingly contradictory concepts - stability and change - and simultaneously problematize the difference between discourse and matter when showing how they territorialize into assemblages.

"[After having received Nessie], we would often walk together to get accustomed to each other" (e-mail, December 2, 2015). For the territorializing process, a time element and reiteration of the same or similar activities (never with the same outcome, though) are pivotal features referring to the continual work that makes the assemblage functional. Eva and Nessie's bond must be maintained on many levels, which involves not only guiding itself but also time spent together beyond this activity. The territory has two significant consequences: "a reorganization of functions and a regrouping of forces" (Deleuze and Guattari 2005, 
320). Distinct species - and activities - are specialized, which holds true also for a human and her or his guide dog. Getting to know each other indicates specializing in tasks and knowing what the other can do; thus, the ability to see is just one of the functions necessary for the guiding assemblage; other activities require different abilities.

The conjunction of a human with a guide dog and specialization in functions within the assemblage contradicts general humanist perceptions about "animals". Taylor (2013), Haslam (2006), and Rasmussen (2011) accentuate that the boundary separating humans from nonhuman animals lies in "specific" characteristics with which only humans are endowed, and which thus confirm human superiority. It is no coincidence that some of the crucial features upon which the modern subject is built are rationality and the ability to make decisions. Animals serve as the "'constitutive outside' or negative example that enables to define human subjectivity as disembodied and autonomous" (Rasmussen 2011, 101). Therefore, a successful territorialization of a guide team depends on deterritorialization of a solid boundary between human and nonhuman animal and a willingness to admit Nessie's abilities that belong to the "human sphere".

Lately, she surprised me when I found out I shouldn't meddle in her guiding because she knows best where she's going. For example, when I was at the faculty X, I would tell her where to turn and so on, and this February, I finally learned I shouldn't do that. When I navigate her, we always get lost, whereas when I leave everything up to her, it never happens. She just knows where she guides me, and when I start to panic and navigate her somewhere else, and she obeys me after all, it usually doesn't end up well.

(E-mail, March 19, 2016)

Deterritorialization requires the will to risk and often goes against the logic (or rather the rhetoric) of dog's training, which builds upon docility and control. Although veterinary research (Batt et al. 2008; Arata et al. 2009) identifies docility and the ability not to be easily distracted as important factors for the successful territorialization of a guide dog, Eva finds Nessie's intelligence and the ability to make decisions more important. Guiding schools in the Czech Republic also count on so-called "intelligent disobedience", which means that a dog must not carry out the order if it puts the owner into a potentially dangerous situation (Pomocné tlapky o.p.s., ${ }^{2}$ 2009). Eva views absolute docility in a negative light.

Nessie doesn't like observing the rules (or I have spoiled her in this respect, and I don't really mind), which means that she doesn't stop at the edge of a sidewalk, nor does she stop when crossing a road 
or going up the stairs; she just runs upstairs right away. So, she's definitely not a dog who wins medals at guide dog competitions. However, her good memory is her upside. Recently, I had an English lesson at the faculty Y, and I had no idea where it was, so my dad accompanied me for the first time [along with Nessie]. I had Nessie just on the leash; nobody showed her the way. Well, when I went there a month later by myself, Nessie perfectly knew her way around the labyrinthine corridors and walked me to where I needed to get. And this is much more important for me than stopping where some rule says.

(E-mail, March 13, 2015)

Michalko $(1999,72)$ talks about the dichotomy between dominance and submission that is not productive for a guide team as dominance and submission are in constant flux. It is the dog who takes control in some situations, and the human being must let her or him make decisions even if they might think they know better what to do than a nonhuman animal. The same holds true for Eva and Nessie. Eva ascribes to Nessie "extraordinary intelligence", which brings up the underlying question of how to study nonhuman animals and how to approach them when human language limits the realm of our thinking. Then again, it is important to focus on the guide team and explore what these human terms $d o$ in the assemblage. When Eva ascribes extraordinary intelligence to Nessie, the assemblage works in a different way than it would if Eva did not do so.

Allowing Nessie to enter the spheres usually associated only with human intellect and rationality raises the question of autonomy and independence. Gibson, Carnevale, and King (2012) draw on the Deleuzo-Guattarian concept of assemblage to contest the conventional perception of autonomy by replacing it with the terms "interconnectivity" and "interconnections" to discuss means of "doing-in-the-world" (1897) - in other words, finding ways to carry out certain activities. An assemblage is defined by which connections it can make and what this "interconnectivity" can do. Thus, the borders of both mind and body are contested and unclear, and they are in constant flux depending on the connections that form the assemblage. Subjectivity is not delimited by distinctions from others but in combination with them.

Instead of interconnectivity, the modern discourse of the autonomous and independent subject results in dependency and in-sufficiency and contributes to the construction of disability as inferior and the constitutive outside of the modern subject. However, Gibson, Carnevale, and King point out that the idea of independence is just an illusion also for able-bodied people.

Nondisabled people's dependencies are not as readily recognized because they are banal instead of extraordinary, but they still open 
and close possibilities and actions. Mimi works within the interview to establish that her dependencies should also be considered unremarkable, but this requires resisting pervasive negative discourses of disability.

(Ibid.)

For the relationship between Eva and Nessie, the pervasive discourse of disability must be contested, along with the delimiting boundary between human and nonhuman animal. Interconnectivity disagrees with the modern subject not only because it challenges the notion of independence but also because the bond that holds this assemblage together often confronts rationality when emotions (like the love between Eva and Nessie) and trust come to the fore.

I have trusted Nessie from the beginning. Basically, I do not have a problem with trust in general. Well, what else can I do, right? On the contrary, people often wonder how I trust them that they tell me in time that stairs are coming, or won't let me hit something. And it is true that Nessie has not brought about any bigger collision yet. When she lets me hit a traffic sign or fall off a sidewalk, it is just because she is observing other dogs or sniffing some dog's news.

(E-mail, March 3, 2015)

For Eva, trust does not mean complete predictability and the ability to know what Nessie or other people will do (which is necessary for technology). She counts on situations in which they might do something other than the expected: a dog is disturbed by dog-related matters, or a person forgets to tell about the stairs that Eva is approaching (which has happened to me as well). Magnus (2014) says that trust involves an element of risk and the knowledge that the dog is not fully under control. Similar to interconnectivity, trust does not concern only disabled people, but disability highlights it. People who wonder that Eva trusts them, trust many other interconnections, which are, however, mediocre and therefore invisible.

Not only the mental dimension and mutual experience territorialize an assemblage; it is physical aspects as well. Deleuze and Guattari (2005) question the nature of a body and perceive it as an assemblage instead of conceiving it in terms of unity, wholeness, stability, and predictability. It is a "disrupted body" that opposes the idea of the "able-bodied" subject (Shildrick 2009), but only because of such disruptions, a body is able to create assemblages that allow it to do some things. Both Eva's and Nessie's bodies evolve, adjusting to each other during their connection. They affect each other's speed and compose "compound bodies" (Shores 2012, 198). Their composition is maintained in certain ways that ensure its functionality. Nessie walks only by Eva's left side, a bit ahead of her. Eva holds the harness in a certain way, which differs substantially from 
the manner in which she holds my arm when we walk together. The assemblage changes its elements - the bodies - which gain new qualities. The body walks, flexes its muscles, feels, moves, takes up space differently with a dog, with another person, or with a cane (or with more of these at once). Consequently, for getting to some place, it is vital to prepare a route that complies with the whole assemblage and not only with its separate parts. It is not only important which way to walk; the way is created by the factors with whom and how you walk. During her or his training, a guide dog is trained to choose a way that is suitable for both a dog and a human - the dog cannot slip under a hurdle or take a narrow path. Also, Eva must know what Nessie can or cannot do and adjust their way accordingly.

She is scared of escalators. Every guide dog can do it but Nessie. I wouldn't dare to go on an escalator because it would probably be a tragedy.

(Field notes, October 15, 2014)

Their co-modification also involves Eva's willingness to let Nessie sniff around, and the latter's sense of smell is an integral part of the assemblage although it sometimes disturbs the guiding process.

\section{Sight and Connective Difference}

When Michalko talks about his experience of going blind, he comes to define what "sight" actually means:

The relationship I had always assumed between blindness and sightedness was quickly losing its cogency. I no longer thought of them as opposites, or even, necessarily, as antithetical. I was not sure what their relationship was; it was more complicated than I'd thought, but its exact nature eluded me.

(Michalko 1999, 15)

One of the outcomes of modernist discourse has been a purification of the senses, detaching them from each other, and creating oppositions consequently, blindness/visual impairment is considered to be "nonsight" (Schillmeier 2010, 45). Oppositions are never lonely and neutral; many other negative demarcations follow. The history of sight and nonsight is therefore also the history of "the good and bad, abilities and disabilities, beauty and ugliness, human and nonhuman, humans and technologies, one and many, nature and culture, etc" (ibid., 77), which refer to each other and reinforce one another. One pole of these oppositions is embedded in the norm, and the other in otherness constituting the borders. "(I)n order to deal with the heterogeneities, differences, 
uncertainties, and fragilities" (ibid., 43), exclusions and marginalization of otherness are practiced.

Deleuze challenges the notion of difference that "is 'mediated' to the extent that it is subjected to the fourfold root of identity, oppositions, analogy, and resemblance. "[It] must leave its cave and cease to be a monster" (Deleuze 2004, 38). Such difference is docile and predictable (i.e. fully territorialized) and serves as a legitimizing tool that declares an asymmetric position between able-bodied and disabled subjects as well as their stable contours and identities. Deleuze (1983, 1990, 2004) perceives difference as a primary power that creates assemblages - thus, it is not dividing but connecting. Besides territorialized contour and articulation, we need to analyze deterritorializing connections that are not predetermined by a stable logic. The relation between sight and nonsight (lack of sight) is a difference between assemblages, but Deleuze focuses on difference within them. By focusing on associations instead of solid entities, it becomes clear why blindness cannot be the opposition of sight - it does not create opposite connections. Conceptualizing sight in terms of the connections it creates (and at the same time, is a result of connections) enables us to analyze its role and character in the EvaNessie assemblage.

Although Michalko (1999, 46-47) says he chose a dog for a guide because he preferred sight for guiding, and the dog's "sight" is a crucial element of a dog guide team, we should not speak about "replacement". Nessie's sight creates different connections than Eva's sight would have in the assemblage. The idea of loss evokes the idea of substitution. I am not to saying that we can never talk about loss when analyzing disability, especially in certain cases, but the problem is the incapability of stepping out of the logic of loss and substitution. There is a significant difference between "replacing" something - which refers to the "original drawback" and thus goes backward - and "adding" something - which is oriented toward production.

When Latour (1995) analyzes the construction of scientific facts, he talks about a series of translations and transformation during which some of the old qualities (and information) disappear while new ones emerge. The same logic can be used to describe transformations in someone's sight in the assemblage. When there is a human as a guide, their sight travels to Eva through connections that are no longer visual. It applies to situations in which a human guide describes the surroundings there is not a direct relation between "the visible" and "the articulable" (Deleuze 2006, 47-69). What is seen is translated into words that Eva absorbs and understands in her own way, and since she used to see and still has a visual imagination, she consequently imagines a picture of the described thing or surrounding in her head. Because of this chain of translations, the original picture is not the same as the seen one. There is, however, still a correspondence since some information remains, for 
example, that there is a shop with souvenirs on the left side or stairs ahead of her. Sometimes, vision is transformed into physical connection, which is primarily the case of a human and her guide dog. Nessie's sight is connected with Eva through a harness.

Thanks to a solid harness in combination with a leash, I can feel 'most everything Nessie's doing. I also feel whether she's looking to the left or the right or sniffing a verge post, which I don't feel if the harness is just loose. So, thanks to the solid harness that transfers Nessie's every move so well, I'm not insecure at all when I walk. I don't feel that I walk into emptiness like I do when I am in a strange environment without a dog, someone's help or a cane.

(E-mail, March 13, 2015)

The guide dog has not replaced Eva's sight but rather has extended her touch, as well as transformed the character of it and changed Eva's experience from insecurity to security. We cannot analyze sight as a unity but only as a part of other assemblages - Nessie's sight would be useless for Eva unless she was trained to become a guide dog. Nevertheless, sight is not a docile function, but changes according to the assemblage it enters.

We took part in a guide competition, but we finished second to last. [...] When we got to the square, my mother was waiting for us since she has always helped everybody, so that they don't have any trouble with me. The instructor who was accompanying us told her to leave, but as soon as Nessie saw my mom, she wanted to run towards her, and from then on, she was distracted and wasn't guiding because she wanted to go to granny. [...] Even if she normally behaves in an intelligent manner, she was pulling me and walking across the lane.

(Interview, October 15, 2014)

When Deleuze and Guattari (2005) oppose the idea of the organism, they criticize its central control and subordination of parts to the wholeness. Perceiving the body as an assemblage is a symbiosis between holism, since the assemblage is intertwined, and fragmentation, as heterogeneous elements sustain their ability to deterritorialize/create new connections independently and these deterritorializations of each element impact the rest of the assemblage. Hence, sight cannot be fully controlled from the center, which is trained to guide Eva. It is a part of a body (of bodies, in this case), and, as such, it does something according to the connections it creates. While most connections (e.g. with a hurdle or with a path) are fruitful for the guiding assemblage, others can lead to its destabilization. When Nessie saw (and smelled and heard) Eva's mother, new connections were created that caused a rupture in the guide team. 


\section{Changing Disability}

Studying connections also brings a perspective into the analysis of disability that does not focus solely on discursive aspects and articulations. Perceiving disability as an assemblage enables us to bridge the distinction between impairment as a functional limitation of a body, and disability as a social system of discrimination that has been criticized over the last two decades (Corker 1999; Samuels 2002; Tremain 2005; Price 2007; Goodley 2013; Abrams 2016). At the same time, it allows taking not only technology but also animals into consideration and offers a way around the "discursive trap", which often causes the disappearance of body and pain, in studies focusing exclusively on language (Vehmas and Mäkelä 2009; Shakespeare 2014).

The word disability evokes a lack of ability and skills, and even if this meaning corresponds to the asymmetrical relationship between an impairment and a norm, at the same time, it characterizes an assemblage. It concerns what this assemblage disables and what it enables. Dis/abilities are not constant since an assemblage is not fixed; it changes according to the connections it creates. Dis/ability is supposed to work as a relatively objectified measure according to which it is possible to say that someone is disabled to do something and someone is not. And thanks to the removal of barriers, a disability can be alleviated (Barnes 1991). People who cannot use their eyes to see cannot create certain connections, but they can create others. However, the discourse of the impaired body does not imply only dis/abilities to carry out certain activities, but also the ways in which they are achieved. People who are "disabled" are also able to carry out many of these activities; they simply do them in different ways and through connections different from those of "healthy" people.

The concept of assemblage enables us to analyze how disability varies according to the ways people utilize to move. One of the negative delimiting lines between able-bodied and disabled people is their movement in space, which differs for those who can or cannot see. Further differences come out in moving dis/abled assemblages: unlike a white cane, a guide dog elicits a more positive reaction from others. ${ }^{3}$ The cane pertains only to blind people and therefore represents a foreign element that does not belong in a territory of "normality". On the other hand, a dog is associated with ordinary people for whom it represents access (that is to say, a very popular and familiar one) to an "unknown" environment, which disability for many of them is.

As Bohan and James (2015), Worth (2013), and Whitmarsh (2005) point out, guide dogs inspire social interactions and the beginnings of a conversation. Eva has had the same experience, especially after she had moved to the United Kingdom with her boyfriend about two years ago, where Nessie facilitates meeting new people and fitting into a new environment. Eva describes that nearly every conversation is about 


\section{Hana Porkertová}

Nessie: what is her name and breed, whether she was trained in England or the Czech Republic (Field notes, April 20, 2015). People start a conversation not only with Eva but also with anybody with whom Nessie (wearing her harness) is at the time. When I had visited Eva, Filip, and Nessie in the United Kingdom last spring, I often overheard someone saying, "What a lovely dog!" People would smile at us, and some of them would start a chat. Furthermore, a guide dog often becomes a source of welcome entertainment, particularly in spaces forbidden to "animals", such as stores or airports (field notes). However, we must be aware that the attention a guide dog draws can eclipse his or her owner (Whitmarsh 2005). Moreover, the presence of a guide dog is not always so positively welcomed as in the Euro-American context (Bohan and James 2015).

\section{Disability as a Post-human Phenomenon}

Although humanism involves rigid, narrow, and normative conventions, which relate to practices of exclusion and discrimination (Goodley, Lawthom, and Runswick-Cole 2014, 350), it has had numerous positive consequences for disabled people by inspiring efforts to include them in the category of "human" (ibid., 344). Simultaneously, even though unintentionally, such efforts have unleashed processes that subvert some of the humanist foundations. On the one hand, disability is a normative concept that constructs rigid identities, such as "the disabled", and is built on the division between a given norm and otherness. On the other hand, disability is extraordinary and steps out of one of the normative realms, little by little disrupting also other realms in which humanist thinking is ingrained, such as the division between a human and nonhuman animal. Shildrick (2009) and Goodley et al. (2014) talk about disability as space that opens up new ways of becoming, which elude normative organization. This subversive potential and the inherent ambivalence of disability are caused by "letting it" into the humanist conception.

The posthumanist character of disability stands out if we analyze not only the construction of disability but also what disability does and what it elicits. Human disabilities and illnesses affect animals to a great extent, from less-controversial assistance animals, including guide dogs, to more controversial animals in medical experiments. If it were not for the concept of disability, Nessie would not have come into existence. A mere acknowledgment of the fact that disability concerns animals would still trap us in humanist thinking; a posthuman perspective re-thinks how to approach and analyze them. It is clear from the above analysis that the pivotal territorializing bonds for a guide dog team are not the human intelligence, superiority, and control that divide human and nonhuman animal subjectivities, but cooperation and trust. 
What is required is a reconfiguration of humanity and nonhuman animality not defined by the characteristics that maintain their asymmetric relationship. Instead of the One and the Other, the collectivity multiplicity - that changes both a human and her or his guide dog comes to the fore. Consequently, the analysis cannot draw on an anthropocentric view. It is important to cease perceiving nonhuman animals as "passive recipients of care and protection" (Rasmussen 2011, 102), as devoted pets (Haraway 2003), or as creatures working for people's needs or as objects given for consumption (DeMello 2012). Such a shift in thinking does not imply that we cannot talk about "protection" or "care" regarding nonhuman animals, or fight their abuse. The humanistic perspective, in either its superior or protectionist form, ascribes agency only to people, and the animal is dependent on human decisions and kindness, which also reflects the discourse of obedience and training. As the examples from Eva's and Nessie's life have shown, their guide team defies such a reductive dichotomy between agentic human and docile dog.

Similarly, Haraway (2003), a social theorist and a biologist, discards the conception of a docile dog bred from a wild wolf - substituting nature by culture - and writes about the mutual co-evolution of humans and dogs instead. According to her, co-evolution is the rule, rather than the exception, and diverse animal species (including humans) develop in mutual co-existence. Thus, a posthumanist approach does not lie only in taking "nonhuman actors" into consideration but in reconfiguring the binarities around which "humanity" and "animality" revolve. Haraway reconciles two seemingly exclusive issues, training and a dog's agency. She finds an example in "agility", a very demanding discipline that requires the coordination of people and their dogs aimed at managing an assault course as fast as possible:

The major demand on the human is precisely what most of us don't even know we don't know how to do - to wit, how to see who the dogs are and hear what they are telling us, not in bloodless abstraction, but in a one-on-one relationship, in otherness-in-connection.

(ibid., 45)

During the training, mutual obedience is necessary to eliminate elements that block trust on both sides. The resulting close bond can be called an assemblage since its logic is similar to the relationship between Nessie and Eva. As Haraway puts it, "Dogs are about the inescapable, contradictory story of relationships - co-constitutive relationships in which none of the partners pre-exist the relating, ant the relating is never done once and for all" (ibid., 12).

The assemblage between a human and a dog is a process that is never established permanently. Correspondingly, the "origin" of a guide dog is an assemblage that has no clear beginning or end. The first written notes 


\section{Hana Porkertová}

about dogs accompanying blind people date back to the Middle Ages (Oxley 1995). Today, there are stories about dogs guiding other dogs that cannot see without anybody training them. Mostly lifestyle websites $^{4}$ feature such stories; journalists and then readers gush over "animal friendship". The popularity of similar friendships does not eclipse the humanist position, but there is a different aspect to these examples - they disrupt the picture about a man using a dog for his needs. It is likely that the impulse for guiding first came from a dog or it was a mutual collaboration. When I shared these stories with Eva, she responded:

It is likely then, that Nessie has the guiding in herself, somehow. I have to tell this to Lenka, so she doesn't think anymore that guide dogs are such poor creatures.

(E-mail, March 21, 2016)

The image of the work and stress that guide dogs sometimes face often opposes the idea of a joyful and playful dog, and Eva tries to reconcile these two opposites by saying, Nessie has the guiding in herself. Guide dogs remind their clients that owning a guide dog is a big responsibility and that those dogs also need time for play and rest.

\section{Nessie, the Guide Dog, and the Menace of the Forest}

I have spoken about the unclear division between a human and a dog. However, there is also another boundary that is challenged by the existence of a guide dog. Nessie is allowed to access places that are otherwise strictly prohibited to "animals", including hospitals, with their uncompromising hygiene standards. The line between a guide dog as an institution and a dog as an animal, which exclude one another in many ways, is disrupted. However, there are several interconnected ways to reconcile this paradox.

First, the dog is subsumed in a human subjectivity - "a dog becomes a notional part of your body", the website Pomocné tlapky o.p.s. (n.d.) proclaims. In the concept of an assemblage, what matters is not the subsuming but a mutual conjunction in which neither is primary. But it is the dualistic Cartesian heritage of a superior mind and an inferior body, in which only a human mind is endowed with rationality, autonomy, and intelligence, that enables us to consider a dog to be part of a human subject. Second, under Czech law, a dog is reduced to technology, a "compensatory aid" (Helppes, ${ }^{5}$ n.d.), and therefore is in the same position as a wheelchair or a prosthetic; the animality is erased. The training is supposed to secure his or her "technological character", that is, control and predictability. Third, ideas that maintain the principle of a whole body and subject, and allow a connection between a human and a guide dog, are related to the discourse of "lack". It is the lack of Eva's vision that is substituted by Nessie's sight. And it is the lack of Nessie's rational, 
autonomous subjectivity that grounds this fusion seemingly only on a bodily level, and it is a human mind that controls it.

The guide dog's "animality" must be sidelined as much as possible so that a well-behaved, controlled, and predictable creature can come forward. But how can we characterize the relationship between a professional assistant and a dog? Is it possible to switch between those modes? What grounds this difference? At first, it seems quite simple:

The dog is a guide when she's wearing her harness. When I put the harness on her, she is guiding me along the street, but when we come home, and I take the harness off, it means a holiday for her, and she's acting like a naughty dog who doesn't have to work.

(Interview, September 22, 2014)

A conjunction with a harness actualizes a guiding assemblage - Nessie becomes a professional who knows what to do and behaves responsibly. Taking her harness off turns off this regime, and she can be a dog again.

Nevertheless, it is not that easy; a harness is not a simple button that switches between diverse dog modes. Nessie does not wear her harness only in situations where she is supposed to guide Eva. In the Czech Republic, and largely in the United Kingdom, many public spaces prohibit dogs from entering, such as churches, castles, museums, and in the United Kingdom, also public transportation and many restaurants. Eva and her boyfriend Filip, who sees and guides her when they are together, take Nessie to most events, trips, or walks, and it is the harness that allows them to take her with them, even though she is just on the leash with no intention of guiding Eva. As I noted earlier, their bond should be strong, and time spent together is thus a part of the assemblage of a guide team. Besides that, Nessie is their pet, and they just want to enjoy time with her. They often do not take off the harness in the city, so that they do not have to put it on and take it off all over again based on the nature of the spaces they enter. Moreover, Nessie is much calmer and does not pull so much when wearing the harness. Even during trips to the countryside, Nessie's harness is always in the car for the occasion when dogs are not allowed to enter a restaurant. After the walk, they put the harness on her, and from a menace of the forest who loves diving in puddles, Nessie transforms into a well-educated guide dog with universal access.

Nessie is Eva's guide dog and, at the same time, a playful, energic animal, and hers and Filip's pet, a member of the family with whom they have a strong emotional bond. Nevertheless, the reactions of other people confirm their image of a guide dog.

I don't feel the difference between "Nessie the guide dog" and "Nessie the menace of the forest anymore," but other people tend to emphasize her guiding side and think that she is a nice doggie when she is a guide. 
Everybody admires her and people always say something like: "She has a such a calm nature, right?; These guide dogs are so nice and skillful!; She's such a quiet sweetheart." And tell those people that she ate shit a moment ago and she was hitting my legs with a stick during the entire trip.

(E-mail, May 13, 2015)

The reliability of training is a crucial part of the discourse regarding guide dogs, and, simultaneously, it is complemented with an image about the calm nature of the dog, which allows this training to happen thus, nature is in agreement with "taming". But Eva shows that docility and responsibility do not exclude an energic character, stubbornness, and disobedience; they just surface in different situations according to an assemblage that the dog creates. This assemblage is changing based on the connections it makes, and some deterritorializations can be fatal for its viability. For example, sometimes, people do not respect Nessie's working status, and approach her like every other dog and stroke her without Eva's permission or knowledge, which distracts Nessie and disrupts the guiding assemblage.

\section{Conclusion}

The way human and nonhuman animals are conceptualized in humanist discourse, that is, their separation and the emphasis on certain characteristics that differ for a human and a dog, does not help explain the workings of a guiding assemblage. Analytical and theoretical approaches that are not ingrained in the humanist heritage can better detect the reconfiguration, heterogeneity, dynamics, interconnectivity, and interchangeability of human-animal connections. Among the suitable theoretical frameworks are Deleuzo-Guattarian philosophy or Bruno Latour's actor-network theory.

In the humanist perspective, built around bodily competence, a healthy subject is an ideal to which everyone else is compared. To approximate to this ideal, so-called disabled people are equipped with compensatory aids, including guide dogs. The loss has been replaced. But a much more heterogeneous process also occurs, which may be imperceptible when considering the relationship between a human and her/his guide dog merely from a humanist point of view - that is, when replacing a "loss".

The idea of loss and its replacement is fulfilled only if a human, a dog, and their bodies are perceived as separate from each other. Their mutual connections reveal fluidity and inner instability, which are stabilized only through the process of territorialization of an assemblage. In the assemblage that not only Eva and Nessie but also the concepts of disability and sight create, the character of these "input elements", which are assemblages themselves, evolves. In short, to be disabled with a human 
guide, a dog guide, or a cane, implies different experiences, creates other connections, and traces different lines. The same goes for being blind, which, in a Deleuzian perspective, is not the opposition of being sighted. Besides interconnections with other people, disability also necessarily produces interdependent connections with nonhuman entities, such as technology or animals (Goodley et al. 2014).

The guide dog is being constantly transformed from a pet into an assistant, which goes against stereotypes about animals in many ways. Even the humanist thinking that stresses the rationality, independence, autonomy, and coherence of the modern subject, in which so-called disabled people inevitably fail (Gibson 2006; Shildrick 2009; Tremain 2015), is not closed to deterritorializations that question these characteristics and expose their paradoxical nature. Shildrick (2009) and Overboe (2007) see disability as an opportunity for creating a new body and experience and for undermining the norm. The same occurs with a dog.

The concept of assemblage not only stresses mutual associations, connective difference, fluidity, and interconnectivity but also opens up space for emotions and feelings, which are often invisible in the modern concept of subjectivity rooted in rational decisions. My research has shown that the feeling of trust is the crucial glue in a human-guide dog assemblage, and trust can be one of the ways of approaching otherness. Perceiving the experience of so-called disabled people from a humanist point of view inevitably leads to comparing them to the so-called healthy experience that cannot see beyond its own limits. Trust could overcome gaps between these experiences that should be perceived as equally valuable - rather than perceiving one as the ideal to which the other can only approximate.

\section{Notes}

1 The research was based in the Czech Republic, and the interviews were carried out in Czech. For the purpose of this text, I translated Eva's quotations into English. She has been informed about the ongoing research, including this chapter.

2 "Helpful paws" is a Czech school for guide dogs.

3 While it is usual that people use both a dog and a white cane while walking, Eva takes out the cane only if she needs to be easily recognized as visually impaired, so that people help her to find a zebra or get on a bus.

4 See, for example, three different stories on the websites Boredpanda (2015), Gizmodo (2012), and MailOnline (2013).

5 "Help-dog" is a Czech guiding school.

\section{References}

Abrams, Thomas. 2016. "Cartesian Dualism and Disabled Phenomenology." Scandinavian Journal of Disability Research 18 (2): 118-128. doi: 10.1080/ 15017419.2014.995219 


\section{Hana Porkertová}

Arata, Sayaka, Yukihide Momozawa, Yuraki Takeuchi, and Yuri Mori. 2010. "Important Behavioral Traits for Predicting Guide Dog Qualification.” Journal of Veterinary Medical Science 72 (5): 539-545.

Barnes, Colin. 1991. Disabled People in Britain and Discrimination. London: Hurst and Co.

Batt, Lara, Marjolyn Batt, John Baguley, and Paul McGreevy. 2008. "The Effects of Structured Sessions for Juvenile Training and Socialization on Guide Dog Success and Puppy-Raiser Participation." Journal of Veterinary Behavior: Clinical Applications and Research 3 (5): 199-206. doi: 10.1016/j. jveb.2008.05.001

Bohan, Daniel Bin, and Chan Tuck Wah James. 2015. "Mobility of a Guide Dog Team in Singapore: A Case Study." British Journal of Visual Impairment 33 (1): 54-65. doi: 10.1177/0264619614561691

Boredpanda. 2015. "This Blind Dog Has His Own Seeing-Eye Guide and They're Looking for a Home.” Accessed March 12, 2015. www.boredpanda. com/blind-dog-guide-best-friends-abandoned-rescued-stray-aid-shelterglenn-buzz/.

Corker, Marian. 1999. "Differences, Conflations and Foundations: The Limits to 'Accurate' Theoretical Representation of Disabled People's Experience?" Disability \& Society 14 (5): 627-642. doi: 10.1080/09687599925984

Davies, Charlotte Aull. 2002. Reflexive Ethnography: A Guide to Researching Selves and Others. London: Routledge.

Deleuze, Gilles. 1983. Nietzsche and Philosophy. Translated by Hugh Tomlison. New York: Columbia University Press.

- 1990. The Logic of Sense. Translated by Mark Lester. New York: Columbia University Press.

- 2004. Difference and Repetition. Translated by Paul Patton. London: The Athlone Press.

- 2006. Foucault. Translated by Seán Hand. Minneapolis, MN: University of Minnesota Press.

—, and Félix Guattari. 2005. A Thousand Plateaus. Translated by Brian Massumi. Minneapolis, MN: University of Minnesota Press.

DeMello, Margo. 2012. Animals and Society: An Introduction to HumanAnimal Studies. New York: Columbia University Press.

Dirksen, Vannesa, Ard Huizing, and Bas Smit. 2010. "Piling on Layers of Understanding': The Use of Connective Ethnography for the Study of (Online) Work Practices." New Media \& Society 12 (7): 1045-1063. doi: 10.1177/1461444809341437

Gibson, Barbara E., 2006. "Disability, Connectivity and Transgressing the Autonomous Body." Journal of Medical Humanities 27 (3): 187-196. doi: 10.1007/s10912-006-9017-6

— Franco A. Carnevale, and Gillian King. 2012. “This Is My Way': Reimagining Disability, In/dependence and Interconnectedness of Persons and Assistive Technologies." Disability and Rehabilitation 34 (22): 1894-1899. doi: 10.3109/09638288.2012.670040

Gizmodo. 2012. "The Incredible Story of the Blind Dog with His Own Guide Dog." Accessed March 12, 2015. http://gizmodo.com/5907399/theincredible-story-of-the-blind-dog-with-his-own-guide-dog.

Goodley, Dan. 2013. “Dis/entangling Critical Disability Studies.” Disability \& Society 28 (5): 631-644. doi: 10.1080/09687599.2012.717884 
_- Rebecca Lawthom, and Katherine Runswick-Cole. 2014. "Posthuman Disability Studies." Subjectivity 7 (4): 342-361. doi: 10.1057/ sub. 2014.15

Haraway, Donna. 2003. The Companion Species Manifesto: Dogs, People, and Significant Otherness. Chicago, IL: Prickly Paradigm Press.

Haslam, Nick 2006. "Dehumanization: An Integrative Review." Personality and Social Psychology Review: An Official Journal of the Society for Personality and Social Psychology, Inc. 10 (3): 252-264. doi: 10.1207/ s15327957pspr1003_4

Helppes, n.d. "Vodící psi pro nevidomé (Guide Dogs for Visually Impaired People)." Accessed March 12, 2015. www.helppes.cz/psi-pomocnici/ psi-pomocnici-pro/vodici-psi-pro-nevidome/.

Hine, Christine. 2007. "Connective Ethnography for the Exploration of e-Science." Journal of Computer-Mediated Communication 12 (2): 284300. doi: 10.1111/j.1083-6101.2007.00341.x

Latour, Bruno. 1995. "The 'Pédofil' of Boa Vista: A Photo-Philosophical Montage." Common Knowledge 4 (1): 144-187.

- 2002. We Have Never Been Modern. Cambridge, MA: Harvard University Press.

Lestel, Dominique, Florence Brunois, Florence Gaunet. 2006. "Etho-ethnology and Ethno-ethology." Social Science Information 45 (2): 155-177. doi: $10.1177 / 0539018406063633$

MailOnline. 2013. "Now THAT'S Brotherly Love! Loyal Milo Becomes Guide Dog for Blind Sibling Eddie after He Loses Sight.” Accessed March 12, 2015. www.dailymail.co.uk/news/article-2288933/Guide-dog-blind-dog-Loyalterrier-Milo-acts-7-year-old-Labrador-Eddies-eyes.html.

Magnus, Riin. 2014. "The Role of Trust in Binding the Perspectives of Guide Dogs and Their Visually Impaired Handlers.” Sign Systems Studies 42 (2-3): 376-398. doi: 10.12697/SSS.2014.42.2-3.10

Michalko, Rod. 1999. The Two-in-One Walking with Smokie, Walking with Blindness. Philadelphia, PA: Temple University Press.

Overboe, James. 2007. "Disability and Genetics: Affirming the Bare Life (the State of Exception)." Canadian Review of Sociology/Revue Canadienne De Sociologie 44 (2): 219-235. doi: 10.1111/j.1755-618X.2007.tb01135.x

Oxley, Julian. 1995. "Tail with a Happy Ending." The British Journal of Visual Impairment 13 (2): 77-79. doi: 10.1177/026461969501300205

Pomocné tlapky o.p.s, 2009. “Časté dotazy o asistenčních psech (FAQ)." Accessed March 12, 2015. www.pomocnetlapky.cz/cz/o-asistencnich-psech/ caste-dotazy/caste-dotazy-o-asistencnich-psech-40.html.

Price, Janet E. 2007. “Engaging Disability.” Feminist Theory 8 (1): 77-89. doi: $10.1177 / 1464700107074199$

Rasmussen, Claire E. 2011. The Autonomous Animal: Self-Governance and the Modern Subject. Minneapolis, MN: University of Minnesota Press.

Samuels, Ellen Jean. 2002. "My Body, My Closet: Invisible Disability and the Limits of Coming-Out Discourse." GLQ: A Journal of Lesbian and Gay Studies 9 (1): 233-255. doi: 10.1215/10642684-9-1-2-233

Schillmeier, Michael. 2010. Rethinking Disability: Bodies, Senses, and Things. New York: Routledge.

Shakespeare, Tom. 2014. Disability Rights and Wrongs Revisited. New York: Routledge. 


\section{Hana Porkertová}

Shildrick, Margrit. 2009. Dangerous Discourses of Disability, Subjectivity and Sexuality. Basingstoke: Palgrave Macmillan.

Shores, Corry. 2012. "Body and World in Merleau-Ponty and Deleuze." Studia Phaenomenologica 12: 181-209. doi: 10.7761/SP.12.181

Taylor, Nik. 2013. Humans, Animals, and Society: An Introduction to Human-animal Studies. New York: Lantern Books.

Tremain, Shelley. 2005. Foucault and the Government of Disability. Ann Arbor, MI: University of Michigan Press.

- 2015. "This is What a Historicist and Relativist Feminist Philosophy of Disability Looks Like." Foucault Studies (19): 7-42. doi: 10.22439/ fs.v0i19.4822

Vehmas, Simo, and Pekka Mäkelä. 2009. “The Ontology of Disability and Impairment: A Discussion of the Natural and Social Features.” In Arguing about Disability: Philosophical Perspectives, edited by Kristjana Kristiansen, Simo Vehmas, and Tom Shakespeare, 42-56. London: Routledge.

Whitmarsh, Lorraine. 2005. "The Benefits of Guide Dog Ownership." Visual Impairment Research 7 (1): 27-42. doi: 10.1080/13882350590956439

Worth, Nancy. 2013. "Visual Impairment in the City: Young People's Social Strategies for Independent Mobility.” Urban Studies 50 (3): 574-586. doi: $10.1177 / 0042098012468898$ 
Part 4

Technological (Co-)Agencies 

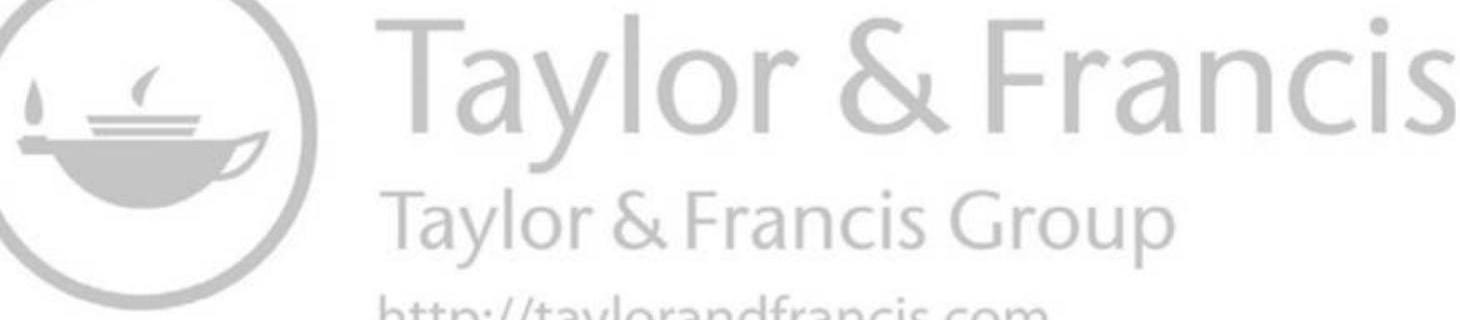
http://taylorandfrancis.com 


\section{Meeting the Machine Halfway}

\section{Toward Non-Anthropocentric Semiotics}

\section{Cléo Collomb and Samuel Goyet}

Human beings evolve in a world that they share with nonhuman entities. Among these nonhuman entities, there are many technical objects that are commonly called "digital media": personal computers, smartphones, tablets, and so on. These are all machines that function on the basis of binary calculations incorporated into electronic machinery. While the term "media" focuses attention on the communicational function of these machines, and therefore on the way in which they organize communication between human beings, we prefer to call them "computational machines" to insist on the fact that they perform calculations and have a certain kind of autonomy.

These calculations are made, however, in a way that is fundamentally different from the way humans compute (Souchier 1996; Collomb and Goyet 2016). Therefore, the term "computational machines" also puts light on the otherness of these machines, reframing the problem of the relationships that human beings have with them. These relationships are constructed not only around the various uses that humans make of machines but also around many texts that build up representations of machines: novels, films, photographs, media productions of different kinds, and so on. In other words, a range of narratives that are read, seen, and heard in daily life builds up the representations that humans have of computational machines and the relationships they can have with them. Narratives play an important part in the way humans and nonhumans interact (Haraway 2003, 2016). In this chapter, we share the need for renewed narratives about digital machines (Collomb 2016), and we try to do so by grounding our work into semiotics and digital materialism (Dolphijn and van der Tuin 2012; Casemajor 2014; Jahjah 2016). This leads to three important ideas that we need to explain in detail: the materiality of narratives, a broad definition of what a text is, a focus on ordinary texts and the ideology they perform.

First of all, narratives are not ethereal. They have a form of some sort; they are produced by certain actors, certain companies and institutions, and so on. Narratives are not independent from their material, concrete, and meaningful forms (MacKenzie 1991). In other words, they are dependent on a text. A "text" is not only to be understood in the sense of a 
literary work or a book, for example. There are also "texts that are not books" (MacKenzie 1991, 30): these may include a film or a web page, for example. We therefore adopt a broad definition of what a text is, and we analyze it under the aspect of power. If we follow the reasoning of Michel De Certeau, a text can actually be a place of power organized by writing (in the broad sense of the term, in other words including pictures, letters, sounds, etc.). When a person writes, s/he produces a text that makes a distinction between objects and subjects, between those who have a say and those who do not - in a typically modern gesture that reduces the world to a set of objects and mechanical forces (De Certeau 1990, 235). In other words, a text - in the sense of De Certeau - is a place of power, a place where power relations are organized.

These relations often involve the use of graphic elements. By graphic elements, we mean everything that makes a text readable for a human being. It goes from typography, layout of the page, color of the text, and spacing between paragraphs to the legend of a picture, the collection in which a book is published or the software used to read a digital document, the screen through which the text is made perceptible for a human being. These graphic elements are not neutral. As the form is meaningful (MacKenzie 1991), they say something about the text they allow the readers to read. They produce a specific kind of utterance: an editorial utterance (énonciation éditoriale, Souchier 1998), where every actor of the editorial chain (typographer, graphic designer, publisher, software designer) has its say, in addition to what is identified as the main author of the text. If the form is meaningful, and if the way the text is visually organized on a page is an act of utterance, then the geography of the page is thus geography of power. For example, placing an element in the "margin" is a devaluation which is at once topographical and symbolic.

In this chapter, the text is broadly defined as an organization of signs on a material substrate. Web pages, or computer screens, can thus be understood as texts that organize power relationships between the entities concerned: humans and machines. The question is then to specify the place attributed to the computational machine in those specific types of text that are ordinary web pages, and what representations of the relationships between humans and machines are thereby constructed on these very pages. A semiotic analysis of ordinary web pages, based on the French media theory of "written writing screens" (Souchier 1996; Jeanneret and Souchier 1999; Souchier and Jeanneret 2005), can thus reveal the dominant ideology that circulates therein, and the way in which this ideology configures the relationship between humans and computational nonhumans.

The dominant ideology in the relationship between humans and technical objects, and found in ordinary interfaces, is anthropocentrism. This ideology is expressed in at least two ways. Either the technical object is reduced to a purely instrumental role: it is a tool that may be more 
or less sophisticated but only exists because of its usefulness to humans. Or else, in an expression of rampant technical fetishism, it is elevated to the rank of a sacred object to which humans delegate their dreams of power. Culture, writes Simondon,

thus entails two contradictory attitudes towards technical objects: on the one hand, it treats them as mere assemblages of matter, bereft of any real meaning, and possessing only a certain utility. On the other hand, it assumes that these objects are also robots and that they are animated by hostile intentions towards humans, or that they embody a permanent danger of aggression towards them, of insurrection. Considering that the first characteristic is a good thing, culture aims to prevent the manifestation of the second, and talks about putting machines to work for mankind, in the belief that reducing them to a status of servitude is a sure means of preventing any rebellion.

(Simondon 1958, 11)

These two anthropocentric perspectives on technology can be found in the different conceptions people have of computational machines. At times, they are considered as tools that serve humans, enabling them to calculate at great speed or to have access to virtually unlimited stores of knowledge, thus giving humans the impression of having great power. At other times, these same machines crystallize the fantasies of human beings who project their own dreams onto the machines, for better or worse as the case may be. These fantasies can go from transhumanist (Bostrom 2008) utopian futures where machines can help humans to transcend their mortal selves to dystopian worlds where computers are at the service of government surveillance or have taken power over human condition, for instance. It is these two attitudes toward machines the one that considers them purely as tools and the other that projects human fantasies of omnipotence onto them - that we find in ordinary interfaces. On the web pages that people consult every day, the machine is most often considered in both of these human terms.

The aims of this chapter are to study how this anthropocentric conception of the machine circulates in daily life, to bring out the extent to which this conception is constructed, to investigate its propagation, and to propose a different way of considering the relationship between humans and machines. The first part of the chapter offers a semiotic analysis of a page of results obtained via Google Search, in order to show, through the example of the calculation time, how the machine is relegated to the rank of a simple tool and how its action is represented in terms that remain specific to humans. However, and this is the concern of the second part of the chapter, if we want to grant machines an agency on their own terms, we need to pinpoint and describe their specific mode 
of action. This mode of action is to put in terms of writing: machines allow humans to write, but they also write (Kittler 1995; Hayles 2002). This writing is not textual but computational: for a computer, to write is to compute, and to compute is to write, since they are rooted into formal logic and a specific conception of calculus as a kind of writing (Lassègue et Longo 2012). But this writing does not necessarily produce a human-readable text. In this sense, computational machines are objects that to some extent lie outside the category of texts. This is the reason why we propose to make a clear distinction between the "textual writing" of humans and the "computational writing" of machines (Collomb and Goyet 2016). We then need to uncover the mark of computational activity in what is most characteristic, through a semiotic analysis that focuses on "computational writing", in objects such as bugs, for example.

\section{Ordinary Anthropocentrism of Web Pages: The Case of Google Search}

We have selected a particularly representative example of the way in which relationships between humans and computational machines are constructed at the interface level. This example illustrates the everyday anthropocentrism through which people interpret the action of the machine in terms of their own categories. We first perform a semiotic analysis of the interface, in order to bring out this everyday anthropocentrism. We then attempt to draw out the consequences that this sort of representation of machines can have for the relationship between humans and machines (Figure 10.1).

This is the results page of a Google Search for "Reindeer", made on September 27, 2015. Three main zones can be identified: the two bars at

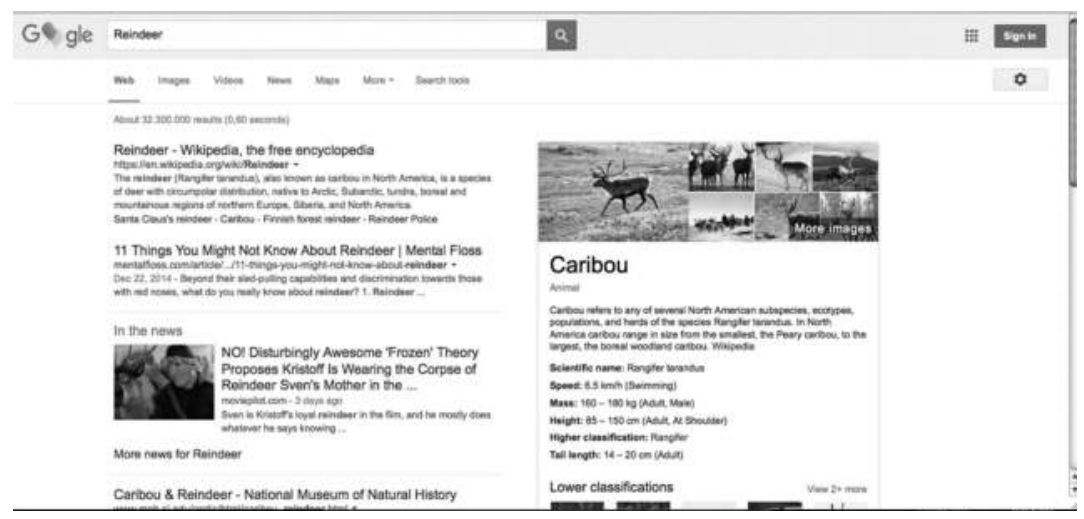

Figure 10.1 Screenshot of a Google Search request for "Reindeer”, carried out on September 27, 2015. 
the top, including the search formula and tabs used to specify the type of search (images, videos, etc.). Next, the column on the left displaying a list of links, each comprising the first lines of the pages to which the links refer. This column is usually interpreted as the search "results". The frame on the right shows pictures followed by a descriptive note concerning "Reindeer", translated in the French screenshot as "Caribou" and apparently taken from Wikipedia.

Google, by means of its interface, assembles a set of documents from a variety of different media (newspaper articles, encyclopedia articles, photographs, zoology fact sheets, etc.), and presents this set as the response to the search request. Through its use of space (the results considered most relevant are at the top of the list) and the typeset (some characters are larger than others and may be colored), the Google Search interface constructs levels of relevance: what is at the top and in the largest print is what we should look at first, because this is where we find the content considered most relevant to the request in question. What is it that makes the semiotic link between the request and the response? It is the inscription in discreet light gray lettering that indicates "About 32.300.000 results $(0,60$ seconds)". This indicates that the list before our eyes is only a tiny fraction of over 32 million results. And this is the work that Google actually does: it performs an algorithmic action that enables it to scan a set of documents, organized as a database, in order to calculate the results it selects as most relevant in this context as rapidly as possible.

The way Google's work is signified can be treated on two levels. First, on the level of the text image (Souchier 1998), the algorithmic action performed by Google occupies a paradoxical position, because it is at once minimized and given prominence. It is minimized if we only consider the aspect of the text: in light gray and small characters, the phrase is barely noticed. On the other hand, its place in the topography of the page is highly symbolic: between the request and the responses, it corresponds to the articulation between the two. This sentence is thus the textualization of Google's mediation, which is based on an algorithmic processing. It is a paradoxical textualization, however. The technical mediation is displayed as a technological prowess in the sense that the calculation time, which is indeed quite short, is shown in a strategic position on the page; at the same time, this technical mediation is kept on the background by the format of the text and the fact that the terms in which it is expressed suggest that it is "immediate" or "very fast" - as if the calculation time was so fast that it is "practically" instantaneous so that from a semiotic point of view, it is invisible, all the more so as it is presented so discreetly as to be practically unnoticeable.

Second, on the level of the textual content, the technical process is denoted by two numbers, one corresponding to the approximate number of pages found ( 32 million) and the other corresponding to the time 
taken by the algorithms to scan these documents and to select some of them. What do such formulae express? In our view, they convey (i) an anthropocentric perspective with respect to computational activity and (ii) a mythification of the action of the machine.

First, these formulae express an anthropocentric vision of the action of the machine. From the point of view of a human, these intervals of time or numbers of documents hardly make any sense. Whether there are 32 million results or 400,000 makes no difference to human beings. Whether scanning these documents took 0.60 or 0.61 seconds is irrelevant. They cannot grasp such orders of magnitude. For computational machines, however, there is a real difference between 0.60 seconds and 0.61 seconds. This is an interval of time within which they are capable of operating: they can scan 32 million pages in 0.60 seconds, but they could go faster or scan more documents in the same period of time. In this context, the difference between 0.60 and 0.61 seconds is relevant.

When human beings see the formula " 0.60 seconds" displayed, they know that it refers to the computational action, but they interpret it as practically instantaneous because such a short interval in time makes little sense to them. The scale of time that people use is one that does make sense to them. They interpret these signs according to their own regime of meaning, although these signs designate an action that takes place in a very different regime. When they do so, humans make no effort to decenter themselves: they keep to an anthropocentric posture and project instantaneity into something that, for the machine, is a genuine duration. This amounts to imposing a human regime of interpretation, with the consequence that the mode of existence of computational machines is overshadowed. The way is then open for the human to occupy the entire space, relegating the machine to the status of a mere tool.

However, this transformation of a period of time into instantaneity, by way of an anthropocentric interpretation, is also the creation of a myth, in the sense developed by Roland Barthes (1957). According to Barthes, a myth is created in three stages: diversion, essentialization, and the negation of otherness. First comes the diversion, through what Barthes calls a "theft of language" (Barthes 1957, 239): the human steals a sign that already exists, and attributes a new meaning to it. What are the rhetorical effects when the human takes the sign " $32,300,000$ results ( 0.60 seconds)" and gives it the meaning of "the machine works very fast"? The initial sign is no longer taken in its literal sense, but to indicate an extraordinary performance: the outstanding power and efficiency of the machine. The human thus diverts the primary meaning to fix and essentialize the action of the machine, which is to supply a response so instantaneous as to be practically magical.

This essentialization is the second stage in myth creation. It no longer matters whether the machine has taken 0.61 or 0.62 seconds: the 
variations of the initial sign are abolished; only the performance counts. In fine, the myth establishes a process of drawing everything into itself, which is profoundly ideological: according to Barthes, the bourgeoisie, through this process of mythification, takes ownership of the Other by transforming it into its own image. This, the third step in mythification, is the negation of otherness, in this case the otherness of the machine. Google is now understood only as a service that some humans (the developers of the firm) place at the disposal of other humans, via a process of technical mediation (the PageRank algorithm). The involvement of the machine in the mediation is relegated to a purely subsidiary role, as an adjuvant to benefit humans and their desires.

This is why mythification and anthropocentrism feed on each other: while the process of mythification is grounded in anthropocentrism, it also reinforces it. Anthropocentrism amounts to apprehending the whole of reality on the basis of the human perspective, thereby wiping out all the differences that cannot be digested into its own system. This anthropocentrism neutralizes the specific mode of existence of machines and is thus both the starting-point and the outcome of the process of mythification. The way Google Search results' computation is made visible and readable can thus be understood as the creation of an anthropocentric perspective on computational machines. But this introduction has nothing creative about it, contrary to the (trivial) process described by Yves Jeanneret (2008). It merely reinforces an already deeply rooted ideology: an ideology that is only capable of conferring an existence to the machine by bringing it back into a human order of understanding. Anthropocentrism and mythification operate in a closed loop: their redundancy leads to their mutual reinforcement. This is why undermining anthropocentrism effectively interrupts this process of self-propagation. And it is here, in this interruption however momentary - that the possibility emerges for humans to open up to the mode of existence of machines.

Of course there are other ways of reading " 32.300 .000 results $(0,60$ seconds)". A software engineer who has the task of optimizing the algorithm knows that 0.61 seconds is not the same as 0.60 seconds just as an online gamer will be sensitive to any change in the response time of the server (or ping), to the millisecond. These various interpretations depend on the literacy of each person, that is, on their knowledge and expertise with respect to the machine and the way it functions. Just as for Barthes, in his analysis of advertising (Barthes 1964), there are several levels of interpretation according to the culture of the person concerned, so there are different ways of reading and understanding the way the activity of the machine is put into signs.

To produce other ways of interpreting the calculation time of the machine, one must shift away from anthropocentrism. These other ways 
are techno-logical (Collomb 2016), in the sense that they pay attention to the technical reality (whereas anthropo-logy is centered by human reality). However, this technological approach to the activity of computational machines represents only a tiny minority compared to the dominant ideology consisting of an anthropocentric interpretation of computational activity ("the machine works fast"). This ideology is so powerful precisely because it is the major interpretation. In fact, Google paves the way for this anthropocentric interpretation since the formula " 0.60 seconds" is already an approximation. It is highly probable that the algorithmic calculation actually took 0.5983687 seconds (for example), depending on the degree of precision chosen by the software developers according to the capacities of their servers. Such a degree of precision points to a different relationship with the machine, a relationship that is focused on its actual mode of operation (calculation) and on the fact that, for the machine, a thousandth or even a millionth of a second is an operational duration. Google, through its choice of the number of decimals to be displayed, is not only enabling but also sustaining a relationship between humans and computational machines that tend toward anthropocentrism, while drawing a veil over the technical reality of calculation.

\section{Reconfiguring Relationships Between Humans and Nonhumans: Toward Non-Anthropocentric Semiotics}

We have just shown, through a semiotic analysis of an ordinary web page - the Google Search service in this case - how the activity of a computational machine is textualized, meaning put into signs in the interface. We have insisted on the fact that this textualization is based on, and reinforces, an anthropocentric view in which the temporality of humans takes precedence over that of the machines, which has the effect of promoting an ideological representation of the relationship between humans and machines that reduces technical reality to an anthropological and purely instrumental scheme.

Our aim, however, is not only to describe how interfaces configure the representations that humans have of machines. We also seek to propose alternative narratives that make it possible to see everyday interfaces as a hybrid reality in which humans and machines are caught up in a common adventure. This means allowing nonhumans, in this case computational machines, to exist in their own right - that is, without subjecting them to an anthropocentric scheme. But how, then, do we allow them to exist? By showing what it is that they actually $d o$. This implies (i) identifying their activity in their own terms, which involves what we can refer to as technological decentering (in the sense of switching the focus to the technical reality), and then (ii) revealing machine activity for what it is. 


\section{Computational Writing as Machines' Activity}

What is it that computational machines do? According to Turing (1936), they can be described as machines that write. Not only because they enable humans to write, but because the way they actually function is based on a certain kind of writing, a form of writing that does not obey the same imperatives as human writing. Thus, binary writing, which obeys the elementary rules of arithmetic and Boolean logic, does not work to the same requirements as the alphabetic writing of humans. In other words, the writing that machines do (organized around calculation) is different from the writing of humans (organized around the text).

In seeking to resolve the problem of decision as posed by Hilbert and Ackermann, Turing - in On Computable Numbers, with an application to the Entscheidungsproblem (Turing 1936) - establishes a clear proximity between writing and calculation. First, when a machine calculates, it inscribes and scans across inscriptions: differences in electrical potential are engraved on a substrate, generally the magnetic tape of a hard disk. Next, because its activity is automatic, its states can only correspond to configurations that have been described in advance by humans, what is commonly called a "programme". This writing of the machine, which we propose to call computational writing, does not work in the same way as human writing, or what we call textual writing. Incidentally, it is interesting to note that whereas the proximity between calculation and writing is very strong in Turing's text, he never says that the machine "reads" or that it "writes". The machine does not read, it scans, and the only symbol that enters into account is the one that it is currently scanning: "the scanned symbol is the only one of which the machine is, so to speak, "directly aware"” (Turing 1936, 236). In other words, the machine has no memory. But it does interpret: in reading a sign, it is informed as to the next operation it must perform. It acts according to what it scans. Scanning means detecting by moving the read head along the tape, so that it "reads" but in a one-dimensional fashion: to the left or to the right. According to Turing, the machine does not write either, since it notes, writes down, or prints symbols (Turing 1936, 230-231, 245-246).

Thus, although he often relies on analogies between machines and human beings, Turing never crosses the line of attributing human behavior to the machine. In following Turing's approach, we do not wish when we state that computational machines are machines that write - to project any human qualities onto them. On the contrary, we aim to recognize the specificity of the computational writing performed by these machines. What is at issue in our text, and in Turing's, is the construction of a relationship between the human and the machine - a relationship that relies on writing. For the "Turing machine" to be conceivable, it had to involve a mechanical reduction of the human. The human-machine 


\section{Cléo Collomb and Samuel Goyet}

relationship is therefore a kind of analogy. What is interesting, however, is that once the machine is conceived and described, the relationship is no longer analogical: the human and the machine do not do the same things - they are different. The human is not a machine, and the machine is not human. They do have something in common: writing. This is the crux of their relationship. The relationship is, however, clearly differentiated, in the sense that humans and computers do not have the same sort of writing.

What then is the specificity of computational writing? It is onedimensional, as we have just said, but it is also based on the monosemic nature of the signs: the machine scans a finite set of signs inscribed on a substrate. It then acts according to these signs and its current internal configuration, and then it moves on. Each sign must therefore indicate a single configuration, the only possible one. If, for a given sequence of symbols, there were several possible subsequent configurations, the machine would not be able to decide by itself which configuration it should adopt. This is why the computational sign is necessarily monosemic, whereas a sign read by a human is characterized in particular by the fact that it is polysemic, which means there is a plural relationship between the signifier and what is signified (De Saussure 1916).

What Turing clearly established in 1936 is that calculation is a writing of signs, an operation that reads and modifies states: the computational machine is thus at once a machine for calculating and a machine for writing. One might ask the point of continuing to use the term "writing" to refer to the activity of computational machines since Turing himself carefully avoided using it. The point is certainly not to support the myth of a human machine, a myth whose political and ideological effects are potentially dangerous and often harmful. But by keeping the term "writing" when referring to the activity of these machines, it is possible to avoid excluding them from the domain of culture in the name of a humanist monopoly over the field of meaning - an exclusion which, according to Simondon, is "the greatest cause of alienation in the contemporary world" (Simondon 1958, 11).

However, if as a matter of principle we admit that computational machines are machines that write, we come to the thorny question of their phenomenological expression. The fact is that these machines execute instructions that are inscribed in a space of less than $100 \mathrm{~mm}^{2}$ within a few ten-thousandths of a second. They therefore function outside the limits of human perception and comprehension of space and time. A human being is not equipped with an adequate perceptual apparatus to detect the difference between 0 and 5 volts, although the difference is entirely meaningful for the machine since this is the binary code that structures the way it stores and processes data. The activity of the computational machine - computational writing - is not directly perceptible as such by humans. It must be textualized, translated into signs 
that humans can perceive. In other words, "bridges have to be built between the technical object and language" because digital technology breaks down the "close and permanent" relationship linking the sign and its substrate (Jeanneret and Souchier 1999, 103). There is a need for mediation to achieve the transition "between the requirements of the machine and those of social exchange" (Souchier and Jeanneret 2002, 102). To take a simple example, between the data that a user enters via a keyboard - letters - and what the user will see displayed on the screen, there is a need for a variety of mediating layers that "translate" between what is readable by a human and what a machine can manipulate. Between the "technical memory trace that is inaccessible to humans" and the "text displayed on the screen" (Souchier and Jeanneret 2002, 102), and vice versa, various mediating layers are inserted to allow for the translating operations. The technical dimension, the space of the machine, remains inaccessible to the human user and needs to be textualized before humans can grasp it.

The technical dimension, which is absent from "the scene of what is visible" (Souchier 1996, 108), is a space for texts that are "coded by and for the machine" (Souchier 1996, 108), which are literally unreadable by humans and beyond their comprehension. According to Emmanuël Souchier, it is a "secret" space which humans can variously people with fantasies, dreams, and fears: "Only the machine can preserve the space of the secret, but this space is purely technical and thus inaccessible to humans. The secret, the intimacy of the machine, is a matter for the algorithm or for fantasy" (Souchier 1996, 118). The technical space for calculation cannot be perceived by humans because it is organized not for them but for the machine. It therefore calls for processes whereby it can be transformed into signs and meanings that can be grasped "anthropo-logically" - in other words, for textualization.

\section{The Problem of Computation for Semiotics}

In attempting to make the activity of computational machines visible, we have established that we must first characterize this activity in its own domain: computational writing that occurs on a scale beyond the scope of human perception. Once we have characterized it, the question is to make it exist and be visible in our own daily lives. How can this be done, since what these machines do is beyond the human scale of perception? Hence, the need to textualize their activity, but the problem is then as follows: if we have to textualize computational processes so that humans can grasp it, how do we approach these computational machines without reducing them to an anthropocentric scheme? In other words, does the necessary textualization of calculation not make it impossible to apprehend computational machines in any way that is not already anthropocentric? 


\section{4}

This amounts to questioning the relevance of semiotics in an approach to computational machines. Semiotics can address the textualization of calculation, but in this case it reduces the activity of the machine to anthropocentric signs. Semiotics can then address calculation itself (thereby becoming techno-logy in the sense that it is geared to the technical dimension), but since the latter, by definition, lies beyond graphic reasoning, it is difficult to describe it, because graphic reasoning only handles the organization of signs. In short, can calculation be apprehended on the basis of its textualization, or is the textualization of calculation always already a reduction of the latter to an anthropocentric scheme? Is semiotics the right method to approach the computational writing if calculation, by definition, always lies outside graphic reasoning (Goody 1977)? Eventually, is it possible to perceive this kind of writing, to make it exist in its descriptions, to tell its story?

\section{What a Non-Anthropocentric Semiotics Could Be?}

The problem has therefore to do with the manifestation of a calculation on the screen. Where would it appear? What would be the objects that are specific to non-anthropocentric semiotics? Where would we find the marks of computational activity in ordinary web pages? What we need are marks that are not already a textualization of calculation as, for example, visitor statistics or numbers of "likes", comments, and shares are.

Computer "calculation" is different from the statistical breakdown of clicks or visits. The machine manipulates 0 s and $1 \mathrm{~s}$ not to add them up but rather as elementary symbols whose encoding corresponds to certain actions. The phrase "18 likes" displayed on the screen is not a mark of computational activity. It is the translation into terms that a human can understand of an accounting breakdown followed by a display of clicks that are considered significant - but all from the viewpoint of the human.

More generally, it is very likely that everyday interfaces such as Google Search or Facebook are so deeply marked by an ideology of inter-human communication that they leave no space for the expression of computational actions in terms that are not already in textual writing; hence, the difficulty of constructing objects of analysis for the non-anthropocentric semiotics is required.

This being so, perhaps we should not be looking into cases where the interface "works" properly from the communicational point of view (i.e. organized with a view to human-human communication), but rather into cases where it does not work properly, where there is a breakdown, whether the breakdown is deliberately sought and provoked - for example, in the case of an art project that is more concerned with potential for the expression of the machine than with the intelligibility for humans or whether it is the fruit of chance, as in the case of a "bug". A bug, 
from this point of view, occurs when a computational writing sequence suddenly appears in the middle of a textual writing sequence. A video that cannot be read properly because a plug-in is out of date; the CSS of a site that does not upload correctly and the text looks disorganized and anarchic on the page; a Google Earth map that apparently defies the laws of physics - "bugs" like these demonstrate the machine-driven composition of every interface, which is frequently denied by the dominant anthropocentrism that refers to them as "bugs". Such incidents are only "bugs" if we adopt the anthropocentric and instrumental perspective according to which the technical object must obey human requirements. In the examples given above, the machine is not making any mistakes; it is doing its job - it is calculating and providing a graphic rendering of the calculation precisely as it supposed to do based on the available information. There is only a "bug", in the sense of an error, by virtue of the ideology of the computer as a tool that serves humans.

This brings us, finally, to the heuristic value of "errors". Georges Perec, in his text on the infra-ordinary, tells that "trains only start to exist when they derail" (Perec 1989). In other words, they exist when the ordinary daily course of events goes wrong and we become conscious of the ideologies that shape our experience of the world. It is in these out-of-the-ordinary moments when the interface goes off the rails that we get a glimpse of the ideology that shapes the relationships between humans and machines. To push the point further, when ordinary daily routine goes offtrack, which is considered unacceptable, we forget that what is really unacceptable is in fact the ordinary situation, where the greatest violence is exercised. In the same way as "the scandal is not the firedamp, it is the working conditions in the mines", the scandal is not that the interface goes derailed; rather, it is the systematic invisibility of the activity of the machine when the screens function "normally". The semiotics that we propose could therefore start by taking "bugs" as opportunities to test our hypotheses. Looking into the out-of-the-ordinary, when the normal daily routine has not yet made the ideology invisible, is a good way to start learning how the machine itself acts and how to detect the signs of computational writing. The empirical content (bugs) of these non-anthropocentric semiotics may be somewhat limited for the moment, but they will necessarily evolve. Because we are still only in the early stages of this new approach, we have to start by investigating what is ignored and hidden in current semiotics, and the ideology that underlies our representations of computational machines, with the ultimate aim of making them evolve.

\section{Conclusion}

In this chapter we have shown the existence of an anthropocentric and instrumental conception of computational machines in ordinary web 


\section{6}

pages like Google Search results. We have done so by using semiotics, and particularly by paying close attention to the way the machine operations are signified. To be able to pay that kind of an attention, we had to understand how a computational machine works and what kind of computation it does. To qualify this computation, we proposed the term "computational writing": the machine writes, but in a way that is significantly different from human writing. This led us to acknowledge the limits of semiotics to analyze computational activity. Even if writing can be a common ground to analyze this activity and the relationship between humans and computational machines, due to the anthropocentric conception we have shown, text is less likely to be a conception that tends to make machines invisible - unless one adopts a technological attitude (Collomb 2016) toward digital texts. This attitude allows paying different attention to these texts, without quickly discarding everything that makes no sense to humans. The example of Google Earth's "bugs" showed the results of this approach, and how it acts both as a way to counteract ordinary anthropocentrism and a way to create new narratives of the relationships between humans and machines.

Eventually, these non-anthropocentric semiotics open up to a political dimension - in the ecological sense that Latour or Descola would give to the term (Latour 2007) - since we use the discourse of the research scientist as a way of intervening in the economics of narratives by introducing new ones. Our hope is that this text will contribute, however modestly, locally, and provisionally, to the reconfigurations of the relationships between humans and nonhumans that we need for the world to make sense.

Translation from French to English by John Stewart and Ilona Bossanyi.

\section{References}

Barthes, Roland. 1957. Mythologies. Paris: Le Seuil.

- 1964. "Rhétorique de l'image." Communications 4: 40-51.

Bostrom, Nick. 2008. "Letter from Utopia." Studies in Ethics, Law, and Technology 271: 1-7. www.nickbostrom.com/utopia.html.

Casemajor, Nathalie. 2014. "Matérialisme numérique et trajectoires d'objets: les artefacts numériques en circulation.” French Journal for Media Research 1. http://frenchjournalformediaresearch.com/index.php?id=263.

Collomb, Cléo. 2016. "Pour un concept technologique de trace numérique.” $\mathrm{PhD}$ diss., Université de Technologie de Compiègne; Université Libre de Bruxelles. — Communication +1 5, article 2. Doi: 10.7275/R5H70CR1.

De Certeau, Michel. 1990. L'invention du quotidien. Arts de faire, volume 1. Paris: Gallimard.

De Saussure, Ferdinand. 1916. Cours de Linguistique Générale. Paris: Payot. 
Dolphijn, Rick, and Iris van der Tuin. 2012. New Materialism: Interviews \& Cartographies. University of Michigan: Michigan Publishing.

Goody, Jack. 1977. The Domestication of the Savage Mind. Cambridge, MA: University of Cambridge Press.

Haraway, Donna. 2003. The Companion Species Manifesto. Dogs, People and Significant Otherness. Chicago, IL: University of Chicago Press.

- 2016. Staying With the Trouble. Making Kin in the Chthulucene. Durham, NC: Duke University Press.

Hayles, Katherine N. 2002. Writing Machines. Cambridge, MA: MIT Press.

Jahjah, Marc. 2016. "De la bibliographie matérielle aux 'Digital Studies'?" Revue française des Sciences de l'Information et de la Communication 8. Doi: 10.4000/rfsic.1968

Jeanneret, Yves, and Emmanuël Souchier. 1999. "Pour une poétique de l'écrit d'écran." Xoana 6: 97-107.

Kittler, Friedrich. 1995. "There Is No Software.” C-Theory: Theory, Technology, Culture 32. https://journals.uvic.ca/index.php/ctheory/article/view/ 14655.

Lassègue, Jean et Giuseppe Longo. 2012. "What is Turing's Comparison between Mechanism and Writing Worth?" In How the World Computes, edited by Barry S. Cooper, Anuj Dawar, and Benedikt Löwe, 450-461. Berlin: Springer Heidelberg.

Latour, Bruno. 2007. Reassembling the Social: An Introduction to ActorNetwork-Theory. Oxford: Oxford University Press.

MacKenzie, Kenneth M. 1991. La bibliographie et la sociologie des textes. Paris: Éditions du Cercle de la Librairie.

Perec, Georges. 1989. “Approches de quoi?” In L'infraordinaire, edited by Maurice Ollender, 9-33. Paris: Le Seuil.

Simondon, Gilbert. 1958. Du mode d'existence des objets techniques. Paris: Aubier.

Souchier, Emmanuël. 1996. "L'écrit d'écran, pratiques d'écriture \& informatique." Communication \& Langages 107: 105-119.

-1998. "L'image du texte. Pour une théorie de l'énonciation éditoriale." Cahiers de médiologie 6: 137-145.

— Pour la Science - Scientific American 33: 100-105.

Turing, Alan M. 1936. "On Computable Numbers, with an Application to the entscheidungsproblem." Proceedings of the London Mathematical Society 42 (2): 230-265. 


\section{Journeys in Intensity \\ Human and Nonhuman \\ Co-Agency, Neuropower, and \\ Counterplay in Minecraft}

\section{Marleena Huubka}

In the end, you know it's all just blocks.

akkashtin (Minecraft Forum, n.d. ${ }^{1}$ )

Once again, I find myself and other entities in a random location in world that is constantly being generated - block upon and next to another - as far as my avatar's body and location let me see. And beyond that, ever so far are the unreachable edges and countless wonders of the virtual world I have just entered. The end of the world is unreachable as the world is constantly, randomly, and infinitely generated as my avatar moves forward in the world. As a result of this procedural creation, the world in question does not exist, yet. Only the algorithm and the code do, but everything else is on the verge of being actualized. This process happens as a shared activity between the player and countless other elements and agents, such as pixels, algorithms, and game developers.

This engagement to creation and co-agency happens inside the player experience of a commercial product called Minecraft. Minecraft is a sandbox videogame first developed by Mojang AB in 2009. In 2018, it was the second best-selling videogame of all time - after Tetris - and available for various platforms including consoles, PCs, and mobile devices (Wikipedia 2018). It can be played both as a single-player and as a group of many players via the Internet, and it has several game modes, which vary in difficulty.

The basic idea of Minecraft is to explore and build a world of one's own. The world consists of blocks of different materials, and the player digs, chops, shovels them up, and then organizes them again in different formations such as houses and railroads. Food is acquired by hunting, gathering, or farming. The basic gameplay has no specific goals; the only set objective is to survive in a sometimes-perilous environment. The game does not end if the player dies; they merely drop all they are carrying at that moment and then respawn again to previously determined coordinates. Even though the game has no set goals or quests, the players easily set them for themselves. The urge to accomplish something - whether it 
is a huge castle or a gate to the Netherworld - makes Minecraft a highly addictive game. As the possibilities are almost endless - limited only by the rules of the game and the players' imagination - one can never win or finish the game.

As said, the world is created and constructed in front of the avatar's/ player's eyes, and it is tied to the movement of the avatar and thus to the choices of direction or speed of movement and action the player makes. Herein lies the immersive power of Minecraft: everything is always new and exciting even though the player might have seen every single block type many times before. It is the specific way the blocks organize; this time is always different from the last. As Minecraft is filled with little bugs and strange incidents, such as a tree growing from air or an abandoned well in the middle of the desert, the player never knows what to expect. The player is constantly invited to wander a step further or to dig one cube deeper. Desire to go further and to dig deeper can rouse desire to possess and to leave traces or signs of one's presence in the virtual environment. This desire can be interpreted as colonial: the narrative of the game rests upon the trope of the great (male) explorer bravely venturing into uncharted, uninhabited lands. This desire is obviously more distinct in multiplayer games, where the players express their presence and accomplishments to other players. However, even when playing alone, the desire to leave a mark on the environment is present.

This chapter sets out to map the human and nonhuman co-agencies at work in videogames and gameplay situations. Videogame studies have multiple and contradictory definitions for the concept of a game. The main disagreement has long been about the ontology of games: whether they are essentially systems of rules, or narratives. I wish to pass this conflict of narratological and ludological theories by relying on Ian Bogost's definition: "video games are a mess" (Bogost 2009). Bogost states that games are by nature vague and effusive and as such they cannot be pushed to fit into strict categories. Games are never either/ or but always both - and thus it is beneficial to abandon hierarchical definitions altogether. Some common elements - which are also present in Minecraft - can, however, be defined. All videogames have some sort of rules limiting and guiding gameplay (e.g. Suits 1978), and they are all characterized by the interaction between human and the game device (Galloway 2006, 2). In addition, all videogames are play, paidia, which is by definition voluntary and meaningful in itself (e.g. Huizinga 1967; Suits 1978; Caillois 2001; Salen and Zimmerman 2004).

This chapter has three key points. The first is to deconstruct the subject-object dichotomy surrounding human interaction with other materialities. Drawing from the works of Baruch Spinoza, Jane Bennett, and Gilles Deleuze and Félix Guattari, I argue that we cannot take responsibility nor glory for our actions, as they are always produced in 
cooperation with forces sometimes unknown and unseen to us. Spinoza argues that everything in this world is made of the same substance. All separate bodies - human and nonhuman - are manifestations of this divine substance (see Spinoza 1994). Deleuze and Guattari follow Spinoza with concepts of rhizome and assemblage, which both are horizontal ways of organizing agencies and relations (Deleuze and Guattari 2014). In her book Vibrant Matter - A political Ecology of Things (2010), Bennett builds upon Spinoza, Deleuze and Guattari, and suggests ways of taking inorganic matter seriously in the contemporary anthropocentric atmosphere.

Second, I build on Pasi Väliaho's (2014) work, which suggests that videogames and their immersive qualities have a role in building docile neoliberal subjects constantly ready for change and insecurity in today's capitalist societies. These building processes rest on the use of "neuropower", which Väliaho defines as follows:

capturing the brain's capacity to simulate in order to teach the political reality of life today based on the management of risk and the securitization of the future, whether through military action, financial speculation, or other means.

(Väliaho 2014, xiii)

Though examples used by Väliaho are mainly from first-person shooter games, similar processes are at work also in Minecraft: the logic of capitalism, conquest, and possession are offered through the narrative and the game mechanics. As previously mentioned, Minecraft is in its infinity an addictive game. This addiction is crucial to videogames as capitalist consumer products, which - however pleasant or educative they might be - invite players to invest both their time and money in global corporations.

Third, I will explore the concept of counterplay used by Rika Nakamura and Hanna Wirman (2005), and Thomas Apperley (2010). Counterplay is a collection of tactics the players can utilize when they wish to do something un-thought of by the developers of the game in question. Toward the end of this chapter, I will discuss two possible ways of resisting the capitalist agenda of colonialism and docile subjectivity available for the player in Minecraft. I wish to draw a (part of a) map of possible resistance through aimless wandering and immobility, which are both seen here as journeys in intensity.

The perspective in this chapter is that of my own body, mind, and avatar; this is an auto-ethnographical piece based on my experiences. Something else, however, is lurking behind the human-produced body of text. Because the perspectives of countless other human and nonhuman entities are constantly influencing my experience of the game, I am never alone on my adventure in this block-shaped world. 


\section{Co-Agencies}

You are the player, and I am the block. Together we make Minecraft.

Pizzamanilla

When I start Minecraft on my Xbox, I am greeted by a random word or a phrase chosen first by the people who created the game and then presented to me by the algorithm managing this particular function. One day this greeting is "Polynomia!!!" I become immediately fascinated by this word. It is the plural of "polynomium", which is a noun for something that is "polynomial". Polynomial is a term used in algebra to mean "an expression of more than two algebraic terms, especially the sum of several terms that contain different powers of the same variable(s)", or in taxonomy to mean "a Latin name consisting of more than two terms". The word consists of the Greek word poly ("many") and the Latin word nomen ("name or part") (Oxford Dictionaries, n.d.). Polynomials are also used in coding, which is probably the reason the word has found its place among other, more content-related words, in the Minecraft menu.

All this seems perfectly understandable in the context of Minecraft. It can indeed be considered an expression consisting of a sum of more than two terms and variables as well as a designation consisting of multiple terms. As such, the word provides an entry point to the co-agential, material rhizomes that are in action and existence during and around my active gameplay sessions.

Gameplay as an action reaches beyond the representational levels of the game in question, and can thus be seen as material activity created through and in the bodies of my human and nonhuman peers and myself. All agencies involved in my game experience are physical bodies, though some of them cannot be reached directly by human senses. A concrete, material body in direct contact with the player is the game device: the computer or the console. It is a composition of metals and plastics that can be extended by additional parts, like a mouse, a screen, or an Internet cable. More bodies can be found behind this device's visible materiality: for example, the body of programming language, that manifests and moves the pixels, and that of electricity, which powers up both my experience and the processes of programming and development before that. Electricity and pixels can easily be seen as something less material, something from the other realm. However, their materiality is undeniable.

All the nonhumans and humans - coders, other players, and designers among others - are located in the common rhizome on the same plane of immanence that is in existence during my gameplay sessions. In other words, I am never alone but always unavoidably connected with countless others and other worlds. This connection surpasses the limitations of time and place and relies on co-agency beyond the differences in 


\section{Marleena Huubka}

materiality. In Minecraft, I am connected with all the forces mentioned above. As also argued above, gameplay is never merely a human experience. In Minecraft, the materiality of the blocks is, in the end, connected to my own as gameplay can be seen post- or antihumanist in nature.

Baruch Spinoza, the philosopher of joy, has been considered one of the first antihumanists. Spinoza implies that if humans are different and separate from the rest of the world and its beings, then humans cannot exist (Hardt and Negri 2005, 103). For Spinoza, there is only one infinite godly substance that is everything and everything is a part of this substance (Spinoza 1994, 54). The world, every single thing in the universe, every single body and being are moduses of this substance (Spinoza 1994, 145). That is to say, all of us, all of these human and nonhuman bodies that form and manifest themselves in this world, are embodiments of the same substance or material. This is Spinoza's antihumanism at its barest: humans cannot be separated from everything else. In other words, hierarchies between beings are - or at least should be - fundamentally non-existent.

Even though all beings have the same fundamental desire to remain in existence, it is hard not to slip into an anthropocentric view of human dominance, in this case myself and my playership, as something of higher relevance to this specific gameplay experience. However, when I strive to see and recognize the ways in which the other agents affect me, this attempt to build a hierarchy with me on top as a facilitator is met by objections. I do not dictate gameplay situation; I am by no means responsible or at the top of the imagined hierarchy. That being said, it is also crucial to recognize the fact that accepting others as equals does not erase all hierarchies. Nonetheless, active attempts to shake them can and should be made. In the era of global environmental catastrophes, deconstructing the dream of human dominance over other species and materialities is crucial. Analyzing videogames through materialist theories is important: videogames, virtual reality, and augmented reality have an increasing influence on how humans - at least in the Occident perceive the world around them, and the agents present in these new environments differ from the ones humans are used to taking into account.

Political philosopher Jane Bennett uses the concept of vibrant matter to show a glimpse of the world in which we humans change our perception of the things normally seen as lifeless. Matter, according to Bennett, is to be taken seriously as companions: active, vibrant bodies of something, which have affective relations with humans (Bennett 2010, viii). At the same time, Bennett sets out to grasp subjectivity outside the notion of humans as the rulers of the world and themselves. This goal can be achieved by searching for horizontal and equal practices in interaction with human and nonhuman matter (Bennett 2010, ix).

According to Bennett, the idea of matter as dead and inactive emphasizes the notion of human as the king of the world. This human dream of omnipotence leads to destructive practices of control, conquest, and 
possession. As humans are eager to trivialize the sensations received from other materialities, we tend to over-emphasize our own liability and control of our actions. However, there is always more in action than a mere human: rhizomes of social relations as well as nonhuman actants influence our actions in unforeseen, yet unavoidable, ways (Bennett 2010, xii).

Bennett's aim is to render the multidirectionality of all relationships visible. In Minecraft, this relationship is seen clearly, as I, as a player, have the power to modify and enhance my environment. That is not all: I operate with pixels directly impacted by the algorithms, which of course are coded by humans, but which inside their margin of operation act freely and sometimes unexpectedly.

This engagement happens in a rhizome of different materialities and entities. Rhizome - a concept used by Gilles Deleuze and Félix Guattari is a way in which agencies organize. It takes its form from the mushroom kingdom and stands in opposition to binary tree-like models of organization. All the points of the rhizome can be connected with all the other points; there are no hierarchies in this model. Everything happens in these lines of connection, not in their meeting points (Deleuze 1992, 27). As every single point of the rhizome is potentially connected with all the others, it can be broken, yet it continues its existence infinitely toward other bodies and via other lines. Deleuze and Guattari use an ant colony as an example of rhizomatic organization. The fate of a single ant or a single nest is meaningless in regard to the fate of the colony, which will continue to grow and exist (Deleuze 1992, 30).

Rhizome is a territory of affiliation and fleeing, which produces endless indeterminate multiplicities and potentialities for infinite freedom of creation. Every single element and entity possible in a videogame, such as Minecraft, comes into existence solely through the lines connecting them. This means that every physical and virtual body - of mine, of the machine, and of the others - is created in relation to other bodies in that specific rhizome.

Assemblage is a form of rhizome, often explained through the concept of love. According to Deleuze and Guattari, love is not love for a person, but rather for an assemblage consisting of the loved one, the lover and all the emotions and memories associated with that relationship.

\section{Acting with the Others In Minecraft}

Gravity is a lifestyle choice for many elements of the world.

Hexus_One

Now that we have acknowledged the others connected to the Minecraftian rhizome, it is time to look more closely at the ways their agencies manifest. The agency of the machine, in this case my Xbox, becomes visible through mistakes. We usually think of computers as extensions 


\section{Marleena Huubka}

of our brains or mind, or - in the case of, for example, game consoles as some kind of cyborg-style extra limbs providing access to the world on the other side of the screen. However, the agency of a machine has always been present, but we only take it into consideration when something unexpected happens, when the computer crashes, freezes, or breaks. The idea of being in control of the machine was thus merely imagination, as the mistake opens up a possibility of withdrawal for all the agents involved.

We can harness and use electricity, but as it is flowing, bouncing, wild, and in a constant process of becoming by nature, its body is beyond our grasp. It can break free from cables and cause blackouts and short-circuits. It can, in cooperation with other agents of the grid, disturb my game experience as well as the infrastructure of entire cities. This moment of interruption and disturbance is where the nonhuman force running our lives becomes and manifests its agency (Bennett 2010, 25-28).

Gameplay as a co-agential rhizome can be explored through Spinoza's philosophy of joy. All entities pursue happiness and greater perfection, and happiness for one is usually happiness for others, the co-actors, close by. For humans, this greater perfection can be pleasure; for electricity, the chance to flow and sparkle; and for the pixels, the chance to arrange themselves repeatedly. Here the danger of anthropocentrism and anthropomorphism, however, lurks near. My knowledge of the sought-after or avoided perfection or imperfection of the nonhuman is always limited; one could say it is merely a guess. However, as I previously argued, for nonhumans there exists a chance to leave this relationship through a mistake: electricity can, for example, fry the circuits, thus allowing for console to crash. As long as our cooperation runs smoothly, I can only assume we are engaging together, somewhat freely, in this rhizome of gameplay.

Above I have discussed human and nonhuman agents. However, this division is problematic. I can declare my body to be human, but I am already many, a mixture of human and nonhuman entities. Together, we are involved in constant processes of subjectivation, of multiplicity, of becoming-something (see Guattari 2010). As Donna Haraway says: "To be one is always to become with many" (Haraway 2008, 4).

Gaming as action is essentially materialistic, rhizomatic, and mimetic, and it is constructed in cooperation with human and nonhuman agencies. As such, it is always in motion, both physically and conceptually. All human actions are constructed in similar cooperative unions. When playing videogames, we gain contact with materialities often thought to be non-material or somehow out of reach. A multitude of electricity, machines, players, and algorithms engages in an assemblage that is Minecraft, and every moment in this assemblage is a potential moment both for creation and for a mistake as a manifestation of human or nonhuman autonomy.

The rhizomatic, shared materiality does not end where the game ends. The acts conducted in-game resonate off-game into and through my 
body, in the electric wires, and so on, forever. The first step toward understanding co-agential rhizomes of humans and nonhumans is to ditch the idea of separateness or material uniqueness.

However, back to polynomia: what captured my attention was the roar of power and freedom embedded in that word. Polynomia resonates, in my ears, with the word autonomia (autonomy). When associated with Minecraft, it uncovers the potential sovereignty of the rhizome, of the collective engaged in the gaming experience. Polynomia reaches beyond me as a subject, inviting along the multiple agents involved. It opens up a possibility to start a journey of finding new ways of resisting immersive passivity of Minecraft. These ways of resistance can be approached via the theory of counterplay.

The power of polynomia is the notion that sovereignty is also shared. It cannot be achieved alone, and thus it is parallel to freedom. Every single agent in Minecraft acts with and in relation to others. Becomingsomething is always rhizomatic: all my tactics and practices inside Minecraft are the result of cooperation. Polynomia is thus an active, political word. It is more than a word: it is a philosophical approach.

\section{Neuropower}

You haven't played Minecraft until you forget what year it is.

Stealthman 917

When playing, I become immersed, drawn into the creative process of gameplay. I lose track of time; I lose track of my body. Robbie Cooper has photographed people engaged in immersive situations, such as gameplay or movie screenings (Open Culture 2013). The kids portrayed mid-game stare with unseeing eyes, their facial muscles are relaxed, leaving their mouths somewhat open. I, too, feel the muscles in my face relax as the muscles in my shoulders and arms tense. These sensations vanish quickly and return only when something interrupts my immersion. Immersion is a thorough experience; it engages all of me: my brain and my body.

What, then, is immersion, and how does it affect my fellow gamers and me? Pasi Väliaho has written about videogames as the site for production of neoliberal, docile subjects. Väliaho reminds that, in modern neuroscience, the brain is considered an adaptive, creative, and constantly self-modifying organ. It is thus not merely copying or picturing but actively predicting and hypothesizing. Brain's primary function is to anticipate the things to come, in other words, to predict the future so that the rest of the body knows what to do and how to react (Väliaho 2014, 40).

Videogames tap into this function and thus into the core characteristics of humanness. In first-person shooter games, the player is sucked into a constantly changing and evolving web - or rhizome - of actions and reactions, which, according to Väliaho, is an accurate portrayal of the 


\section{Marleena Huubka}

way games offer "movement and contingency as an adaptive challenge". This is a way in which the biopolitical power structures of the techno age operate: the player engages with preemptive processes that happen somewhere out of reach of conscious awareness. The rhythms and excitements produced by the speed of certain games engage the brain: they ready all our senses in the face of this virtual danger (Väliaho 2014, 40). This is the desire of conquest and thus colonization. Even though $M i$ necraft has a different pace and visual identity than first-person shooter games, it is no less efficient in generating immersion and engaging the player with colonial, capitalist practices. The game itself as well as the materialities engaged with the player are active participants and agents in this production of desire and neoliberal subjectivity.

Väliaho writes:

For player, then, the screen exists as a simulated future, capturing our bodily rhythms and prenoetic adjustments through which the affective and predictive functions of the brain merge with the video screen and vice versa.

(Väliaho 2014, 41)

The body, however, does not engage merely through simulations of bodily functions. In Minecraft, the movements of the character are not reproductions of human movements, but something existing in their own right. The character is stiff, "unnatural", more of a pixel than a representation of an actual human entity. It can be seen as an extension of human agency, although it clearly has agential qualities itself. The likeness, or mimicry, does not play a significant role here. The immersion emerges from the actual bodily engagement of the human player, and screen is merely a device in between. I would argue that the simulated future is thus created within the player, in the desire of conquest and possession, and manifested through the cooperational rhizome of the gameplay situation. The whole gameplay situation is thus inherently nonhuman.

Minecraft caters to the desire of infinite conquest and colonization, the infinite lust of being in control. It is a platform for domination and god-like fantasies, however educational its uses might sometimes be. But are there ways to immerse oneself in Minecraft without being subjected to these oppressive and compelling processes?

\section{Counterplay}

Thank you for helping us help you help us all with building.

Axalto

Contemporary theories of gameplay build upon Roger Caillois's theory of play. Caillois defines two modes or opposites that govern all play, 
paidia and ludus. Ludus - which also gives the name to ludology - is a disciplinary form of play, which is characterized by skill, effort, patience, and other such traits. Paidia is an opposing (or complementing) type of play: it is based on joy and improvisation (Caillois 2001, 13). Most forms of play obviously contain both characteristics with varying intensities. According to Caillois, ludus-guided rules are essential to play: for play to be play, basic freedoms and stimulation for fantasy are needed. The two are always complementary and related, though Caillois considers ludus to be a refinement of paidia (Caillois 2001, 27-29).

Thomas Apperley $(2010,141)$ brings up the discussion over the importance and meaning of paidia. Ludus has been considered to hold some meanings that contribute to institutional practices, such as rites and sports. Paidia, however, is another thing entirely: it opens up a view to play as something that does not necessarily provide any cultural values outside itself. According to Apperley, Caillois seems to set ludus and paidia in a hierarchical order. Ludus refines and disciplines paidia and turns the wild and naive elements of play into something that has meaning outside the playing field. This does not mean that paidia is insignificant outside the play act, rather that the significance of it is extracted through/with ludus.

The relevance of ludus and paidia and their different hierarchical positions comes clearer when approaching the areas where counterplay happens. Apperley describes these areas as the margin where one is free to express oneself within the limits set by the rules (and their errors) and the material requirements and limits of the game. This margin is created when the creative and unruly forces and practices are combined with the formal rules. As the "margin" is not, according to Apperley, "a realm of pure potentiality"; it is vulnerable to exploits or acts of counterplay (Apperley 2010, 140).

According to Apperley, "there is a tension between the society of control, or 'algorithmic culture' and counterplay: the emergent practices of digital game players". This tension comes from the alleged notion that the algorithms of a game already contain all the possible meanings, leaving no room for critical approach or new engagements (Apperley 2010, 132). Apperley sees counterplay as something unthought of by the developers, practiced by the players on the margins of possibility offered by the game. This approach distinguishes it from counter-gaming, which relies on interference to the code as its method (see Galloway 2006).

The significance of the human player is, according to Apperley, to be the force that sets things into motion. As long as the human does not use or tap into the code, it is mere potential. However, everything is in existence, material, yet dormant until utilized (Apperley 2010, 143). In other words, counterplay can be perceived as active participation that arises from the human need or will to do something. As long as the code just exists, it is not counterplay, even though everything needed for an action already exists. 


\section{Marleena Huubka}

Is potentiality action? Or is something considered an action merely when human influence is added to the mix? Apperley seems to think that human activity is the catalyst, the force that can bring forward the hidden potentialities embedded in the mishaps and the unthought-of thought of the code. This is clearly an anthropocentric approach, which sees the human as the only relevant actor. Everything else is just preparing. However, if we look at Minecraft as an example, things happen without direct human engagement. If we look past the act of turning the game on, all sorts of processes run even when the player does not actively practice counterplay. Thus, the potentiality is always more than mere opportunity waiting to be seized. Apperley's approach also sees action as something related to movement: something must be done to actualize the potentialities left in the margins of the code. Yet we can assume that there are other modes of moving and resisting than those that require movement in space: for example, those that concern the body of the player or temporal engagement.

Apperley points out that as gameplay is always situated and created through the human body, there are limitations to the modulation of the algorithmic culture. In order for the gameplay to actually happen, the algorithms must work in some cooperation with the rhythm of everyday life. The rhythm of everyday life is the location where, according to Apperley, the practice of counterplay takes place and from which it arises (Apperley 2010, 132). When approaching games as material environments, one may easily become stuck with the idea that the code somehow limits what one can and cannot do. It is clear that the material foundation formed upon code and algorithm do define the actions one may perform inside a game world as every single choice has to be coded in order to be made. This, however, is only one and clearly limited approach to materiality and games themselves.

According to Apperley, in order to understand the effects of everyday life and its rhythms in digital games, we must see games as more than mere codes and algorithms (Apperley 2010, 134). He does not deny the influence the regime of compulsion or discipline has on gameplay, but emphasizes the more complex ways gameplay affects and is affected:

Rather than in relation to compulsions it is ambiguous and paradoxical; disciplinary and adaptive. It operates both as a mediator and intermediary; consequently game play is in some contexts an impartial transferor of culture, but in others, a source of new culture and relations. This is not a binary relationship: adaptation and compulsion exist in an imbricated spectrum.

(Apperley 2010, 134)

To move beyond the binaries of compulsion and adaptation, Apperley draws from Bruno Latour and his discussion of mediators and 
intermediaries. In Latour's actor-network theory, the roles of actors tend to be largely immaterial. An object, such as a videogame, can function in a social ensemble undictated by its essence or status. Instead, the role or function is formed in relation to other actors and connections. Apperley states that reducing games to their code is to reduce a complex activity into a closed circuit of player and the game, which already contains everything, all the meanings and possibilities (Apperley 2010, 134). With the concept of counterplay, Apperley strives to open that relationship and to follow human and nonhuman interactions further down or around the rhizome.

Following Apperley's theoretical approach does not undermine the importance of the materiality of games and gameplay. Rather, it opens up a possibility to take in consideration the different materialities entwined in gameplay processes. Counterplay can thus be seen as something that may get a little out of human or machine hands, thus creating something that cannot be described solely as one or the other. In other words, counterplay emphasizes play over gaming, which downplays the role of calculated achievements.

Counterplay is formed and practiced through actions and affordances that are already available and allowed within the rules of the game. However, actions of the counterplayer are typically something that was left to be done by mistake or that was not intended to be of any/much relevance to the gameplay. Apperley calls these actions emergent forms of play, which overlap and cross with the ways the game is meant to be played. The player may cooperate in these intersections with other human players via Internet or with machinic forces (Apperley 2010, 140). Counterplay is thus a shared affair and hence one manifestation of polynomia.

In their article "Girlish Counter-Playing Tactics", Rika Nakamura and Hanna Wirman list various ways of practicing counterplay in videogames still very much dominated by male players and developers. These tactics include "non-violence", "peaceful pace", and "alternative pathways" (Nakamura and Wirman 2005). As my emphasis lies within resisting the capitalist, goal-oriented ways of gameplay, these tactics are useful, as they highlight a more equal relationship between the game and the player.

In order to take the agency of the nonhuman seriously, the possibility of nonhuman counterplay must also be considered. Do the pixels, algorithms, game devices, or electricity have a desire to commit counterplay? One way of looking at this is to consider mistakes or bugs as forms of nonhuman counterplay. As I argued previously, machines and also algorithms make their agency noticeable through mistakes, or when something the player had not expected occurs. In Minecraft, it can be a non-player character getting stuck behind a rock or in mid-air, a tree growing from air, or other such quirks. If the agency of the machine is shown through the mistakes it 
makes, is it not possible to see misbehaving pixels and NPCs as an act of a rebellion? Algorithms have means of deciding for themselves. It is true that their actions are limited to the programming, but so are - according to Apperley - the possibilities of humans in a similar situation. Everybody operates in the margin defined by the developers of the game. A problem lies, however, in the access to nonhuman counterplay and its intentions. As I can never know the intention of a pixel or a specific NPC, I can only guess and hypothesize about it.

The restrictions imposed by the mysteriority of the other guide my attention to another realm of counterplay. I am interested in processes that happen mostly in the player herself. This aspect of counterplay resides in the area of imagination and thus play, paidia. It is something undisciplined and therefore beyond strict limits or characteristics. It is also without direct consequences or benefits. This imaginary act of counterplay can be called a journey in intensity. It stems from doing much and nothing simultaneously. Counterplay is thus expanded to the body of the player: it is relevant how and what the player feels at a specific moment, what kind of resonances leave and return to the body, what is the relation between my body and, for example, the controller I am holding, and so forth. The things done or left undone are equally important: the practice can thus sometimes be situated solely in immobility. Practices of resistance and counterplay can also take place in the body of the player/ performer. As discussed earlier, gameplay alters human tissues with its immersive potential as well as with the physical injuries and aches that prolonged gaming session may produce.

Counterplay may sometimes be as simple as choosing to immerse in the game world without moving the avatar at all. Immobility may, however, be intense and thus active gameplay in itself. What is active then is the performative aspect of both the player and the avatar. What is radical in this exercise is the refusal to anticipate the future, refusing to anticipate the stimuli the game is about to offer. In other words, the player rises, no matter for how briefly or incessantly, against the production of neoliberal subject described by Väliaho.

\section{Nomadic Resistance}

It's a big world. But someone has to explore it.

Tic_Tac_Toe

My counterplay in Minecraft has taken the form of nomadic expedition, which challenges the urge for productivity that the game promotes. I will give two examples of my own counterplay practices: aimless wandering and immobility. In order to truly open their potentiality, a brief explanation of nomadism as a philosophical concept is in order. 
Gilles Deleuze and Félix Guattari describe the nomad as someone who does not move. This may seem weird, as wandering and displacement is characteristic to traditional nomads, but Deleuze and Guattari point to a conceptual difference. Movement requires a plan, a destination; it is something that happens between two or more predetermined points. Nomad has no plan and no destination, nomad travels via speed and intensity (Adkins 2015, 206). For Rosi Braidotti, nomadism "refers to the kind of critical consciousness that resists settling into socially coded modes of thought and behavior". Thus, a nomad does not necessarily travel along physical roads or paths but engages on journeys that take place in a specific place. Nomadism is defined by its power to unravel and break conventions and norms (Braidotti 1994, 5). Deleuze, Guattari, and Braidotti all see nomadism as an active practice, which is possible in both philosophy and art, and in other areas of life.

As mentioned before, the modulation of the algorithmic culture has a material limit. The practices I am proposing do not erase the materiality of gameplay, but rather tap into different kinds of materialities. When traveling in intensity and engaging in speed rather than in movement, the limits of actions inside the game world are no longer of concern. In other words, nomadic attitude to counterplay is more a philosophical than an operational practice and, as such, relevant for developing a different approach to game studies.

As Minecraft is all about building and establishing locations of virtual residence, wandering around aimlessly can be seen as a means of counterplay. If I start Minecraft in "Survival mode" in the easiest setting possible, "Peaceful", I will face no enemies nor will I die of hunger. This means that there is nothing I need to do or avoid - the only exception is falling from a place high enough for the blow to be lethal - in order to keep existing in the world (Figure 11.1).

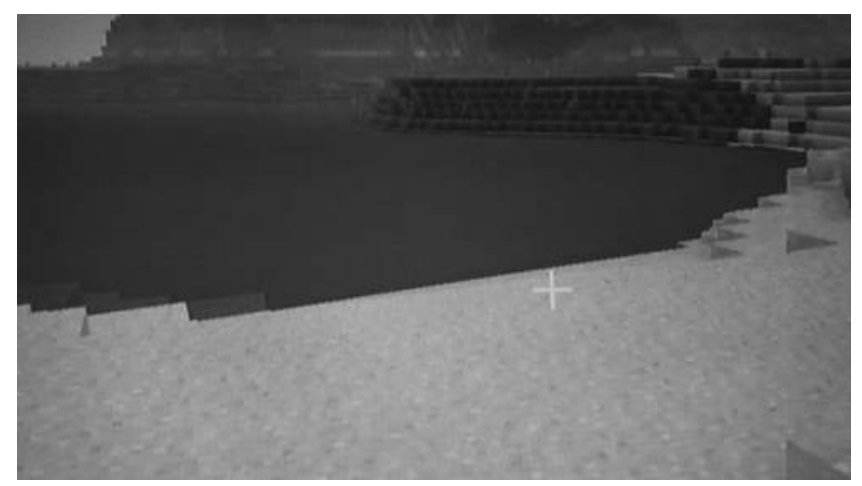

Figure 11.1 Wandering. ${ }^{2}$ 


\section{Marleena Huubka}

When the players choose to exist in a wandering state, they refuse to stop and claim ownership of the possible wonders and quirks they encounter. This is obliviously a goal in itself, but one that resists the basic hierarchies provided within the gameplay ideals. Leaving things behind can be a challenging practice, at least in my own experience. When I encounter a village full of non-player-characters or a temple rising in the middle of a jungle, a part of me wishes to claim some kind of ownership or to acquire a lasting memory of that place. However, there is nothing to possess or acquire; the fleeting moments spent inside the game leave material mementos within the game, but they tend not to be accessible to the player and their materiality. This acceptance of the impossibility of colonialism and, thus, power, can be considered one of the possible radical implications of counterplay.

Remaining in immobility is the other form of counterplay I have practiced on my adventures. This means that the player spawns to the world and then remains immobile. The avatar does not do or accomplish anything, and neither does the player. This results in something that can be described as traveling in intensity. I, both my physical body and my avatar's, engage in active nothingness, active non-movement that still resonates with speed. Intensity is traveling in place. We choose not to engage in movement and, thus, choose not to deliver the expected behavior. This tactic pushes Nakamura's and Wirman's "peaceful pac" to the extreme (Figure 11.2).

Both of these practices set the player against the inherent colonialism of the game: my objective is no longer to expand, own, and possess. In fact, I no longer have an objective. Thus, this approach is the refusal to succumb to the logic of capitalism. As all means of counterplay, these as well are provided to the player by the game and its mechanics. However, these practices cannot be absorbed or capitalized on by the game company - there are no added value or innovations present here. The intensity produced in the player in cooperation with nonhumanity around them is all that it is.

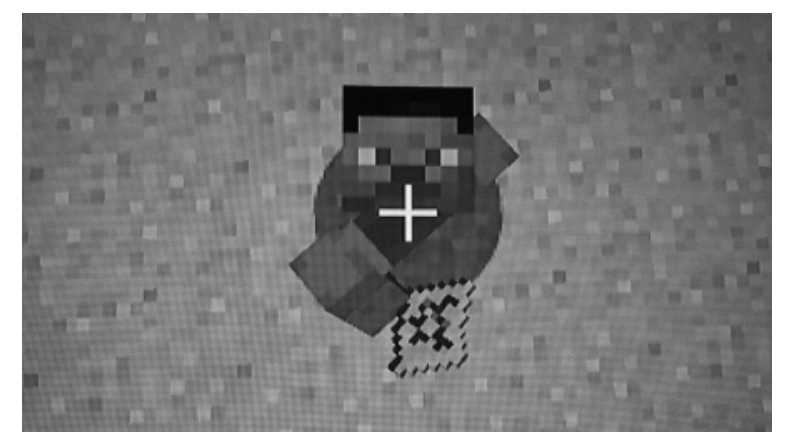

Figure 11.2 Traveling in intensity. 
A nomadic way of playing, of remaining in immobility can be a way to engage in resistance and in counterplay. When both, the player and the avatar, remain in fixed locations, the prospects for the future change radically.

\section{Conclusion}

The thing is, there's only six sides to a block.

This chapter has pieced together a picture of gameplay - especially that of Minecraft - as a rhizome of human and nonhuman co-agencies affecting our brains and our bodies. Practices of colonialism, conquest, and possession intertwine with immersive pleasure during gameplay, thus strengthening and enforcing harmful, capitalist, and anthropocentric power structures. To challenge these processes, I have introduced some tactics of counterplay practices by Nakamura, Wirman, and Apperley, and then expanded the concept with my own examples from Minecraft.

The force of these practices lies in the refusal of the player to be subjected as a vehicle of capitalist dreams of expansion. My interpretation of counterplay is that it is a philosophical practice, which extends outside mere gameplay. In other words, taking passive actions and engaging in resistance in videogames are bound to have an effect on the player also in other situations. Acknowledging one's position in the hierarchy helps to undermine and deconstruct it. It is also crucial to see other agencies and materialities affecting the player.

Doing nothing is, however, still a choice, and a choice is always a question of internality that somewhat dismisses other agencies despite their influence on me. The choice here restores the hierarchy in favor of the human: it makes room for oppression of the other. The power of capitalism is to restore human rule, ensure that the human - and a very certain kind of human - stays on the top of the hierarchy. Counterplay might not be able to abolish hierarchies, but it can make them visible.

The absence of plan and destination in my examples of counterplay is set against the logic of capitalism, however brief these moments of resistance may be. The possibility for the subject to choose such an approach, one that acts or at least tries to act outside a possessive and destructive ideology, is indeed a contested one. The notion of the end of the history, of current status quo as the best and final one is hard to overcome. Cultural and artistic practices are, however, keys to resistance, as they approach the question through pleasure and play instead of pain and gain. 


\section{Marleena Huubka}

\section{Notes}

1 All the quotes are from the same discussion thread on Minecraft Forum. In the thread, players invented their own Minecraft-related quotes.

2 All the images are screenshots from Minecraft taken by the author and used under fair use according to Digital Games Research Association guidelines.

\section{References}

Adkins, Brent. 2015. Deleuze and Guattari's A Thousand Plateaus: A Critical Introduction and Guide. Edinburgh: Edinburgh University Press.

Apperley, Thomas. 2010. Gaming Rhythms: Play and Counterplay from the Situated to the Global. Theory on demand \#6. www.networkcultures.org/_ uploads/TOD\%236\%20total\%20def.pdf.

Bennett, Jane. 2010. Vibrant Matter: A Political Ecology of things. Durham and London: Duke University Press.

Bogost, Ian. 2009. Videogames are a Mess. http://bogost.com/writing/ videogames_are_a_mess/.

Braidotti, Rosi. 1994. Nomadic Subjects. New York: Columbia University Press.

Caillois, Roger. 2001. Man, Play and Games. Urbana, IL: University of Illinois Press.

Deleuze, Gilles. 1992. Autiomaa: Kirjoituksia vuosilta 1967-1986. Edited and Translated by Jussi Kotkanvirta, Keijo Rahkonen, and Jussi Vähämäki. Helsinki: Gaudeamus.

—, and Félix Guattari. 2014. A Thousand Plateaus. Capitalism and Schizophrenia. Translated by Brian Massumi. London: Bloomsbury.

Galloway, Alexander R. 2006. Gaming. Essays on Algorithmic Culture. Minneapolis, MN: University of Minnesota Press.

Guattari, Félix. 2010. Kaaosmoosi. Translated by Mariaana Fiendt-Jäntti and Heikki Jäntti. Helsinki: Tutkijaliitto.

Haraway, Donna J. 2008. When Species Meet. Minneapolis, MN: University of Minnesota Press.

Hardt, Michael, and Antonio Negri. 2005. Imperiumi. Translated by Arto Häilä, Mika Ojakangas, Taina Rajanti, Olli Sinivaara, Akseli Virtanen, and Jussi Vähämäki. Helsinki: WSOY.

Huizinga, Johan. 1967. Homo Ludens. London: Routledge and Kegan Paul.

Minecraft Forum. n.d. “Minecraft Quotes!” Accessed November 4, 2018. www.minecraftforum.net/forums/off-topic/forum-games/428637minecraftquotes.

Nakamura, Rika, and Hanna Wirman. 2005. "Girlish Counter-Playing Tactics." Game Studies 5 (1). www.gamestudies.org/0501/nakamura_wirman/.

Open Culture. 2013. “Artist Robbie Cooper's Video Project Immersion Stares Back at Gamers and YouTubers.” www.openculture.com/2013/03/artist_ robbie_coopers_video_project_iimersioni_stares_back_at_gamers_and_ youtubers.html.

Oxford Dictionaries. n.d. Polynomium. Accessed November 4, 2018. www. oxforddictionaries.com/definition/english/polynomial.

Salen, Katie, and Eric Zimmerman. 2004. Rules of Play: Game Design Fundamentals. Cambridge, MA: The MIT Press. 
Journeys in Intensity 235

Spinoza, Benedictus. 1994. Etiikka. Translated by Vesa Oittinen. Helsinki: Gaudeamus.

Suits, Bernard. 1978. The Grasshopper: Games, Life and Utopia. Edinburgh: Scottish Academic Press.

Väliaho, Pasi. 2014. Biopolitical Screens: Image, Power, and the Neoliberal Brain. Cambridge, MA: The MIT Press.

Wikipedia. 2018. Minecraft. https://en.wikipedia.org/wiki/Minecraft. 


\section{Cyborganic Wearables \\ Sociotechnical Misbehavior and the Evolution of Nonhuman Agency}

\section{Patricia Flanagan and Raune Frankjoer}

The evolution of wearable technology is blurring the boundaries between the inside and the outside of the body. Wetware ${ }^{1}$ (Borresen and Lynch 2009) extends the reach of traditional hardware to the biological spaces of the internal body; electronics are becoming smaller and flexible, embedded into our textiles and our bodies; concurrently, bio-textile materials are being grown rather than woven. This chapter proposes that the emergence of wearable technology offers opportunities for an expanded understanding of what it means to be human. It describes how human perception and sensual capacity are augmented with wearable technology. This techno-genesis of the body, in collaboration with advanced materials and tools, has the potential to foster interconnected ways of understanding our place within the Neganthropocene. This chapter adopts Bernard Stiegler's use of the term Neganthropocene to highlight a nonhuman-centric era, as opposed to the dystopic notion of a self-fulfilling, nihilistic Anthropocene (Stiegler 2017). The authors propose a flat ontology between human and nonhuman actors, making reference to historically, anthropologically, and ethnographically diverse examples that illuminate the polarization of our current epistemology. Drawing a critical theoretical framework influenced by Rosi Braidotti, Karen Barad, Donna Haraway, Bernard Stiegler, Peter-Paul Verbeek, and Bruno Latour to arrive at a theory of cyborganic ${ }^{2}$ wearables, the following pages describe the potential of these artifacts in reconfiguring the way human beings live in, participate in, and understand the world around us. The cyborganic describes a fictional posthuman entity, a human-nature-machine hybrid. The section concludes with the proposition that redefining what it means to be human in relation to cyborganic mutation and creativity is an essential requirement for humanity's understanding of its future sense of self.

\section{Speculative Research with Experimental Wearables}

Bamboo Whisper is the latest in a series of experimental wearables by the authors of this text, Tricia Flanagan and Raune Frankjær, that 
explores body-centric human to nonhuman relationships. In this speculative project, participants wear conical forms of woven-bamboo around their heads, reminiscent in shape to Victorian bonnets. Through the headwear, communication between human and computer is made possible without conscious thought. Bio-data in the form of voice sonance is transformed into a kinesthetic experience surrounding the head of a second person. Oscillation is experienced through the vibration of the bonnets' brim sticks that rattle and shake in response to the other hat wearer's voice intonation and volume. When in motion, Bamboo Whisper "speaks" like the wind in the trees in an isolated immersive experience. There is an innate emotional response to being immersed in such an environment, as if trees were talking, warning of an approaching storm or gently lulling us humans to sleep. Experience has taught humans to respond to environmental cues, for example, in adrenalineinduced excitement or fear when the wind picks up before a storm hits. Just as in weather environments, the wearer of the Bamboo Whisper may experience a torrent of notes, a thunderous ending, or a vacuum of silence (Vella). The systems work in pairs by exploring language and communication between the wearers. The devices generate patterns of information in the form of rhythmic percussive structures that represent the source bio-data in new forms. In this way, anomalies that were previously invisible can become apparent (Figure 12.1).

The first wearable created in the series is Blinklifier ${ }^{3}$ (Flanagan, Vega, and Fuks 2012), which converts eye blinking into a visible light array in a wearable headdress. In this work, the eye muscle movements act as a switch: the participant wears electroplated false eyelashes and conductive eyeliner to connect the bio-data signal to an Arduino microcontroller (Figure 12.2).

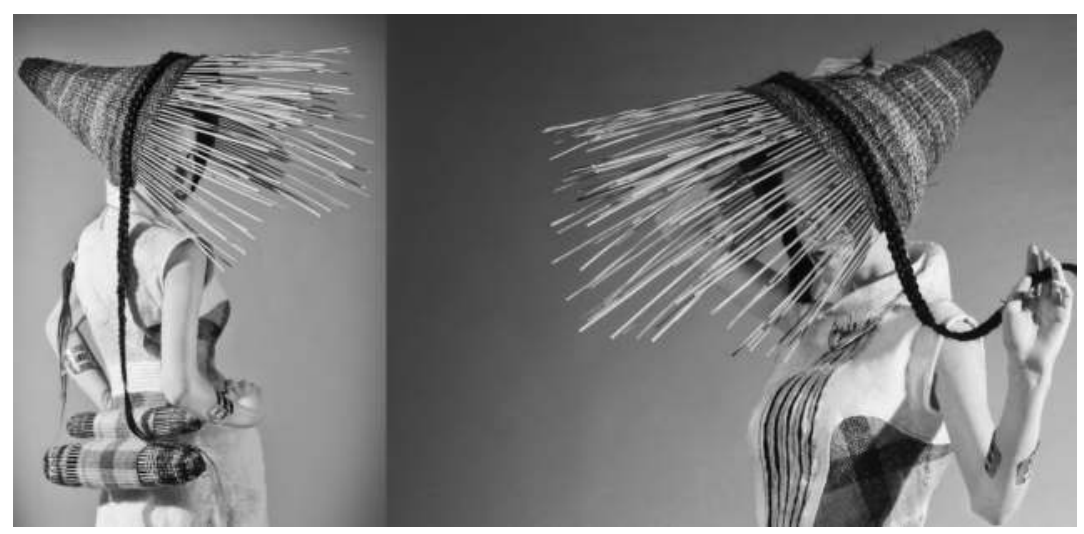

Figure 12.1 Bamboo Whisper, Tricia Flanagan and Raune Frankjær. Photo @Tricia Flanagan 2012. 


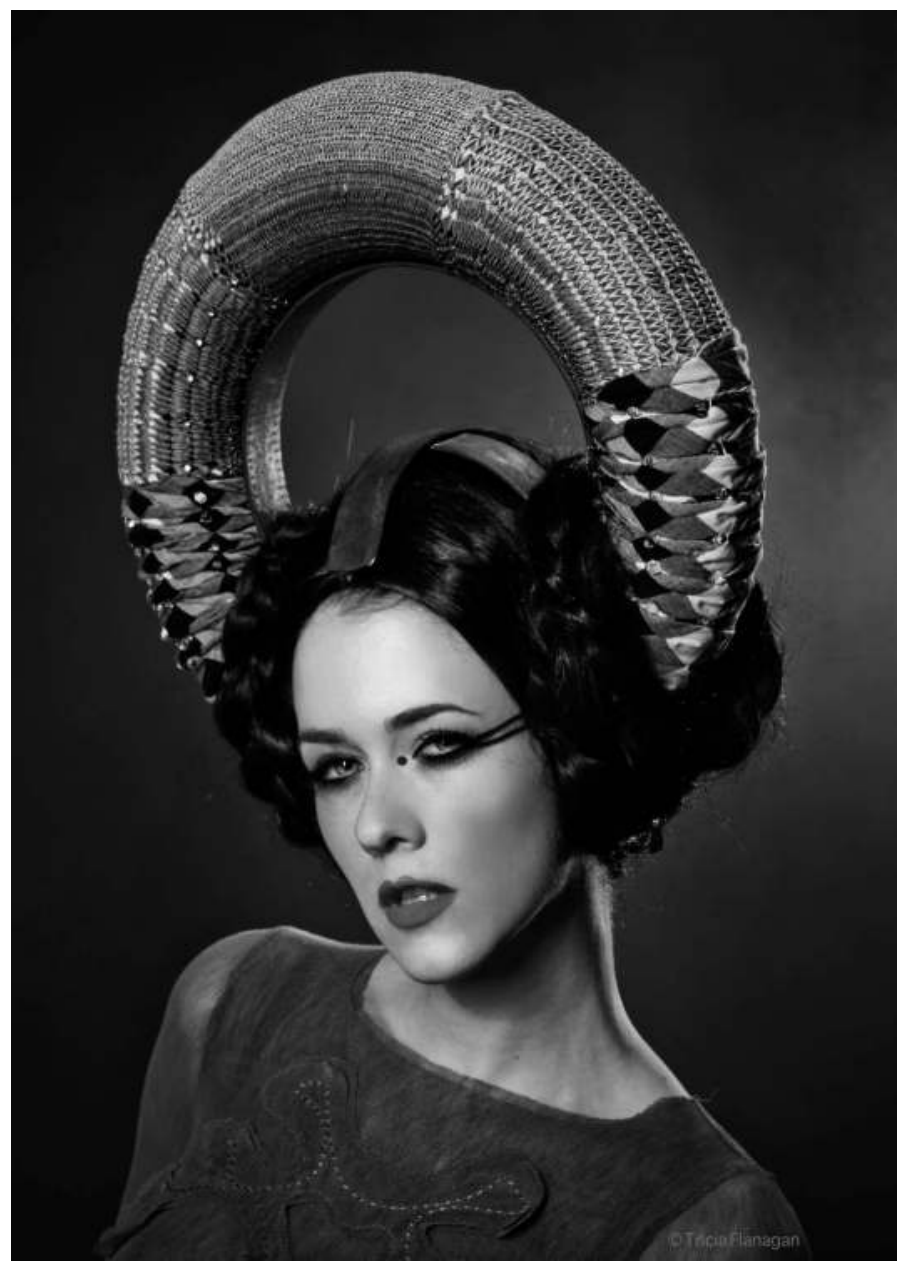

Figure 12.2 Blinklifier, Tricia Flanagan and Katia Vega. Photo by Dicky Ma. (CTricia Flanagan 2012.

Another experimental design, BIOdress (Walter Collective 2015), expands the bodies perceptive capacity in order to enhance empathy with entities other than human. By streaming and mapping environmental and plant-generated data through a textile interface onto the wearer's body, the plant's experience is reinterpreted as a haptic and aesthetic experience. In both works, bio-data is directly connected to techno-data, and systems modify behavior through feedback loops that trigger certain outputs (Figure 12.3).

The creation of environmental systems such as Bamboo Whisper, BIOdress, and Blinklifier can be viewed as sensory explorations, and 


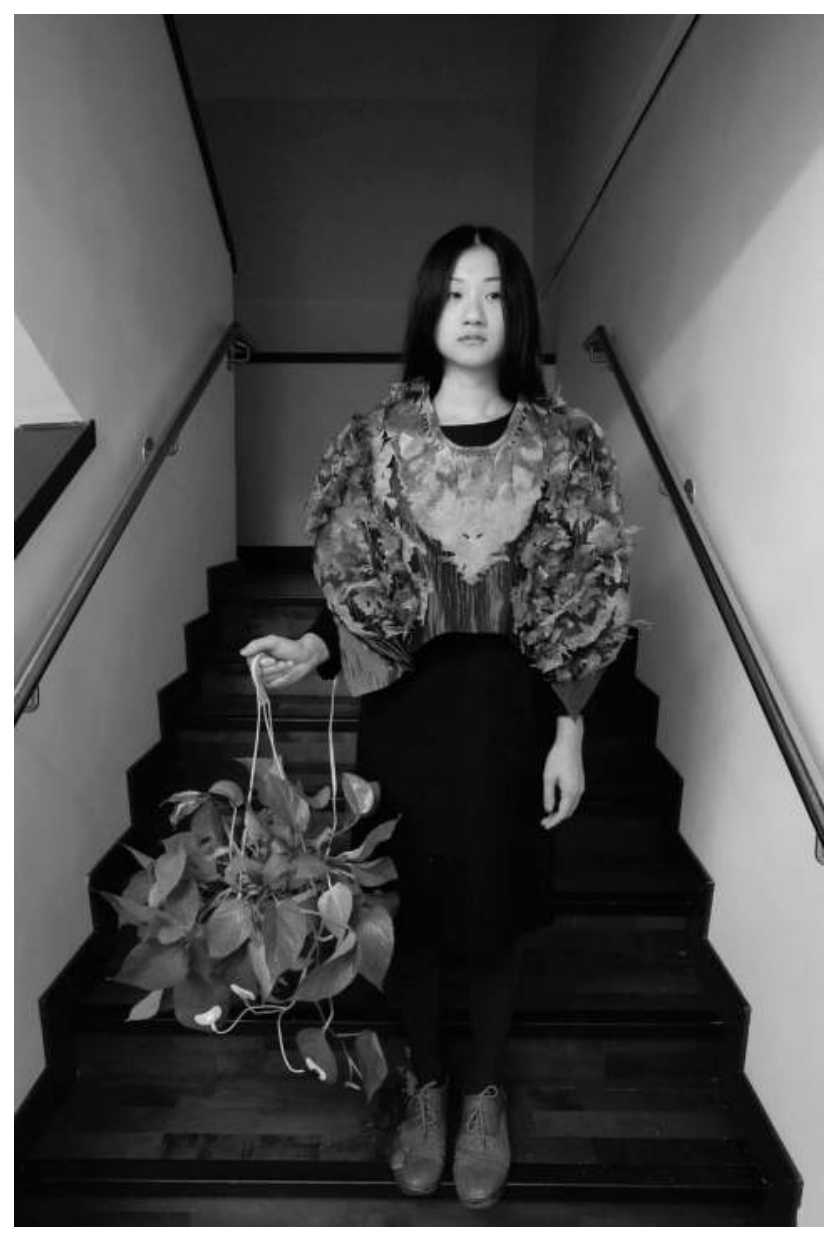

Figure 12.3 BIOdress 2014, The Walter Collective (Sara Adhitya, Beck Davis, Tricia Flanagan, and Raune Frankjær).

Photo by Nick Ashby.

their deployment as ethnographic devices or cultural probes. These artifacts demonstrate different ways of perceiving environmental data and so provide experiences that enable empathetic relationships with others, outside of what is generally constituted as part of the human experience. This could extend to plants, insects, and other animals residing outside of the experiential realm of the human, thus inducing experiences usually reserved for the sensory impaired, participants in shamanistic practices, the mentally ill, or the severely intoxicated. Our research is primarily praxis-based, an iterative process of research and experimentation where new questions and knowledge are generated. 
Applications extend to human-computer interaction and haptic interface design. This chapter describes ideas conceived whilst making and conducting experiments with the aforementioned wearables. It describes and analyzes key questions that undermine the traditional conception of human to nonhuman relations by using wearables as catalysts, probes, and test cases. At a time when wearables are colonizing spaces without regard to traditional boundaries of the internal and external body, as seen, for example, in nanotech and biotech, critical and speculative design can leverage the affordances of wearable and implantable technology to reimagine the human-nonhuman Neganthropocene.

The haptic stimulation of sensing another body's rhythms as experienced when wearing the Bamboo Whisper, paradoxically creates an intimate yet estranged relationship between wearers. Dislocating the spoken word from its origin illustrates its nonverbal components. The percussive rhythmic movement of the sticks from which the device is constructed resembles original language patterns, and the tacit stimulation activates memories of intimate touch - as inter-human haptic contact is usually experienced in close physical relationships. On the other hand, the public experience of body-worn technologies propagated through fashion, sport, and medicine tends to feel overtly artificial and futuristic, and is generally met with considerable resistance. The fear of the machine taking over our humanness has long been part of our cultural narrative, expressed, for example, in stories of malicious androids or the novel Frankenstein (Shelley 2010) and amplified with the advent of the assembly line. In contrast, applying ancient crafting techniques, such as basketry, weaving, and felting, creates an organic augmentation that is not alien to the human but feels integral, safe, and trusted due to its deep cultural and historical intertwinement.

Augmentation by haptic sensation of organic objects alludes to the innate vibrations at the atomic level of matter. In this way, this project explores the concept of a flat ontology between objects and human actants. The research is a physical manifestation of the evolution of objects, that is, in our perception of them, and expresses the interconnectedness between us and between objects and materials in the world.

\section{Experiencing the Nonhuman in Ontological Practice}

In his seminal text from 1974, "What Is It Like to Be a Bat", philosopher Thomas Nagel argues that due to the elusive nature of consciousness, ontological inquiry into the nonhuman can only remain speculative. Enclosed in its own humanness, the human viewpoint will at all times remain anthropocentric and incapable of comprehending not being human. In the future, it may well be possible to connect the human brain to other neurologically functioning beings and transmit sensory 
input. For example, researchers at Harvard University have developed a non-invasive brain-to-brain interface, effectively linking a human and nonhuman brain (Yoo et al. 2013), and research in brain-machinebrain-interface technology is exploring transmission of tactile input to help humans control prosthetics. But even if humans do develop the ability to access the experiential faculties of nonhumans, then the methods of processing will differ through the way an individual's neural networks have been forged through a lifetime of experience. In other words, any attempt to understand the essence of the nonhuman is, and most likely will remain, fictional, as direct experience is not possible. However, this does not mean that we, as humans, should refrain from trying, nor that it necessitates resorting to guesswork, as a substantial amount of knowledge about animal perception is available. The sonar of a bat, or a dog's dichromatic vision, is widely explored and to a large extent quite easily transferrable to human understanding. Granted, animals are biological creatures just like us and we share a genetic past. Mediating non-biological perception may prove more difficult.

How do we go about learning the experiences of something so "other" that its perceptual facilities are fundamentally different from our own? Traditional folk-wisdom states: "You cannot understand another's experience until you've walked a mile in their shoes". In other words, one has to immerse oneself in the environment of the other, use the artifacts they use, live with the possibilities and restrictions they live with, and try to feel like the other by emulating their conditions as closely as possible. Toisissa Tiloissa (In Other Spaces), a Finnish art collective, has developed over one-hundred different bodily exercises through which, the group claims, the "human shape and state of being starts to become permeable to other states, shapes and spaces" (Elo 2013). Storytelling, with its use of metaphors and allegories, is a method for accessing the unapproachable and dates back to the beginnings of human history. These myths and fables, which often aim to explain incomprehensible phenomena, constitute the foundation culture. But as fictional stories constitute representational experiences, they have certain caveats, most notably the exclusion of materiality and embodied ways of knowing. Imagining, rather than enacting, lacks the possibility of validating the properties of the fictional narrative by obtaining feedback from the surrounding environment.

In Alien Phenomenology, Ian Bogost suggests adopting a pragmatic form of applied object-oriented ontology by practicing what he terms "carpentry". This is antonymous to discourse, which Bogost rejects as "the consequences of the semiotics obsession [...] [due to] [...] an over abundant fixation on argumentation, such that pedantry replaces curiosity" (Bogost 2012, 9). The notion of "carpentry" is a constructive example of applied ontology, practiced by making and doing. Being, according to Bogost, can only be understood by working with things that 


\section{Patricia Flanagan and Raune Frankjoer}

"are" on a material level. The constructed artifacts become philosophy, illustrating the perspective of objects (Bogost 2012, 93). In line with Nagel, Bogost recognizes the limitations imposed by the subjective nature of experience, and so alien phenomenology can only be performed by analogy, using tools such as misrepresentation and distortion to approach and approximate the essence of that which is nonhuman (Bogost 2012, 65). Bamboo Whisper simultaneously restricts and alters the sensorial experience of the wearer, and so, framed within the practice of carpentry, wearing the device provides an experiential ethnographic study of "cyborganic being". It offers an insight into a sensory realm, similar to, yet profoundly different to, that of the human and so allows its wearer to develop a conceptual apparatus which can be used to approach and, depending on the level of engagement of the human wearer, even reconfigure human and nonhuman states of being.

Sensoriality is fundamental to how any biological being experiences and engages with its environment. However, since the Enlightenment in Western culture, vision has taken a dominant position over all the other senses, and modern screen-based technology increasingly exacerbates this heavily ocular-centric mode of perception in humans. In addition, most research on the senses operates with a standard five senses model under the assumption this represents a biological universal standard applicable to the entire human species. In fact, the sensorium is much more fluid; scientists estimate there are between ten and thirty-three senses (Howes 2009, 22-25). Surprisingly though, the perception and processing of sensorial input is not bound to physiology, but is to a large extent culturally defined (Jütte 2005, 33). For example, old medieval languages including Old English deploy sensory taxonomies that differ greatly from the "Roman idea" of individual sensory faculties. The Hausa, a Nigerian tribe, differentiate between two senses, gain (sight) and ji. The latter signifies an assemblage of hearing, smelling, tasting, touching, understanding, and emotional feeling, seemingly forming a synergistic whole (Howes 2013). Classical Indian philosophy distinguishes between eight senses, ascribing superior importance to Prana, the breathing organ, that is, the nose, and includes the mind as a sense in stark contrast to the Western division of body and mind (Elberfeld 2003, 483). The sensory confusion induced by wearing the Bamboo Whisper triggers a certain amount of cognitive dissonance, which is necessary to break from the habitual and subconscious processing of sensory input through which we as humans normally experience the world. Ethnographer David Howes stresses the importance of overcoming one's own sensory bias to develop sensory objectivity: in other words, cultivate a multiplicity of sensory expressions and the "capacity to be in two sensoria about things" in order to understand how others relate (Howes and Classen 1991, 260). Sense-based approaches to ontological inquiry have been extended across species boundaries and have explored the experiences of animals (Forister 2007; Kirksey 
and Helmreich 2010), plants, and even cells (Myers 2006, Myers and Dumit 2011; Chamovitz 2012).

When donning the Bamboo Whisper, the wearer potentially becomes an ethnographer of a possible cyborganic future of biological otherness, as the device alters the senses so that speech becomes a kinesthetic experience and movement translates to tactility. This kind of displacement of input onto other sensory channels than customary can cause the brain to analyze and interpret signals otherwise discarded. The mapping dislocates the signal from its usual processing centers, and so interrupts automatic interpretation. In extreme cases, the incoming data may even activate an alternate form of processing. For example, Ben Underwood, a boy whose eyes had to be amputated at the age of three because of cancer, taught himself to echolocate so proficiently, he claimed to be able to visually perceive the objects around him. His claim was supported by the fact that his calcimine cortex, the part of the brain that normally deals with visual processing, was shown to be stimulated by the audible input of the returning echoes of the clicks of his tongue. In addition, he was able to navigate completely autonomously without use of any mobility aids, even on skates and bicycle (McCaffrey 2014).

Speculating that speakers of clicking languages may have a different spatial awareness through the addition of data perceived from non-conscious echolocation to speakers of non-clicking languages, the Bamboo Whisper may allow its wearer to approximate this kind of experience in a non-invasive and experiential manner. Using clicking sounds within speech is an integral part of many Southern African languages believed to constitute the original languages of humankind, as spoken before the African diaspora. For example, the very complex phonetic systems of the indigenous African Khoi and San languages have more than one hundred different sounds, whereas English has about forty-five. Hawaii, which was one of the last places to be settled, has a mere thirteen. These findings correlate with a decrease in genetic diversity in relation to distance from Africa (Atkinson 2011) and so pose the question not as to why the tribal languages of Southern Africa include clicks but rather as to how the rest of humanity lost theirs and to what effect.

"The eyes reach but the ears receive" writes Juhani Pallasmaa, referencing architectural spaces in The Eyes of The Skin (1996). He uses the term "acoustic intimacy" to explain that sound infers an interior experience, whilst sight infers exteriority. Through the eyes, we look out to the world, but through the omni-directional experience of sound, the body experiences centering. We gain an understanding of space through hearing. Sound incorporates, whereas sight isolates. Pallasmaa attributes the dominance of vision in our culture and the subsequent loss of integrity of the audible world to a mental loss of a sense of center, of which he claims the contemporary world suffers (Pallasmaa 1996, 53). In line 


\section{Patricia Flanagan and Raune Frankjoer}

with the work conducted by the Russian futurist poets Khlebnikov and Krucënykh who coined the term Zaoum in a search for a primal and preadamic language that could be instinctively understood by all people, and the Dadaist Hugo Ball who performed non-lexical phonetic poems with the aim to rebirth a pure language (Watts 1988), the Bamboo Whisper - by reintroducing clicking sounds as a part of speech - brings its wearers closer to the original language of humankind and hence to a time when humans themselves were nonhumans.

\section{Emplacement and Embodiment}

Recent findings in cognitive science support what Donna Haraway (1988) has long insisted: that "knowledge is situated" - the same data means different things in different contexts. In digital culture, time and place are disembodied, so context between communication nodes may have little in common, resulting in dislocation and miscommunication. How can we communicate empathetically even though we may not have a common culture, environment, or language? In addition to presenting an assemblage of meta-level meanings, mannerisms of speech also affect the perception of individual being in relation to the world. As with the senses, the linguistic concepts of varying cultures challenge the Western idea of stable universal structures defining the world around us into distinct and intrinsically predictable objects. Other cultures use different taxonomies along the color spectrum, different means of gendering, and deploy varying concepts of time and coordinate systems. As an example, the Guugu Yimithirr, an aboriginal group native to Australia, used a global coordinate system to locate as opposed to the Western local system of left and right, which is based on individual orientation. ${ }^{4}$ In order to communicate with others, they would at all times need to be aware of their geographical positioning, which they did even when removed from their accustomed environment and placed inside buildings with no access to outside markers (Hong and Deutscher 2012). Being so acutely attuned to the world around them is inconceivable to most Westerners and suggests a vastly different sense of emplacement. The user of a local coordinate system sees the world in relation to themselves.

Creating an encapsulating structure, such as the Bamboo Whisper, highlights the user's emplacement. The protruding brim-sticks provide a respectably steady or unsteady environment for the wearer, subject to the auditory conditions of the environment and the behavior of the cyborganic "other". Inactivity signifies silence, whereas vocal intonations provide vibrancy, movement, and the appearance of life-likeness of the object. Similar causations can be found in various creation myths ${ }^{5}$ (Wilson and Fitzedward 2008), with equivalents in contemporary quantum mechanics, that state all matter exists as vibration. In the future, objects and materials may be augmented to amplify the vibrating matter 
at the core of their molecular structure. In this way, Bamboo Whisper explores the concept of a flat ontology between objects and human actants (Flanagan 2014, 675) as well as raises questions about the distinction between zoé and bios (Braidotti 2008).

Bio-centric thought defines organic, that is, carbon-based, organisms as being life per se, whereas the notion of zoé extends the concept of life to encompass non-organic systems, such as the sky and water (Ziarek 2011, 24). Lovelock's Gaia Theory, and Earth System Science, support the definition of life to extend beyond commonly accepted biological restrictions (Lovelock 1995; Skinner 1999). Likewise, advances in the life sciences have raised questions to what extent humans and other animals can be viewed as discrete organisms at all: should they rather be regarded as systems themselves, delicate assemblages of thousands of symbionts reacting to the environment (Turnbaugh et al. 2007, 804)? Almost fifty years ago, Gregory Bateson stated that "the unit of survival is organism plus environment" $(1972,491)$. In spite of evidence that a discrete and singular self does not exist, current developments show that political and technological trajectories are moving deeper toward an individualized, neo-liberal world where all responsibility of survival and well-being is removed from the collective and placed on the subject, continuing the ideal proposed by the Enlightenment project of a perfected liberal subject.

Human computer interface design has been dominated by ocularcentrism, relying on visual semiotics and screen-based interfaces. Alternately, by technocrafting cyborganic artifacts, in the case of Bamboo Whisper, augmenting communication with haptic and vibrational sensation, organic objects seem to come to life. In this manner, we perceive our research as a physical manifestation of the evolution of objects as actants. The cyborganic expresses the interconnectedness between us and between objects and materials in the world. In the hand crafting of cyborganic artifacts, the direct trace of human action on materials can be viewed like archaeology, a physical manifestation of memory of the materials. This can also be said of digital crafting, only rather than the direct mark of the hand, computer-aided design augments thinking beyond the physical confines of body-bound perception. A keyboard or a touch pad may serve as the interface, but the outcome is an object as a physical manifestation of an idea that was drawn in the mind's eye. What new modes of expression can be deduced from digital traces? Tacit experiences with materials need to be acknowledged as intra-active processes. Karen Barad's notion of "intra-action" offers an alternative to the word "interaction", which is based on the assumption that two entities are separate to begin with; alternatively, intra-action describes the same space but with full awareness of the agential nature of each entity. Barad offers a theory that hinges on causal relationships between materials and practices which can be viewed as an alternative to representationalism, 


\section{Patricia Flanagan and Raune Frankjoer}

and in this sense, intra-action is a profound conceptual shift (Flanagan 2016). She writes, "phenomenon is a dynamic relationality that is locally determinate in its matter and meaning as mutually determined (within a particular phenomenon) through specific causal intra-actions" (Barad 2003,820 ). In line with Barad, neuroscience's discovery of mirror neurons identified empathy in a physiological sense (Keysers 2009). Mirror neurons not only exist between humans but extend to nonhuman entities; hence, the shaking of brim-sticks in a cyborganic wearable can stimulate a physiological reaction in another wearer.

In the post-industrial era, we have the opportunity to re-unit skill and intellect. The challenge is to design digital tools that enable empathetic relationships in holistic ecosystems, and in this way maintain the humanity inherent to craft (Ingold 2013). The craftsperson's knowledge extends beyond materials and techniques, out into the world:

[...] his eyes stopped in awareness of the earth around him. He looked at the granite. To be cut, he thought, and made into walls. He looked at a tree. To be split and made into rafters. He looked at a streak of rust on the stone and thought of iron ore under the ground. To be melted and emerge as girders against the sky. These rocks, he thought, are here for me; waiting for the drill, the dynamite and my voice; waiting to be split, ripped, pounded, reborn; waiting for the shape my hands will give them.

(Rand 1993, 16)

Written in the 1940s, Ayn Rand's description above reflects a time when nature appeared endless and boundless. Traditional crafts were often directly connected to the environments in which they were practiced, simply because materials usually needed to be locally accessible. In globalized societies facing environmental degradation, the notion of thinking globally and acting locally is a fundamental principle of sustainability. In predominantly urban environments, do we still have the knowledge and ability to read the landscape in these terms? Robert Lawlor describes this connection in less hedonistic terms than Rand above:

Aborigines maintain that the masculine role is not to act on the material world but to participate in the balance of natural creative forces on the metaphysical plane. To act on that which has entered the physical world is already too late; once spirit energy has materialized, a chain of reactions changes the entire pattern of nature.

(Lawlor 1991, 181)

According to this sentiment, the "self" is deeply connected to the ecosystem. Across the globe, a new mind-set is emerging, which sees the need to renegotiate the resources we have at hand rather than simply producing more artifacts (Openshaw 2015, 6). Instead, we must build 
to protect the biological and cultural historicity of the human being. We must acknowledge that being human is biological and historical and that it is through the material world we construct and remember who we are.

We have remnants of the tail in our skeletal structure deriving from our arboreal life tens of millions of years ago, we have traces of the horizontally closing eyelid in our eyes to remind us of our reptilian past, and we even have remains of gills in our body as a reminder of our aquatic life hundreds of millions of years ago. It is clear that we also have a number of existential reactions secured in our nervous systems, and they need to be acknowledged in architecture.

(Pallasmaa 2013, 215)

The Bamboo Whisper can be viewed in this light, as architecture around the body. References can be drawn from history: the form is not unlike a Victorian bonnet or the reed headdress worn by South African Xhosas to perform the ceremonial rite of passage to manhood. In the late twentieth century, ${ }^{6}$ North Congo Ngbende initiates still wore grass outfits that include a fringe of grass concealing their face. ${ }^{7}$ "In Japanese history originating in the late Ashikaga period, we find examples of woven grass-reed, rattan, or bamboo basket-shaped hats called Tengai (天蓋). Etymologically - ten "sky-heaven" and gai "cover", worn by Komoso "straw mat monks" whose numbers grew rapidly in the Tokugawa period and came to be known as (薦層) Komūso or "monks of no-thing-ness" (虚無僧). The basket hats hide the identity of the individual and hence reinforce the collective identity. A parallel can be drawn between the function of Tengai and the Bamboo Whisper in that they are used as a tool to help suppress the ego and encourage people to focus on listening by diminishing visual distraction (Sanford 1977, 413) (Figures 12.4 and 12.5).

By adopting ancient crafting techniques and blending them with technological materials and data, we attempt, in experimental wearables such as the Bamboo Whisper, to create organic augmentations that are not alien to the human, but integral, safe, and trusted due to their deep cultural and historical intertwinement. The cyborganic embraces both the artificially constructed and the organically grown, thereby proposing a third construct that transcends the divide of artificial and natural. Blending digital and artisanal practices results in a composite, a material that combines digital computations with material properties, enabling that material to behave beyond its usual capabilities (Vallgårda and Redström 2007, 513-522). Examples of such combination are extremely varied as any material can potentially become part of such composite. Organic materials are unruly and chaotic: they can never be subdued to absolute consistency of expression as their inherent uniqueness is further enhanced by hand-processing and deploying age-old techniques for example, felting and weaving that date back to the Paleolithic. Combined with digital technology, temporal hybrids of prehistoric and 


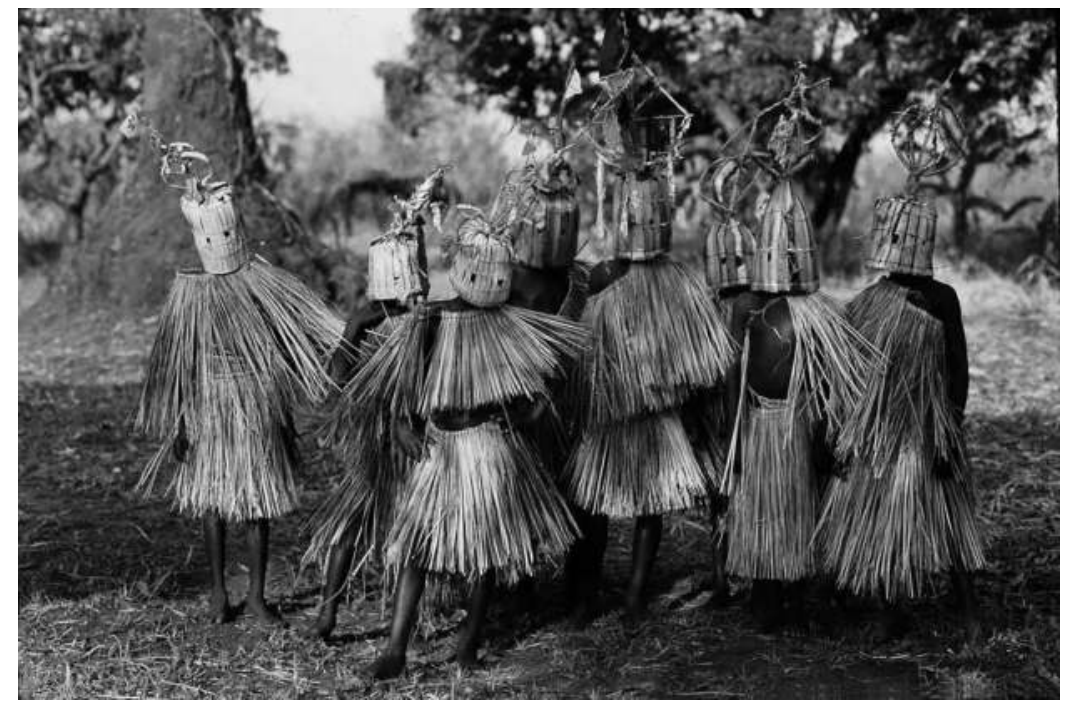

Figure 12.4 Malawi boys in initiation ritual.

Photo by CCBY2.0 Steve Evans. (Image courtesy of Creative Commons - 2.0 Generic license)

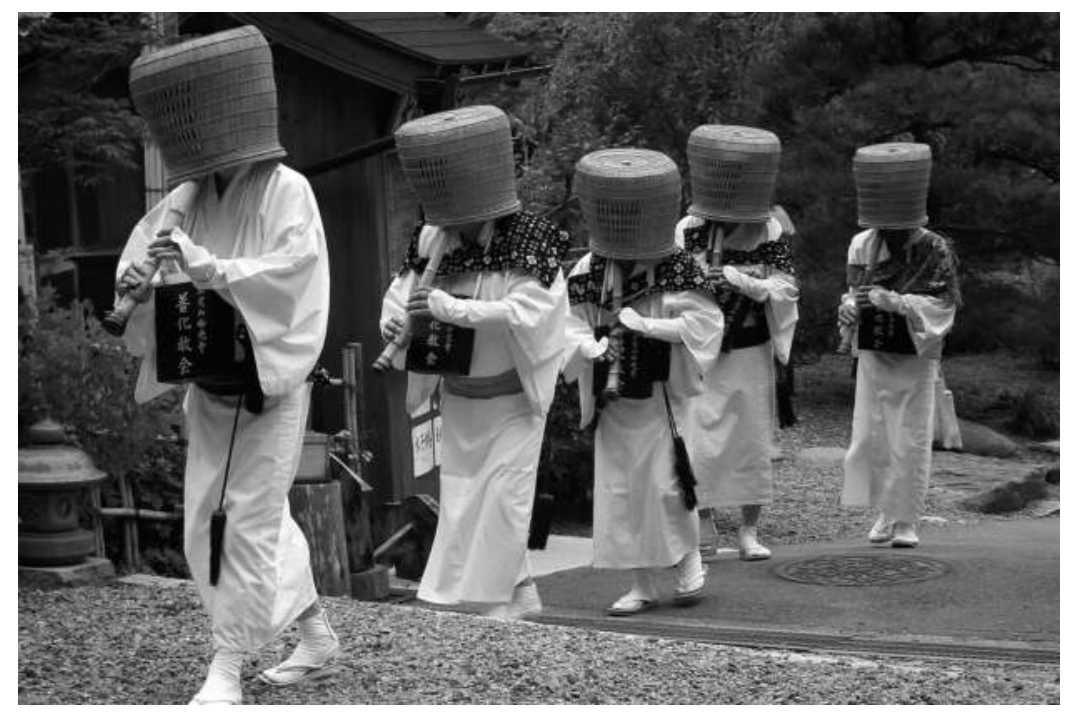

Figure 12.5 Japanese Komuso wearing Tengai.

Photo by CCBY3.0 松岡明芳. (Image courtesy of Creative Commons - 3.0 Unported license) 
contemporary technologies emerge. Spanning “The Great Divide” between the archaic and the modern is described by Bruno Latour (1993) as the main concept of separation which traps humanity in a destructive modernist narrative. The temporal hybridity of the object reveals the longitudinal fluidity of time and the errors of assuming a linear and one-directional temporal reality. Cyborganic objects are not unique in this regard as most - if not all - of our materializing practices consist of these kinds of temporal assemblages.

\section{Cyborganics, Agency, and Sociotechnical Misbehavior}

At the end of the last millennium, Esther Dyson $(1996,295)$ declared:

[t] he central event of the 20th century is the overthrow of matter. In technology, economics, and the politics of nations, wealth - in the form of physical resources - has been losing value and significance. The powers of mind are everywhere ascendant over the brute force of things.

The cybernetic paradigm continued the Cartesian trajectory of liberating the eternal mind from the finite flesh, and the liberal humanist subject of the Enlightenment project seemed to finally have reached its destiny as the spirit triumphed and gained immortality and embodiment ceased to be a requisite for human being. Soon, the mind could be mapped into a binary signal and uploaded onto a computer, which - complete with bionic, serviceable, and replaceable limbs - would constitute a new, highly improved superior species. Situated somewhere between Six Million Dollar Man, Bionic Woman, Star Trek, Tron, and Bernard Wolfe's Limbo, this narrative still carries appeal to early tech adopters and Silicon Valley culture as personified by Google's chief engineer Ray Kurzweil and the transhumanist movement. The transhumanists believe the merging of humans with technology signifies the next evolutionary step of humanity, effectively eliminating disease and bestowing the human species with eternal life. The key is "whole brain emulation", where the basic premise is to produce a digital copy of a persons' mind, which will then control an artificial body. Whilst this might sound somewhat fantastical, the research is well on the way. Over the last decade, a slew of heavily funded initiatives has emerged with the purpose to reverse-engineer the human brain, such as the BRAIN Initiative (USA, see National-Institute-ofHeath 2017), Human Brain Project (EU), and Blue Brain (Switzerland). In 2014, the connections between the 320 neurons found in a roundworm (Caenorhabditis elegans) were successfully mapped, simulated in software, and given a Lego body which subsequently behaved and moved like a worm (Szigeti et al. 2014, 137).

However tempting the prospect of immortality and the ending of suffering and disease might be, the idea of a cyborg future is still generally 
met with severe resistance. In the USA, the majority of the population believes augmentative technologies will have an overall negative impact if they become commonplace (Smith 2014, 4). Surely this can be viewed as a general fear, which always accompanies transitions into new and unknown territories. On the other hand, the fear of the machine is deeply ingrained in the cultural narrative, and its potency does not seem to diminish, even though machines have become an integral part of human life. The machine - the cold, hard, emotionless super-brain - robs the human of empathy and enslaves it with its overpowering and gruesome logic. In Technophobia, Daniel Dinello examines the narratives of dystopian science fiction dominating popular culture. He argues that the fear of technology is closely related to the fear of the virus, which has replaced the cold-war era's fear of the bomb. Technology, according to Dinello, is perceived as an insidious and invasive force that, just like a viral infection, invisibly infiltrates and undermines human integrity by manipulating and mutating its host to promote its own existence and evolution (Dinello 2005, 211).

In this narrative, humans are no longer in control of the technology they have created. In Autonomous Technology: Technics-out-of-control as a Theme in Political Thought, Langdon Winner writes: "Under present conditions men are not at all the masters of technological change; they are its prisoners" (Winner 1977, 55). The notion of the technological creation developing its own unforeseen and uncontrollable agency can be traced back 200 years to the novel Frankenstein written by Mary Shelley in 1818. Here, the protagonist Dr. Frankenstein seeks to gain power over nature, yet realizes he has created a monster and exposed the world to it, without any previous consideration of the consequences. Subsequently, his creation - the monster - becomes

an autonomous force, with a structure of its own, with demands upon which it insists absolutely. Provided with no plan for its existence, the technological creation enforces a plan upon its creator.

(Shelley 2010, 313)

Yet the machine may still become something else completely: it could be warm, ancient, and organic; even alive. The posthuman project, as predominantly proposed by feminist, postcolonial critics, opposes the objectivist, disembodied, and dominating mind-in-control, with its unrelenting desire for mastery and subduing of nature. The posthuman, as opposed to the transhuman, suggests an entity of embodied wisdom, dynamically intertwined with both the intelligence of machines and the intelligence of nature. In the posthuman, humanity's progressive thought and constant technological striving for invention result in the creation of ever evolving and expanding ecologies of being, for both humans and other life-forms, whether biological, artificial, or both. 
The materiality of the Bamboo Whisper transgresses the naturalartificial dichotomies by using digital technology to augment and amplify natural elements. It rejects the Cartesian narrative of the disembodied machine-mind by transcending the culture-nature divide and invites us to adopt a perspective of a holistic posthuman possibility. $\mathrm{Hu}-$ mans possess an innate propensity toward natural environments; this bias was coined by Edward Osborne Wilson as the Biophilia Hypothesis and has been affirmed by a substantial body of research, especially in the area of child development (Verbeek and De Waal 2002). The Biophilia Hypothesis states that "humans have an innate tendency to focus on life and life-like processes" (Kellert and Wilson 1995, 4). According to Wilson (1984), as a result of biocultural evolution, biophilia is not an instinct but sets of complex rules of learning that fall along several emotional spectra, that is, attraction, aversion, awe, peacefulness, and anxiety. The hypothesis states that when humans remove themselves from a natural environment and move into an artificial environment, the biophilic learning rules are not abandoned and replaced by modern ones that would be better adapted to a world of artifacts but survive in atrophied forms. One aspect of particular relevance to cyborganics is the aesthetic response which, although not completely understood, remains an indisputably powerful factor (Ulrich 1983). Experiencing nature produces feelings of awe, tranquility, peace of mind, well-being, and confidence. So far, the Biophilia Hypothesis has influenced developmental psychology (Kahn 1997), preventive medicine (Frumkin 2001), and architectural theory (Joye 2007; de Chardin 2015). Over the last decade, biophilic theory has increasingly been incorporated into urban design, as ecology and greening have become central elements in city planning and development (Kenworthy 2006).

Scaled down to artifacts, the effect is equally observable: traditional modernist interiors and objects comprised of steel, concrete, and glass are perceived as cold and alienating, whereas structures and furnishing made from natural materials make the space warm and welcoming. This principle can even be extended to the machine, as observable in the elaborate objects and garments crafted and used by adherents of the steampunk movement. Steampunk can best be explained as "Victorian science fiction", and since the 1980 s, it has slowly grown from a literary subgenre into a multifaceted counterculture built around Neo-Victorian physical artifacts strongly influenced by the Arts and Craft Movement of the turn of the twentieth century. Steampunk envisions an alternate future as if digital technology had become a reality in the beginning of the nineteenth century, when Charles Babbage and Ada Lovelace ${ }^{8}$ succeeded in building a computer. This vision was described by William Gibson and Bruce Sterling in The Difference Engine, one of the founding novels of the steampunk movement. Steampunk embraces technology, but rejects the modernist factory mass-production of sleek, interchangeable, 


\section{Patricia Flanagan and Raune Frankjoer}

and disposable objects (Onion 2008, 1). The mostly self-made steampunk artifacts are striking, with the essence of the machine brought to the fore as an impressive and tangible construct of cogs, wheels, gears, copper, brass, leather, and wood. Another example of this are the weird, wonderful, and strangely "alive" "Strandbeests" by Theo Jansen. These wind-powered animal-like kinetic machines, which roam the beaches of the Netherlands, provide a striking example of craftsmanship and engineering skill. Just like the "Strandbeests" and steampunk artifacts, cyborganic wearables explore the aesthetic possibilities of the machine, transcending temporal confines, and the separation of artificial and organic, dead and alive.

As humans, we tend to view technical devices that demonstrate odd behaviors as socio-technical misbehavior. There is a tendency to anthropomorphize that leads to deductions and explanations, resentment of the seemingly autonomous misbehavior, or imaginary conspiracy theories of collaborative misbehavior between technological devices. This could be understood as "configuring the user" (Woolgar 1991) or, as Lupton proposes, a case of humans facing the dilution of their agency (Lupton 2015). During the design process of the Bamboo Whisper, the artifact developed a sense of entity that was not anticipated. It grew in the gap between what the (human) designers expected it to do and the capacities and sensibilities that surround the materials and components it embodied. Human bias makes us distinguish between voice and other auditory input. The microphone in Bamboo Whisper does not make such distinctions but will amplify and mediate any signal without imposing a system of hierarchical classification, other than a predefined threshold level. What starts out as a human conversation soon transforms into a much broader exchange including environmental signals such as ambient noises. Also included are signals from the object itself as the clatter from the reeds gets picked up by the microphone, which, in turn, transmits a signal to the other device, and so on. Not only does this make the Bamboo Whisper appear to "talk back" and so develop an emotional character which communicates directly with the human capacity, it also dramatically changes the power balance between the wearer and the device. Where the Bamboo Whisper was initially perceived as an appendage to a human subject, the shift in activity now suggests the wearer should rather be considered a host facilitating the agency of the device (Figures 12.6 and 12.7).

Similarly, the transmission of the auditory signal has a fundamentally different functionality in the Bamboo Whisper's radio-based way of "hearing and talking". Humans perform these tasks continuously, as a flow, whereas Bamboo Whisper bundles signals and transmits them in little data packages, which are then subsequently mapped kinetically onto the reeds. Its single processor renders it a rather simple creature without the ability to multitask, that is, it is unable to listen and talk simultaneously, much like communicating through walkie-talkies. From an anthropocentric perspective, this may be perceived as a flaw or fault. 


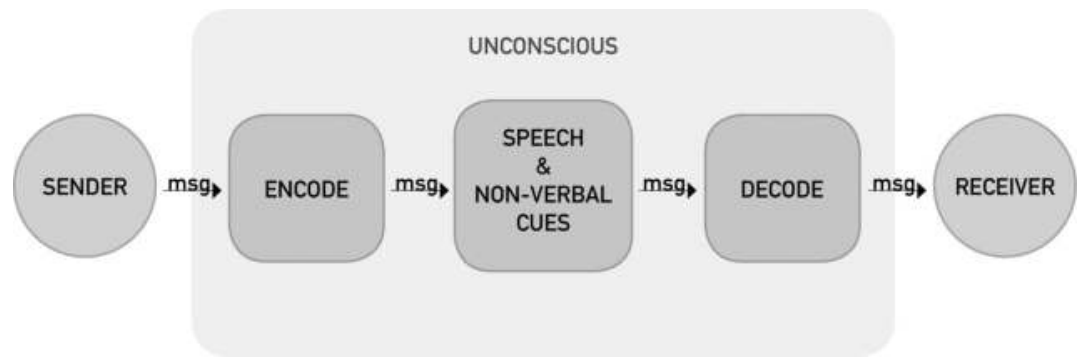

Figure 12.6 Inter-human communication in the form of speech is generally mastered and internalized once past toddlerhood. The act of speaking is accompanied by series of nonverbal cues, performed as well as received and analyzed subconsciously by both sender and receiver. As 70-90 percent of the process is nonverbal, and predominantly takes place unconsciously, it is not uncommon to see people interact almost automatically with the subtle signals of the other, in mutually reinforcing feedback loops (cf. Hogan and Stubbs 2003, 121).

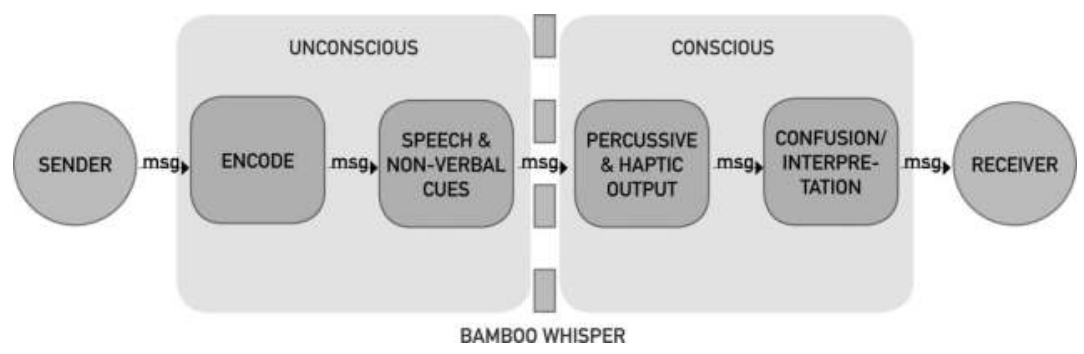

Figure 12.7 The agency of the Bamboo Whisper is disruptive to the experience and expectations of the human wearers (or hosts) within the system.

It could, however, also be accepted as an expression of the agency of the object itself, meaning that nuances such as delay in the signal and the perceptive ability of the sensor to pick up ambient sounds are ways to experience "being" with fundamentally foreign sensory and processing abilities. This signifies the emergence of entirely new forms of sociality, a techno-sociality. It is a performative nexus of intra-actions between semi-autonomous digital objects that form social bonds and interrelations among humans, between humans, and amid digital artifacts (Michael 2016).

\section{Conclusion}

In this chapter, we have presented the Bamboo Whisper, a body-worn artifact that, deployed as an ethnographical sensory device, explores 


\section{Patricia Flanagan and Raune Frankjoer}

body-centric human to nonhuman relationships. We defined the Bamboo Whisper as a cyborganic wearable, that is, a human-naturemachine hybrid framed as a fictional posthuman entity. We position this research within speculative and critical design practice, framed as a form of experiential and applied ontology. We have shown how both the constructed objects - the cyborganic device and the construction process in itself - provide opportunities for valuable insights into the nature of the nonhuman. The immersive experience provided by wearing the Bamboo Whisper offers direct experience of a sensory realm different from what is generally accepted as human.

Understanding how others relate presupposes overcoming one's own sensory bias, a process which the Bamboo Whisper facilitates through inducing a certain amount of sensory displacement and confusion. Additionally, we have offered the theory that the clattering sounds produced by the Bamboo Whisper may induce an altered perception of the spatial environment, that is, provide its wearer with alternate means of both perception and embodied knowing; whilst linguistically bringing the human wearer closer to its nonhuman origin. Likewise, the physical limitations and the emplacement enforced by the Bamboo Whisper, in communication with its cyborganic twin, positions the wearer in a symbiotic experience of the other-in-space as a synergy arises between the self and the other, relating to a surrounding environment.

Bamboo Whisper emerged through a generative and iterative design praxis that embraced the inherent behaviors and diversity of the deployed materials to produce results that were not predetermined. Emergent qualities resulted from the intra-action of many elements and produced outcomes that equated to exponentially more than what would be obvious from their individual properties. An analogy can be drawn to biomimicry as the simulation of natural processes. Biomimicry denotes the branch of technological development which emulates nature's patterns and strategies. Swarm behaviors of insects, for example, reveal highly complex, unpredictable behaviors generated from many individual organism's compliances with relatively few simple rules. In Bamboo Whisper, relationships developed as haptic communication that induced reactive behaviors, or feedback loops. Sociotechnical relationships such as these represent new possibilities for design.

In our human techno-genesis, trial and error provides the evolution of our technical development. In biological terms, we may refer to Darwin's notion of natural selection. In a simulation of this process, "un-natural" selection can be found in the space we have articulated in this chapter, between the objective of the designer and the reality of what is designed, between the black and white of Cartesian logic, between human and nonhuman agency. This cyborganic mutation grows in unexpected places: in the unassisted survival of Theo Jansen's "Strandbeests" on the beaches of the Netherlands and in the apparent entity of the non-living 
assimilation of data and materials into speculative designs as exemplified by the Bamboo Whisper. It demonstrates how the relationship between human and nonhuman actants can be reconfigured through practice-based construction with organic and digital materials, where the affordances and capabilities of the materials can extrapolate material agency when emerging as composites.

We have argued that redefining what it means to be human in response to the increasing techno-genesis of our species is an essential requirement for humanity to comprehend the essence of its future self. Building on the Biophilia Hypothesis that claims humans have an innate propensity toward natural materials and systems, we have offered the notion of the cyborganic as a materially manifested fictional concept in order to approach humanity's mutation unencumbered by technophobia, the age-old fear of the machine that is deeply embedded within Western cultural narratives similarly to the way myths and fables offer a safe space of nonhuman encounter. Lastly, we propose that the development of the cyborganic transcends the Cartesian divide and its transhuman endpoint, in line with the call for a posthuman entity of embodied wisdom, gently interweaving the intelligence of the machine with the intelligence of nature.

\section{Acknowledgments}

Bamboo Whisper was developed as part of Haptic InterFace 2012, with support from the Wearables Lab, at the Academy of Visual Arts Hong Kong Baptist University, Seeed Studios, Woolmark Company, and the Media and Film Grant of Rhineland-Palatinate (Medienförderung).

\section{Notes}

* Malawi boys from southeast Africa similarly concealed their face with rattan head covers for their initiation ritual.

1 Wetware is the principle of using biological neurons to perform digital calculations and logical operations. See, for example, research by Borresen and Lynch (2009).

2 Not to be confused with the pioneer internet collective of the 1990s of the same name: Cyborganic was an online and face-to-face collective which brought Wired magazine online; launched Hotwired, set-up web production for CNET; led the open-source Apache project; and staffed and started dozens of other Internet firms and projects - from Craig's List to Organic Online - during the first phase of the web's development as a popular platform (1993-1999). See Cool (2008).

3 See also project website http://triciaflanagan.com/blinklifier/.

4 The Guugu Yimithirr are an Australian aboriginal tribe of Far North Queensland.

5 For example, the Bible states "in the beginning was the word" (John 1:1), whereas Vedic tradition ascribe the beginning of creation with the sound "Aum". See Wilson and Fitzedward (2008).

6 As photographed by Alfred I. Hart, of Xhosas doning reed outfits for a rite of passage to manhood, South Africa 1925. In Cathy Newman National 


\section{Patricia Flanagan and Raune Frankjoer}

Geographic Fashion, National Geographic Society, Washington, 2001, 26-27.

7 As photographed by Carol Beckwith and Angela Fisher of North Congo, Africa, Ngbende initiates wearing grass skirts, late 20th century. In Koda Harold, Extreme Beauty The Body Transformed, The Metropolitan, Museum of Modern Art, New York, 2001, 122.

8 Charles Babbage (1791-1871) is credited to have invented the first mechanical computer together with Ada Lovelace (1815-1852).

\section{References}

Atkinson, Qd. 2011. "Phonemic Diversity Supports a Serial Founder Effect Model of Language Expansion from Africa.” Science 332 (6027): 346-349. doi: 10.1126/science.1199295

Barad, Karen. 2003. "Posthumanist Performativity: Toward an Understanding of How Matter Comes to Matter.” Signs 28 (3): 801-831.

Bateson, Gregory. 1972. Steps to an Ecology of Mind. New York: Ballantine Books. Bogost, Ian. 2012. Alien Phenomenology, or, What It's Like to Be a Thing. Minneapolis, MN: University of Minnesota Press.

Borresen, Jon, and Stephen Lynch. 2009. "Neuronal Computers.” Nonlinear Analysis Theory, Methods and Applications 71 (12): E2367-E2371. doi: 10.1016/j.na.2009.05.060

Braidotti, Rosi. 2008. "The Politics of Life as Bios/Zoe." In Bits of Life: Feminism at the Intersections of Media, Bioscience, and Technology, edited by Anneke Smelik and Nina Lykke, 177-192. Seattle: University of Washington Press.

Chamovitz, Daniel. 2012. What a Plant Knows: A Field Guide to the Senses. 1st ed. New York: Scientific American/Farrar, Straus and Giroux.

Cool, Jennifer. 2008. Communities of Innovation: Cyborganic and the Birth of Networked Social Media. PhD diss. December 2008. University of Southern California. www.cool.org/portfolio/PDF/jcooldissertationFINAL.pdf.

De Chardin, Teilhard. 2015. The Future Belongs to those Who Give the Next Generation Hope, Designing for Hope: Pathways to Regenerative Sustainability. Oxon, NY: Routledge.

Dinello, Daniel. 2005. Technophobia: Science Fictions of Posthuman Technology. Austin: University of Texas Press.

Dyson, Esther. 1996. "Cyberspace and the American Dream: A Magna Carta for the Knowledge Age." (Release 1.2, August 22, 1994) An International Journal 12 (3): 295-308. doi: 10.1080/019722496129486

Elo, Mika. 2013. "Catalog of the Finnish expedition Falling Trees.” Venice Biennale. Accessed April 14, 2017. http://toisissatiloissa.net/98-2/.

Elberfeld, Rolf. 2003. "Sensory Dimensions in Intercultural Perspective and the Problem of Modern Media and Technology." In Technology and Cultural Values: On the Edge of the Third Millennium, edited by Peter D. Hershock, Tigranovna Stepaniants, and Roger T. Ames, 478-489. Honolulu, HI: University of Hawaii Press.

Flanagan, Patricia. 2014. "A Vibrant Evolution: From Wearable Devices to Objects as Mediators of Experience." In Design, User Experience, and Usability. User Experience Design for Everyday Life Applications and Services. DUXU 2014. Lecture Notes in Computer Science, vol. 8519, edited by Aaron Marcus, 675-686. Toronto, CA: Springer. 
2016. "Visceral Design: Sites of Intra-action at the Interstices of Waves and Particles." In Design, User Experience, and Usability: Novel User Experiences, 5th International Conference, DUXU 2016, Held as Part of HCI International 2016, July 17-22, edited by Aaron Marcus, 3-15. Toronto, CA: Springer.

_ Loops for Amplifying Expressions through Bodily Worn Objects.” 10th Asia Pacific Conference on Computer Human Interaction (APCHI 2012), Conference Proceedings Vol. 2, Matsue, Japan, 2012.

Forister, Ann. 2007. Review of The Elephant's Secret Sense. Library Journal, February 1, 2007: 94.

Frumkin, H. 2001. "Beyond Toxicity: Human Health and the Natural Environment." American Journal of Preventive Medicine 20 (3): 234-240. doi: 10.1016/S0749-3797(00)00317-2

Hachi. Japanese Komuso wearing Tengai. https://commons.wikimedia.org/ wiki/File:Daikokuji-Sasayama_Komus.jpg.

Haraway, Donna. 1988. "Situated Knowledges: The Science Question in Feminism and the Privilege of Partial Perspective." Feminist Studies 14 (3): 575.

Hogan, Kevin, and Ron Stubbs. 2003. Can't Get Through: Eight Barriers to Communication. Gretna, LA: Pelican Publishing Company.

Hong, Zhong, and Guy Deutscher. 2012. "Through the Language Glass: Why the World Looks Different in Other Languages." Language in Society 41 (1): 152-153. doi: 10.1017/S0047404511001096

Howes, David, ed. 2009. "Introduction: The Revolving Sensorium." In The Sixth Sense Reader, edited by David Howes, 1-52. Oxford: Berg.

- 2013. "The Expanding Field of Sensory Studies." Accessed July 1, 2018. www.sensorystudies.org/sensorial-investigations/the-expanding-fieldof-sensory-studies.

—_ and Constance Classen. 1991. "Sounding Sensory Profiles.” In The Varieties of Sensory Experience, edited by David Howes, 257-288. Toronto, CA: University of Toronto Press.

Ingold, Tim. 2013. Making: Anthropology, Archaeology, Art and Architecture. London and New York: Routledge.

Joye, Y. 2007. "Architectural Lessons from Environmental Psychology: The Case of Biophilic Architecture." Review of General Psychology 11 (4): 305328. doi: 10.1037/1089-2680.11.4.305

Jütte, R. 2005. A History of the Senses: From Antiquity to Cyberspace. Cambridge, MA: Polity Press.

Kahn, Jr., Peter. H. 1997. "Developmental Psychology and the Biophilia Hypothesis: Children's Affiliation with Nature.” Developmental Review 17 (1): 1-61.

Kellert, Stephen R., and Edward O. Wilson. 1995. The Biophilia Hypothesis. Washington: Island Press.

Kenworthy, Jeffrey R. 2006. “The Eco-city: Ten Key Transport and Planning Dimensions for Sustainable City Development." Environment and Urbanization 18 (1): 67-85. doi: 10.1177/0956247806063947

Keysers, Christian. 2009. "Mirror Neurons - Are We Ethical by Nature." In What's Next? Dispatches on the Future of Science: Original Essays from a New Generation of Scientists, edited by Max Brockman, 16-24. New York: Vintage Books. 


\section{Patricia Flanagan and Raune Frankjoer}

Kirksey, S. Eben, and S. Eben Helmreich. 2010. "The Emergence of Multispecies Ethnography.” Cultural Anthropology 25 (4): 545-576. doi: 10.1111/ j.1548-1360.2010.01069.x

Latour, Bruno. 1993. We Have Never Been Modern. Cambridge, MA: Harvard University Press.

Lawlor, Robert. 1991. Voices of the First Day: Awakening in the Aboriginal Dreamtime. Sydney: Inner Traditions International.

Lovelock, James. 1995. The Ages of Gaia: A Biography of Our Living Earth. Rev. and expanded New York: W. W. Norton.

Lupton, D. 2015. Digital Sociology London: Routledge.

McCaffrey, E. 2014. "Extraordinary People: The Boy Who Sees Without Eyes.” Accessed January 20, 2019. www.imdb.com/title/tt1273701/.

Michael, Mike. 2016. "Speculative Design and Digital Materialities: Idiocy, Threat and Com-promise." In Digital Materialities: Design and Anthropology, edited by Sarah Pink, Elisenda Ardévol, Débora Lanzeni, and Corporation Ebooks, Ch. 6. London and New York: Bloomsbury Academic.

Myers, Natasha. 2006. "Animating Mechanism: Animations and the Propagation of Affect in the Lively Arts of Protein Modelling." Science and Technology Studies 19 (2): 6-30.

— Experimental Life." In A Companion to the Anthropology of the Body and Embodiment, edited by Frances E. Mascia-Lees, 239-261. Chichester, UK and Malden, MA: Wiley-Blackwell.

Nagel, Thomas. 1974. "What Is It Like to Be a Bat?" The Philosophical Review 83 (4): 435-450. doi: 10.2307/2183914

National-Institute-of-Heath. 2017. "BRAIN Initiative.” Accessed April 14, 2017. www.braininitiative.nih.gov/.

Onion, Rebecca. 2008. "Reclaiming the Machine: An Introductory Look at Steampunk in Everyday Practice.” Neo-Victorian Studies 1 (1): 138-163.

Openshaw, Jonathan. 2015. Craftmakers Ahead of the Curve. Financial Times, June 26, 2015. www.ft.com/content/87e1a626-15a5-11e5-be5400144 feabdc0.

Pallasmaa, Juhani. 1996. The Eyes of the Skin: Architecture and the Senses, edited by Steven Holl. London: Academy Editions Lanham.

- 2013. "Mental and Existential Ecology." In Rethinking Aesthetics: The Role of Body in Design, edited by Ritu Bhatt, 215-230. New York and London: Routledge.

Rand, Ayn. 1993. The Fountainhead. London: Penguin.

Sanford, James H. 1977. "Shakuhachi Zen. The Fukeshu and Komuso." Monumenta Nipponica 32 (4): 411-440. doi: 10.2307/2384045

Shelley, Mary Wollstonecraft. 2010/1818. Frankenstein. California: Intervisual Books.

Skinner, Brian J. 1999. The Blue Planet: An Introduction to Earth System Science, edited by Stephen C. Porter, and Daniel B. Botkin. 2nd ed. Hoboken, NJ: J. Wiley.

Smith, Aaron. 2014. "U.S. Views of Technology and the Future, Science in the Next 50 Years." InFuture ofTechnology, April17,2014.Pew Research Centre. www.pewinternet.org/2014/04/17/us-views-of-technology-and-thefuture/. 
Sörlin, Sverker. 2012. "Environmental Humanities: Why Should Biologists Interested in the Environment Take the Humanities Seriously?" BioScience 62(9, September), 788-789.

Stiegler, Bernard. 2017. "Escaping the Anthropocene." In The Crisis Conundrum. How to Reconcile Economy and Society, edited by Mauro Magatti, 149-163. New York: Springer Nature.

Szigeti, Balázs, Padraig Gleeson, Michael Vella, Sergey Khayrulin, Andrey Palyanov, Jim Hokanson, Michael Currie, Matteo Cantarelli, Giovanni Idili, and Stephen Larson. 2014. "OpenWorm: An Open-science Approach to Modeling Caenorhabditis Elegans." Frontiers in Computational Neuroscience 8 (137). doi: 10.3389/fncom.2014.00137

Turnbaugh, Peter, Ruth Ley, Micah Hamady, Claire Fraser-Liggett, Rob Knight, and Jeffrey Gordon. 2007. "The Human Microbiome Project." Nature 449 (7164): 804-810. doi: 10.1038/nature06244

Ulrich, Roger S. 1983. "Aesthetic and Affective Response to Natural Environment." In Human Behavior and Environment, edited by Irwin Altman, and Joachim F. Wohlwill, 85-125. New York: Plenum.

Vallgårda, Anna, and Johan Redström. 2007. "Computational Composites." Proceeding CHI '07, Proceedings of the SIGCHI Conference on Human Factors in Computing Systems, 513-522. https://dl.acm.org/citation. cfm?id=1240706.

Vella, Richard. "Creative Thinking with Sound and Textures.” Accessed June 29, 2017. www.squelch.com.au/creativethinking/musicenv.html.

Verbeek, P., and F. B. B. De Waal. 2002. "The Primate Relationship with Nature: Biophilia as a General Pattern.” In Children and Nature: Psychological, Sociocultural and Evolutionary Investigations, edited by Peter. H. Kahn, Jr., and Stephen R. Kellert, 1-27. Cambridge, MA: MIT Press.

Walter Collective, The. Sara Adithya, Beck Davis, Tricia Flanagan, Raune Frankjær, and Zoe Mahony. 2015. BIOdress by The Walter Collective. Accessed April 15, 2017. www.the-walter-collective.com/.

Watts, Harriett. 1988. "The Dada Event: From Transubstaniation to Bones and Barking." In "Event" Arts and Art Events, edited by Stephen C. Foster, 119-131. Ann Arbor, MI: UMI Research Press.

Wilson, Edward Osborne. 1984. Biophilia. Cambridge, MA: Harvard University Press.

Wilson, Horace Hayman, and Fitzedward Hall. 2008/1864. The Vishnu Purán: A System of Hindu Mythology and Tradition. London: Trübner \& co. https:// archive.org/details/vishnupurnsyst01wils/page/n4.

Winner, Langdon. 1977. Autonomous Technology: Technics-out-of-control as a Theme in Political Thought. Cambridge, MA: MIT Press.

Woolgar, S. 1991. "Configuring the User: The Case of Usability Trials." In A Sociology of Monsters, edited by J. Law, 58-97. London: Routledge.

Yoo, Seung-Schik, Hyungmin Kim, Emmanuel Filandrianos, Seyed Taghados, and Shinsuk Park. 2013. "Non-Invasive Brain-to-Brain Interface (BBI): Establishing Functional Links between Two Brains.” PLoS One 8 (4). doi: 10.1371/ journal.pone.0060410

Ziarek, K. 2011. “The Limits of Life. A Non-anthropic View of World and Finitude." Angelaki. Journal of the Theoretical Humanities 16 (4): 19-30. doi: 10.1080/0969725X.2011.641342 

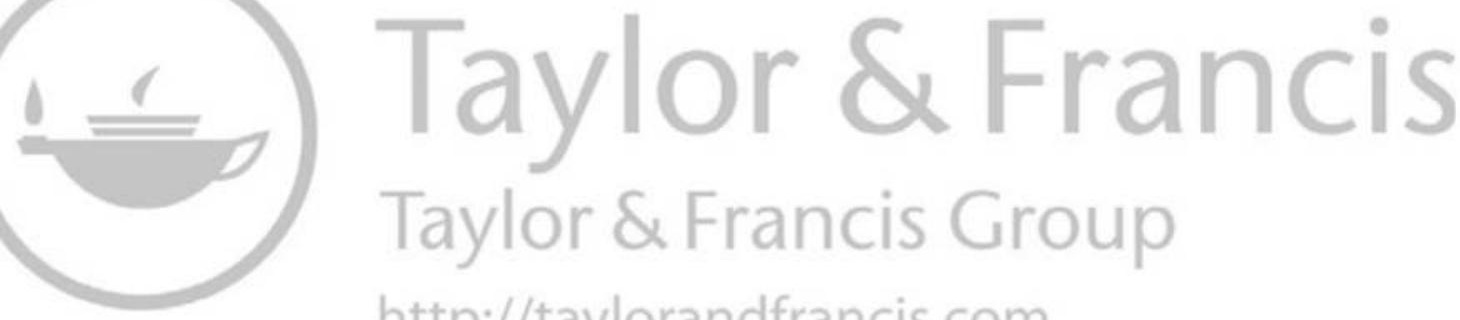
http://taylorandfrancis.com 


\section{Part 5}

Afterword

Unnarratable Matter? 

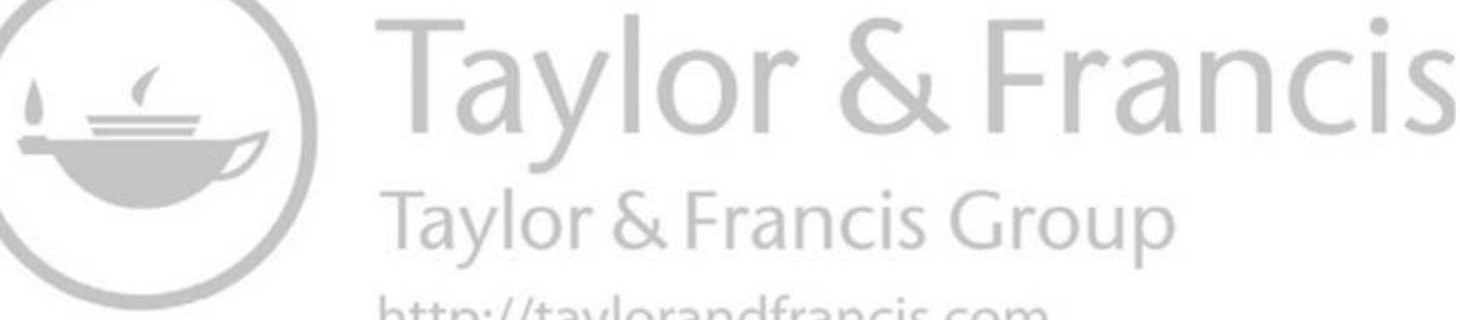
http://taylorandfrancis.com 


\title{
13 Unnarratable Matter \\ Emergence, Narrative, and Material Ecocriticism
}

\author{
Juha Raipola
}

How can we make sense of the emergent, self-organizing capacities of the material world? This question has been recently addressed by two otherwise quite divergent fields of literary and narrative theory cognitive narratology and material ecocriticism. In both approaches, the problem of anthropocentrism is often a guiding principle of investigation. For cognitive narratology, this is typically a question about how narrative fails in the representation of a certain kind of complex causality, and how "we", ${ }^{1}$ as members of a certain natural species, almost invariably use narrative logic to make sense of both ourselves and our environment. According to the situated and enactivist paradigm of the field, human understanding of temporal phenomena is, at its heart, based on narratives; storytelling is an ability that allows us, as human individuals, to manage time by discovering or imposing links between different cultural and material phenomena. There is, however, an anthropocentric and anthropomorphic bias in the narrative logic used by such sense-making: we have a general tendency to approach the world through narrative explanations, even when they crudely misrepresent the systemic logic of emergent behavior under investigation.

In the theoretical horizon of material ecocriticism, a similar question is more standardly addressed in terms of nonhuman agency. Drawing from the recent discourses of "new materialisms" and the wider "material turn" ${ }^{\prime 2}$ in humanities and social sciences, material ecocriticism investigates the capacity for material objects to act with effectivity - to have agency or even a "voice" (or several voices) of their own. This is contrasted to the more traditional, anthropocentric view of human individuals as the only beings endowed with mind and agency, a perspective where the material world - including both "inanimate" matter and nonhuman forms of living - is seen as largely passive, inert, and unable to communicate any independent expression of meaning. Material ecocriticism aims to situate human agency in an ecological field of more-than-human forces and substances, which often merge with the life of our bodies and environments. In this complex landscape of both human and nonhuman "actants" - to use Bruno Latour's terminology - agency is not the sole property of intentional human beings but something that also belongs 


\section{Juha Raipola}

to such entities as hurricanes, rocks, environmental pollutants, or nonhuman animals, to mention just a few examples. Critically informed by Karen Barad's theory of agential realism, material ecocriticism situates all phenomena as the "intra-actions" of material and discursive practices and agencies, which co-emerge at once in the world's "ongoing becoming". In contrast to the usual "interaction", which presumes the prior existence of independent entities, the notion of intra-action proposes that distinct entities do not precede, but rather emerge through, their intraactions (Latour 2004, 237; Barad 2007, 33; Iovino and Oppermann 2014, 1-10).

One of the key concepts of material ecocriticism is storied matter, which emphasizes the capacity of nonhuman matter to participate in the construction of stories. The two foremost architects of the field, Serenella Iovino and Serpil Oppermann $(2012,83)$, posit that matter, "in all its forms, becomes a site of narrativity, a storied matter, embodying its own narratives in the minds of human agents and in the very structure of its own self-constructive forces". In this way, material ecocriticism sees material reality as endowed with a narrative agency - an ability to partake in the narrative process. In fact, Iovino even questions our conventional notions about storytelling as a mere human activity. For her, "every living being tells us evolutionary stories of co-existence, co-dependence, extinctions and survivals" (Iovino 2015, 71), and for a similar reason, she also wonders:

[W] ho is the storyteller of these stories narrated through and across bodies by actants such as toxic waste, sick cells, individual organisms, and social forces? Who is really the "narrating agent", if things' agency is a narrative agency? Rather than (metaphorically, of course!) "killing" the author, we should maybe re-draw the boundaries of authorship in a more realistic way.

(Ibid. 83; emphasis in the original.)

In Iovino's account of material ecocriticism, human individuals are not the true "authors" of the stories we tell about our nonhuman surroundings. According to her, part of the story is always "told" by nonhuman agencies - such as electricity, toxins, fungi or climate patterns, and their entangled co-dependencies - in the creatively emergent becoming of the material world. From this perspective, "reality emerges as an intertwined flux of material and discursive forces, rather than as complex of hierarchically organized individual players" (Iovino and Oppermann 2014, 3). This means that the anthropomorphization of things, places, natural elements, and nonhuman animals is recognized as a narrative technique employed to stress the agentic power of matter and the horizontality of its elements. Drawing upon the assumption that narratives about the agentic capacities of matter can be enlightening and important 
ways to involve nonhuman entities into our social, cultural, epistemological, and ethical landscape, material ecocriticism treats stories as a form of "strategic" anthropomorphism, which liberates things from their silence.

With its task of giving voice to nonhuman matter, material ecocriticism has so far remained silent about the failures of narrative in addressing the complex behavior of the material world. In this chapter, I will try to remedy this oversight: rather than focusing upon the "storied" nature of matter - the capacity of nonhuman agencies to influence our narrative sense-making - examined so far by the majority of studies in material ecocriticism, I will employ the theoretical landscape of cognitive narratology as an entry-point to the inherent creativity of "unnarratable" matter. With this move, I aim to highlight how a central attribute of complex natural-cultural systems is actually unrepresentable in narrative discourse and thought, and how narratives are often antithetical to our aspiration to grasp the true complexity of material processes. By exploring the creative tendencies of matter beyond narratives, I will thus try to demonstrate why the creativity of matter should not be equated to mere narrative agency. In fact, my intention is to sketch out a notion of unnarratable matter, of material agency that defies our human sense-making by not conforming to the implicitly anthropomorphic logic of narrative.

\section{Narrative and Complex Material Systems}

Material ecocriticism, as defined by Iovino and Oppermann $(2014,7)$,

is the study of the way material forms - bodies, things, elements, toxic substances, chemicals, organic and inorganic matter, landscapes, and biological entities - intra-act with each other and with the human dimension, producing configurations of meanings and discourses that we can interpret as stories.

Intrinsically, it is a theory which "investigates matter both in texts and as a text" (ibid., emphasis in the original). This means, first of all, that it is an approach which focuses on the way matter's (or "nature's") nonhuman agentic capacities are described and represented in narrative texts. As such, material ecocriticism can be seen as a method for literary and cultural interpretation: it is an approach for analyzing narrative representations with its focus on the agentic power of matter. Second, however, it also means that material ecocriticism focuses on matter's own "narrative" power of creating configurations of meanings and substances. Matter itself is seen as a "text", where "dynamics of 'diffuse' agency and nonlinear causality are inscribed and produced" (Iovino and Oppermann 2012,79-80) - material ecocriticism attends to the stories and the narrative potentialities that develop from matter's process of becoming. 


\section{Juha Raipola}

Taking matter as a text means, quite obviously, questioning the very idea of text: for material ecocriticism, text includes both human material-discursive constructions and nonhuman things such as water, soil, stones, metals, minerals, climate, bacteria, toxins, food, electricity, cells, atoms, and all cultural objects and places. The characteristic feature of these material configurations is that they are not made of single elements, isolated from each other. Rather, they form complexes that are both natural and cultural, and in many cases, human agency and meanings are intensely entwined with the emerging agency and meaning of these nonhuman beings. From such a perspective, the separation between human and nonhuman agency is ultimately blurred: it is often impossible to draw clear lines between the subjects and objects of actions in line with modern thought. In our contemporary world, this is rather uncomfortably demonstrated by global environmental problems such as climate change, where the material "nature" is always escaping from the assumed human control.

Cognitive narratology may seem like a strange bedfellow to the discourses of this kind of ecocritical theory: cognitive science is not a field particularly well known for its environmental awareness. Contemporary narratological theory, however, is often informed by the post-computational, embodied, and enactivist paradigm of cognitive science, which shares a significant number of similarities with the basic tenets of new materialisms. Most importantly, it is based on a non-anthropocentric view of human cognition: it approaches human individuals as biological organisms among others, and is typically concerned with embodiment as well as the interactive "structural coupling" of all organisms with their environments. According to cognitive narratologist Richard Walsh $(2011,75)$, for example, "the laws of natural selection represent the base level of a complex system from which genes, organisms, species, ecosystems, and the whole of natural history are emergent phenomena". Why is this kind of evolutionary view of the material world relevant for narrative theory? Mainly because of the limitations of our narrative understanding: in narrative accounts of evolutionary processes, we can only attribute agency to one or other of these phenomena and so "inevitably traduce the way the laws of natural selection operate" (ibid.).

One of the inherent key characteristics of all narrative representation, as noted by Walsh, is the fact that it tacitly gives agency to both human and nonhuman entities, be they individual organisms (such as humans or ants), collectives (human societies or ant colonies), inanimate objects (power lines or pheromone trails), or abstractions (the stock market or natural selection). As the theories of material ecocriticism and the new materialisms suggest, we can use such narratives to make sense of the complex "intra-actions" of the material and the cultural spheres. The problem with this kind of narrative representation is, however, that it 
also imposes an anthropocentric perspective on the ongoing processes; it renders them intelligible, as Walsh $(2016,274)$ puts it, "by representing them in fundamentally human terms". With this quasi-automatic act of narrative sense-making, we are actually actively reducing the complexity of the more-than-human world to deceptively clear narrative patterns and causalities.

According to Walsh, there are several problems associated with the anthropocentric and the anthropomorphic features of narrative representations. First of all, they ascribe human-like intentionality to nonhuman entities: narrative agents are portrayed as the initiators of their own actions - as if they chose what they do and what they want to do (Walsh 2016, 274-275). Here, the problem of anthropomorphism is not really the attribution of agency to the nonhuman environment, but rather the mistaken notion that all agency is based on centralized "topdown" control. Even when the creative tendencies of matter are wholly appreciated and approved, this kind of intentionality typically seems like a misrepresentation of the complex actions of the material processes. Nonhuman entities and material bodies can certainly "do stuff", act on each other and on us with different kinds of meaningful effectivity, but not really in the same manner as human individuals. Ignoring the differences between human and nonhuman agency might seem like a move that disputes human exceptionality, but in actuality, it may just as well serve as a universalizing cognitive strategy, which reduces the threatening unpredictability and the causal complexity of the material world to more humanly understandable terms.

Second, Walsh also notes the perspectival quality of narrative. Narratives are constrained by the fact that "every unit of narration involves selection, from the systemic network of relations in any conceivable situation, of a foreground, a line of action, a protagonist" (ibid. 275). This means that we cannot represent the systemic interaction (or, for that matter, intra-action) of multiple concurrent events in narrative. We can either follow the behavior of one ant, for example, or the congregate behavior of a collective group of ants, but we cannot form a satisfying narrative representation of all the reciprocal and recursive networks of interaction in a complex system. Since the logic of narrative is sequential, it is inherently based on the idea of a chain of cause and effect, which cannot really account for the multi-causally interrelated behavior of material systems. Finally, Walsh (ibid.) also mentions how "the global logic of narrative is driven by its orientation towards an end": instead of focusing upon the systemic logic of complex material and cultural processes, we use the logic of narrative to explain the behavior in terms of humanly understandable goals and conclusive endings.

Keeping these observations in mind, it is rather easy to see why the stories or the narrative potentialities that emerge from matter's process of becoming should not be too eagerly accepted as the central objects 


\section{Juha Raipola}

of inquiry for material ecocriticism. Once we have acknowledged that "all constituents of nature from the subatomic to the higher levels of existence possess agency, creativity, expression, and enduring connections that can be interpreted as a mélange of stories" (Oppermann 2013, 57), we should be able to move on to the next question: can we really understand the creative dynamics of matter through narrative logic? From the point of view of both material ecocriticism and today's cognitive narratology, the notion of nonhuman agency is inextricably linked to meaning. Nevertheless, in the light of the recent discussions in narrative theory, it would seem like a rather unfortunate mistake to assume that the meanings produced by such agency are already in some sort of narrative form. Stories, instead of pre-existing in the matter as meaningful units to be picked up by us, are employed in order to make sense of the complex interchanges between innumerable human and nonhuman agencies. Matter can, sure enough, produce meaningful actions, which can then be represented and interpreted as stories by human individuals and collectives. The problem with nonhuman agency, however, is exactly the fact that these actions are not compatible with narrative explanations, and for this reason, instead of positing these nonhuman "voices" as our narrative partners in crime, it might be more reasonable to recognize our own limitations in interpreting them.

\section{Plausible Stories}

According to contemporary cognitive narratologists such as Walsh and H. Porter Abbott, our narrative logic fails us every time we try to make sense of emergent behavior in natural or cultural systems. In fact, Abbott $(2008,228)$ even defines "emergence" as a certain kind of complex causality which cannot be readily represented in narrative form. This kind of behavior includes - among other things - such systemic processes as traffic, the stock market, the immune system, ant trails, hurricanes, landslides, flocks of birds, schools of fish, the growth of cities, the construction of beehives, and the neurology of thought. All of these behaviors demonstrate the coming into being of objects or patterns that are not the result of any kind of intention: they are not caused by any sort of centralized authority, plan, guiding hand, or any other kind of overarching control. Instead, they are the result of countless local interactions. There are several ways in which this kind of temporal action can be converted into a coherent narrative, but the most obvious in producing the impression of narrativity is causality. Indeed, many narrative theorists hold the opinion that there is no narrative without a causal sequence of events. According to Abbott, emergent behavior presents a special challenge to our need or desire to perceive narrative "belonging", meaning some sense of how the details of events in time make it possible to perceive a story of change. 
In effect, he explains that emergent behavior can actually be understood as a gap between different levels of narrative explanation.

The main example provided by Abbott $(2008,234-238)$ concerns the logic of natural evolution. By examining the evolutionary story of dolphins and their ancestors, for instance, we can readily see the gaps between different levels of narrative. The species of Ambulocetus - also called the walking whale - was an ancestor of modern whales and dolphins that lived in the Early Eocene (50-48 million years ago), and could both walk and swim. The fossilized remains of Ambulocetus belong to so-called transitional fossils as they show how whales evolved from land-living mammals. Based on the fossil remains of Ambulocetus individuals, we can create a story or several stories about a specific male Ambulocetus that lived during that time period. We can follow the temporal progression of the individual's life - how he was born, how he grows up, suffers hunger, escapes from predators, mates, and how he finally dies. This kind of a chain of events can be readily portrayed as a narrative, and with millions of instances of comparable narrative material, this story belongs to the micro level.

Out of these actions of Ambulocetus individuals emerges another story - the story of the evolution of modern dolphins. Without any overarching plan, guidance, or coercion, and without any intention of their own, the individuals participate in the production of a macro-level story, where the protagonist is no longer the individual Ambulocetus but the whole species. The story goes like this: Ambulocetus evolves into Kutchicetus; Kutchicetus evolves into Protocetus; Protocetus evolves into Basilosaurus; and so on, until we get to the modern, extant family of dolphins, Delphinidae. This narrative, which tells the evolutionary story of dolphins, has the phrase "evolves into" as its moment of causal action. We can narrate this story just as we can narrate the fluctuations of the stock market, the construction of a beehive, or the growth of a nation, without any reference to the emergent processes that actually bring them into being. In each case, the pattern of change at the macro level is produced by aggregate behavior at the micro level, yet we cannot tell a coherent story about the relationship between the two.

In emergent behavior, the necessary sense of narrative "belonging" is lost in a massive distribution of cause among agents, all of which interact, to some degree, by chance and each of which lacks a dominant role in the emergent behavior of which it is a part. The changes that occur at the macro level are the combined consequence of thousands, millions, or billions of small stories that play out at the micro level. For this reason, there is no narratable thread between the micro level and the macro level: massive distribution of causal agents means that there is "action" but not really a "chain of events" needed for a coherent story. In fact, according to Abbott (2008, 233-234), emergent behavior is by definition unnarratable: it is action that specifically defies the formal structure of 
narrative for its representation. Something happens, and we can see it happening or even chart its progress, but we cannot really employ narrative logic to explain what is actually going on - how the changes at the macro level emerge out of the systemic actions at the micro level.

According to Abbott $(2008,238)$, the unnarratability of emergent behavior means that we are prone to representing such action as a narrative of centralized control, which assumes that the collective behavior of a process must be under the control of an entity distinct from the mass. Typically, this leads to misinterpretations about the causal relationships between the participants responsible for the emergent phenomenon. For example, before the bottom-up approach to producing emergent behavior was introduced in modern computing, the flocking of birds was often thought to be based on the leadership of one bird. Similarly, we are also prone to introducing anthropomorphic gods and spirits into our stories about our environment and our own coming into being. If we are to believe Abbott, these sorts of stories with centralized control actually indicate a fear of losing cognitive control. By reducing causal complexity and the role of chance and unpredictability, the narrative of centralized control allows the perceiver to gain the sense of cognitive control in their imagination. Especially in times of personal or national stress, we have a tendency to use cognitive heuristics and produce quick, reductive narrativizations of cause and effect, somewhat plausible stories that help us manage the complexity of the world - with often disastrous results.

The language we have for describing any kind of action over time is almost inevitably saturated with narrative discourse. In the words of Abbott $(2008,240):$ " $[\mathrm{i}] \mathrm{t}$ is the language of characters and events, of action and reaction, feeling and intention". In fact, each and every narrative about emergent processes is responsible for reducing hugely complex causal relationships into stories with single causal actors. Narratives are then based on such anthropomorphic actors as Evolution, Nature, Nation-State, City, Climate Change, Stock Market, or Intentional Human Individual, which are portrayed as the protagonists or antagonists responsible for different actions and changes. Instead of explaining the complexities of the stock market, we can simply note how "the market responded with panic to today's news". Instead of explaining the full range of, for example, social, neurological, bacterial, chemical, and ecological complexities behind all human actions, we can tell a story about an intentional human individual writing a scholarly chapter. With such stories, we are constantly misrepresenting the reciprocal interactions of the system by assigning agency to a singular actor with "humanlike" motives and objectives.

\section{Agency in the Anthropocene}

Agency, in modern philosophy and sociology, has typically been defined as the human capacity to make choices and act on them. In the 
discourses of new materialisms and material ecocriticism, in contrast, matter is considered as a form of "emergent" agency that is combined and interferes with every act of "intentional" human agency - and for this reason, none of our intentional acts is restricted to the sphere of pure intentionality, but always "situates itself within a setting of co-emerging material configurations" (Iovino and Oppermann 2012, 86). Heather Sullivan $(2013,147-150)$ explains that this viewpoint modifies the modern conception of agency in two important respects. First, it expands the sense of agency to include the more-than-human world, where such entities as nonhuman animals, power grids, environmental toxins, floods, rivers, or blood cells are moving through space and creating an effect in their surroundings. At the same time, however, it also diminishes the agency of the human subject as it is no longer seen as an outside force freely shaping the world: embodied human individuals are examined as part of a larger, interlinked system of things, matter, and living beings, where people, animals, artifacts, technologies, and elemental forces share powers and operate in entangled but often disharmonious conjunction with each other.

One of the defining features of our current time period of the Anthropocene - the geological epoch during which humanity has come to play a critical role in the planet's ecology and geology - is the emergence of the human species as a material agency of its own. Perhaps the most prominent indication of this newly gained agency is the global environmental crisis set in motion by anthropogenic climate change. According to historian Dipesh Chakrabarty (2009, 201-212), anthropogenic explanations of global warming have led to a collapse of the modern distinction between natural and human history: in this day and age, humans are considered a force of nature in the geological sense. Thinking of humans as a geological force involves positing "human species" as an actor responsible for the current ecological problems. As Timothy Clark $(2015,14-15)$ has noted, this "transpersonal agency" of the species consists of the emergent effects of collective human actions on the scale of the entire planet. As such, this species-level agency is not "capable of voluntary action or planning" (ibid. 15) - it arises from the typically unforeseen consequences of the plans and acts of its constituents.

With the methodological framework of material ecocriticism, the emergence of the human species as a geological force could be interpreted as a material story - a story about the combined effects of human activity as a material agency among others. In fact, Bruno Latour $(2014,3)$ has recently suggested that in the age of the Anthropocene, human history is to be joined to planetary ecology in what he calls a "geostory" - a dynamic unfolding of human and nonhuman forces where neither humans nor ecosystems are in complete control. If one actually tried to construct such a story, however, one would quickly 


\section{Juha Raipola}

encounter the restrictions of narrative in representing the complex causality of material processes. At the outset, one would have a hard time identifying the main actors - protagonists and antagonists - of the story. Climate change and other global environmental problems are based on numerous, interrelated changes in our environment, none of which are truly "responsible" for the potentially catastrophic outcomes of the current developments. In order to narrate the progress of the ongoing environmental crisis, one would need to be able to point out such individual anthropomorphic actors as the Greenhouse Effect, Carbon Dioxide, Fossil Fuels, Livestock, Deforestation, Waste, Human Species, Ecological Footprint, Natural Processes, Ecosystems, Petroleum Industry, or Global Capitalism, all of which then supposedly contribute in different ways to the permanent changes in global weather patterns. With such a multiplicity of active participants - which vary depending on the choices made by the storyteller - narratives have a tendency to become perplexingly complex, and even then, they cannot account for the true complexity of the ongoing material processes. Furthermore, narrative logic struggles to track the nonlinear behavior of the systems, and it cannot really explain, for example, the emergence of climatological "tipping points", where a relatively slight rise in Earth's temperature can cause an intensely more dramatic change in climate. It is no wonder, therefore, that the typical everyday representation of the climate change still consists of a hugely simplified narrative of centralized control - one in which the intentionally acting "Humanity" has unconsciously disturbed the peaceful functioning of the outside "Nature", and now needs to revert this process or at least minimize its impact.

The problem of agency in narrative sense-making has already been tacitly implicated by much of the discussion surrounding the emergent notion of the Anthropocene. One of the most pertinent criticisms of the concept has stemmed from the purported role of the entirety of the human species as the main perpetrator of planetary-scale ecological problems. In their critique of the "Anthropocene narrative", Andreas Malm and Alf Hornborg (2014) point out how the standard story of the newly found Anthropocene epoch essentially ignores the socio-critical fact that uneven distribution and exploitation of resources is a basic condition for modern fossil fuel technology. By tracing the historical development of fossil energy as the quintessential productive force in modern capitalist economy, Malm and Hornborg suggest that the global ecological impact of fossil fuels has not truly been effected by humankind in general, but rather by the richest subset of the human population. The Anthropocene narrative, which depicts the emergence of the entirety of humankind as a geological force, is thus based on a crude misrepresentation of intra-species inequality. With the abstract ensemble of Anthropos as its main actor, the story of collective human impact and responsibility evades any questions of the unequal role of different 
social and ethnic groups, genders, and social classes or societies in the production of global-scale ecological change.

Similar issues have been raised by Christophe Bonneuil and JeanBaptiste Fressoz (2016), whose historical account of the Anthropocene strives to critically deconstruct the standard story of the newly found geological epoch. This naturalist "grand narrative" of the new geological epoch dominated by human activity originates from the same group of specialists in Earth system sciences whose work helped to establish the entire scientific debate on the question of the Anthropocene. Rather than simply producing data about the current state of the planet or suggesting a systemic view of its possible future, the scientists who named the Anthropocene also provided it with a certain history - an authorized narrative account of the Earth system and its co-evolution with the human species over the last centuries. Approaching the issue from the point of view of humanities and social sciences, Bonneuil and Fressoz remain acutely critical about several aspects of this naturalized account of geohistory. As historians of science, their objective is not to undermine any of the empirical measurements or material realities related to the concept of the Anthropocene but rather to question the relevance of the official narrative, especially in its managerial and depoliticized overtones.

As stated by Bonneuil and Fressoz, a major issue of the standard story of the Anthropocene stems from its depiction of history as a contest between the human species and the planet, "with societies as ignorant and passive masses who can only be guided by scientists and saved by green technologies" (2016, xiv). With this kind of narrative orientation, the Earth is habitually represented as a totality to be governed: historical facts are only relevant in as far as they can be measured as quantifiable data, and the entire planet is routinely observed from a strategic external viewpoint from which it can be "objectively" studied as a global system subjectable to human management and control. The managerial emphasis of the naturalist grand narrative is accompanied by the abstract category of "humanity" as a universal agent uniformly responsible for the Earth's new geological regime. The historical story is regularly construed around the idea of sudden enlightenment: after hundreds of years of ill-fated ignorance, during which the human species has unconsciously destroyed the planet to the point of shifting it into new geological epoch, "we" are now finally awakening to the planetary-scale environmental consequences of collective human action. According to Bonneuil and Fressoz, however, such a shift from unawareness to awareness only exists as a story maintained by present-day scientists: historical evidence clearly suggests that the destructive practices and technologies of the modern capitalist economies have not been adopted in any sort of blissful ignorance, but more often in full knowledge of their potentially harmful effects.

With similar reasoning to Malm and Hornborg, Bonneuil and Fressoz argue against the dominant conception of the Anthropocene as the 


\section{Juha Raipola}

collective result of undifferentiated human action: in the standard narrative of the new epoch, the abstract category of "human species" effectively masks huge dissimilarities of responsibility between different actors and institutions in the complex production of global ecological disturbance. The problem stems mainly from the natural scientific background of the main popularizers of the Anthropocene narrative: while the Earth system sciences can productively continue to pursue their quantifiable research interest with a generalized notion of human impact, any kind of social or cultural analysis of the development of planetary-scale environmental change would clearly require a more differentiated view of humanity. In order to confront the main issues of the naturalist narrative, Bonneuil and Fressoz seek after a more culturally and socially informed perspective on the questions of Anthropocene - a view that would "have to take into account social asymmetries and inequalities, exploring how these are mutually constructed - on different scales, including the global - with the distribution of flows of matter and energy through economic, political and technological mechanisms" (Bonneuil and Fressoz 2016, 69). In their account, such a differentiated viewpoint is needed not just to maintain historical accuracy, or to evaluate the responsibilities of the past, but also to pursue future policies that would be more impartial and more effective.

While the above evaluations of the standard narrative of the Anthropocene bring forth a number of important insights about the questionable results of utilizing the abstract totality of "human species" as an anthropomorphic narrative actor, their socio-critical viewpoint comes with its own set of problems and dilemmas. One of the most pressing issues concerns the distinctly anthropocentric orientation of the critique: by focusing their attention on the questions of social action and responsibility, researchers in the humanities and social sciences run the constant risk of overemphasizing the role of intentional human agency as the main causative factor responsible for the future of the Earth. Pinpointing the guilty parties through social and cultural analysis, even when it is ourselves who are shown to be guilty, can generally produce a false sense of agency: as Slavoj Žižek $(2011,423)$ has argued in his account of the Anthropocene, "we like to be guilty" for environmental threats since the admission of guilt can successfully delude us to think that the situation depends primarily upon our own choices. In the time of the Anthropocene, however, human agency can no longer be conceived as existing in such a void. The new geological epoch indicates a reunion between human and natural histories; it bridges the great divide between nature and society that widened in the nineteenth and twentieth centuries, and suggests a co-entangled relationship between human and nonhuman agencies.

Even though the concept of the Anthropocene is commonly conceived in predominantly anthropocentric terms, as an account of how "we" 
have presently arrived at a new geological epoch due to the emergence of human species as a geological force, the consequential effects of global environmental transformation also suggest the idea that humanity is not making its history by itself but in constant interaction with a dynamically changing planet. In the words of Nigel Clark, the Anthropocene is thus "as much about the decentring of humankind as it is about our rising geological significance" (Clark 2014, 25; emphasis in the original). According to Clark (2014; Clark and Gunaratnam 2017), there exists a widespread tendency to portray humans, and humans alone, as the sole actors and players of environmental changes. While much of the discussion surrounding the Anthropocene adheres to this idea, the notion of a new geological epoch also proposes a decidedly less anthropocentric viewpoint on the matter: it allows one to "replace the narrative of humanization of geology with an approach to the geologization of human history" (Granjou 2016, 145). As stated by Clark, there has been a growing consensus in natural sciences of past decades that Earth systems are inherently changeable, with or without human influence. From the perspective of the Earth system sciences, the Anthropocene can thus be considered as merely one more set of transformations in the vast and eventful history of the planet - a history in which human agency is portrayed as one kind of physical agency among numerous others. This means a fundamental shift in the basic orientation of the narrative - the story of increasing human impact upon nature is substituted with a bigger picture of dynamic Earth processes whose timescales reach back far beyond recorded history. Such a shift in narrative scale extends agency to nonhuman telluric elements and forces, and explains human history as conditioned by the Earth's powers of transformation.

In the light of the recent interdisciplinary discussion relating to the Anthropocene, the foremost eco-narrative problem of the current situation does not truly seem to concern the narrative agency of nonhumans, but rather the newly required merging together of socio-cultural and natural perspectives in the interpretation of planetary environmental changes. While the global environmental issues characteristic to the new epoch can certainly give rise to different kinds of stories, their narrative agency appears secondary to their raw material effectivity - the climate change or the ongoing mass extinction of species, for example, can hardly be described as processes that are primarily related to questions of narrative. Both the causes and the effects of anthropogenic planetary changes take place as dynamic material shifts resulting from a complex interrelationship between innumerable human and nonhuman participants. When these co-entangled material forces are subjected to narrative form, their physical effectivity is reshaped into narrated agency of clear-cut actors acting upon each other. Depending on the scale and orientation of the narrative, the complex planetary changes may then be explained as the effects produced by such actors as greenhouse gases, 


\section{Juha Raipola}

fossil fuel technologies, human individuals, social groups, the human species, or the entire Earth itself. As the Anthropocene erodes the modern separation between the sphere of actively produced human history and the slow changes of natural processes, it also brings forth the dilemma of selection: since narrative choices always delimit the scale and the perspective of the narrative, there is no real possibility for a construction of a neutral, singular "geostory" of human and nonhuman agencies in action.

The Anthropocene seems to involve a narrative impasse, which manifests itself as a set of incompatible stories about the origins and the future of the latest planetary epoch. On one end of the spectrum, there are the anthropocentric stories of human action on either physical or social level - narratives of the entire human species or different social groups acting upon natural systems and altering their behavior. Some of these accounts tend toward a more structural view, emphasizing the role of anthropomorphized social institutions and policies in the production of planetary change. On the other end, human agency is diminished to the point of non-existence as it is situated within a vast history of climatic and geophysical transformation. Such a viewpoint highlights the creative role of more-than-human material forces but can also ultimately lead to a political or ethical paralysis: by downplaying the impact of intentional human agency, narratives focused on the fluctuations of Earth systems provide very little room for socially induced change. In all varieties of Anthropocene narratives, the perspective always remains limited - instead of providing a clear view into the dynamics of distributed and diffuse agency, narrative form binds environmental change into the shape of human or natural protagonists and antagonists, subjects or objects of the Earth's ecological shifts.

\section{Conclusion}

Contrary to some recent accounts of material ecocriticism, there are really no "ongoing stories" in the material world - no previously unaccounted Great Book of Nature opening before our eyes. Instead of continuing stories, matter consists of countless emergent processes which can never be reduced to our narrative representations. Thus, when we interpret the more-than-human world through a narrative lens, we must also remain wary of our own tendency to narrativize complex, emergent behavior into simplified and anthropocentric stories. If we want to respect the creativity of matter in its own terms, we have to acknowledge that its numerous agencies are not performing stories for the human audience, but exist and act of their own accord. No matter how hard we try to fit this world into our cultural landscape of narrative sense-making, a major part of its behavior always remains unreachable. 
On the whole, better understanding of the agential capacities of nonhuman things and processes seems to require a clearer distinction between two different notions of material agency. The first variety of agency is the actual, distributed agency of emergent processes: it is the agency of entangled, non-specified human and nonhuman "forces" that continuously come into being without plan or intentional guidance. This entails the intertwined, systemic behavior of material objects and organisms - the entwined activity of different agencies - which can later be interpreted as narratives. There is, however, no pre-given meaning attached to this agency - the behavior of material systems does not consist of any kind of narratives, and can go on just fine without narrative explanations. When approached through narrative logic, a major part of the complex entanglements of human and nonhuman agencies is ultimately lost and ignored. Thus, this kind of agency might be termed a "semiotic agency" or "meaning-producing agency", but identifying it as a "narrative agency" seems like a definite misnomer. Outside the most metaphoric use of the term, material things are not telling their "own stories" to anyone, but are simply behaving in a way that can be interpreted as a story or several stories.

The second type of nonhuman agency is an attribute assigned to someone or something in narrative representation. This kind of narrated agency is always ascribed after the fact or in anticipation of a fact, in an effort to make sense of the temporal progress of the action. With this interpretative act, one projects agency to singular actors within the systemic behavior: the non-definable intra-actions of material processes are transformed into subjects and objects, protagonists and antagonists of narrated events. Here, one can encounter such entities as human individuals, genes, seas, volcanoes, methane, carbon sinks, evolution, or climate change acting upon each other. Even though these narratives are based on the actual agency of creative matter, they are bound to narrative logic, which ultimately fails in its representation of the complex causality of material systems. With their limited perspectives, unwarranted human-like intentionality, and tendency toward teleological explanations, narratives skew the emergent, distributed agency of matter to far too familiar forms. Paradoxically, however, we still need these stories to make sense and respect the role of the world beyond us.

Narrative, of course, is not the only cognitive strategy we can use to make sense of the world, but it is one of the most prominent and weighty. Accordingly, instead of endless celebrations of the "narrative" agency of matter, it might often prove more fruitful to analyze the numerous ways in which matter escapes our desire for narrative descriptions. With only a slight change of perspective, material ecocriticism could even be seen as the study of all the complex relationships that are lost when active and emergent matter is in fact "storied" and brought into our 


\section{Juha Raipola}

cultural landscape. The focus would no longer be on the question of nonhuman agency, which is taken as a given, but on the question of how even the most accommodating narrative representations of matter inevitably leave out important details, disentangle significant interdependencies, or simplify the ongoing emergence and emergency of the material world into linear stories of cause and effect. Stories, in such an approach, would not be seen as the patent answer to our global environmental crisis, but rather as a major part of the problem.

\section{Notes}

1 As can be deduced from the overall argument of the chapter, usage of inclusive terms such as "we" or "one" is highly problematic in the context of environmental humanities. This kind of imprecision in discourse is, however, hardly avoidable, and I will continue to use these terms throughout the chapter for the sake of rhetoric.

2 The material turn, as a field of inquiry, generally considers inanimate matter to possess agency and vitality. In the new modes of materialist analysis, complex issues such as climate change or population dynamics are approached as subject matters that require a reorientation in the methodology of the humanities and social sciences. By highlighting the significance of material factors and corporeality in different aspects of social and cultural life, scholars in new materialisms wish to abandon the idea that the main task of cultural theory is to study the world as it is represented and interpreted by human beings. Matter, in such an approach, is to be understood as a vibrant force, and culture is to be reconceptualized as a material entanglement of humans and nonhumans. For an overview and a philosophical introduction about the material turn, see Coole and Frost's introduction to New Materialisms (2010).

\section{References}

Abbott, H. Porter. 2008. "Narrative and Emergent Behavior.” Poetics Today 29 (2): 227-244.

Barad, Karen. 2007. Meeting the Universe Halfway: Quantum Physics and the Entanglement of Matter and Meaning. Durham, NC: Duke University Press.

Bonneuil, Christophe, and Jean-Baptiste Fressoz. 2016. The Shock of the Anthropocene: The Earth, History and Us. Translated by David Fernbach. London: Verso.

Chakrabarty, Dipesh. 2009. "The Climate of History: Four Theses." Critical Inquiry 35 (2): 197-222.

Clark, Nigel. 2014. "Geo-Politics and the Disaster of the Anthropocene." The Sociological Review 62 (suppl. 1): 19-37.

— cializing the Anthropocene' to Geologizing the Social.” European Journal of Social Theory 20 (1): 146-163.

Clark, Timothy. 2015. Ecocriticism on the Edge: The Anthropocene as a Threshold Concept. London: Bloomsbury. 
Coole, Diana, and Samantha Frost. 2010. "Introducing the New Materialisms." New Materialisms: Ontology, Agency, and Politics, edited by Diana Coole and Samantha Frost, 1-43. Durham, NC: Duke University Press.

Granjou, Céline. 2016. The Futures of Nature. London: ISTE Press.

Iovino, Serenella. 2015. "The Living Diffractions of Matter and Text: Narrative Agency, Strategic Anthropomorphism, and how Interpretation Works." Anglia 133 (1): 69-86.

$\longrightarrow$, and Serpil Oppermann. 2012. "Material Ecocriticism: Materiality, Agency, and Models of Narrativity.”Ecozon@ 3 (1): 75-91.

- 2014. "Introduction: Stories Come to Matter." In Material Ecocriticism, edited by Serenella Iovino and Serpil Oppermann, 1-17. Bloomington and Indianapolis: Indiana University Press.

Latour, Bruno. 2004. Politics of Nature: How to Bring the Sciences into Democracy. Translated by Catherine Porter. Cambridge, MA: Harvard UP. 2014. "Agency at the Time of the Anthropocene." New Literary History 45 (1): 1-18. doi: 10.1353/nlh.2014.0003

Malm, Anders, and Alf Hornborg. 2014. "The Geology of Mankind? A Critique of the Anthropocene Narrative." The Anthropocene Review 1 (1): 1-8.

Oppermann, Serpil. 2013. "Material Ecocriticism and the Creativity of Storied Matter." Frame: Journal of Literary Studies 26 (2): 55-69.

Sullivan, Heather. 2013. "Material Ecocriticism: Goethe as a Case Study." Literatur für Leser 12 (3): 147-160.

Walsh, Richard. 2011. Emergent Narrative in Interactive Media. Narrative 19 (1): 72-85.

- 2016. "Narrative Theory at the Limit." In Theory Matters: The Place of Theory in Literary and Cultural Studies Today, edited by Martin Middeke and Christoph Reinfandt, 265-280. London: Palgrave Macmillan.

Žižek, Slavoj. 2011. Living in the End Times. London: Verso. 

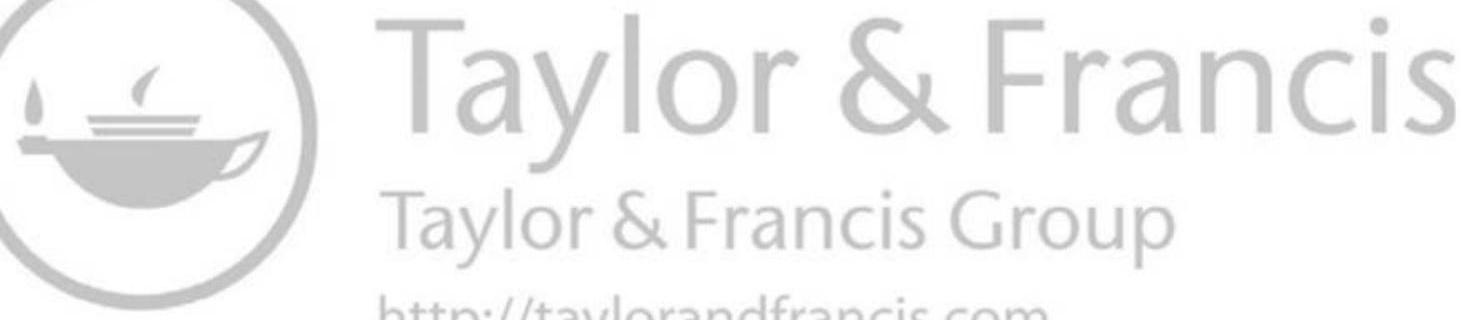
http://taylorandfrancis.com 


\section{Index}

Note: italic page numbers refer to figures and page numbers followed by " $n$ " denote endnotes.

Abbott, H. Porter 268-70

agency $6,7,15,16,26,30,31,42$, $45,48,50-4,58,68,71,85,86$, $96,105,126,193,205,218,221$, 223, 224, 226, 229, 250, 252, 253, 254, 255, 263-8, 270-2, 274-8, $278 \mathrm{n} 2$

Ahmed, Sara 4

AI 30, 31, 38n3, 95

Alaimo, Stacy 59

Alber, Jan 82-4

alien/alienating $13,54,90,91,93$, 95, 97, 99, 102, 104, 114-16, 118, $122 \mathrm{n} 4,126,128,129,132,136$, $138,139 \mathrm{n} 1,148,153,212,240-2$, 247,251

alien experience $110,112,120-2$

Alien vs. Predator 13, 108, 110, 112-14, 119-22, 122n5

Althusser, Louis 42

amplification 67

animals/animalization $2,3,6,8,14$, $15,25,27,31,32,38 \mathrm{n} 3,41,42$, $45-8,50,53,58,82,83,87,88,93$, $95,116,122 \mathrm{n} 2,128,129,132-6$, 139n6, 145, 147-9, 151-4, 158, 159, 160n7, 163-5, 167-71, 173-6, $178,179,182-7,191-7,239,241$, $242,245,252,264,271$

animal studies $6,48,147,164,170$ Annibilation 12, 57, 61-8, 70, 71, $72 \mathrm{n} 1$

Anthropocene 1-5, 9, 133, 138, 236, 270-6; see also Neganthropocene anthropocentrism 8, 25, 36, 41, 44, 54, 104, 122, 147, 160, 204, 206, 209, 210, 215, 216, 224, 263 anthropomorphism 44, 45, 85, 86, 94, $126,137,146,148,224,265,267$ anthropomorphization $86,87,145$, 146, 264; as cognitive necessity or heuristic 87,270 ; visual means of 88

Apperley, Thomas 16, 220, 227-30, 233

Armbruster, Karla 147, 148, 152, 158 artifacts $59,85-7,125,132,156$, 236, 239, 241, 242, 245, 246, 251-3, 271

assemblage 14, 15, 183-6, 183-91, 193-7, 220, 223, 224, 242, 244 autonomy 15, 186, 194, 197, 203, 224

B, David 88

Badmington, Neil 12, 42-4

Ballard, James Graham 62, 63

Bamboo Whisper 236-8, 237, 240, 242-5, 247, 251-5, 253

Barad, Karen 6, 16, 236, 245, 246, 264

Barrie, J. M. 135

Barthes, Roland 42, 43, 208, 209

Bechdel, Alison 88

becoming 14, 135, 136, 171 , 172, 174-9, 184, 192, 214, 224, 225, 236, 264, 265, 267

becoming-instrument $12,57-72$

Bennett, Jane 48, 219, 220, 222, 223

Bernaerts, Lars 87, 89, 148, 149

Bettelheim, Bruno 136

Beville, Maria 126

body $5,15,16,24,35,45,57,58,60$, $63-6,68,69,71,95,108,109,116$, 


\section{Index}

133, 136, 148, 149, 154, 159n1, 163-5, 167, 171-3, 175, 176, 186-8, 190, 191, 194, 197, 218, 220-6, 228, 230, 232, 236-8, 240, 242, 243, 245, 247, 249, 251, 253, 254

Bogost, Ian 51, 219, 241, 242

Bonneuil, Christophe 273, 274

Braidotti, Rosi 16, 25, 38n1, 231, 236

bug 214-15

Bulgakov, Mikhail 159n1

Burroughs, William Seward II 62, $72 \mathrm{n} 3$

Butler, Judith 3, 4, 173, 175

Caillois, Roger 226, 227

calculation 203, 205, 207, 209-15, 255n1

Callon, Michel 48

Callus, Ivan 12, 28, 29, 33, 42-5, 47

canids $145,146,153,155-6,159$

Caracciolo, Marco 12, 59, 60, 61, 64, 70, 72n $3,72 \mathrm{n} 4,84,95,148$, $160 \mathrm{n} 11$

Certeau, Michel de 204

Cervantes, Miguel de 145

Chakrabarty, Dipesh 271

Chambers, Ross 160n7

character 13, 24-6, 29, 34, 37, 44, 60, 64, 70, 79-82, 85-97, 99, 100, 104, 105, 111, 113, 130, 136, 139n1, 159, 170, 176, 177, 184, 189, 190, 192, 194, 196, 226, 229, 252;

theories of 80,85

Chatman, Seymour 30

childhood 125, 127, 130, 132, 134-7, 139n5

children's literature 12-14, 125-7, 130, 132, 134-6, 138, 139n3

Clark, Nigel 29, 275

Clark, Timothy 271

clones 11, 23, 27, 29, 32-6, 65

cognition $12,42,45,57,58,60,65$, 83, 105, 148, 159, 266; embodied cognition 13, 108, 109, 122n1; in narrative theory à (see narrative theory); nonhuman cognition $108-9,159$; readerly cognition $12,60,83$

cognitive estrangement $62,73 \mathrm{n} 7$

cognitive narratology $9,16,86,263$, 265, 266, 268

Cohen, Tom 2, 12, 42, 44 comics $13,79,80,83,85,88,89$, 90, 93, 94, 95, 96, 97, 98, 99, 100, 101, 103, 105; comics storytelling (see visual storytelling) communication $6,8,11,14,23,26$, $27,30,31,34,44,51,95,98,128$, 136, 145-7, 153, 154, 182, 203, 214, 237, 244, 245, 253, 254

computation 15, 46, 203-6, 208-16, 247

contemporary art $9,14,163,171,178$

counterplay 16, 220, 225-33

Cross, Gary 125

Cumptich, Roberto de Vicq de 45

cyborg 12, 24, 25, 38n 3, 41, 43, 45, $109,132,139 \mathrm{n} 4,224,249-50$

cyborganic $16,236-55,255 \mathrm{n} 2$

\section{Daggett, Cara 65}

dark ecology 61, 64, 65

Davies, E. W. 160n10

defamiliarization 13, 85, 87-90, 92, 94, 102, 105, 148, 154, 155; (de) familiarization (see also speculative fiction); visual means of 90, 105

Deleuze, Gilles 14, 184, 187, 189, 190, 219, 220, 223, 231

DeMello, Margo 147

Derrida, Jacques 42, 43, 51, 147, 173, 174

design 15, 24, 66, 72n4, 80, 90-2, 94, 97, 106n1, 110-12, 115, 116, 121, 129, 150, 151, 204, 208, 221, 238, 240, 245, 246, 251, 252, 254, 255; see also digital design; synesthetic design

digital design 245, 246

digital literature 26, 29, 37

disability 4, 14-15, 182, 183, 186, 187, 189, 191-4, 196, 197

dogs $14,15,27,35,36,59,72,111$, 145-59, 159n1, 159n6, 159n7, 159n9, 168, 182-97, 197n3, 197n5, 241; see also guide dogs; talking dogs

Doležel, Lubomír 60, 67

early science 163

edibility 14

embodied cognition 13, 108, 109,

122n1; see also cognition

embodied reader 35

emergence 45, 58, 154, 163, 167, 236, $253,268,271,272,275,278$ 
empathy $5,60,87,88,148,238$, 246, 250

enactivism: enactive approach to literature 58-60

enactment $12,61,67-70$

environmental change $57,58,66,71$, 274-6

Escher, M. C. 100

ethics 3, 34, 44, 54, 127, 173, 174

experientiality $8,12,57,59,64$, $66,67,72 \mathrm{n} 4,73 \mathrm{n} 7,81,86$, $102,149,159$

factors of communication 26, 26

fictionality 12, 61, 64

first-person narrative $12,57,60,61$, 64,69

Fludernik, Monica 8, 72n4, 81-3, 86

folk psychology 88, 104; see also cognition

Foster, Charles 14, 164, 175

Foucault, Michel 25, 42

Frankenstein 129, 240, 250

Fressoz, Jean-Baptiste 273, 274

Fukuyama, Francis 24

Gaiman, Neil 13, 79, 84, 88, 92, 93, 96, 98, 100, 101, 103

Galen 164-9

gender, gendering 3, 29, 123n6, 130, $131,244,273$

Genette, Gérard 38n5

ghost 41-5, 69

Gibson, Barbara 186

Goodley, Dan 192

Guattari, Felix 14, 219, 223, 231

guide dogs $15,182-6,188$, 190-7, 197n2

haptic interface 240,255

Haraway, Donna 1, 4, 5, 8, 9, 14, 16, 24, 43, 48, 59, 132, 164, $174,193,224,236,244$

Hayles, Katherine N. 12, 25, 31, 42, $46,47,50,52$

Herbrechter, Stefan 12, 23, 26-9, 33, 38n1, 38n3, 39n11, 41-7, 54

Herman, David 9, 81-3, 88, 89, 93, 159

Herman, Luc 148

Heteronormativity 130

history of science 164, 273, 275

Hornborg, Alf 272, 273
Houellebecq, Michel 11, 23, 27, 30-4, $36,38 \mathrm{n} 6$

human 1-16, 24, 26-37, 41-8, 50, $51,53,59-62,64-7,71,72,79-83$, 85-90, 92-7, 96 99, 102, 103, 104, $105,108-11,113-22,115,117$, 122n3, 126-38, 145-59, 160n11, 163-5, 170-9, 182-90, 192-7, 203-6, 208-16, 219-24, 226-30, 233, 236-42, 245, 247, 249, 250, $252,253,254,255,263-8,270-7$, $278 \mathrm{n} 2$; see also human body; human species

human body 24, 66, 109, 165, 228

human-computer interaction (HCI) 240

human species $25,34,86,129,134$, $242,249,271-6$

hyperobject $58,65-8$

Hyperobjects 12, 57, 58, 61, 64-7, $70,71,72 \mathrm{n} 1,72 \mathrm{n} 6$,

Ibsen, Henrik 155

immersion 61, 225, 226

impression 46, 52, 58, 66-8, 70, 99, $100,111,152,205,268$

independence $15,132,183,186$, 187,197

interaction design 81, 122, 245, 275

interobjectivity 67

Iovino, Serenella 6, 7, 264, 265

Jakobson, Roman 11, 23, 26, 26, 31-3

Jansson, Tove 136

Jaques, Zoe 138

Jeanneret, Yves 204, 209

Jenkins, Henry 130

Jones, Owain 132

Kafka, Franz 145, 148, 149, 172

Kahn, Douglas 47

Keen, Suzanne 88, 89, 90

Kervinen, Jukka-Pekka 12, 42, 52, 52,53

Kim, Miru 14, 163, 171-9

Kipling, Rudyard 135

Kukkonen, Karin 59

Kuzniar, Alice A. 158, 160n6

Lacan, Jacques 42, 46

language (animal, human) 8, 10, 11, 14, 25-7, 31-4, 36, 37, 45, 47, 48, $51,54,65,90,93-5,101,128,136$, 


\section{Index}

147, 148, 150-4, 175, 186, 191, 208, 221, 237, 240, 242-4, 270

Latour, Bruno 7, 16, 48, 54, 189, 196, 216, 228, 229, 236, 249, 263, 271

Law, Nick 48

Lem, Stanislav 62

Lindgren, Astrid 135

Lovecraft, Howard Philips 62

Lucian, Horace 145

ludus 227

machine $8,15,16,32,34,35,44$, 47, 82, 129, 132, 133, 152, 153, 203-16, 223, 224, 229, 240, 250-2, 255

McCormack, Donna 126

McHugh, Susan 147

Malafouris, Lambros 12, 53

Malm, Andreas 272, 273

material 3, 6, 7, 9, 10, 14, 16, 45, 48, 50-4, 58, 59, 65-7, 69, 73n10, 81, $85,108,138,158,163,179 \mathrm{n} 1,183$, 203, 204, 221, 222, 224, 225, 227, $228,231,232,242,246,247,255$, 263-78, 278n2

material ecocriticism $6,9,16,48$, 263-6, 268, 271, 276, 277

matter $1,4,7,16,31,45,63,73 n 10$, $83,85,95,97,122,128,131,163$, 184, 212, 213, 220, 222, 230, 240, 244, 246, 249, 263-8, 271, 274-8, 278n2

Merleau-Ponty, Maurice 109

Merrill, Christopher 150, 151

Michalko, Rod 183, 186, 188, 189

mindreading 153

Minecraft 15, 218-26, 228-31, 233, 234n1, 234n2

mirroring effect 95; see also cognition; empathy

Moe, Aaron 12, 50

monster 43, 126-38, 139n3, 189, 250

Monster Nanny 13, 127-30, 133-7; see also Tolonen, Tuutikki

Morton, Timothy 12, 57, 61, 64-7, $71,72 \mathrm{n} 1,72 \mathrm{n} 6$

Muecke, Stephen 64

Nagel, Thomas 4-5, 12, 80, 81, $82,101,108,111,146,160 \mathrm{n} 4$, 240,242

Nakamura, Rika 16, 220, 229, 232, 233 name $4,9,23,45,46,57,62,63$, 72n $6,83,85,87,94,95,97$, $99,102,111,116,119,150-3$, 176, 182, 192, 212, 221, 227, $255 \mathrm{n} 2,273$

naming $82,151,152$

narration $11,12,14,38 \mathrm{n} 5,60,61$, 63, 65, 67, 70, 72n1, 89, 90, 92, $94,100,102,133,145,148-2$, 154, 267; reverse 156-9; backward 156-9; counterfactual 156-9

narrative $6,7,10,11,13,16,26,30$, $31,33-5,38 n 5,41,44,60,62,64$, $71,72 \mathrm{n} 4,73 \mathrm{n} 8,80,81-3,85-7$, $89,94,95,104,105,126,127$, 137, 148, 151, 152, 156, 157, 159, 164, 219, 220, 240, 241, 249-51, 263-70, 272-8; see also: narrative theory; narration

narrative theory $10,13,263,266$; cognitive narrative theory 13 ; natural narratology $8,80,81,86$; unnatural narratology 86 ; see also narratology

narratology 30, 105; see also narrative theory

nature-culture divide 133

Nechvatal, Joseph 50

Neganthropocene 2, 5, 16, 236, 240; see also Anthropocene

Neimanis, Astrida 59, 60, 67 neuropower 15, 220, 225-6

Niemi, Marko 12, 42, 45-8, 50, 53

Nietzsche, Friedrich 146, 148

Noë, Alva 58, 59

noise 50-3, 110, 111, 119, 148, 159,252

nomad 231

nonhuman agency $6,48,54,71,254$, 263, 266-8, 277, 278

nonhuman animals $3,6,14,15,45$, 47, 48, 50, 83, 129, 132-4, 147-9, 158-9, 164, 168, 171, 173, 182-97, 264, 271

objects $14,44,48,50-3,57,62,64-7$, $71,122 \mathrm{n} 2,125,128,149-51,155$, 163, 182, 193, 203-6, 214, 240, 242-5, 249, 251-4, 263, 266-8, 276, 277

ontology $8,43,51,219,236,240$, $241,245,254$

Opperman, Serpil 6, 7, 264, 265 
otherness $11,43,86,88,125-7$, 129-32, 134, 136-8, 147, 149, 188, 189, 192, 193, 197, 203, 208, 209, 243

paidia 219, 227, 230

Perec, Georges 215

personal change 71

Phelan, James 85

Piercy, Marge 43

pigs $14,163-79$

play $7,13,27,47,51,73 n 7,108,121$, 122n2, 127, 130, 170, 177, 194, 203, 219, 226-30, 233, 269, 271

Plumwood, Val 63

Polvinen, Merja 12, 59, 67

Possibility of an Island, The 11, 23, 27, 29-34, 36, 38n6

posthuman future 11,24

posthumanism $3,4,11,23-5,27-30$, 34, 36, 37, 38n1, 38n 3, 38n7, 41-54, 147; critical posthumanism $38 \mathrm{n} 3,59$

posthumous $14,145,150,158$, $159,159 \mathrm{n} 1$

poststructuralism (poststructuralist) 42

Pynchon, Thomas 145

queer(ness) 4, 130, 131

Rasmussen, Claire 160n2, 185

reconfiguration $1,6,15,16,57$, 61, 65, 71-2, 127, 147, 193, 196,216

rhizome 220, 221, 223-6, 229, 233

Ricoeur, Paul 23, 26

Rilke, Rainer Maria 150

Roden, David 73n9

Russell, John 160n10

Satrapi, Marjane 88

Saussure, Ferdinand de 46

science fiction $6,12,33,44,62,63$, $71,73 n 7,84,108,122,133,152$, 250; see also speculative fiction

Sedgwick, Eve Kosofsky 130

semiotics 203, 210, 213-16, 241, 245

Sendak, Maurice 13, 127, 132, 138, 139n2; see also Where the Wild Things Are

sense-making $16,62,84,263,265$, $267,272,276$ sensory $64,65,89,94,111,114$,

119, 152, 238, 239, 240, 242,

243, 253, 254

Shields, Kevin 66

Shildrick, Margit 192, 197

Shklovsky, Viktor 87

Siebert, Charles 14, 145, 148, 149, $151,155,158,159$

sign (linguistic sign) 28, 41, 53, 54, 187, 208, 209, 211-13

Simondon, Gilbert 205, 212

Smith, Pamela H. 163, 166

Souchier, Emmanuel 204, 213

speaking animals 147-8; see also talking dogs

spectral(ity) 12, 41, 42, 47, 54, 173

speculative fiction $33-7,84,88,105$; fantasy $12,71,79,84,88,108$; science fiction $6,12,33,44,62$, 63, 71, 73n7, 84, 108, 122, 133, 152,250

Spiegelman, Art 88

Spinoza, Baruch 219, 220, 222, 224

Stiegler, Bernard 16, 236

Stein, Garth 159n1

Stewart, Dave 79

"Stick Figures" 13, 127-9, 131, 133, 138; see also Tan, Shaun

subjectivity $12,13,42,60-3,65$, $67,69,71,83,87,90,102,147$, 172, 185, 186, 194, 195, 197, $220,222,226$

Sullivan, Heather 271

Suvin, Darko 73n7

synesthetic design 110-12, 115, 116, 118; see also design

systems $1,2,9,25,43,53,64,65,92$, 109, 112, 119, 133, 135, 154, 163, $191,209,219,237,238,243-5$, $247,252,253,255,265-8,270-7$

Tales of Outer Suburbia 13, 127; see also Tan, Shaun

talking dogs 145, 150,160n7; see also speaking animals

Tan, Shaun 13, 127; see also "Stick Figures"; Tales of Outer Suburbia text $7,8,11,28,32,49,50,52,54$, 57-9, 62, 67, 68, 70, 72n4, 82, 87, 100, 108, 114, 115, 164-8, 182, 197n1, 203, 204, 206, 207, 211, 215, 216, 220, 236, 240, 265, 266

Thompson, Evan 58 


\section{Index}

Tolonen, Tuutikki 13, 127-30,133-8; see also Monster Nanny

Tossavainen, Jouni 12, 42, 49-51, 49, 53,55

translation 50, 146, 152-4, 156, 164, $166,189,214$

Trexler, Adam 133

Troscianko, Emily 59

trust 63, 64, 73n6, 187, 192, 193, 197

Uexküll, Jakob von 83

unnatural $8,14,33,80,82,84,86$, $88,116,122 \mathrm{n} 3,145,148,149$, 157, 226; see also speculative fiction; narrative theory, unnatural narratology

user interface $15,110,204-7,210$, 214, 215, 238, 240, 241, 245

Väliaho, Pasi 220, 225, 226, 230

VanderMeer, Jeff 12, 57, 61, 66, 72n1

Varela, Fransisco 61

Verbeek, Peter-Paul 16, 236

Vervaeck, Bart 148

videogame(s) 16, 108-12, 118, $119,123 n 7,218-20,222-5$, 229, 233

violence 129-31, 133, 134, 170, $173,176,178,215$

visual impairment 188

visual storytelling 91 voice $49,73 \mathrm{n} 8,95,150-3,158$, 160n1, 165-8, 237, 246, 252, 263, 265

Waber, Dan 12, 42, 45-8, 50, 53

Wallace, Jeff 28

Walsh, Richard 266-8

Watterson, Bill 89

wearable technology 16, 236

Weaver, John 135

weird $62,65,73 \mathrm{n} 9,128,130$, 231, 252

weird ecology 12, 61

Warner, Marina 125, 136

Where the Wild Things Are 13, 127, 131-4, 136, 137; see also Sendak, Maurice

Williams, J. H., III 13, 79, 95, 96, 98 , $100,101,103$

Wirman, Hanna 16, 220, 229, 232, 232, 233

Wolfe, Cary 6, 48, 147

Woolf, Virginia 145

writing 4, 6, 7, 14-16, 23-31, 34, 37, 38n1, 38n2, 41, 42, 48, 54, 61-9, 154, 155, 159, 175, 204, 206, 211-16, 270

Ziolkowski, Theodore 160n7

Žižek, Slavoj 274

Zunshine, Lisa 86 